DEMETRIO JACKSON DOS SANTOS

\title{
ESTUDO EXPERIMENTAL DA RESISTÊNCIA MECÂNICA DE JUNÇÕES ADESIVAS
}

\author{
Dissertação apresentada à Escola \\ Politécnica da Universidade de \\ São Paulo para a obtenção do \\ Título de Mestre em Engenharia Mecânica
}

São Paulo 


\section{ESTUDO EXPERIMENTAL DA RESISTÊNCIA MECÂNICA DE JUNÇÕES ADESIVAS}

Dissertação apresentada à Escola
Politécnica da Universidade de
São Paulo para a obtenção do
Título de Mestre em Engenharia Mecânica

Área de concentração:

Engenharia Mecânica de Projeto de

Fabricação

Professor Orientador:

Prof. Dr. Gilmar Ferreira Batalha

São Paulo 
Este exemplar foi revisado e alterado em relação à versão original, sob responsabilidade única do autor e com anuência de seu orientador.

São Paulo, 24 de Setembro de 2007.

Assinatura do autor

Assinatura do orientador

FICHA CATALOGRÁFICA

Santos, Demetrio Jackson dos

Estudo experimental da resistência mecânica de junções adesivas / D.J. dos Santos. -- São Paulo, 2007.

$140 \mathrm{p}$.

Dissertação (Mestrado) - Escola Politécnica da Universidade de São Paulo. Departamento de Engenharia Mecatrônica e de Sistemas Mecânicos.

1. Junções adesivas 2. Propriedades mecânicas 3. Resistência dos materiais I. Universidade de São Paulo. Escola Politécnica. Departamento de Engenharia Mecatrônica e de Sistemas Mecânicos II. t. 


\section{DEDICATÓRIA}

Dedico este trabalho às minhas três famílias:

a de origem, a constituída e a formada por amigos.

Com especial sentimento à meu pai e avô,

Dorival Alves dos Santos e Hermínio Doce. 


\section{AGRADECIMENTOS}

Ao amigo e orientador Prof. Dr. Gilmar Ferreira Batalha, pelo constante apoio e incentivo.

A minha esposa e filhas, Edileide de Carvalho dos Santos, Nicole de Carvalho dos Santos e Alanis Carvalho dos Santos pela compreensão e apoio nos momentos em que estive ausente.

À minha mãe e irmã, Deolinda Doce dos Santos e Débora Doce dos Santos por tudo o que sempre me ensinaram.

À minha tia Luiza de Fátima Doce pela confiança depositada, nos momentos mais difíceis.

Aos senhores Guilherme Andrade, gerente do Centro de Engenharia de Adesivos Loctite, Luiz Augusto Moreira, Marcelo Cardaci e Wilson Bueno, gerentes comerciais da divisão automotiva da Henkel Ltda. pela oportunidade e recursos concedidos.

À André Cunha, Andrea Monteiro, Bruno Guerato, Danilo Clemente, Danilo Stocco, Gerson dos Santos, Juliana Almeida, Natasha Cruz e Valdomiro Alves Cerqueira que colaboraram diretamente com a realização deste trabalho.

À toda equipe de vendas da divisão automotiva da Henkel Ltda por disponibizarem toda a ajuda e incentivos solicitados, especialmente à Paulo Melchert, Carlos Kuhn e Ana Paula Porto.

À Marisa Simões Dias por me guiar nos momentos em que não pude ver.

À todos que cooperaram direta ou indiretamente na realização deste trabalho. 
Deus conceda-me a serenidade, para aceitar o que não posso modificar, a coragem para modificar o que eu posso e a sabedoria para reconhecer a diferença.

(Oração da Serenidade) 


\section{RESUMO}

Este trabalho tem como objetivo estudar a resistência mecânica de junções adesivas. A influência das condições de superfície e de cura na resistência de junções adesivas, unidas por adesivo acrílico, foi quantificada através da realização de ensaios de cisalhamento de chapas sobrepostas, com resultados processados através do Planejamento Fatorial $2^{k}$. Sobreposição simples de chapas também foi utilizada nos ensaios que permitiram analisar outro fator, o comportamento da resistência em função do comprimento de sobreposição das chapas. Esclarecendo contradição apresentada em diferentes publicações. Um dispositivo modificado de Arcan foi utilizado na realização de experimentos, os quais tornaram possível analisar o comportamento de junções adesivas submetidas a esforços combinados, com diferentes velocidades no deslocamento. Este estudo contribui em projetos que envolvem junções adesivas, apresentando informações de alto nível de importância, a serem utilizadas para determinar a melhor condição de trabalho destas junções.

Palavras-chaves: junção adesiva, adesivo estrutural, planejamento fatorial, esforços combinados, Arcan. 


\begin{abstract}
The aim of this work is to study the mechanical strength of adhesively bonded joints. The influence of surface and cure conditions on the strength were taken in consideration. Such influences were sized through shear tests of single lap joints, with results processed by Factorial Design $2^{\mathrm{k}}$. Single lap joints were also used in tests, which made possible to analyze another factor, the influence of overlap length on the joint mechanical strength. A modified Arcan Device was used, with specific specimens, to analyze the joints behavior, when submitted to combined strengths. This study provided important informations, which are able to be applied to adhesively bonded joints design.
\end{abstract}

Keywords: adhesive joint, structural adhesive, factorial design, combined strength, Arcan. 


\section{LISTA DE FIGURAS}

Figura 1 - Vedação de cárter usando silicone (Handbook Loctite) ....................23

Figura 2 - Adesão de front end automotivo com adesivo acrílico.......................23

Figura 3 - Curva de cura por poliadição e policondensação ................................29

Figura 4 - Formulações de adesivos acrílicos ................................................29

Figura 5 - Reação redox em adesivos acrílicos .................................................30

Figura 6 - Tipos de curas de adesivos acrílicos ...............................................

Figura 7 - Regiões de adesão e coesão de junções adesivas .............................33

Figura 8 - Falha adesiva por contaminação ........................................................34

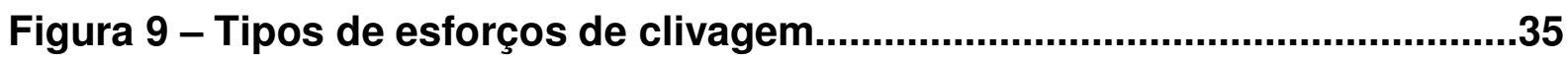

Figura 10 - Tipos de esforços de peeling …..........................................................

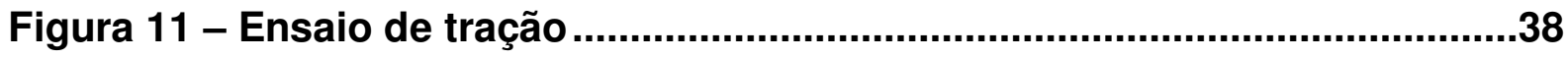

Figura 12 - Análise de um ensaio de cisalhamento ..........................................41

Figura 13 - Parâmetros geométricos e de materiais ................................................44

Figura 14 - Dispositivo para testes com esforços combinados ..........................48

Figura 15 - Corpo de prova utilizado por Lee ....................................................48

Figura 16 - Corpos de prova utilizados por Cognard .........................................49

Figura 17 - Corpo de prova e dispositivo de Arcan utilizado por Duncan.........50

Figura 18 - Resistência do adesivo Loctite $326 \times$ temperatura de trabalho.......57

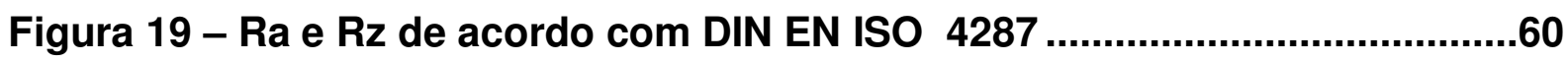

Figura 20 - Nanotubos de carbono de parede simples......................................64

Figura 21 - Nanotubos de carbono de multi-paredes .........................................64

Figura 22 - Nanotubos de carbono em matriz de nanopolímero ........................65

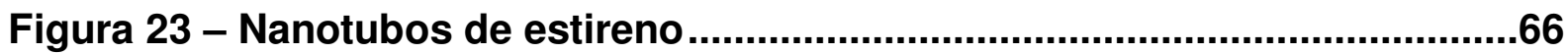

Figura 24 - Estrutura cristalina da camada de fosfato tricatiônico....................68

Figura 25 - Painéis com aplicação de Fosfato de Ferro (esquerda) e nanocerâmica Bonderite NT-1 (direita) após 504h em "Neutral Salt Spray"......70 Figura 26 - Região de contato entre superfície metálica e adesivo epóxi polimerizado ............................................................................................72

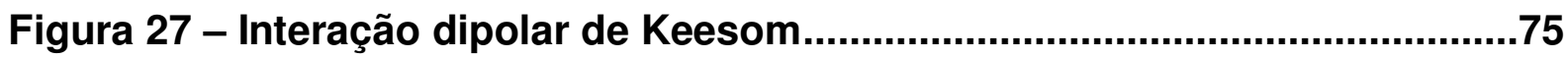

Figura 28 - Superposição de orbitais na formação de Orbitais Moleculares ....77

Figura 29 - Matriz ferrítica com aproximadamente $10 \%$ de perlita .80 
Figura 30 - Camada de óxido formada na superfície das chapas.

Figura 31 - Equipamento Climats utilizado para controle de temperatura e umidade relativa do ar.

Figura 32 - Tanques com produtos para aplicação de nanocerâmica Bonderite NT1. .85

Figura 33 - Corpos de prova em processo de tratamento superficial. 85

Figura 34 - Configuração geométrica dos corpos de prova. 88

Figura 35 - Corpos de provas aguardando ensaio de cisalhamento. 88

Figura 36 - Equipamento EMIC DL5000 com célula de carga de 50kN. .90

Figura 37 - Configuração geométrica dos corpos de prova para análise do comprimento de sobreposição. .93

Figura 38 - Corpos de prova baseados em Lee (1998).......................................94

Figura 39 - Região de aplicação do adesivo...................................................95

Figura 40 - Dispositivo de Arcan desenvolvido por Kavamura ..........................95

Figura 41 - Dispositivo de Arcan para junções adesivas.....................................96

Figura 42 - Corpos de prova para junções adesivas (borboleta). ......................97

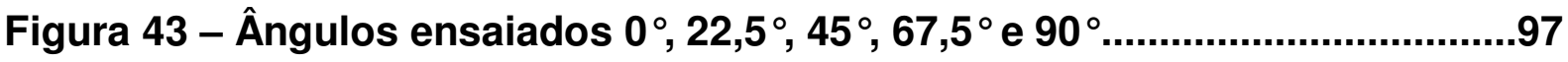

Figura 44 - Efeito Pareto das tensões médias de ruptura..................................102

Figura 45 - Efeitos principais das tensões médias de ruptura. ........................102

Figura 46 - Representação dos efeitos de interação.......................................104

Figura 47 - Desplacamento da camada de óxido nas extremidades $(40 \mathrm{~mm}) . .108$

Figura 48 - Resultados experimentais - comprimento de sobreposição. ........109

Figura 49 - Curva da média das tensões médias de ruptura ..........................110

Figura 50 - Distribuição da tensão com sobreposição de $10 \mathrm{~mm}$....................112

Figura 51 - Distribuição da tensão com sobreposição de $20 \mathrm{~mm}$....................112

Figura 52 - Distribuição da tensão com sobreposição de $30 \mathrm{~mm}$....................113

Figura 53 - Distribuição da tensão para com sobreposição de $40 \mathrm{~mm}$.............113

Figura 54 - Distribuição da tensão com sobreposição de $50 \mathrm{~mm}$....................114

Figura 55 - Drucker-Pager x Resultados experimentais $-2 \mathrm{~mm} / \mathrm{min}$................119

Figura 56 - Drucker-Pager x Resultados experimentais - 10mm/min .............119

Figura 57 - Curvas obtidas através do Critério de Escoamento de DruckerPager. 


\section{LISTA DE ABREVIATURAS}

$\begin{array}{ll}\text { ABS } & \text { Acrilonitrila-butadieno-estireno } \\ \text { ASTM } & \text { American Society for Testing Materials } \\ \text { CEAL } & \text { Centro de Engenharia de Adesivos Loctite } \\ \text { DIN } & \text { Deutsches Institut fuer Normung } \\ \text { ISO } & \text { International Organization for Standardization } \\ \text { PE } & \text { Polietileno } \\ \text { PMMA } & \text { Polimetacrilato de Metila } \\ \text { PP } & \text { Polipropileno } \\ \text { PS } & \text { Poliestireno } \\ \text { PU } & \text { Poliuretano } \\ \text { PVC } & \text { Poli Cloreto de Vinila } \\ \text { SAE } & \text { Society of Automotive Engineers } \\ \text { Tg } & \text { Temperatura de Transição Vítrea } \\ \text { TOM } & \text { Teoria do Orbital Molecular } \\ \text { UV } & \text { Ultravioleta }\end{array}$




\section{SUMÁRIO}

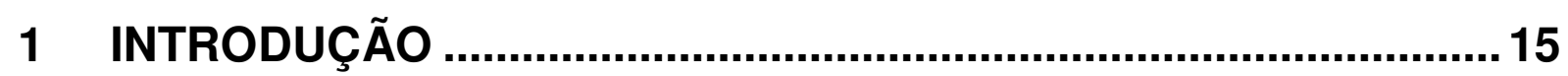

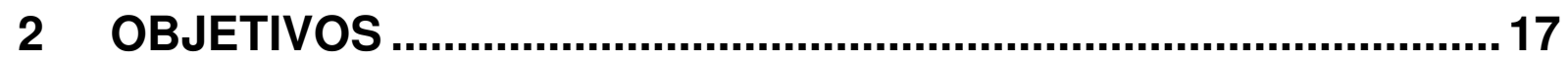

3 ESTUDO MERCADOLÓGICO DE ADESIVOS...............................18

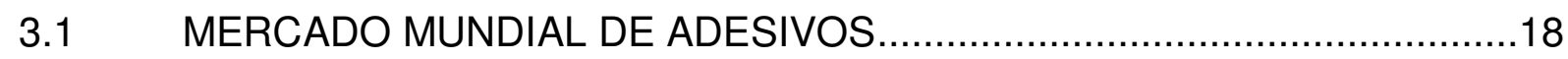

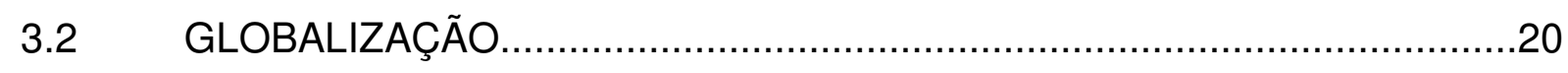

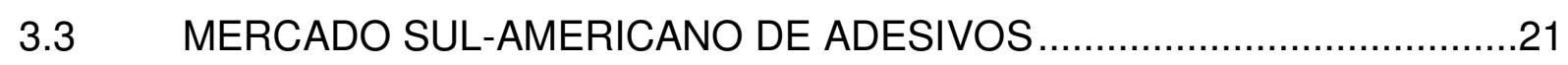

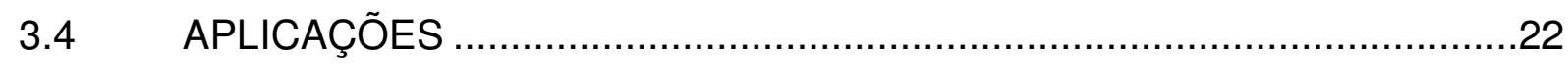

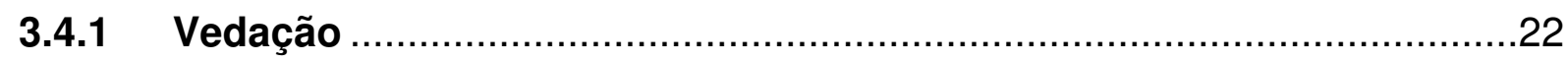

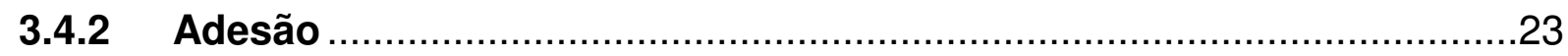

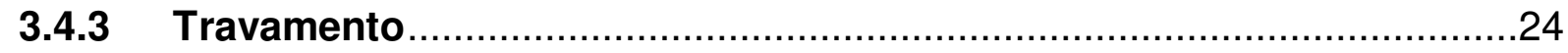

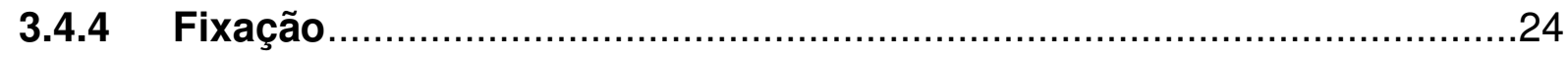

3.5 BENEFÍCIOS DA UTILIZAÇÃO DE ADESIVOS …..................................25

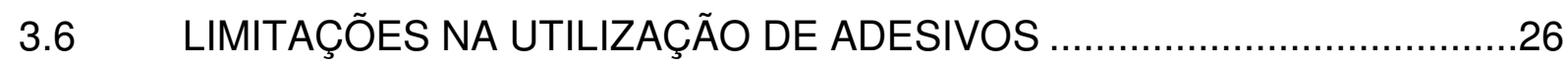

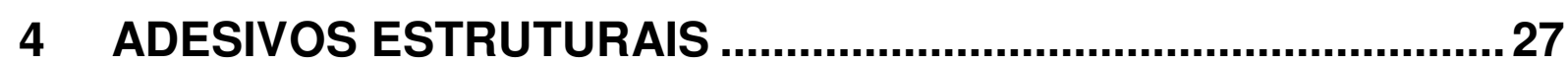

4.1 MERCADO MUNDIAL DE ADESIVOS ESTRUTURAIS …......................27

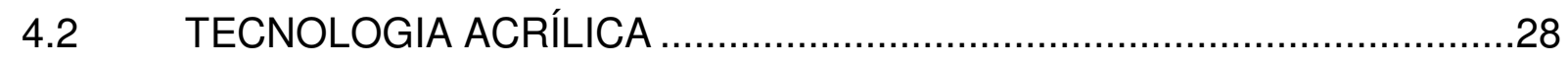

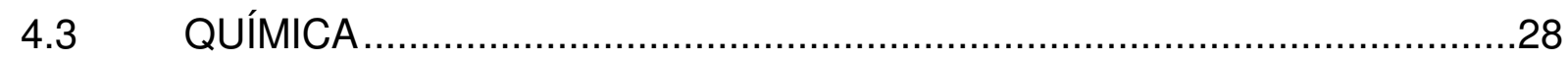

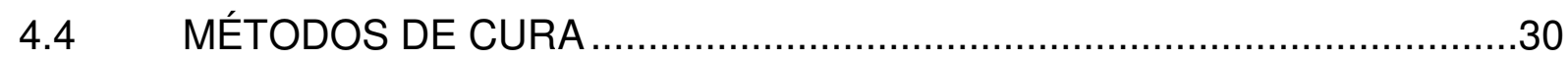

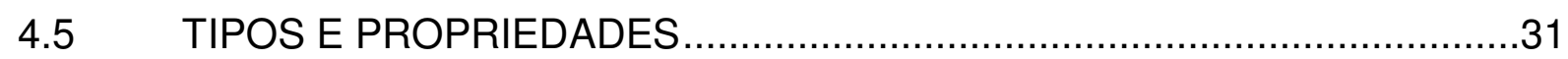


5 ESFORÇOS MECÂNICOS EM JUNÇÕES ADESIVAS 33

5.1 TIPOS DE FALHAS EM JUNÇÕES ADESIVAS ......................................33

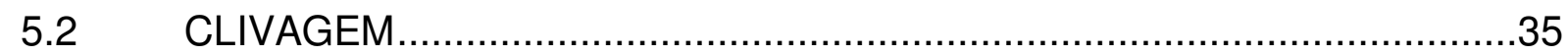

5.3 DESCASCAMENTO

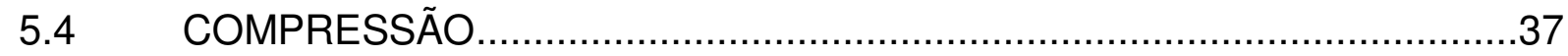

5.5 TRAÇÃO

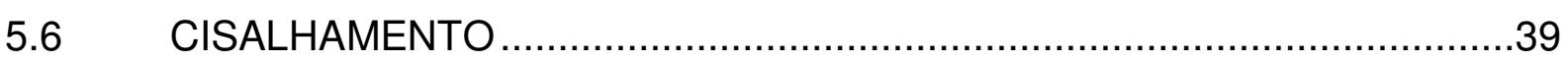

5.6.1 Análise matemática de ensaios de cisalhamento simples....................39

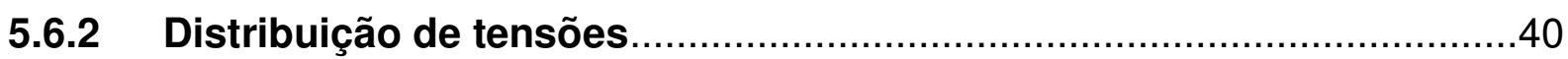

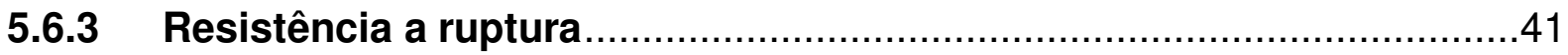

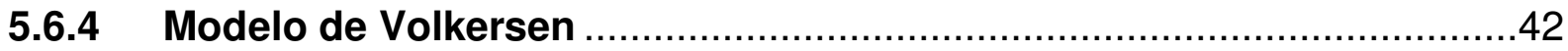

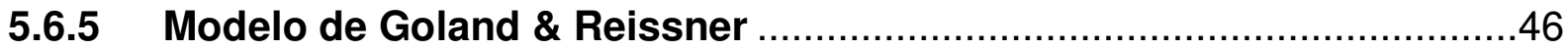

5.6.6 Vantagens e Desvantagens do Ensaio de Cisalhamento Utilizando Junções por Sobreposição Simples de Chapas................................................46

5.6.7 Método de Arcan Aplicado à Junções Soldadas.................................47

5.6.8 Forças Combinadas - Modelo de Arcan Aplicado à Junções adesivas49

5.6.9 Critério Modificado de Von Mises Aplicado à Junções Adesivas .........50

5.6.10 Vantagens e Desvantagens da Utilização do Método de Arcan.............53

6 FATORES INFLUENTES NA RESISTÊNCIA DA JUNÇÂO .......... 54

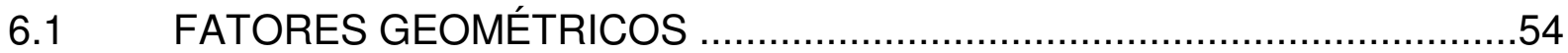

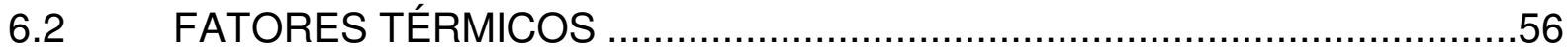

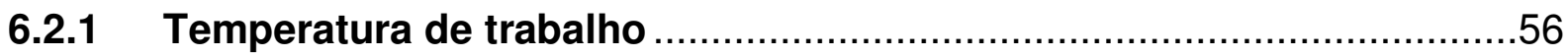

6.2.2 Temperatura de transição vítrea ....................................................57

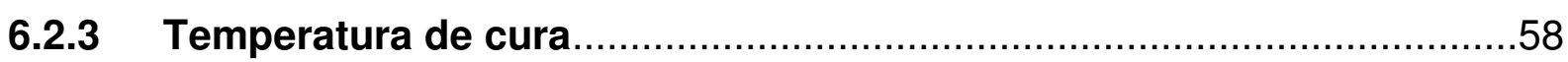

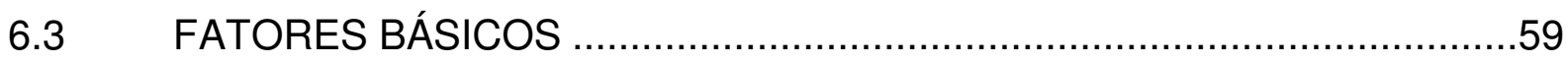

6.3.1 Rugosidade

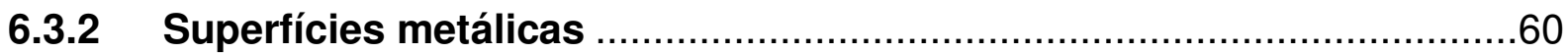

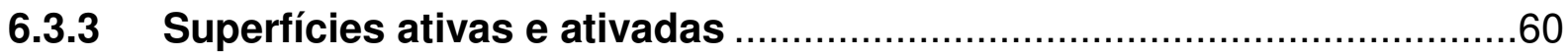

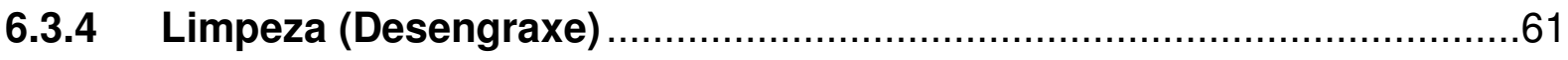




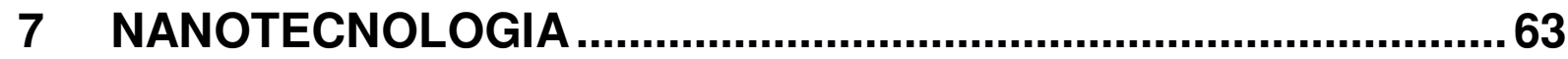

7.1 COMPETITIVIDADE DO MERCADO MUNDIAL DE MATERIAIS...............63

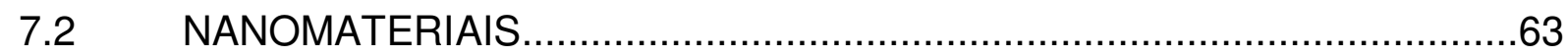

7.3 NANOCERÂMICA APLICADA COMO TRATAMENTO SUPERFICIAL ......66

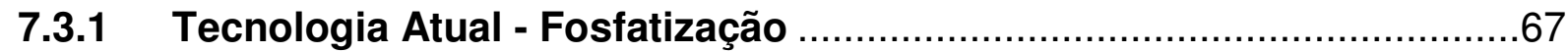

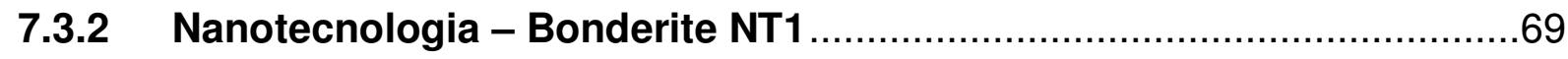

8 MODELOS TÉORICOS DE ADESÃO .............................................71

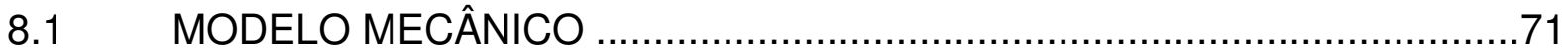

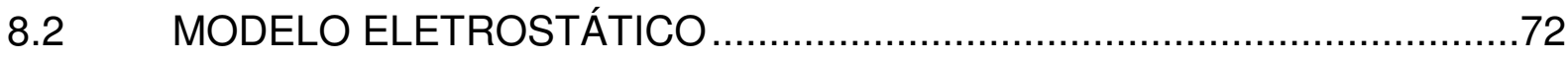

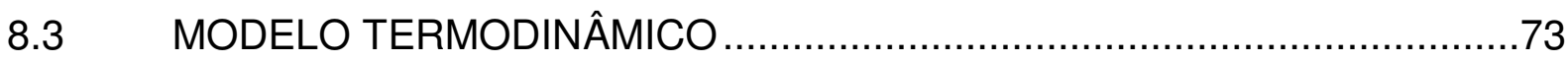

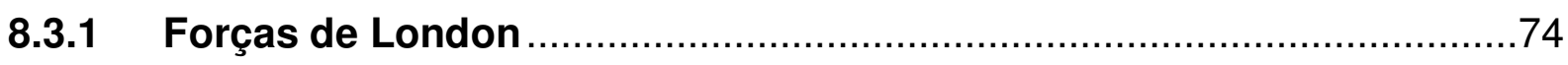

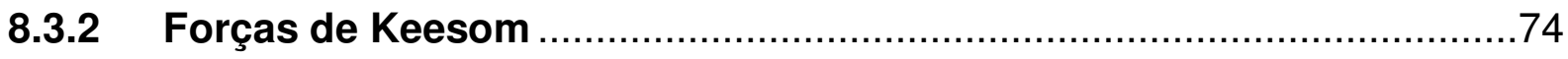

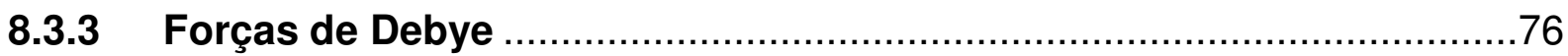

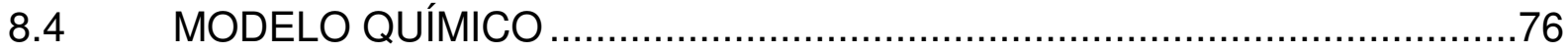

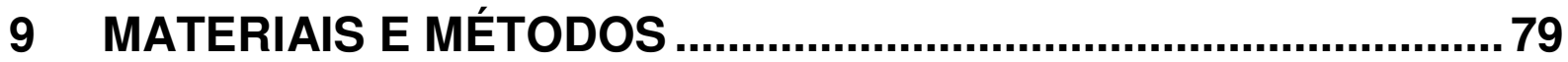

9.1 PRIMEIRO MÉTODO - ANÁLISE DOS FATORES DE INFLUÊNCIA ........79

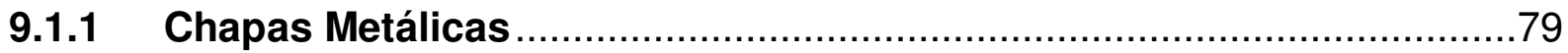

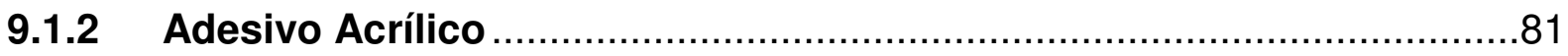

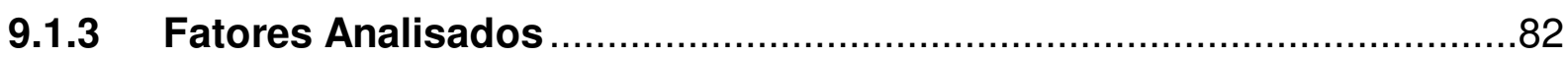

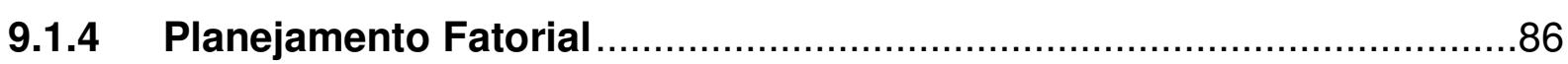

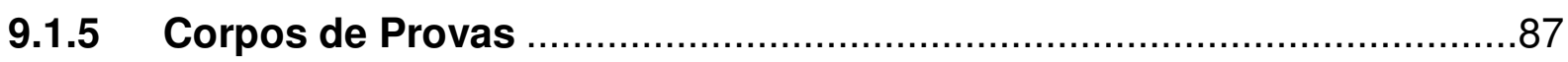

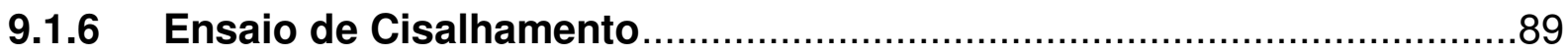

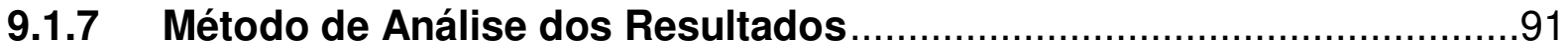

9.2 SEGUNDO MÉTODO - INFLUÊNCIA DO COMPRIMENTO DE

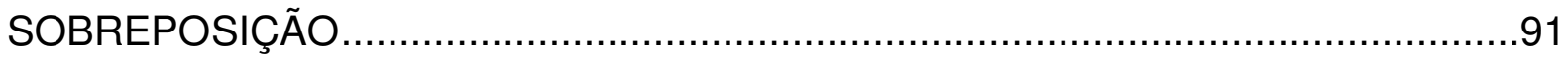

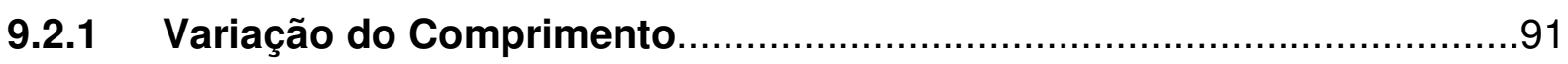

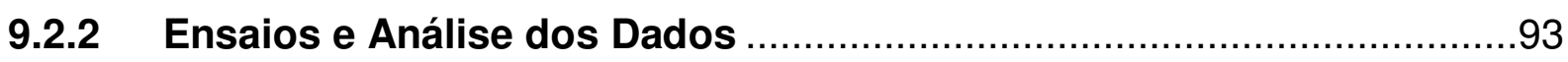

9.3 TERCEIRO MÉTODO - COMPORTAMENTO DA JUNÇÃO SUBMETIDA À

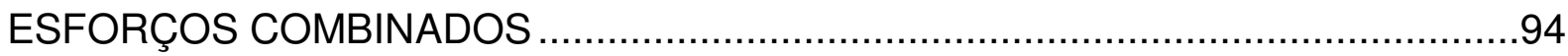

9.3.1 Aplicabilidade dos Corpos de Prova de Lee.....................................94

9.3.2 Corpos de Prova para Junções Adesivas ................................................95 
10.1 INFLUÊNCIA DOS FATORES DE SUPERFÍCIE E DE CURA DO ADESIVO

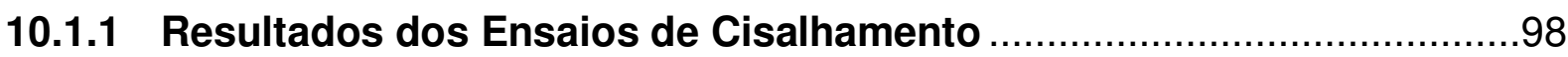

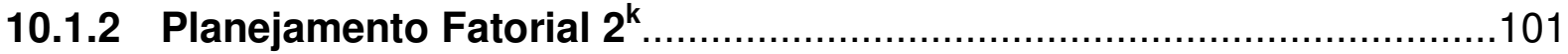

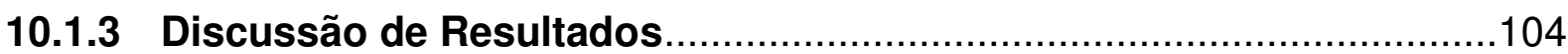

10.2 INFLUÊNCIA DO COMPRIMENTO DE SOBREPOSIÇÃO.....................107

10.2.1 Resultados dos Ensaios de Cisalhamento …..................................107

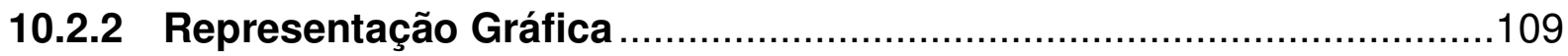

10.2.3 Modelos Aplicados aos Resultados Experimentais.........................110

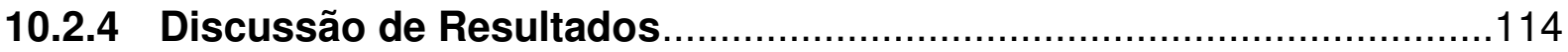

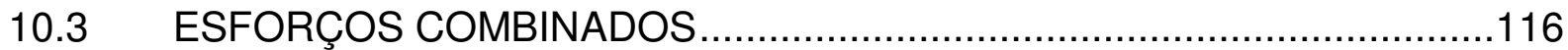

10.3.1 Resultados Experimentais com Corpos de Prova de Lee ...................116

10.3.2 Resultados Experimetais com Corpos de Prova Específicos.............117

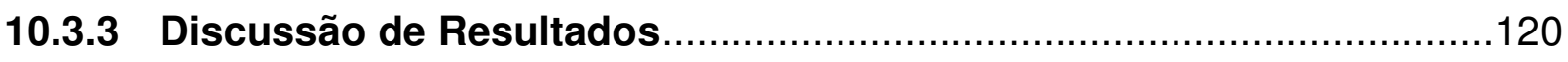

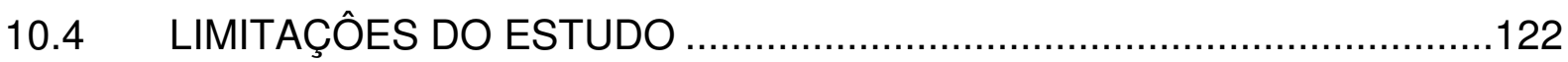

11 CONCLUSÕES ....................................................................... 123

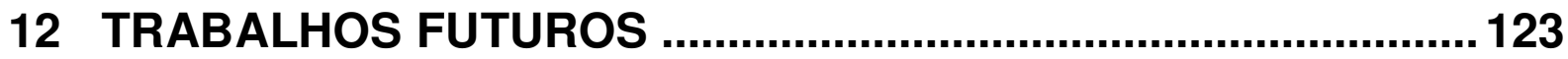

13 REFERÊNCIAS BIBLIOGRÁFICAS ...................................... 126

APÊNDICE A - RESULTADOS EXPERIMENTAIS........................... 130 


\section{INTRODUÇÃO}

O alto nível de exigência dos diversos segmentos da indústria gera a crescente necessidade de desenvolvimento de novas tecnologias. As quais devem resultar em alta produtividade e qualidade, com permanente redução de custos. A tecnologia de adesivos é uma das ferramentas que permite o alcance de tais objetivos.

Segmentos industriais dos mais variados utilizam adesivos em seus processos e produtos. Tal utilização varia de aplicações simples como a adesão de placas identificadoras até aplicações que exigem alto nível de engenharia e desenvolvimento, como a vedação de caixas de transmissões e adesão estrutural de componentes da carroceria de veículos.

Embora a utilização de adesivos seja ampla e apresente altas taxas de crescimento, pouco se conhece sobre a tecnologia de adesão. Modelos de adesão vêm sendo desenvolvidos desde 1938, sendo o Modelo de Volkersen o primeiro modelo publicado. Ainda hoje não se conhece com profundidade suficiente os fatores de interface adesivo substrato. Estudos mais recentes tentam provar que ocorrem reações do tipo química nesta interface, baseadas na Teoria do Orbital Molecular.

Este trabalho visa cooperar com o desenvolvimento de aplicações de adesivos na indústria, através da geração de conhecimento sobre o assunto. Bem como contribuir, através das informações geradas, com projetos que envolvam junções adesivas.

A sobreposição simples de chapas é o método de união de chapas mais utilizado pela indústria, sendo o esforço de cisalhamento o mais comum neste tipo de montagem, porém não o único tipo de esforço.

Diversos trabalhos já foram publicados apresentando modelos que consideram a influência das condições geométricas da junção na resistência final da mesma. Porém, não foi encontrado na literatura nenhum trabalho que quantifique a influência de fatores de superfície do substrato como rugosidade e tratamento superficial, bem como de fatores de cura do adesivo como temperatura e uso de ativadores na resistência da junção, fatores estes considerados neste trabalho.

Este trabalho contemplou a realização de ensaios de cisalhamento, sendo que a configuração das condições das junções foi determinada pela aplicação de Planejamento Fatorial $2^{k}$. Os resultados foram analisados pelo Software Minitab, 
tornando possível quantificar a influência de determinados fatores de cura e substrato na resistência das junções.

As poucas informações existentes sobre a utilização de adesivos em alguns momentos se contradizem. Durante a realização de revisão bibliográfica foi encontrada divergência entre trabalhos de alguns autores, no que tange a influência do comprimento de sobreposição na resistência das junções. Foram realizados ensaios variando o comprimento de sobreposição das junções, com o intuito de verificar a variação da resistência em função do comprimento de sobreposição.

Conforme citado anteriormente, o esforço de cisalhamento é o mais presente em junções adesivas, porém não é o único. Devido à este fator foram realizados ensaios com esforços combinados, através da utilização de um dispositivo modificado de Arcan. Os dados gerados tornaram possível determinar um critério de falha a ser utilizado em projetos de junções adesivas, gerando maior embasamento técnico para a aplicação de junções adesivas. 


\section{OBJETIVOS}

O objetivo principal deste trabalho é contribuir com projetos que envolvam junções adesivas, através da geração de conhecimento referente à resistência das mesmas. Como objetivo inicial foi quantificada a influência de fatores de superfície do substrato e de cura do adesivo na resistência das junções. Alcançar tal objetivo foi possível através da realização de ensaios de cisalhamento de junções adesivas por sobreposição simples de chapas. As quais foram unidas por adesivo estrutural de base acrílica. Ensaios complementares objetivaram determinar o comportamento destas junções em função da variação do comprimento de sobreposição. Apresentando solução para a divergência encontrada em publicações, a qual é baseada no Modelo de Volkersen. Como objetivo final foram realizados ensaios considerando esforços combinados, visando apresentar o comportamento do adesivo analisado quando submetido a esforços combinados. Gerando desta forma um critério de falha para junções adesivas. $O$ qual associado aos dados anteriores contribui em projetos que envolvem junções adesivas. 


\section{ESTUDO MERCADOLÓGICO DE ADESIVOS}

\subsection{MERCADO MUNDIAL DE ADESIVOS}

De acordo com Possart (2006) adesivos são substâncias capazes de unir diferentes substratos através da interação com suas superfícies. Apresentam-se inicialmente na fase líquida, com posterior solidificação causada por processo físico, por exemplo, evaporação de solvente, ou processo químico, por exemplo reação entre duas substâncias, resina e endurecedor. Este processo de solidificação denomina-se polimerização.

Estão disponíveis no mercado mundial diversos tipos de adesivos, sendo que os principais adesivos são basicamente divididos em cinco diferentes famílias, as quais podem se subdividir de acordo com base química, tipo de aplicação e tipo de cura entre outras características (CARLAC, 2002). São apresentadas na Tabela 1 as principais famílias de adesivos, com as respectivas aplicações e bases químicas.

Tabela 1 - Principais famílias de adesivos, aplicações e participação no mercado mundial (CARLAC, 2002, p. 15).

\begin{tabular}{|c|c|c|c|c|}
\hline $\begin{array}{l}\text { Família de } \\
\text { Adesivos }\end{array}$ & Apresentação & Aplicação & $\begin{array}{l}\text { Participação } \\
\text { no Mercado }\end{array}$ & Bases Químicas \\
\hline $\begin{array}{l}\text { Base } \\
\text { Aquosa }\end{array}$ & $\begin{array}{l}\text { Emulsão } \\
\text { Solução }\end{array}$ & $\begin{array}{c}\text { Embalagem } \\
61 \%\end{array}$ & $43 \%$ & $\begin{array}{c}\text { Acetato de Vinila } \\
\text { Acrílicos } \\
\text { Borrachas }\end{array}$ \\
\hline $\begin{array}{l}\text { Termo- } \\
\text { fundíveis }\end{array}$ & $\begin{array}{c}\text { Sólidos à } \\
\text { temperatura } \\
\text { ambiente }\end{array}$ & $\begin{array}{c}\text { Embalagem } \\
63 \%\end{array}$ & $15 \%$ & $\begin{array}{l}\text { Etileno } \\
\text { Nylon }\end{array}$ \\
\hline $\begin{array}{c}\text { Base } \\
\text { Solvente }\end{array}$ & & $\begin{array}{l}\text { Embalagem } \\
\text { Construção }\end{array}$ & $11 \%$ & $\begin{array}{c}\text { Borracha natural } \\
\text { e sintética }\end{array}$ \\
\hline Reativos & $\begin{array}{c}\text { Compostos } \\
\text { Macromoleculares }\end{array}$ & $\begin{array}{l}\text { Aplicações } \\
\text { que exijam } \\
\text { alta } \\
\text { resistência }\end{array}$ & $8 \%$ & $\begin{array}{l}\text { Acrílicos } \\
\text { Epóxis }\end{array}$ \\
\hline UV & $\begin{array}{l}\text { Cura por exposição } \\
\text { à radiação UV }\end{array}$ & $\begin{array}{l}\text { Adesão } \\
\text { Estrutural }\end{array}$ & $1 \%$ & $\begin{array}{l}\text { Acrílicos } \\
\text { Silicones }\end{array}$ \\
\hline
\end{tabular}


Segundo Will et al. (2003) anualmente o mercado mundial de adesivos movimenta quantias superiores à EUR26 bilhões, representadas em volume por mais de 12 milhões de toneladas de adesivos. A principal área de aplicação é a industria de embalagens, com $42,5 \%$ do mercado mundial (em valores), seguida pelas industrias de construção civil com $17,5 \%$ e de transporte com $10 \%$ do mercado. Juntos estes três segmentos da indústria representam mais de dois terços do faturamento global de adesivos.

Os adesivos à base de solvente perderam participação no mercado mundial nos últimos anos, devido à preocupação com a emissão de substâncias nocivas ao meio ambiente. Tal condição estimulou o investimento em adesivos de base aquosa, tornando-os a família com maior participação no mercado nos últimos anos. A segunda família com maior participação refere-se aos "Hotmelts" (termo-fundíveis), sendo a terceira família os adesivos de base solvente.

Grandes empresas investem forte em pesquisa e desenvolvimento com o intuito de criar novos produtos e patentes. Dentre estas empresas estão os dois maiores fabricantes mundiais de adesivos, com destaque para empresa Henkel que sozinha detém $12 \%$ do mercado mundial, além de estar entre os cinco maiores criadores de patentes, conforme é apresentado pela Tabela 2.

Tabela 2 - Empresas com maior número de patentes e respectiva participação no mercado mundial (CARLAC, 2002, p. 18).

\begin{tabular}{llll}
\hline Empresa & Número de Patentes & País & Participação \\
\hline NITTO-DENKO & 1100 & Japão & -- \\
$3 M$ & 975 & EUA & $9 \%$ \\
KANEKA & 325 & Japão & -- \\
BEIERSDORF & 285 & Alemanha & -- \\
HENKEL & 215 & Alemanha & $12 \%$ \\
\hline
\end{tabular}

Dados de 2000 apontaram a América do Norte como região de maior representação para o mercado mundial de adesivos, detendo $38 \%$ do mercado em valores, seguida pelo Oeste Europeu com 36\% e Ásia/Pacífico com 20\%. Em volume a região Ásia/Pacífico encontra-se em primeiro lugar com $42 \%$ do mercado, seguida pela América do Norte com 32\% e Oeste Europeu com 20\%. 


\subsection{GLOBALIZAÇÃO}

Will et al. (2003) afirma que fabricantes de adesivos operam em uma mistura de mercados regionais e globais, dependendo do segmento de atuação de cada fabricante. Fornecedores para as indústrias automotiva, de embalagens e geral operam usualmente de forma global. Enquanto fornecedores de adesivos para construção civil trabalham regionalmente, devido às diferenças culturais de cada região. O segmento de construção civil exige que a individualidade do comprador seja respeitada.

No mercado mundial de adesivos os fornecedores seguem seus clientes em novos mercados, como exemplo, pode-se citar a indústria automotiva. A instalação de uma nova planta representa possibilidade de negócios para os fornecedores de adesivos. É usual a realização de "joint ventures" entre empresas globais e fornecedores locais, como uma forma de acesso rápido ao mercado, utilizando o conhecimento do fornecedor local sobre o mercado regional.

Alguns fatores considerados críticos são de extrema importância para o sucesso no mercado de adesivos. Estes fatores são similares na maioria dos mercados, porém com uma leve variação do grau de importância para cada mercado especifico:

- Desempenho do produto: embora os adesivos representam uma pequena parte dos produtos onde são utilizados, seu desempenho geralmente é de extrema importância. A falha no desempenho do adesivo pode comprometer a integridade e operação do produto. Por isso os clientes finais desprendem tempo e esforços na escolha do fornecedor de adesivo.

- $\quad$ Especialistas técnicos e de mercado: outro fator importante para o sucesso no mercado de adesivos é o especialista técnico, independente do segmento de adesivo ou tamanho da empresa. Porém o tipo de especialista técnico necessário depende de adesivo e segmento onde a empresa atua.

- Assistência técnica: como na utilização da maioria dos produtos químicos de alto desempenho, a assistência técnica é um fator crucial para o sucesso da empresa também no segmento de adesivos. O serviço de assistência técnica compreende treinamentos, preparação de formulações específicas e solução de problemas na planta do cliente. 
- Bom relacionamento com o cliente: bom relacionamento pessoal com funcionários de compras e produção é essencial para construir e manter parcerias de sucesso com clientes. Mesmo que assuntos referentes à fatores financeiros e técnicos não sejam considerados, pode-se através de funcionários destas áreas obter informações sobre novas possibilidades de negócio e sobre concorrentes.

- $\quad$ Especialização em segmento: especialização em determinado segmento de produtos e aplicações é particularmente importante para fabricantes de adesivos com baixo volume de produção. Algumas empresas são reconhecidas por fornecer uma grande quantidade de produtos para um determinado segmento do mercado.

- Organização de Vendas e Marketing: o desenvolvimento e implantação de mercados e canais de distribuição é fator crítico para o mercado de adesivos. No mercado de adesivos industriais, particularmente no mercado de adesivos de engenharia, desenvolvimento de produtos, profundo conhecimento das necessidades do cliente, resposta técnica rápida e efetiva, boas relações custo/beneficio e disponibilidade de equipamentos para aplicação são fatores chave para o sucesso.

\subsection{MERCADO SUL-AMERICANO DE ADESIVOS}

Carlac (2002) aponta a América do Sul como uma das regiões de menor participação no mercado mundial de adesivos, aproximadamente $1 \%$ do mercado em valores e $2 \%$ em volume. Porém, o crescimento da produção de adesivos no mercado Sul-Americano, medido entre 1996 e 2000, teve taxa de crescimento maior em volume que a média mundial neste intervalo de tempo. O mercado sul-americano ficou atrás somente da região Ásia / Pacífico. Enquanto a taxa média anual de crescimento do mercado mundial foi de 3,7\%, a América do Sul cresceu aproximadamente $4,8 \%$ ao ano, inferior somente ao crescimento do mercado Ásia / Pacífico que foi de 5,3\%.

Em valores, a América do Sul foi a região de maior crescimento no mundo, mantendo grande superioridade à taxa média mundial. A produção de adesivos na América do Sul teve crescimento anual de $8 \%$, sendo a taxa média mundial em valores de $1,6 \%$. O que mostra que a região aumentou a produção de adesivos com 
maior valor agregado, já que o crescimento em valores foi superior ao crescimento em volume, além de comprovar o grande potencial da região para produção e consumo de adesivos.

\subsection{APLICAÇÕES}

A indústria em todos os seus níveis utiliza adesivos para as mais diversas finalidades desde "hotmelts" para fabricação de fraldas, poliuretanos expansíveis na construção civil, passando por adesivos acrílicos de cura UV na fabricação de agulhas médicas, até epóxis estruturais aplicados na carroceria de veículos. Os adesivos de engenharia, normalmente são utilizados em quatro tipos de aplicações diferentes: vedação, adesão, travamento e fixação.

\subsubsection{Vedação}

Neste tipo de aplicação os adesivos são utilizados entre áreas de contato de superfícies de duas ou mais peças, a função é impedir a passagem de gás ou líquido entre estas superfícies. Diferentes condições geométricas e de aplicação necessitam diferentes tipos de adesivos.

Vedação de flanges flexíveis, normalmente quando uma das partes é obtida por processo de estampagem, requer a utilização de adesivos com alta capacidade de preenchimento de folga e alto alongamento, para este tipo de aplicação utiliza-se comumente silicone. A Figura 1 ilustra a aplicação de adesivo à base de silicone, utilizado para vedação de cárter de motor veicular.

Flanges denominadas rígidas, normalmente usinadas, com reduzida amplitude de movimentos relativos e pequenas folgas, requerem a utilização de adesivo anaeróbico. 


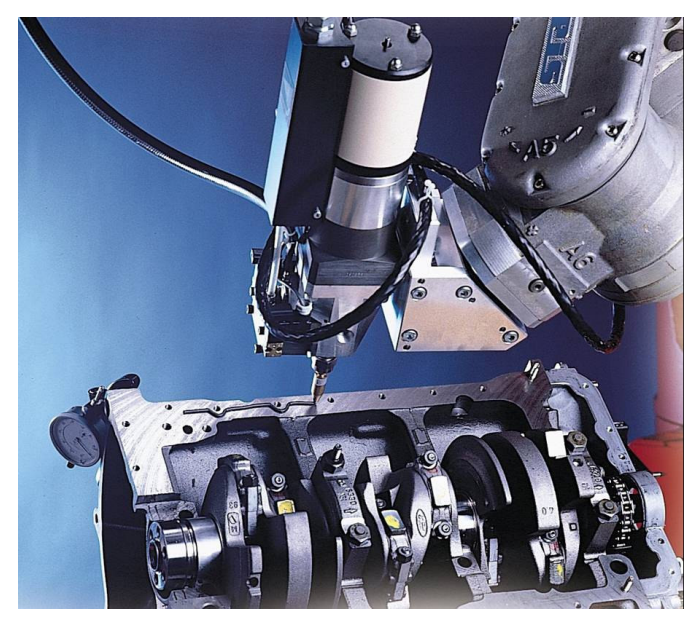

Figura 1 - Vedação de cárter usando silicone (Handbook Loctite, 1995).

\subsubsection{Adesão}

A adesão é caracterizada pela união de duas ou mais partes não cilíndricas. $O$ tipo de adesivo a ser utilizado é determinado através da análise das características da aplicação. Na indústria automotiva, por exemplo, adesivos à base PU são utilizado na adesão de vidros em carrocerias de veículos. Outro exemplo de adesão, porém na industria geral, é a utilização de adesivo acrílico na união de ferrites à carcaças de motores elétricos. É apresentado na Figura 2 componente veicular estrutural feito de PP, o qual é aderido à carroceria do veículo, normalmente em aço, através da utilização de adesivo acrílico especial.

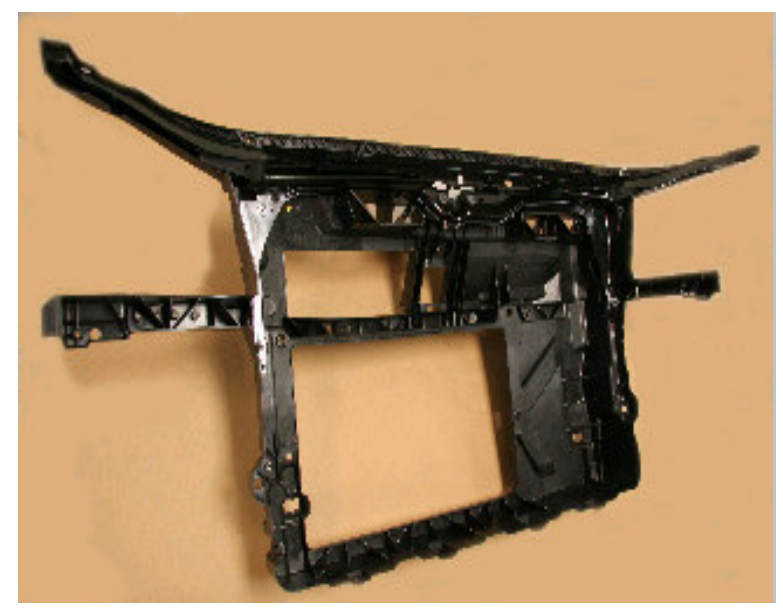

Figura 2 - Adesão de "front end" automotivo com adesivo acrílico (VW PÓLO). 


\subsubsection{Travamento}

O conjunto porca/parafuso ainda é um dos sistemas mais utilizado para união de partes. A função deste sistema é unir e manter peças unidas através do esforço de compressão, além de possibilitar a desmontagem e manutenção destas peças, o que o diferencia, por exemplo, de processos como o de solda. Devido a fatores externos como vibrações, corrosão ou até mesmo ao relaxamento de tensão causado pelos ciclos de trabalho do parafuso, existe a possibilidade de falha. A utilização de adesivos anaeróbicos entre as superfícies roscadas impede a falha. Isto se deve ao fato do adesivo preencher todos os espaços vazios entre as roscas, agindo como amortecedor para as vibrações e aumentando a área de contato e respectivamente $o$ atrito entre as partes. Além das funções acima citadas, o adesivo proporciona aumento e controle do torque de desmontagem e proteção contra agentes oxidantes, devido à formação de película polimérica entre as partes. Travamento é o processo pelo qual é impedido o movimento relativo entre os elementos roscadas e conseqüentemente sua soltura.

\subsubsection{Fixação}

A união de elementos cilíndricos por adesivo é denominada fixação, tem-se como exemplo de fixação a união de engrenagem à eixo ou de rolamento em mancal. No caso da engrenagem, além de impedir o deslocamento, o adesivo é responsável por transmitir os esforços para o eixo. Nas aplicações citadas o adesivo pode substituir ou complementar processos de montagem por interferência ou montagem à quente, além de proporcionar melhor distribuição de tensões e impedir de certa forma concentrações de tensão no material. Em casos críticos o adesivo pode ser utilizado em conjunto com processo de interferência ou montagem à quente, aumentando a resistência à extração ou aliviando as condições de interferência. 


\subsection{BENEFÍCIOS DA UTILIZAÇÃO DE ADESIVOS}

A utilização de adesivos para união de materiais cresceu e continua crescendo consideravelmente nos últimos anos. De acordo com Zoran et al. (2001) a razão para isto encontra-se em certas vantagens oferecidas pelas junções adesivas, quando comparadas com outras tecnologias competitivas e no crescente número de informações e conhecimento gerado sobre $o$ assunto. Estas vantagens oferecem como resultado final melhorias de processo, aumento da qualidade e redução de custos para a indústria. Tais benefícios são obtidos devido as seguintes características oferecidas pelos adesivos ou por sua utilização:

- Distribuição uniforme de esforços mecânicos. Por não depender de elementos mecânicos, os quais geram concentrações de tensão nos locais onde são alojados, os adesivos permitem melhor e mais uniforme distribuição das tensões solicitadas pela aplicação (LUCIC, 2006).

- Possibilidade de unir diferentes materiais, com as mais diversas configurações geométricas.

- Vedação e proteção contra corrosão. Depois de polimerizado o adesivo oferece aos substratos além da proteção à corrosão, a possibilidade de vedação, quando necessária.

- Conservação das características mecânicas dos substratos, quando aplicado em metais, mesmo que curado por temperatura. Geralmente as temperaturas de cura e aplicação dos adesivos são inferiores à $200^{\circ} \mathrm{C}$, não alterando as propriedades mecânicas dos substratos, quando aplicados em metais.

- Amortecimento de vibrações. Propriedades mecânicas dos adesivos como alta resistência à compressão e alto alongamento, possibilitam a utilização de adesivos em grande número de aplicações onde se faz necessária a absorção de vibrações, de impactos e ocorrem variações dimensionais.

Um dos fatores chaves na utilização de adesivos é a possibilidade de calcular antecipadamente a resistência das junções, assim como predizer o comportamento dos adesivos no que se refere ao envelhecimento e enfraquecimento das junções (TAKIGUCHI, 2004). O desenvolvimento de modelos matemáticos e a realização de estudos para tal finalidade diminuem a necessidade de testes destrutivos para determinação do adesivo ideal para determinadas aplicações. 


\subsection{LIMITAÇÕES NA UTILIZAÇÃO DE ADESIVOS}

As limitações da utilização de adesivos devem ser respeitadas visando melhores resultados nas aplicações:

- Limite máximo de temperatura de trabalho. Adesivos anaeróbicos, por exemplo, usualmente apresentam temperatura máxima de trabalho de $150^{\circ} \mathrm{C}$. Os silicones são os adesivos com melhor resistência à altas temperaturas, podendo chegar à $320^{\circ} \mathrm{C}$.

- Boas condições de limpeza das superfícies de aplicação. A utilização de adesivos requer que as superfícies a serem aderidas estejam isentas de qualquer tipo de sujeira, poeira, graxa ou óleo. A presença de qualquer um destes fatores impede o contato entre o adesivo e o substrato, comprometendo as propriedades desejadas. Desta forma, em alguns casos é necessário a inclusão de um processo de limpeza ou preparo da superfície com tratamentos especiais antes da aplicação do adesivo (HANDBOOK LOCTITE, 1995).

- Tempo de cura. Algumas aplicações requerem testes mecânicos logo após a montagem das peças, em alguns destes casos a utilização de adesivos é impossibilitada ou limitada. A utilização de adesivos é indicada para as aplicações onde os testes não comprometem o desempenho do adesivo. 


\section{ADESIVOS ESTRUTURAIS}

A adesão estrutural é uma junção capaz, enquanto parte integrante de uma estrutura, de apresentar um nível específico de resistência, quando submetida a ação de esforços por tempo especifico (VILLENAVE, 2005).

\subsection{MERCADO MUNDIAL DE ADESIVOS ESTRUTURAIS}

Carlac (2002) descreve que os adesivos estruturais representam $5 \%$ do mercado mundial de adesivos, sendo que $22 \%$ das aplicações com adesivos estruturais são realizadas pela indústria automotiva. $O$ setor automotivo é também o segmento de mercado, junto com o segmento aeronáutico, com melhores perspectivas de crescimento. No Oeste Europeu o mercado de adesivos estruturais foi dimensionado em EUR817 milhões em 1997. Os tipos mais utilizados nestas aplicações são os adesivos acrílicos, PUs e epóxis, sendo que os adesivos UV apresentam promissor crescimento em aplicações nas indústrias eletroeletrônicas (WILL et al., 2003).

As aplicações de adesivos estruturais devem resistir basicamente a cinco tipos de esforços: clivagem, "peeling" ou descascamento, compressão, tração e cisalhamento. Sendo que cada família de adesivo possui características particulares que oferecem maior resistência a determinado tipo de esforço. Os adesivos epóxis, por exemplo, devido sua alta rigidez podem apresentar limitações quando utilizados em aplicações submetidas a esforços de clivagem ou "peeling". Porém oferecem altíssimo desempenho em aplicações que exigem resistência a esforços de cisalhamento e intempéries, este último devido sua alta resistência química. Pode-se citar como exemplo a utilização de adesivos epoxis na carroceria de veículos automotivos, ilustrando desta forma a longa vida útil e alta resistência a esforços, oferecidas por este tipo de adesivo. 


\subsection{TECNOLOGIA ACRÍLICA}

Brinson (1990) descreve os adesivos acrílicos como adesivos estruturais com base de monômeros de metacrilato e cura iniciada por radicais livres. O primeiro desenvolvimento de adesivo acrílico foi realizado na Alemanha Oriental na década de sessenta, tendo como base o polimetacrilato de metila (PMMA). Os adesivos acrílicos, anteriores a este desenvolvimento citado, tratavam-se na verdade de soluções de PMMA dissolvidas em solvente específico. Tais adesivos eram utilizados na união de alumínio, mais precisamente em portas e janelas de alumínio. A partir de então vários estudos foram realizados, resultando nos sofisticados adesivos acrílicos existentes hoje no mercado.

\subsection{QUÍMICA}

Os adesivos acrílicos são caracterizados pelo processo de cura, a qual é realizada pela adição de agentes de polimerização. Estes agentes de polimerização são peróxidos geradores de radicais livres, os quais ao reagir com os monômeros dão início à rápida formação de cadeias, através da quebra de ligações duplas dos monômeros. Desta forma os próprios monômeros, após terem sua ligação quebrada, passam a atuar como agente de polimerização.

Os geradores de radicais livres adicionados aos adesivos acrílicos proporcionam a esta tecnologia de adesivos certas vantagens em relação a outros tipos de adesivos, como epóxi e uretano. Este tipo de cura, adição de geradores de radicais livres, permite que haja movimento relativo entre os substratos, por tempo determinado, mesmo após a montagem e conseqüentemente contato dos substratos com o adesivo. A Figura 3 mostra que por determinado tempo é baixo o nível de cura do adesivo acrílico, permitindo a movimentação citada sem o comprometimento das propriedades finais do mesmo. No caso de adesivos que polimerizam por policondensação, a cura se inicia de força acelerada, imediatamente a montagem dos substratos, desta forma caso haja a movimentação relativa dos substratos, haverá também o comprometimento das propriedades finais do adesivo. 


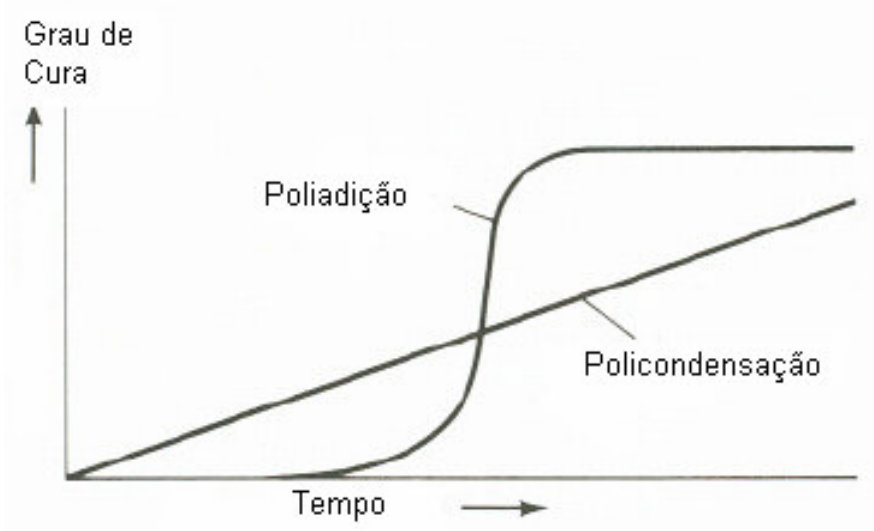

Figura 3 - Curva de cura por poliadição e policondensação (Brinson, 1990)

A Fig. 4 mostra as formulações químicas do metilmetacrilato e de outros monômeros normalmente utilizados em adesivos acrílicos.<smiles>C=C(C)COC</smiles>

Metil Metacrilato<smiles>C=C(C)C(=O)OCCCC</smiles>

Butil Metacrilato<smiles>C=C(C)C(=O)OCCOCCOC(=O)C(=C)C</smiles>

Dietileno Glicol Dimetacrilato

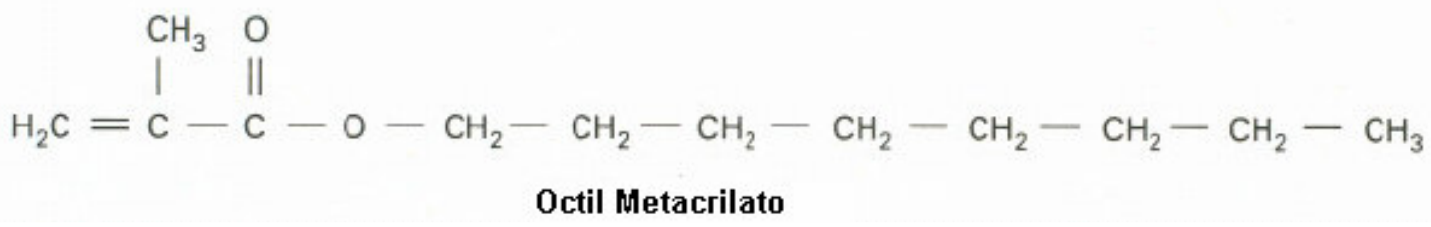

Figura 4 - Formulações de adesivos acrílicos (Brinson, 1990).

Alguns monômeros de adesivos acrílicos tendem a apresentar forte odor, isso se deve ao seu baixo peso molecular. Tais monômeros tendem a apresentar também baixo ponto de fulgor. Monômeros com alto peso molecular oferecem menor odor e elevado ponto de fulgor. Uma característica importante geralmente apresentada por adesivos acrílicos de baixo peso molecular é a melhor adesão proporcionada pelos mesmos (BRINSON, 1990).

Como se pode notar, a cura de adesivos acrílicos, com base de monômeros de metacrilato, necessita da geração de radicais livres. A seguir encontra-se um típico modelo de formação de radicais livres, representado na Figura 5, este método é 
denominado redox (redução e oxidação). Reações "redox" em adesivos acrílicos geralmente envolvem uma amina aromática, como dimetil anilina e outra parte de resina de adesivo.

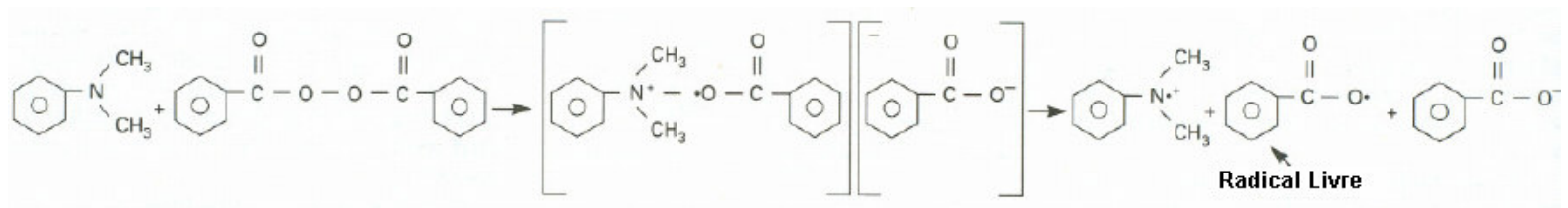

Figura 5 - Reação redox em adesivos acrílicos (Brinson, 1990).

Existem algumas condições que resultam no fim do processo de polimerização e conseqüentemente interrupção na formação da cadeia (CARNEVAROLO, 2002). Tal interrupção ocorre quando não há mais monômeros, quando dois radicais livres reagem e formam um par de elétrons estável ou devido ao excesso de estabilizantes.

A tendência de polimerização espontânea de adesivos acrílicos torna necessária a utilização de estabilizantes, visando inibir a polimerização espontânea e indesejada dos adesivos e aumentar a vida útil dos mesmos. Além dos estabilizantes, outros elementos importantes que podem ser adicionados aos adesivos acrílicos são os elastômeros de alto peso molecular, os quais são responsáveis pelo aumento da resistência ao impacto, "peeling" e flexibilidade dos adesivos.

\subsection{MÉTODOS DE CURA}

O processo de polimerização de adesivos acrílicos se dá pela adição de geradores de radicais (HANDBOOK LOCTITE, 1995). Estes agentes podem ser adicionados aos adesivos através de dois veículos: ativador ou segundo componente.

O primeiro veículo refere-se à utilização de um ativador, o qual é aplicado sobre o substrato e torna-se um gerador de radicais livres, devido à presença das cargas depositadas na superfície.

O segundo método se refere aos adesivos formados por dois componentes, os adesivos acrílicos bi-componentes. As partes geralmente são classificadas como $\mathrm{A} e$ $B$, sendo cada uma elas aplicada em um dos substratos a serem unidos, ao colocá- 
los em contato as partes de misturam dando início à polimerização, devido ao fato de um dos componentes ser o veículo para os geradores de radicais livres. Como no caso da cura com ativador, os adesivos acrílicos não exigem a mistura homogênea entre as partes, apenas com contato superficial é iniciada a geração de radicais livres, os quais se propagam de monômero para monômero. A Figura 6 apresenta duas formas possíveis de cura para adesivos acrílicos, indicando o sentido de propagação da cura para adesivos monocomponentes e a forma de aplicação para alguns adesivos acrílicos bi-componentes.

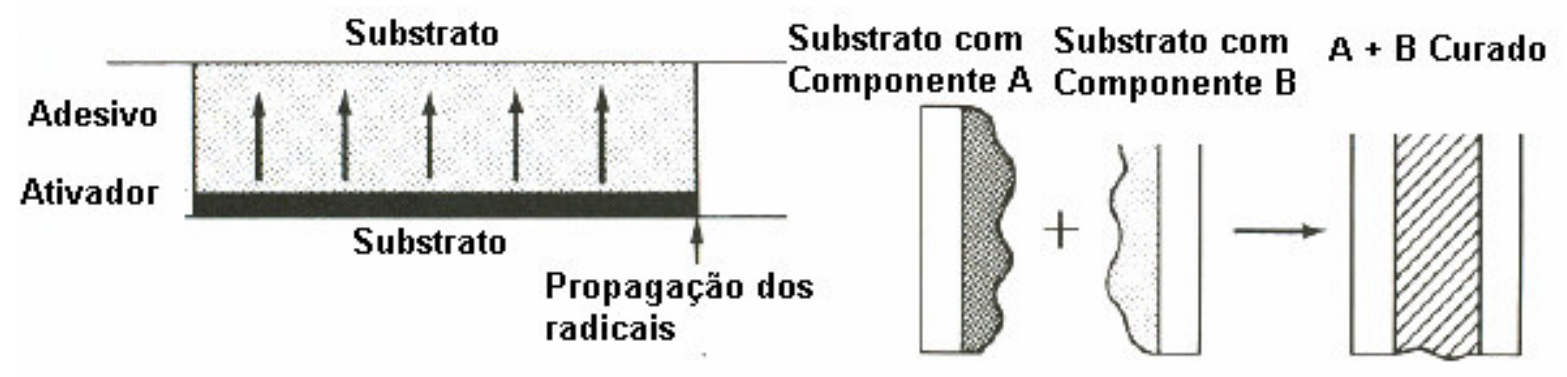

Figura 6 - Tipos de curas de adesivos acrílicos (Brinson, 1995).

\subsection{TIPOS E PROPRIEDADES}

Os adesivos acrílicos denominados convencionais foram desenvolvidos na década de setenta e permanecem no mercado até os dias atuais. Estes adesivos geralmente são utilizados na adesão de termoplásticos como PS, PVC, ABS e borrachas, além de proporcionar boa adesão em aço e alumínio. Este tipo de adesivos acrílicos tem alto poder de preenchimento de folga, cura rápida e ótima resistência mecânica.

A evolução dos adesivos resultou no surgimento dos adesivos acrílicos de alto desempenho e acrílicos resistentes a impacto. Este segundo tipo de adesivos mostra-se capaz de unir diversos tipos de metais, como bronze, níquel, manganês, cobre e aço inoxidável. O grande diferencial desta família é a tolerância dos adesivos às superfícies levemente oleadas.

Os adesivos resistentes a impacto possuem elastômeros de alto peso molecular em sua formulação, modificante que aumenta o alongamento do adesivo. Sendo que tanto os adesivos de alta performance como os de alta resistência ao impacto 
continuavam apresentando dificuldade de cura em superfícies zincadas. A crescente utilização de materiais zincados na indústria automobilística, incentivou, em meados dos anos oitenta, o desenvolvimento de adesivos acrílicos que apresentassem boa adesão em superfícies zincadas. Nestes casos a própria cura do adesivo é catalisada pelo contato com o zinco da superfície.

O principal desenvolvimento de adesivo acrílico dos últimos anos foi realizado para sanar uma necessidade da indústria automotiva, a adesão estrutural de componentes de PP ou PE em aço. Algumas montadoras passaram a utilizar componentes estruturais em PP ou PE, os quais devem ser aderidos à carroceria do veículo, suportando altos carregamentos. Comparando com a resistência obtida ao utilizar adesivos acrílicos em aço, verifica-se que a resistência oferecida pelo adesivo ao ser aplicado em PP e aço pode chegar até $60 \%$ de resistência do adesivo quando aplicado dois substratos de aço. 


\section{ESFORÇOS MECÂNICOS EM JUNÇÕES ADESIVAS}

\subsection{TIPOS DE FALHAS EM JUNÇÕES ADESIVAS}

Quando submetidas aos esforços mecânicos as junções adesivas podem apresentar dois tipos de falhas, a coesiva, relacionada às propriedades mecânicas dos polímeros, e a adesiva, relacionada com a região de interface polímero-substrato (MENDES, 2005). A Figura 7 representa as regiões de adesão e coesão das junções adesivas, indicando as regiões onde cada tipo de falha ocorre.

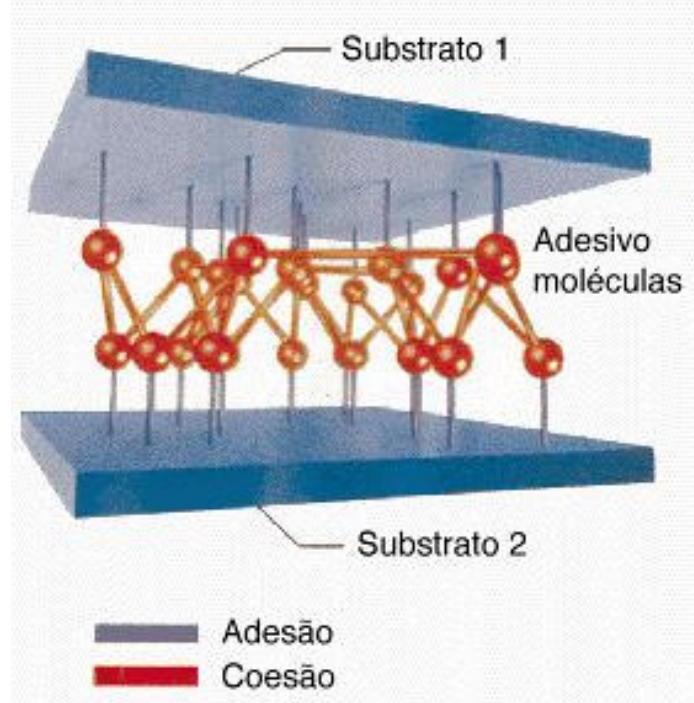

Figura 7 - Regiões de adesão e coesão de junções adesivas (Handbook Loctite, 1995, p. 22)

Falha Adesiva - este tipo de falha ocorre na região de interface polímero-substrato, sendo caracterizada pelo desplacamento do polímero de um dos substratos. Em análise a olho nu, após a falha, todo o filme de adesivo se encontra sobre uma das superfícies. As prováveis causas para este tipo de falha são: a possível contaminação dos substratos, ou incompatibilidade do material com o adesivo. Segundo Handbook Loctite (1995) em caso de incompatibilidade de materiais um tratamento superficial pode ser utilizado para aumentar a resistência da junção. A Figura 8 mostra esquema representando falha adesiva por contaminação de substrato, causada pelo impedimento do contato entre adesivo e substrato. 


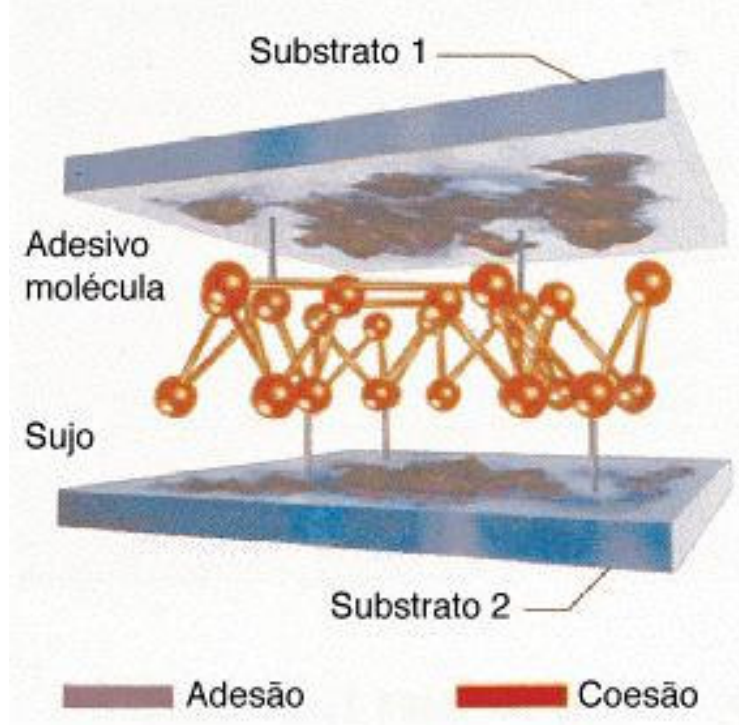

Figura 8 - Falha adesiva por contaminação (Handbook Loctite, 1995, p. 38)

Falha Coesiva - caracterizada pelo rompimento do filme de adesivo devido a carregamento superior ao limite mecânico do polímero formado. Em análise sem auxilio de equipamento é possível identificar resíduos de adesivos em ambos os substratos. De acordo com Handbook Loctite (1995) é possível evitar falhas coesivas precoces selecionando o adesivo a ser utilizado de forma correta, atentando para condições como temperatura de trabalho da junção e folgas utilizadas.

Devido as possíveis interações químicas entre adesivo e substrato, modelo químico de adesão, Possart (comunicação pessoal, 2006) sugere que a maioria das falhas que ocorre em junções adesivas é coesiva, existindo a presença de adesivo em ambos os substratos, mesmo que em escala microscópicas. Desta forma uma das poucas condições capazes de gerar falha adesiva em substratos é a presença de filme de material estranho entre substrato e adesivo, ou seja, contaminação conforme Figura 8.

Possart (comunicação pessoal, 2006) afirma que uma boa adesão não é garantia de alta resistência coesiva, pois as reações decorridas na região de interface se diferenciam das reações em outros pontos do polímero formado, com propriedades mecânicas diferenciadas.

Dois outros tipos de falhas relacionadas exclusivamente ao substrato podem ocorrer ao submeter a junção adesiva a esforços mecânicos, devido a isso, elas não foram consideradas como falhas em junções adesivas: 
Quebra de Substrato - ocorre o rompimento do corpo de prova antes de ocorrer falha coesiva ou adesiva na junção, devido elevada resistência do adesivo utilizado para o material do substrato.

Falha do revestimento - ocorre o desplacamento do revestimento superficial, em caso de superfícies tratadas, antes de falha adesiva ou coesiva da junção.

\subsection{CLIVAGEM}

Villenave (2002) descreve que a clivagem, assim como o "peeling", é um esforço localizado, iniciado por falha microscópica, como posterior propagação. A Figura 9 descreve três modos possíveis de solicitação por clivagem: abertura (modelo I), cisalhamento de acordo com comprimento (modelo II) e ruptura por cisalhamento de acordo com a amplitude do esforço (modelo III).
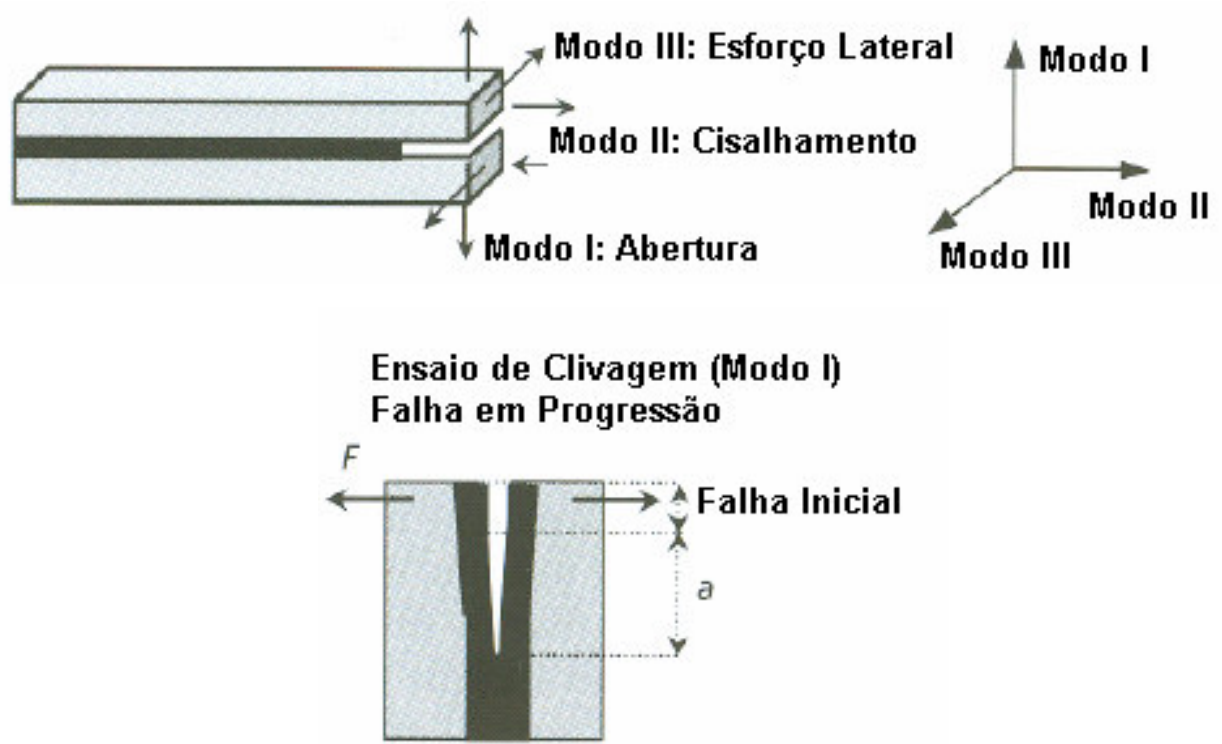

Figura 9 - Tipos de esforços de clivagem (Villenave, 2005, p. 223)

Dos três modelos apresentados, é o modelo I aquele que apresenta maior severidade. De acordo com os conceitos da mecânica da fratura, onde a energia disponível (representada pela taxa de conservação de energia) deve ser superior à resistência à fratura oferecida pela junção (representado pela energia necessária para a propagação da falha inicial). 
A Figura 9 traz um esforço de clivagem representativo do modelo I. Como se pode ver, as duas chapas são afastadas por ação de uma força imposta $F$, gerando uma fissura inicial que se desloca progressivamente ao desenrolar do ensaio. Para uma análise matemática, a mecânica da ruptura se apóia em diferentes conceitos para representar as relações que dão origem à energia de fratura $G_{r c}$, relações estas expressas em função das características de montagem. Por exemplo:

$$
G r c=\frac{12 F^{2} a^{2}}{E b^{3} t^{3}}
$$

Onde:

$\mathrm{F}$ : força externa aplicada;

a : comprimento da fissura;

E : módulo de elasticidade do adesivo;

b : largura da chapa;

$t$ : espessura da chapa .

\subsection{DESCASCAMENTO}

Assim como no esforço por clivagem, o rompimento por descascamento (peeling) se inicia devido à falha inicial em um dos substratos, dando continuidade ao processo de ruptura. Porém, enquanto o esforço de clivagem é gerado com a utilização de substratos espessos, rígidos e de módulo de elasticidade elevado. O esforço de "peeling" é resultado da utilização de substratos flexíveis, de baixa espessura e módulo de elasticidade.

O "peeling" é obtido através da tentativa de separação de dois substratos flexíveis, ou de um substrato flexível aderido à uma base rígida. A separação dos substratos, ocorre através da atuação de solicitação externa com velocidade constante, aplicada com ângulo $\theta$ em relação ao plano da junta. A energia de fratura por "peeling" é representada nas equações pela variável $G_{r p}$. A Figura 10 contém informações sobre diversos tipos de esforços de "peeling", os quais podem ter a energia de ruptura $G_{r p}$ determinada pela aplicação das equações 2 e 3. 


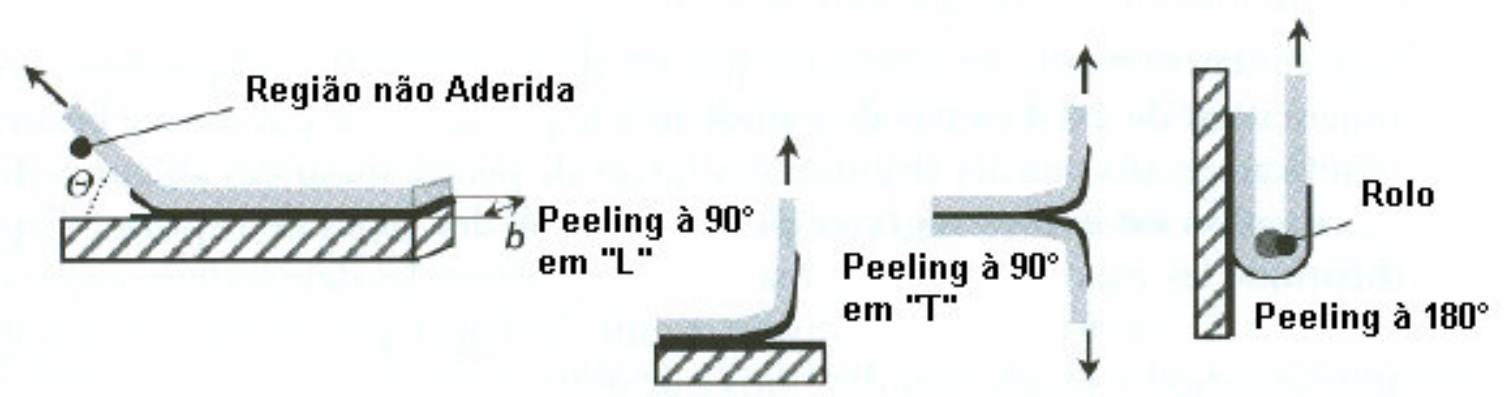

Figura 10 - Tipos de esforços de peeling (Villenave, 2005, p. 225).

Para aplicações onde os substratos apresentam comportamento flexível e indeformável, como filmes poliméricos, a resistência à ruptura é dada pela equação:

$$
G r p=\frac{F}{b}(1-\cos \theta)
$$

Para esforços de descascamento com força $\mathrm{F}$ atuando à $90^{\circ}$, tem-se:

$$
G r p=\frac{F}{b}
$$

Onde:

$\Theta$ : ângulo de atuação de $F$.

A força $F$ é registrada em junção do tempo e conseqüentemente da progressão da fissura. Em termos práticos, o diferencial do ensaio de "peeling" é a facilidade de interpretação dos resultados experimentais. A limitação, entretanto dá-se em função da não consideração de condições existentes em aplicações reais, como a deformação e rigidez do substrato (VILLENAVE, 2005).

\subsection{COMPRESSÃO}

Atualmente encontra-se na indústria um grande número de aplicações onde junções adesivas são solicitadas por esforços de compressão: revestimento de solos, colagem de vidros e tampas de motores. Tratam-se de aplicações com geometrias 
particularmente favoráveis, onde um substrato é forçado contra o outro, geralmente em aplicações de vedação. Embora muito utilizada, as junções que exigem este tipo de esforço raramente são modeladas ou testadas pelos seguintes motivos:

- Desenvolvimentos teóricos injustificáveis;

- $\quad$ Dificuldade em simular condições reais de aplicação;

- $\quad$ Dificuldade em analisar resultados devido à baixa amplitude das deformações e pelo esmagamento do substrato.

Estudos de compressão revelam-se igualmente perigosos para os equipamentos de testes, os quais após o esmagamento dos substratos oferecem riscos de sobrecarga, mesmo que instalados sistemas de desacoplamento nas máquinas de tração.

\subsection{TRAÇÃO}

Os ensaios de tração normalmente são realizados com a utilização de dois corpos de prova cilíndricos, através da união de suas faces perfeitamente polidas. Um dos cilindros é tensionado estando o outro fixo na base do equipamento de tração. $O$ ensaio é finalizado com a ruptura do filme de adesivo entre os corpos de prova, resultado do esforço de tração em velocidade pré-determinada.

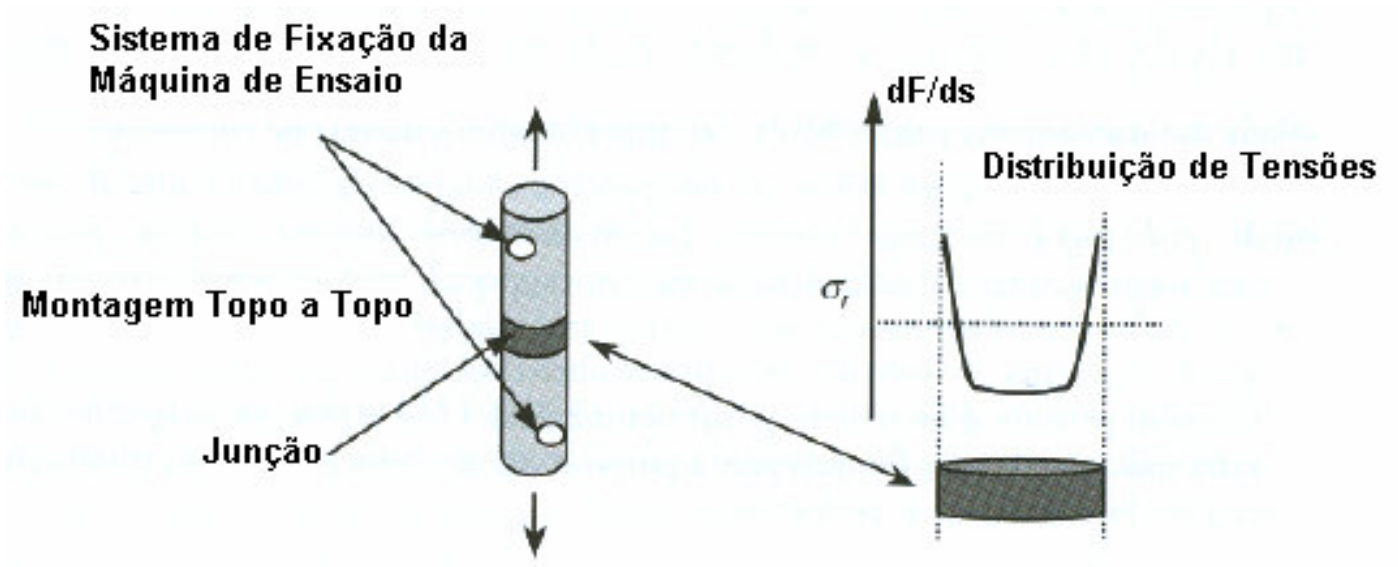

Figura 11 - Ensaio de tração (Villenave, 2005, p. 228). 
Uma informação chave fornecida pelo ensaio de tração é a curva de esforços. A Figura 11 representa a distribuição das tensões em ensaios de tração com corpos cilíndricos, ilustrando que as tensões são maiores no perímetro dos cilindros e reduzem à medida que se aproxima do centro.

\subsection{CISALHAMENTO}

Grande parte das junções adesivas é dimensionada com base em dados obtidos através de ensaios de cisalhamento, devido à possibilidade de transposição dos dados obtidos nos ensaios para as condições reais de aplicação. Tais dados permitem a determinação de parâmetros mecânicos e desenvolvimento de modelos matemáticos. A seguir encontram-se alguns dos dados obtidos através da análise dos resultados deste tipo de ensaio:

- Força máxima $F_{\text {máx }}$ e tensão média de ruptura $\tau_{\text {média }}\left(F_{\text {máx }} /\right.$ b.I $): \tau_{\text {média }}$ é um indicador amplamente utilizado, sendo a resultante da força aplicada sobre a área inicialmente aderida (força por unidade de área).

- Módulo de cisalhamento do adesivo $G_{c}$ : dado pela inclinação da curva $F=f(\Delta l)$, representa o módulo elástico de cisalhamento para falhas coesivas.

- Energia de cisalhamento $G_{c i s}$ : dada pela área abaixo da curva $F=f(\Delta l)$,

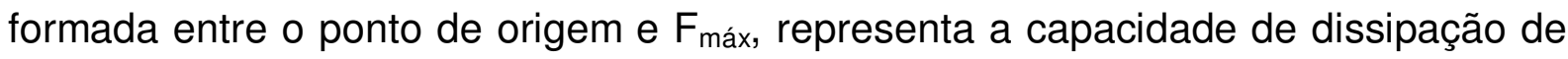
energia da junção, dado de extrema importância para dimensionamentos reais de junções.

\subsubsection{Análise matemática de ensaios de cisalhamento simples}

De acordo com Villenave (2005) o objetivo da análise matemática é relacionar o esforço de tração exercido sobre os substratos com o comportamento do cisalhamento, através de características da junção (módulo de cisalhamento G; espessura e), dos substratos (módulo de elasticidade $E$, espessura t) e da 
montagem (largura b e comprimento de sobreposição das chapas). Os modelos para cálculo da resistência de junções adesivas, desenvolvidos antes da metade do século XX, derivam da análise de inflexão das junções. Os modelos, ainda hoje, mais utilizados são o Modelo de Volkersen e o Modelo de Goland e Reissner.

\subsubsection{Distribuição de tensões}

Lucic (2006) afirma que os métodos de simulação disponíveis atualmente, análise por elementos finitos, mostram os seguintes resultados: a concentração de tensão é maior nas extremidades da junção, quando comparada à tensão média de ruptura $\tau_{\text {média }}\left(F_{\text {máx }} /\right.$ l.b). Como representa a Figura 12, a distribuição de tensões também depende do comprimento de sobreposição:

- Para "I" pequeno, ilustrado pelo caso 1 da Fig 12, todo o comprimento de sobreposição é submetido a esforços máximos.

- $\quad$ Na medida que "I" aumenta, ocorre a redução da região submetida à esforços máximos, como no caso 2.

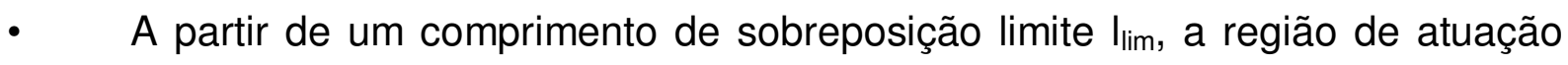
das tensões máximas é reduzida, minimizando a tensão média de ruptura $\tau_{\text {média, }}$ representado pelo caso 3.

No que se refere aos esforços de clivagem, fora do plano de cisalhamento, pode ocorrer a deformação de substratos de baixa espessura e simultaneidade de tipos de rupturas: coesiva para a região central e adesiva para as extremidades. Precauções tomadas quanto à geometria dos substratos podem eliminar a ocorrência de esforços de clivagem em ensaios simples de cisalhamento. 


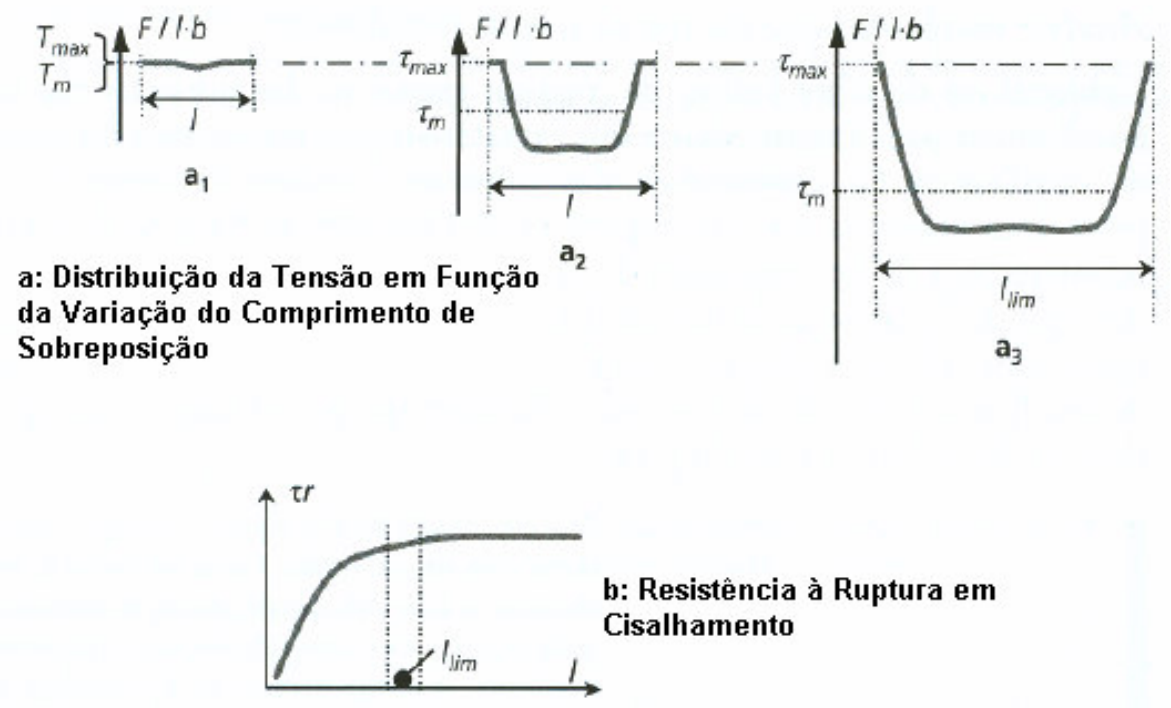

Figura 12 - Análise de um ensaio de cisalhamento (Villenave, 2005, p. 236)

\subsubsection{Resistência a ruptura}

Para determinados corpos de prova, a medição da força máxima $F_{\text {máx, fornece um }}$ valor de tensão média de ruptura $T_{\text {média }}\left(F_{\text {máx }} /\right.$.b). Este parâmetro é dado, e aceito, como uma característica do adesivo: este representa o valor médio das solicitações mais severas sofridas e a distribuição das tensões. Os limites de atuação de $\tau_{\text {média, }}$ como propriedade da junção, são confirmados pelos modelos matemáticos. Segundo Villenave (2005) o Método de Volkersen, por exemplo, estabelece uma relação entre a tensão média e ruptura $\tau_{\text {média }}$ e a tensão máxima $\tau_{\max }$.

Um balanço rápido põe em evidência a ambigüidade do parâmetro resistência ao cisalhamento. Mesmo com dispositivos experimentais otimizados, o resultado de força (ou tensão) média de ruptura, só tem significado quando obtido em condições onde a espessura do substrato não mais influencia no resultado. Contudo $\tau_{\text {média }}$ é ainda um dos dados mais utilizados no dimensionamento de junções adesivas, a literatura mostra que ainda há escassez em dados sobre comportamento mecânico dessas junções, ocasionando coeficientes de seguranças desmedidos e motivando a utilização de modelos matemáticos. 


\subsubsection{Modelo de Volkersen}

O desenvolvimento de modelos teóricos de junções adesivas vem sendo realizado ao longo de mais de seis décadas. Para junções adesivas por sobreposição simples de chapas. Volkersen (1938) apud Tsai et al. (1997) propôs um modelo teórico de ruptura por cisalhamento simples, considerando um esforço unidirecional com deformações por cisalhamento somente no filme de adesivo. Este modelo não considera deformações nos substratos. Outros modelos foram desenvolvidos posteriormente, os quais consideram deformações nos substratos e esforços de cisalhamento em diversas direções. Como o modelo de Goland e Reissner, o qual na verdade é uma extensão do método de Volkersen.

No modelo de Volkersen os substratos são modelados como barras, as quais se deformam uniformemente ao longo da espessura do filme. Por negligenciar a deformação e os esforços de momento nas barras, este modelo apresenta a forma mais simples de analisar parâmetros mecânicos de junções adesivas, especialmente para junções desbalanceadas.

Tsai et al. (1997) propôs alterações ao Modelo de Volkersen apresentando modelo que considera as tensões de cisalhamento e conseqüentemente a deformação dos substratos. Este modelo é baseado na Lei de Hooke, sendo válido para região de temperatura onde o polímero se comporta como material rígido. A Equação 4 define a tensão de cisalhamento do adesivo como:

$$
\left.\tau_{c}=\frac{G_{c}}{\eta}\left(\mu_{c i}-\mu_{c 0}\right)\right)
$$

Onde:

$\mathrm{G}_{\mathrm{c}}$ : $\quad$ módulo de cisalhamento transversal do adesivo;

$\tau_{\mathrm{c}}: \quad$ tensão de cisalhamento no filme de adesivo;

$\left(\mu_{\mathrm{ci}}-\mu_{\mathrm{co}}\right) / \eta$ : deformação do filme de adesivo.

$\eta$ : $\quad$ espessura do filme de adesivo; 
Derivando a Equação 4 em função de "x", obtém-se:

$$
\frac{d \tau_{c}}{d x}=\frac{G_{c}}{\eta}\left(\frac{d \mu_{c i}}{d x}-\frac{d \mu_{c 0}}{d x}\right)
$$

Aplicando as Equações 6 e 7, referentes à tensão em função da deformação dos substratos, na Equação 5, obtém-se a Equação 8:

$$
\begin{aligned}
& T_{o}=E_{1} t_{1}\left(\frac{d \mu_{c o}}{d x}-\frac{t_{1}}{3 G_{1}} \frac{\tau_{c}}{d_{x}}\right) \\
& T_{i}=E_{2} t_{2}\left(\frac{d \mu_{c o}}{d x}-\frac{t_{2}}{6 G_{2}} \frac{\tau_{c}}{d_{x}}\right)
\end{aligned}
$$

Onde:

$T_{0}$ : $\quad$ força aplicada por unidade de largura no substrato superior;

$T_{i}$ : força aplicada por unidade de largura no substrato inferior.

$$
\frac{d \tau_{c}}{d x}=\frac{G_{c}}{\eta}\left[\frac{T_{2}}{E_{2} t_{2}}-\frac{T_{1}}{E_{1} t_{1}}-\left(\frac{t_{2}}{6 G_{2}}-\frac{t_{1}}{6 G_{1}}\right) \frac{d \tau_{c}}{d x}\right]
$$

Ao derivar a Equação 8 em relação à "x" e aplicar as condições de equilíbrio dos substratos, propostas por Tsai (1997), obtém-se a Equação 11. A qual governa a tensão de cisalhamento no filme de adesivo. As condições de equilíbrio são apresentadas nas Equações 9 e 10.

$$
\begin{aligned}
& \frac{d T_{o}}{d x}+\tau_{c}=0 \\
& \frac{d T_{i}}{d x}+\tau_{c}=0
\end{aligned}
$$




$$
\frac{d^{2} \tau_{c}}{d x^{2}}=\frac{G_{c}}{\eta}\left[\frac{2 \sigma_{c}}{E_{2} t_{2}}+\frac{\sigma_{c}}{E_{1} t_{1}}-\left(\frac{t_{2}}{6 G_{2}}+\frac{t_{1}}{6 G_{1}}\right) \frac{d^{2} \tau_{c}}{d x^{2}}\right]
$$

A Equação 11 é apresentada de maneira simplificada a seguir:

$$
\frac{d^{2} \tau_{c}}{d x^{2}}-\beta^{2}=0
$$

Onde $\beta$ é pode ser definido por dois parâmetros: $\lambda$ (parâmetro de alongamento) e $\alpha$ (parâmetro de deformação do substrato), como mostrado abaixo:

$$
\begin{gathered}
\beta^{2}=\lambda^{2} \alpha^{2} \\
\lambda^{2}=\frac{G_{c}}{\eta}\left(\frac{1}{E_{1} t_{1}}+\frac{1}{E_{2} t_{2}}\right) \\
\alpha^{2}=\frac{1}{\left[1+\frac{G_{c}}{\eta}\left(\frac{t_{1}}{3 G_{1}}+\frac{t_{2}}{3 G_{21}}\right)\right]}
\end{gathered}
$$
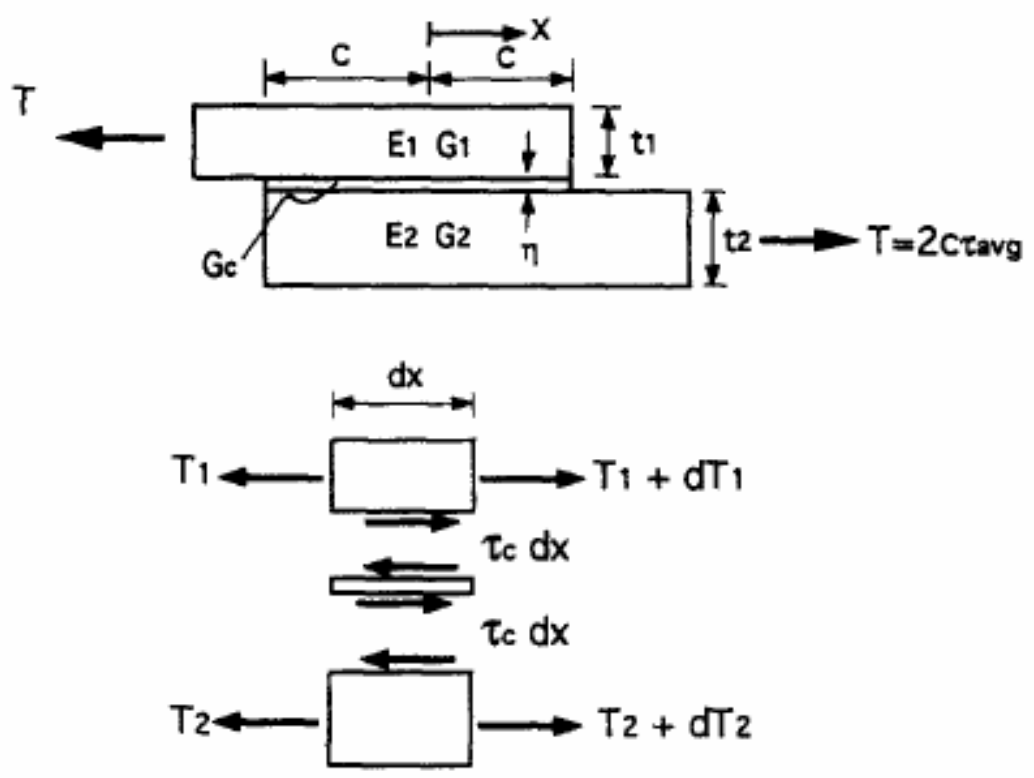

Figura 13 - Parâmetros geométricos e de materiais (Tsai, 1997). 
Os parâmetros geométricos e de material para junções adesivas por sobreposição simples de chapas são mostrados na Figura 13. O comprimento da sobreposição I e a espessura do filme de adesivo $E_{1}, G_{1}$ e $t_{1}$ representam respectivamente módulo de elasticidade, módulo de cisalhamento e espessura do substrato superior. Enquanto $E_{2}, G_{2}$ e $t_{2}$ são os valores correspondentes aos valores referentes ao substrato inferior. $T_{1}$ e $T_{2}$ representam forças longitudinais por unidade de largura agindo nos substratos superior e inferior. T é uma força aplicada por unidade de comprimento. Considerando uma distribuição linear de tensões de cisalhamento nos substratos, a tensão média de ruptura adesiva $\tau_{\text {média }}$ é dada por:

$$
\tau_{c}=A \operatorname{senh}(\beta x)+B \cosh (\beta x)
$$

Onde:

$$
\begin{gathered}
A=\frac{\beta c \tau_{\text {média }}}{\cosh (\beta c)}\left[\frac{1-\frac{E_{2} t_{2}}{E_{1} t_{1}}}{1+\frac{E_{2} t_{2}}{E_{1} t_{1}}}\right] \\
B=\frac{\beta c \tau_{\text {média }}}{\operatorname{senh}(\beta c)}
\end{gathered}
$$

e,

$$
\beta^{2}=\frac{\frac{G}{\eta}\left(\frac{1}{E_{1} t_{1}}+\frac{1}{E_{2} t_{2}}\right)}{\left[1+\frac{G}{\eta}\left(\frac{t_{1}}{3 G_{1}}+\frac{t_{2}}{3 G_{2}}\right)\right]}
$$

Desta forma quando $\alpha=1$ o modelo modificado apresenta a solução de Volkersen, simulando substrato com rigidez tendendo à infinito e conseqüentemente sem deformação. 


\subsubsection{Modelo de Goland \& Reissner}

Baseado no mesmo desenvolvimento matemático apresentado, Goland \& Reissner (1944) apud Tsai et al. (1997) apresentou o Modelo de Goland e Reissner. Este considera as deformações dos substratos. A Equação 20 apresenta o Modelo e Goland e Reissner:

$$
\tau_{c}=\frac{1}{4} \tau_{\text {médio }}\left[\frac{\beta c}{t}(1+3 k)-\frac{\cosh \left(\frac{\beta c}{t} \frac{x}{c}\right)}{\operatorname{senh} \frac{\beta c}{t}}+3(1-k)\right]
$$

Os parâmetros de alongamento e deformação dos substratos, para o Modelo de Goland \& Reissner são dados por:

$$
\begin{gathered}
\lambda^{2}=\frac{8 G_{c} t}{E \eta} \\
\alpha^{2}=\frac{1}{\left[1+\frac{2 G_{c} t}{3 \eta G}\right]}
\end{gathered}
$$

\subsubsection{Vantagens e Desvantagens do Ensaio de Cisalhamento Utilizando Junções por Sobreposição Simples de Chapas}

Broughton \& Gower (2001) apresentam uma relação de vantagens e desvantagens provenientes da aplicação do ensaio de cisalhamento em junções obtidas por sobreposição simples de chapas. 
- Vantagens: os autores citam como vantagem a aplicabilidade deste ensaio à substratos de metal e polímeros, bem como a facilidade de obtenção de corpos de prova e equipamentos para ensaio.

- Desvantagens: segundo Broughton \& Gower (2001) a dependência da resistência da junção está associada à fatores geométricos. Neste trabalho, porém considerações apresentadas por Villenave (2005) foram adotadas, com o intuito de reduzir esta influência neste estudo. Outro fator citado como desvantagem, como a elevada tensão nas extremidades da junção é também apresentada em condições reais de aplicação. Porém a escolha da espessura correta do corpo de prova tende a reduzir este efeito (Villenave, 2005). A espessura correta do corpo de prova também reduz a possibilidade de início de falha por clivagem durante o ensaio.

\subsubsection{Forças Combinadas - Método de Arcan Aplicado à Junções Soldadas}

A análise de esforços individuais, cisalhamento ou tração, gera dados aplicáveis no dimensionamento de junções adesivas, porém muitas vezes não representa as condições reais da aplicação. Em aplicações reais os esforços de cisalhamento e tração coexistem.

Vários modelos foram desenvolvidos para tratar esforços combinados em junções soldadas. Segundo Kavamura (2007) negligenciar a atuação de esforços combinados pode resultar em falhas prematuras nas regiões de solda. As mesmas considerações podem ser feitas para junções adesivas.

O comportamento de junções soldadas, quando submetidas à esforços combinados, é determinado pela associação de ensaios experimentais com dispositivo de Arcan modificado e critérios de falha de materiais, como Critério de Von Mises, por exemplo.

O dispositivo modificado de Arcan altera o ângulo de aplicação dos esforços, variando de um ensaio de cisalhamento puro, passando por ensaios combinados até o ensaio de tração pura (arrancamento). A Figura 14, por exemplo, apresenta o dispositivo modificado de Arcan utilizado por Lee (1998), com quatro fixações e conseqüentemente quatro ângulos possíveis. 


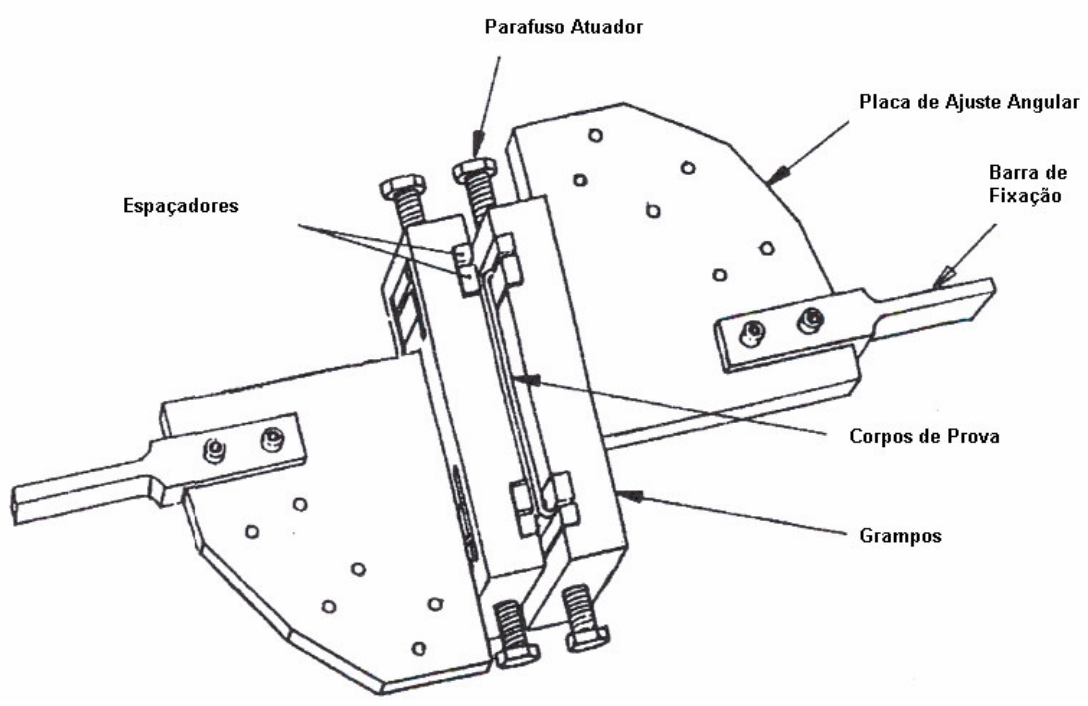

Figura 14 - Dispositivo para testes com esforços combinados (Lee, 1998)

De acordo com análise de Kavamura (2007) o modelo de Langrand e Combescure (2004) apresenta os melhores resultados práticos na análise de junções soldadas, porém os corpos de provas utilizados possuem certa complexidade gerando alta custo em sua obtenção. Enquanto o modelo de Lee (1998) apresenta bons resultados com corpos de prova simples em formato de "U", conforme mostrado na Figura 15.

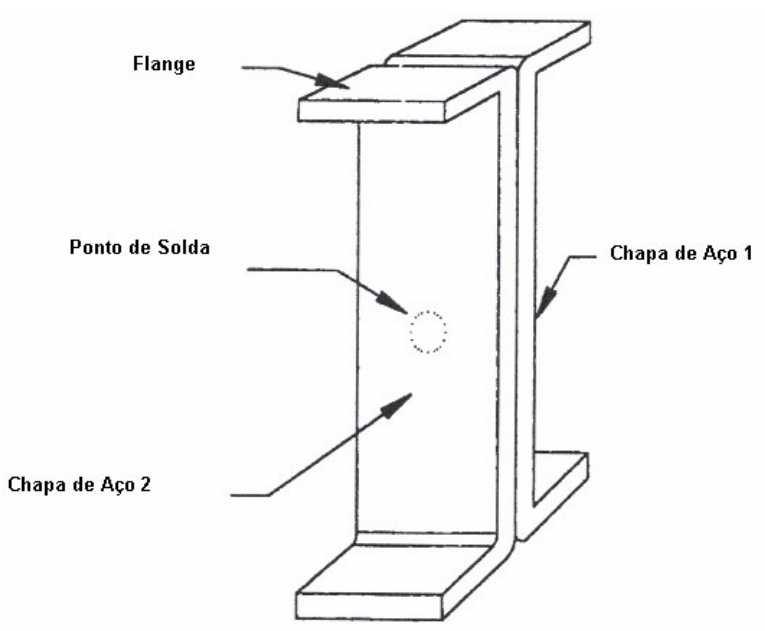

Figura 15 - Corpo de prova utilizado por Lee (1998). 


\subsubsection{Modelo de Arcan Aplicado à Junções adesivas}

Broughton \& Gower (2001) apresentam o Modelo de Arcan como uma possibilidade de ensaio para quantificar a resistência mecânica de junções adesivas, porém citam a ausência de norma internacional para realização destes ensaios. O Método de Arcan permite combinar esforços de tração e cisalhamento, exatamente como nos ensaios com junções soldadas.

Cognard (2004) utilizou corpos de prova em formato de paralelepípedos, com plano de contato com dimensões de $10 \mathrm{~mm}$ de largura por $70 \mathrm{~mm}$ de comprimento, corpos mostradas na Figura 16. Os paralelepípedos foram ensaiados com dispositivo de Arcan, combinando esforços de cisalhamento e tração, sendo que em alguns casos o esforço de compressão também esteve presente.

Duncan (2001) comparou dados de resistência ao cisalhamento de junções adesivas, obtidas por ensaios de cisalhamentos de junções por sobreposição simples de chapas e de corpos de prova trapezoidais ensaiados em dispositivo de Arcan, com simulação em Método de Elementos Finitos. Concluindo que houve boa relação entre os resultados obtidos nos três métodos.

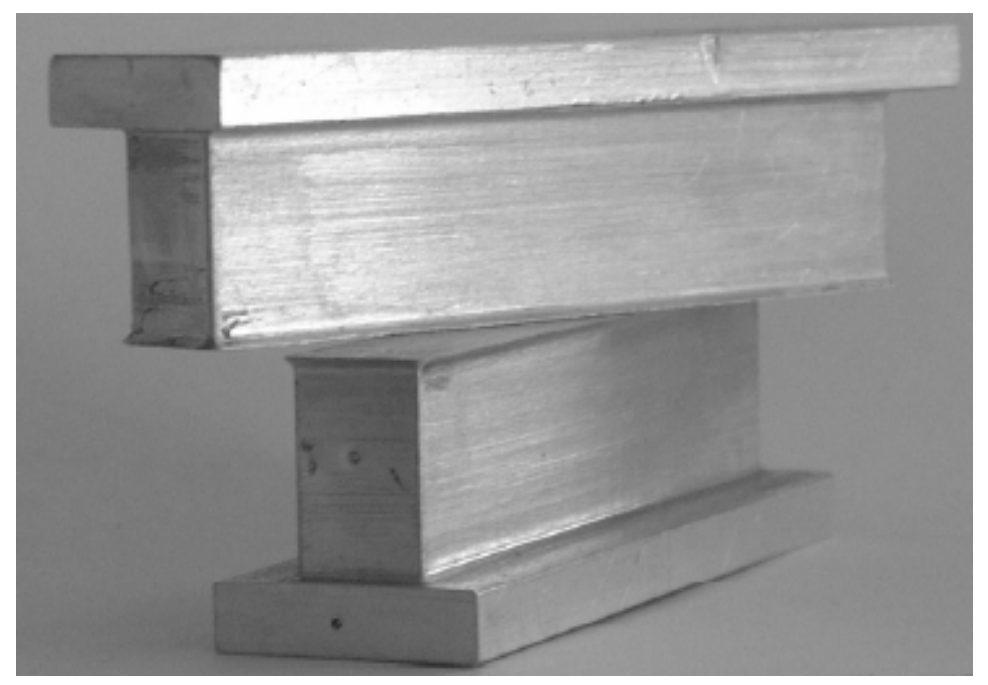

Figura 16 - Corpos de prova utilizados por Cognard (Cognard, 2004). 


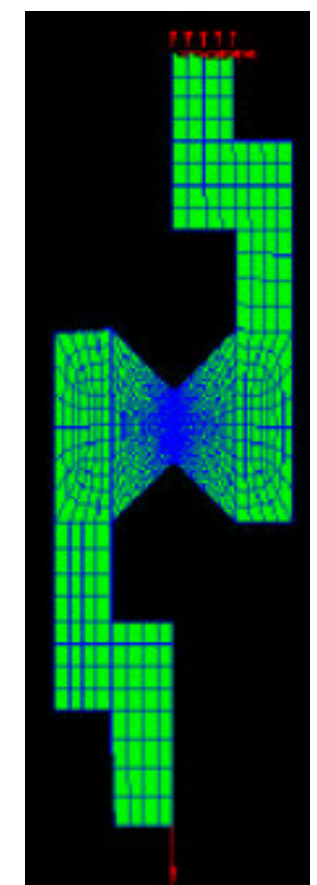

Figura 17 - Corpo de prova e dispositivo de Arcan utilizado por Duncan (Duncan, 2001).

\subsubsection{Critério Modificado de Von Mises Aplicado à Junções Adesivas}

O comportamento dos polímeros normalmente é descrito através de modelos de resistência de materiais, para as regiões de temperatura de trabalho onde estes se comportam como corpos rígidos, ou seja, abaixo da Tg. Para as regiões acima da Tg, onde os polímeros adquirem o comportamento visco-elástico, o comportamento dos polímeros é descrito por modelos da mecânica dos fluídos. Esta segunda região é de extrema importância para os processos de conformação mecânica dos polímeros.

Critérios de escoamento com de Von Mises e Tresca são comumente utilizados para descrever o comportamento de polímeros na condição rígida. O modelo modificado de Volkersen (Tsai et al.,1997), apresentado neste trabalho ,se baseia na Lei de Hooke para descrever a distribuição de tensão ao longo do comprimento de chapas sobrepostas, unidas por adesivo.

Kreuzer \& Romanos (2006) discordam da aplicação do modelo original de Von Mises para adesivos (polímeros), pelo fato deste não considerar tensões hidrostáticas. Segundo os autores esta é de extrema importância para determinar critérios de falha para polímeros. Um critério de escoamento modificado de Von Mises é apresentado 
por Drucker-Prager apud Kreuzer \& Romanos (2006) o qual considera as tensões hidrostáticas e pode ser aplicado tanto para polímeros amorfos, como para cristalinos. Este é chamado Critério de Escoamento de Drucker-Prager.

$$
\lambda_{m} \sigma_{f}^{2}-\left(\lambda_{m}-1\right) \sigma_{f} I_{1}-3 J_{2}=0
$$

Onde $\lambda_{\mathrm{m}}$ representa é um parâmetro do material e representa a sensibilidade do critério de falha à tensões hidrostáticas. $\sigma_{\mathrm{f}}$ representa a tensão de escoamento ou de falha para esforços unidimensionais. $I_{1}$ e $J_{2}$ são respectivamente 0 primeiro e segundo invariante do tensor de tensão, dadas por:

$$
\begin{gathered}
I_{1}=\sigma_{x}+\sigma_{y}+\sigma_{z} \\
J_{2}=\frac{\left(\sigma_{x}-\sigma_{y}\right)^{2}+\left(\sigma_{y}-\sigma_{z}\right)^{2}+\left(\sigma_{z}-\sigma_{x}\right)^{2}+6\left(\tau_{x y}^{2}+\tau_{y z}^{2}+\tau_{z x}^{2}\right)}{6}
\end{gathered}
$$

O parâmetro do material $\left(\lambda_{\mathrm{m}}\right)$ pode ser definido através de ensaios unidirecionais de cisalhamento ou tração aplicados às seguintes equações:

$$
\begin{gathered}
\lambda_{m}=\frac{1}{6}\left(\beta_{m}^{2}+\beta_{m} \sqrt{\left(\beta_{m}^{2}+12\right)}+6\right) \\
\beta_{m}=3 \frac{1-v}{1+v} \frac{\tau_{\text {max }}}{\sigma_{z, \text { max }}}-\frac{(1-2 v)^{2}}{(1-v)(1+v)} \frac{\sigma_{z, \text { max }}}{\tau_{\text {max }}}
\end{gathered}
$$

Onde $\tau_{\max }$ é a maior tensão média de ruptura por cisalhamento medida em ensaios unidirecionais e $\sigma_{z, \max }$ é a maior tensão média de ruptura por tração medida em ensaios unidirecionais. Ambos os valores podem ser usados para determinar $\sigma_{\mathrm{f}}$, quando aplicados nas seguintes equações: 


$$
\begin{gathered}
\sigma_{f}=\left[\frac{\lambda_{m}-1}{2 \lambda_{m}} \frac{1+v}{1-v} \sqrt{\frac{1}{\lambda_{m}}\left(\frac{1-2 v}{1-v}\right)^{2}+\left(\frac{\lambda_{m}-1}{2 \lambda_{m}}\right)^{2}+\left(\frac{1+v}{1-v}\right)^{2}}\right] \sigma_{z, \max } \\
\sigma_{f}=\sqrt{\frac{3}{\lambda_{m}}} \tau_{\max }
\end{gathered}
$$

A equação 28 utiliza o valor da maior tensão média de ruptura por tração $\left(\sigma_{z, \max }\right)$, enquanto a equação 29 utiliza o valor da maior tensão média de ruptura por cisalhamento $\left(\tau_{\max }\right)$, obviamente esta segundo oferece maior facilidade de aplicação. Em junções adesivas com substratos metálicos, normalmente a rigidez do substrato é significativamente superior à rigidez do filme de adesivo. Desta forma, ao submeter a junção adesiva à esforços, o filme de adesivo tende a deformar, sem causar deformação no substrato em plano normal à superfície do mesmo. Da Teoria da Elasticidade têm-se:

$$
\sigma_{x}=\sigma_{y}=\frac{v}{1-v} \sigma_{z}
$$

Onde $v$ é o coeficiente de Poisson do substrato.

Aplicando a Equação 30 à Equação 23, com algumas manipulações algébricas, obtém-se a Equação que apresenta o comportamento de adesivos submetido à esforços combinados. Isto através da utilização de dados obtidos por ensaios de tração e cisalhamento puros:

$$
\left(\frac{\tau_{\max }}{\sqrt{\frac{\lambda_{m}}{3} \sigma_{f}}}\right)^{2}+\frac{\lambda_{m}-1}{\lambda_{m}} \frac{1+v}{1-v} \frac{\sigma_{z, \max }}{\sigma_{f}}+\frac{1}{\lambda_{m}}\left(\frac{1-2 v}{1-v}\right)^{2}\left(\frac{\sigma_{z, \max }}{\sigma_{f}}\right)^{2}=1
$$




\subsubsection{Vantagens e Desvantagens da Utilização do Método de Arcan}

Broughton \& Gower (2001) apresentam uma relação de vantagens e desvantagens provenientes da aplicação do método de Arcan na obtenção de dados de resistência mecânica de junções adesivas.

- Vantagens: os autores consideram a utilização do método de Arcan capacitada para a obtenção de dados para desenvolvimento de projetos que envolvam junções adesivas, no que tange esforços de cisalhamento, bem como aplicável à ensaios de fluência. Estes benefícios são ainda associados às reduzidas exigências de materiais para a obtenção dos corpos de provas.

- Desvantagens: segundo Broughton \& Gower (2001) a taxa de tensão por cisalhamento não é uniforme, existindo também a possibilidade de falha por tensão interfacial dos corpos de prova. A falta de normas internacionais e a necessidade de dispositivo especial para fixação dos corpos de prova dificultam a aplicação do método. 


\section{FATORES INFLUENTES NA RESISTÊNCIA DA JUNÇÃO}

Segundo Broughton \& Gower (2001) inúmeros fatores não citados nas normas internacionais podem afetar os resultados obtidos através de ensaios mecânicos de junções adesivas. Fatores como alinhamento dos corpos de prova e do equipamento de teste, armazenagem do adesivo, variáveis de processo (cura) e tratamentos superfícies devem ser levados em consideração. Além de complementar os fatores já considerados, como geometria do material, normalmente considerada nas normas internacionais.

Segundo Zoran et al. (2001) os fatores que interferem diretamente na resistência de junções adesivas, aumentando ou reduzindo a resistência dessas junções à esforços, podem ser classificados como: fatores geométricos, térmicos e básicos. Independente da classificação, estes fatores interferem de forma e em quantidade diferentes na resistência e devem ser levados em consideração no desenvolvimento de aplicações de adesivos.

Inúmeros estudos realizados confirmaram a influência dos fatores geométricos na resistência de junções adesivas, quantificaram quanto cada variável interfere nesta resistência e permitiram o desenvolvimento de modelos matemáticos para cálculo da resistência de junções adesivas.

\subsection{FATORES GEOMÉTRICOS}

O primeiro trabalho apresentado considerando fatores geométricos foi o Modelo de Volkersen, que quantificou a influência destes fatores na resistência da junção. Recentemente Zoran et al. (2001) desenvolveu um modelo matemático através da utilização de Planejamento Fatorial $2^{k}$, através do qual foi possível identificar, além da influência de cada fator individualmente, a influência da interação entre os fatores na resistência da junção. Neste mesmo trabalho, o autor sugere a realização de estudos considerando a influência de fatores de superfície dos substratos como: tratamento superficial, atividade da superfície, rugosidade e nível de oleosidade (limpeza). 
Zoran et al. (2001) considerou as espessuras do filme e substrato, o comprimento e a largura de sobreposição. Abaixo seguem algumas das conclusões obtidas no trabalho:

- Todos os fatores estudados são significantes, espessuras, comprimento e largura de sobreposição.

- $\quad$ aumento da largura da sobreposição resulta em leve fortalecimento da resistência.

- Grandes folgas, espessuras de filme, resultam em decréscimo da resistência da junção.

- Grandes espessuras de substratos resultam em junções com alta resistência.

O Modelo de Zoran foi aplicado a cinco outros tipos de substrato, comparando os resultados obtidos com os resultados fornecidos pelo Modelo de Volkersen, obtevese as seguintes conclusões:

- $\quad$ O Modelo de Zoran (Zoran et. al., 2001) fornece resultados mais próximos da realidade para substratos de aço, devido ao fato de ser baseado em resultados experimentais e considerar a deformação dos substratos.

- $\quad$ O Modelo de Volkersen (Tsai et. al., 1997) fornece melhores resultados para substratos de alumínio.

- A principal vantagem do Método de Volkersen é o fato de apresentar bons resultados para a grande maioria de materiais.

- A utilização do Modelo Estatístico Planejamento Fatorial $2^{\mathrm{k}}$ permite o desenvolvimento de modelos matemáticos para cálculo de resistência de junção adesiva.

- A principal desvantagem destes dois métodos, assim como de todos os outros é não considerar as condições de tratamento de superfície antes da adesão.

As informações obtidas na revisão bibliográfica mostraram a escassez de informações sobre a influência dos tipos de material na resistência da junção, motivando e justificando a realização deste trabalho, o qual considera este tipo de fator (variável). 


\subsection{FATORES TÉRMICOS}

Embora de elevada importância, é reduzido o número de trabalhos direcionados à influência de fatores térmicos na resistência de junções. Segundo Possart (comunicação pessoal, 2006), grupos de pesquisa da Europa, Japão, China e EUA se concentram em estudos para determinar mecanismos de adesão na interface entre polímeros e metais. $O$ foco das pesquisas ao longo de décadas foi a influência de fatores geométricos na resistência das junções.

As pesquisas sobre adesivos passaram por recente processo de fortalecimento e valorização, devido ao grande aumento do número de aplicações e desenvolvimento de tecnologias de adesão.

As aplicações na indústria demonstram a importância de fatores térmicos na resistência das junções, onde os dois principais fatores considerados são as temperaturas de trabalho e cura.

\subsubsection{Temperatura de trabalho}

Assim como todos os materiais, os polímeros possuem suas limitações. No caso da utilização de adesivos, a temperatura de trabalho é um importante fator na resistência da junção. A partir de uma determinada temperatura o desempenho dos polímeros passa a ser afetado, gerando uma redução da resistência da junção. Esta determinada temperatura depende de propriedades de cada polímero. Silicones existentes no mercado, por exemplo, resistem à temperaturas de até $320^{\circ} \mathrm{C}$. Outros adesivos, como os cianoacrilatos, são limitados à uma temperatura média de trabalho de $82^{\circ} \mathrm{C}$. A Figura 18 mostra a variação da resistência oferecida pelo adesivo Loctite 326, utilizado neste trabalho, em função da variação da temperatura de trabalho. 


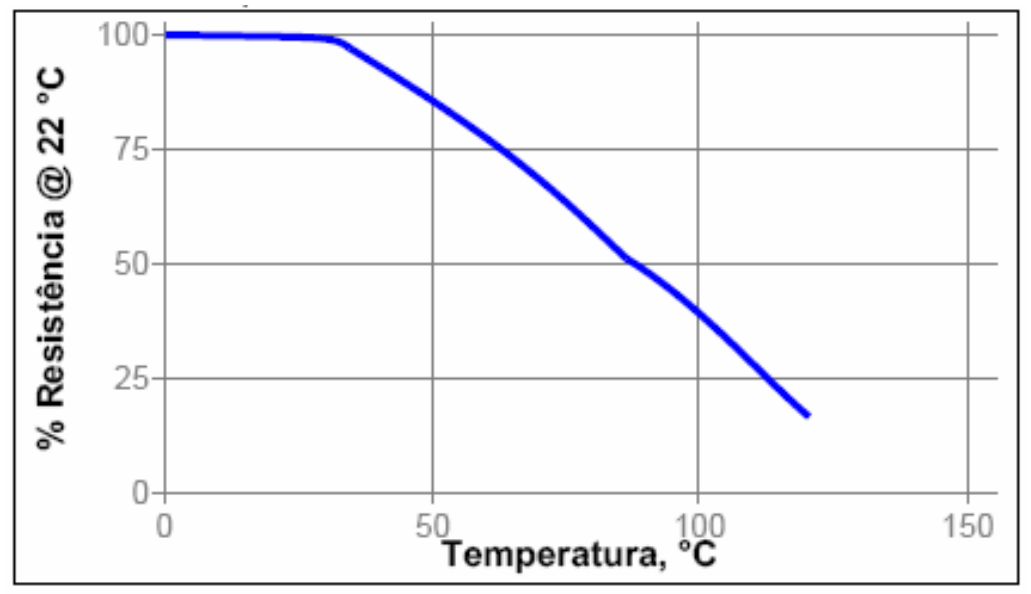

Figura 18 - Resistência do adesivo Loctite 326 x temperatura de trabalho (HENKEL, 2006).

\subsubsection{Temperatura de transição vítrea $(\mathrm{Tg})$}

Uma das mais importantes características dos polímeros em estado amorfo é o comportamento destes durante a transição do estado sólido para líquido. Se o polímero amorfo no estado vítreo é aquecido, a energia cinética das moléculas aumenta, sendo esta movimentação restrita à vibrações e rotações (STEVENS, 1997). Aumentando a temperatura do polímero atinge-se um ponto onde ocorrem alterações em seu comportamento, o polímero perde propriedades de materiais rígidos e assume propriedades similares as dos elastômeros (CARNEVAROLO, 2002). A temperatura onde ocorrem essas modificações é chamada Temperatura de Transição Vítrea $(\mathrm{Tg})$. Com menor freqüência alguns polímeros possuem uma Temperatura de Transição Vítrea de Segunda Ordem. Caso o polímero continue a ser aquecido, provavelmente este perderá suas propriedades de elastômeros e se tornará líquido, afirmação válida para termoplásticos. No caso de termofixos,os polímeros degradam em caso de superaquecimento.

A Tg é uma das características fundamentais do polímero e relata suas propriedades e processabilidade. A partir da $\mathrm{Tg}$ ocorre um aumento da liberdade rotacional e conseqüentemente maior movimentação das cadeias. $O$ aumento da liberdade de movimentação ocasiona maior distância entre os átomos, aumentando desta forma o volume especifico do polímero. O monitoramento da variação do volume especifico é uma forma de determinação da temperatura de transição vítrea. A temperatura de 
transição vítrea marca uma brusca alteração de entalpia, gerando outra possibilidade de determinação da Tg por calorimetria.

Além da dependência da liberdade de rotação das moléculas, diretamente ligada à estrutura química do polímero, outra variável de forte influência na $\mathrm{Tg}$ é o peso molecular, o mesmo polímero com pesos moleculares diferentes apresentam Tg's diferentes. $\mathrm{O}$ poliestireno, por exemplo, apresenta $\mathrm{Tg}$ variando de $40^{\circ} \mathrm{C}$ até $100^{\circ} \mathrm{C}$, dependendo do peso molecular, quando maior o peso molecular, maior a temperatura de transição vítrea (STEVENS, 1997).

O melhor desempenho de polímeros em aplicações é obtido em situações onde a temperatura de trabalho da aplicação é inferior à temperatura de transição vítrea do mesmo. Desta forma evita-se que haja alteração do comportamento e aquisição de propriedades de elastômeros, por polímero inicialmente com características de material rígido (WIEBECK, 2005).

\subsubsection{Temperatura de cura}

Broughton \& Gower (2001) citam a temperatura de cura dos adesivos como fator de influência na resistência das junções e afirmam que esta deve ser monitorada durante o processo de cura, podendo gerar alterações na resistência em caso de variações. As propriedades de cada polímero e conseqüentemente dos adesivos, dependem das condições em que a cura é realizada, sendo a temperatura um dos mais importantes fatores para a cura.

A elevação da temperatura durante a cura, a níveis diferentes de acordo com o tipo de adesivo, favorece a formação de cadeias longas de polímero. Estas cadeias proporcionam melhores características mecânicas ao material. Cada adesivo possui uma determinada faixa de temperatura, na qual se obtém as melhores condições de cura e por conseqüência as melhores propriedades mecânicas. Adesivos epóxis utilizados na indústria automotiva, por exemplo, geralmente são curados em temperaturas entre 150 e $190^{\circ} \mathrm{C}$. 


\subsection{FATORES BÁSICOS}

Os fatores classificados como básico estão relacionados à propriedades dos adesivos e materiais a serem unidos. O tipo de adesivo, por exemplo, é diretamente influente da resistência da junção, cada tipo de adesivo apresenta melhor desempenho em determinados tipos de aplicações.

O material dos substratos influencia na polimerização e conseqüentemente nas propriedades mecânicas do adesivo. Cada tipo de superfície interage de forma diferente com os diversos tipos de adesivos, segundo Possart (comunicação pessoal, 2006) ocorrem reações químicas na região de interface metal/adesivo, reações que variam com tipo de superfície e adesivo.

\subsubsection{Rugosidade}

As irregularidades das superfícies, rugosidade, numa faixa de dimensões que variam de 0,1 à $100 \mu \mathrm{m}$, tem influência considerável na adesão. Como efeito favorável podese citar o aumento da área de contato, melhor interação e ancoragem entre adesivo e substrato. A rugosidade permite melhor dissipação da energia proveniente das solicitações sofridas pela junção (VILLENAVE, 2005).

A existência de irregularidades traz também efeitos desfavoráveis, cada vale representa um potencial início de fissura. Superfícies com alta rugosidade podem caracterizar folgas e causar redução na resistência. Adesivos muito viscosos podem não manter contato íntimo com toda a superfície, assim como adesivos pouco viscosos podem se alojar nos vales e não contatar ambas superfícies simultaneamente. Outra desvantagem trazida pela rugosidade é a possibilidade de acúmulo de água, óleo ou sujeira nos vales, impossibilitando o contato adesivo substrato e conseqüentemente comprometendo a resistência.

As rugosidades são apresentadas em $\mathrm{Ra}$ e $\mathrm{Rz}$. Ra é a média dos valores absolutos dentro de uma região $I_{r}$ medida, conforme apresentado na Figura 19. Enquanto Rz é obtido dividindo a somatório das rugosidades medidas, em uma determinada região $\mathrm{I}_{\mathrm{r}}$, pelo número de valores medidos. 

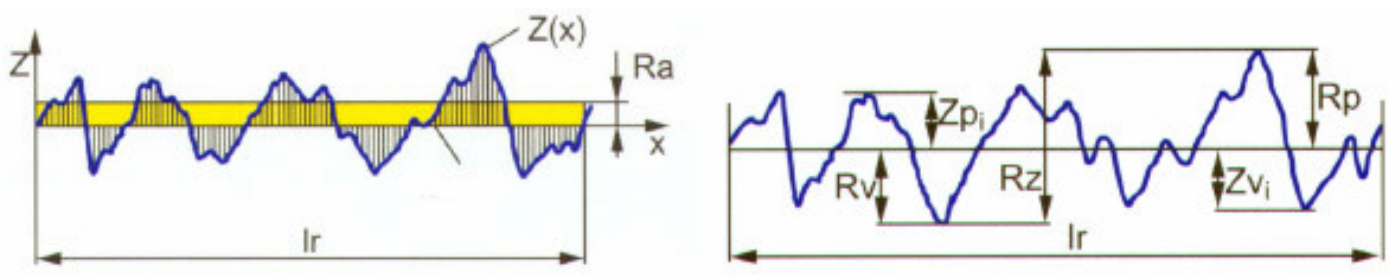

Figura 19 - Ra e Rz de acordo com DIN EN ISO 4287 (HENKEL, 2006).

$$
R a=\frac{1}{l r} \int_{0}^{l r}|Z(x)| d x
$$

\subsubsection{Superfícies metálicas}

A superfície da maioria dos metais diferenciasse dos outros materiais pela sua complexidade, desorganização e sensibilidade à corrosão. As duas primeiras características são ligadas à concentração de elementos estranhos na superfície. A qual é gerada pela reação de carbono com outros materiais ou elementos de liga combinados, como magnésio e alumínio, cobre e níquel com ouro. A principal conseqüência da presença e combinação de materiais é o grande número de combinações possíveis, tornando ímpar cada amostra de metal (VILLENAVE, 2005). No plano químico, as superfícies metálicas têm a particularidade de se oxidar quase instantaneamente ao entrar em contato com ar e umidade atmosférica. Mesmo os metais nobres mostram-se oxidáveis, é formada uma camada superficial constituída geralmente da reação de oxigênio com os elementos que compõe o metal. Desta forma as superfícies dos metais mostram-se ricas em óxidos e hidróxidos, sendo estes de extrema importância na determinação das características químicas e físicoquímicas das superfícies, assim como em seu comportamento.

\subsubsection{Superfícies ativas e ativadas}

As propriedades das superfícies ativas e ativadas estão essencialmente relacionadas à estrutura da superfície, dependendo da atividade físico-química e da 
reatividade das camadas de óxido e hidróxido. As características das superfícies variam muito de acordo com o metal. O ferro, por exemplo, gera camadas de diferentes tipos óxidos $\left(\mathrm{Fe}-\mathrm{Fe}_{3} \mathrm{O}_{4}-\mathrm{Fe}_{2} \mathrm{O}_{3}-\mathrm{FeO}(\mathrm{OH})\right.$ do centro para a interface.

O oposto ocorre com o alumínio, a oxidação do alumínio da origem à uma camada de óxido com $0,5 \mu \mathrm{m}$ de espessura, estrutura bem organizada e forte poder de coesão. A camada de óxido de alumínio fornece proteção para as camadas subjacentes e proporciona boas condições de ancoragem mecânica.

Grande parte dos metais encontra-se em condições intermediárias à estes dois metais: ferro e alumínio. Justificando desta forma a realização de tratamentos de superfícies e utilização de ativadores de superfície, com os seguintes objetivos:

- $\quad$ Eliminação de camadas de coesão inadequadas.

- Menor variação da rugosidade da superfície.

- Aumento do número de regiões com condições ideais para a cura e fortalecimento da resistência da junção.

Os tratamentos superficiais e uso de ativadores podem oferecer riscos à superfície, tais riscos não justificam ignorar tais processos. Muitas vezes pode ocorrer a associação de um tratamento superficial com a utilização de ativador.

\subsubsection{Limpeza (Desengraxe)}

De acordo com Broughton \& Gower (2001) as condições de limpeza das superfícies a serem aderidas é um dos fatores mais críticos no processo de adesão. A existência de contaminação, sujeira, óleo ou graxa na superfície interfere diretamente na resistência e vida útil da junção. A escolha do método correto de limpeza, ou desengraxe, é de extrema importância para a junção.

Métodos de limpeza são apresentados por Broughton \& Gower (2001) e divididos como métodos que alteram ou não as características químicas da superfície. Dentre os métodos que não alteram as características químicas da superfície, encontra-se a utilização de solvente, classificada como de média eficiência e baixo custo. Estas são seguidas em eficiência por desengraxe por vapor e abrasão mecânica. Uma 
relação com tempo máximo de exposição à estes processos também é apresentada, sendo que a exposição máxima à solvente sugerida é de 2 horas.

O termo desengraxe se refere às sujidades superficiais depositadas sobre os materiais expostos ao ambiente. Além disso, como o próprio termo deixa-se subentender, desengraxe também é a retirada de óleos e graxas das superfícies através da utilização de solventes orgânicos ou detergentes. Estes agentes de desengraxe devem ser capazes de dissolver ou ao menos desplacar a camada de sujidade.

Os solventes apresentam um grande número de inconvenientes: inflamáveis, capazes de explodir, tóxicos, agressivos ao meio-ambiente e dispendiosos - devido às severas exigências feitas para a autorização da utilização de alguns solventes.

O principal benefício proporcionado pelos solventes é sua forte volatilidade, secando e limpando rapidamente os substratos, permitindo a adesão ou tratamento quase que imediatamente. Outro fator importante é a simplicidade da forma de utilização, não requerendo equipamentos especiais para sua utilização. Os solventes geralmente são utilizados em substratos de pequenas dimensões e baixo volume de produção, ou limpeza de corpos de provas para ensaios (VILLENAVE, 2005).

Tais solventes podem ser aplicados com um pedaço de tecido ou papel embebido, atritando-o contra a superfície a ser limpa. A eficácia deste método de desengraxe depende muito do operador, sendo que para condições ideais de limpeza deve-se utilizar um pedaço de pano ou papel para cada peça, evitando desta forma a transferência de poluentes entre substratos ou reservatório de desengraxante.

A utilização de alguns solventes é controlada por órgãos federais. As disposições regulamentares relativas aos compostos orgânicos voláteis fixam tolerâncias especificas para cada tipo de produto, tanto no que tange a utilização como a emissão para atmosfera. 


\section{NANOTECNOLOGIA}

\subsection{COMPETITIVIDADE DO MERCADO MUNDIAL DE MATERIAIS}

De acordo com AIMPLAS (2001) para sobreviver na competitividade mundial as organizações devem fazer duas coisas: adaptar e mudar os produtos e serviços que elas oferecem, mudando e adaptando também a forma como estes são produzidos. Estes dois conceitos são denominados inovação de processo e inovação de produto. É evidente hoje que o mercado oferece várias oportunidades de inovações tecnológicas, cabe as empresas identificarem essas oportunidades, através de sinais que o mercado apresenta, e planejar suas estratégias de acordo com estes sinais.

\subsection{NANOMATERIAIS}

$\mathrm{Na}$ área de materiais, diversos estudos vêm sendo realizados com o intuito de desenvolver novos materiais com excelentes propriedades. Estas propriedades podem ser mecânicas, térmicas ou elétricas. Esta nova tecnologia de materiais se destaca pelo fato de se concentrar em escala nanométrica, classificando-os como nanomateriais.

Estudo da Fundação Steinbeis (Steinbeis-Europa-Zentrum, 2005) afirma que a definição de nanomateriais deve ser feita da maneira mais simples possível, por isso classifica as sete principais categorias de nanomateriais em:

- Nanomateriais base carbono: são materiais que possuem como nanocomponente carbono puro, dentre os principais nanomateriais desta categoria encontram-se os nanotubos de carbono. Estes são compostos basicamente de camadas sobrepostas de grafite, as quais formam tubos com diâmetros da ordem de $0,4 \mathrm{~nm}$. Nanotubos podem ser colocados dentro de outros nanotubos, o que possibilita a classificação de nanotubos de parede simples e nanotubos de multiparedes. As principais características destes materiais são a capacidade de transmissão de elétrons, armazenamento de energia elétrica e propriedades ópticas. 


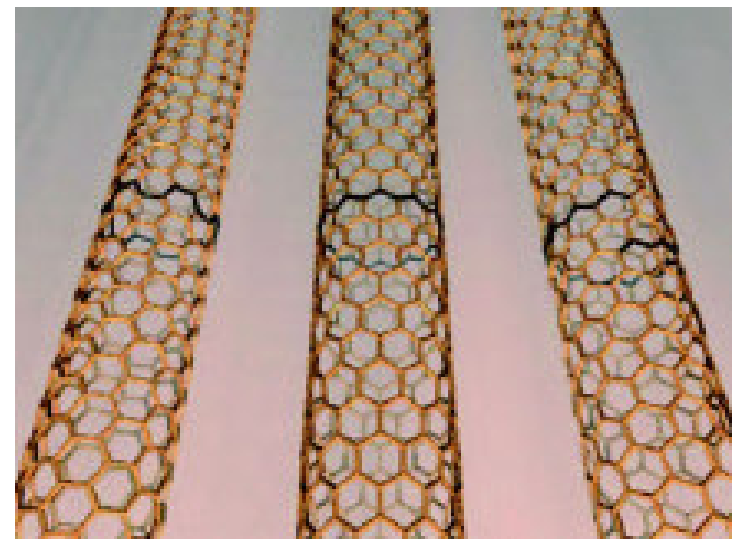

Figura 20 - Nanotubos de carbono de parede simples (Steinbeis-Europa-Zentrum, 2005).

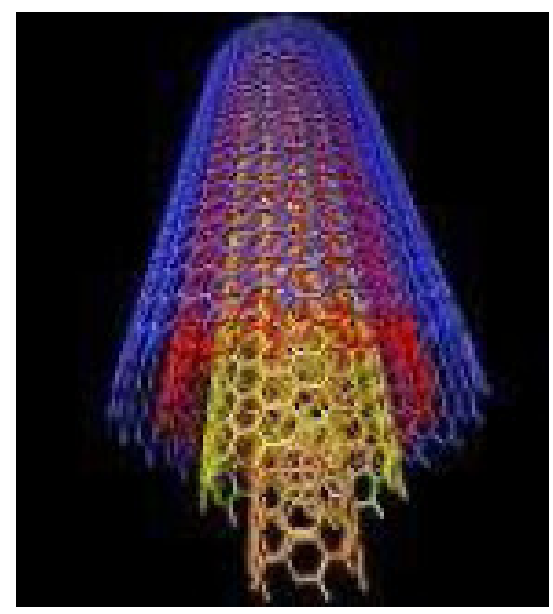

Figura 21 - Nanotubos de carbono de multi-paredes (Steinbeis-Europa-Zentrum, 2005).

- Nanocompósitos: podem ser divididos em duas categorias. Alguns nanocompósitos são compostos por uma matriz não-nanocristalina preenchida com nanopartículas ou nanofibras de outro material. Pode-se citar como exemplo de nanocompósito o preenchimento de uma matriz de nanopolímero preenchida com nanotubos de carbono. Pesquisas com nanocompósitos estudam a viabilidade de aplicação destes no armazenamento, economia, produção e transformação de energia. 


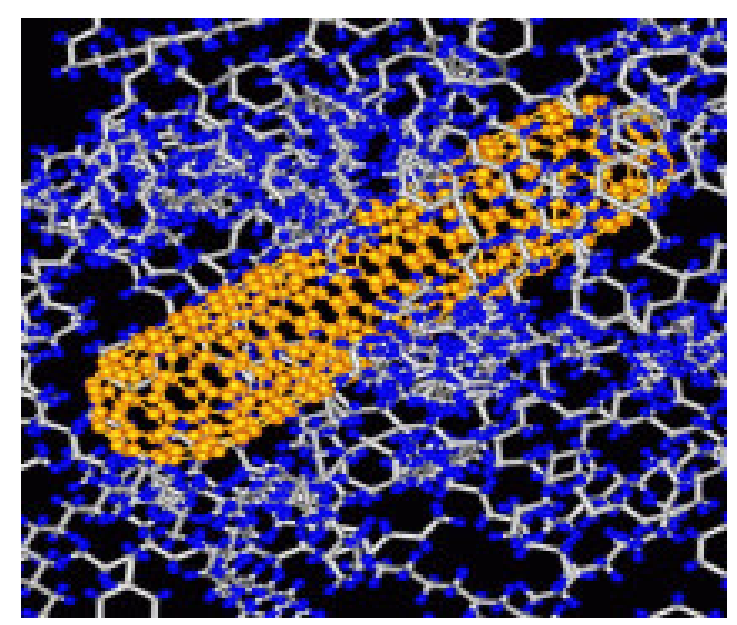

Figura 22 - Nanotubos de carbono em matriz de nanopolímero (Steinbeis-Europa-Zentrum, 2005).

- Nanometais e nanoligas: podem ser classificados em ferrosos ou não ferrosos. Como exemplo pode-se citar a aplicação de nanopartículas de prata, ou outros metais nobres, em aplicações relacionadas à saúde. Nanoligas metálicas magnéticas podem reduzir perdas de transmissão de energia devido ao reduzido tamanho de seus grãos.

- Nanomateriais biológicos: são definidos como materiais, de origem biológica, usados em aplicações tecnológicas. Enzimas, por exemplo, têm estruturas muito bem definidas, em níveis nanométricos, que trabalham como "nanomáquinas". Nanomateriais inorgânicos como a amina, pode ser utilizada em aplicações biológicas, como implantes.

- Nanopolímeros: são polímeros nanoestruturados, sendo que a nanoestrutura resulta em significantes alterações nas propriedades intrínsecas. Os polímeros se distinguem de outros materiais devidos ao grande número de repetições de suas unidades básicas (monômeros) na formação da cadeia. As moléculas do mesmo polímero podem ter número de átomos diferentes, o que não ocorre com outros tipos de materiais. Devido ao alto peso molecular os polímeros apresentam elevada atração intermolecular, esta atração por sua vez, influencia diretamente nas propriedades mecânicas dos polímeros. Os polímeros com maior peso molecular apresentam propriedades mecânicas elevadas. Segundo Steinbeis-Europa-Zentrum (2005) os nanopolímeros estão entre os mais importantes nanomateriais do futuro, com aplicações na medicina, energias e ciência de materiais. 


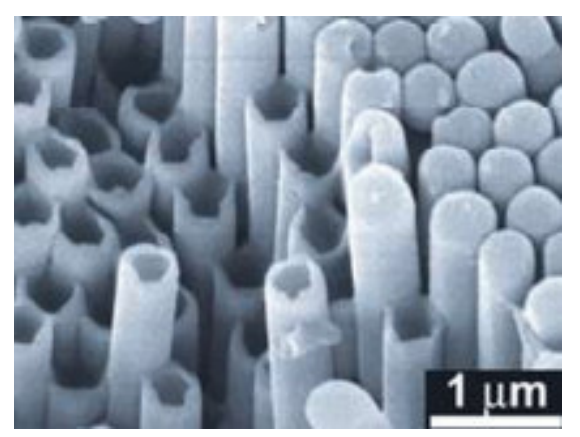

Figura 23 - Nanotubos de estireno (Steinbeis-Europa-Zentrum, 2005).

- Nanovidros: são nanomateriais amorfos com aplicações destacadas na área óptica, nanomateriais como vidro, cristais e outros materiais amorfos oferecem excelente resposta óptica na formação de nanoestruturas, o que contribui para constituir nanoópticos.

- Nanocerâmicas: são nanomateriais cerâmicos óxidos ou não óxidos, silicatos e metais pesados tais como compósitos destes grupos de materiais. Quando aplicada em superfícies, a nanocerâmica pode gerar aumento da resistência mecânica desta superfície, aumento da ductilidade do material, melhora da tenacidade e aumento do calor específico do material. As principais nanocerâmicas produzidas em escala industrial hoje são: sílica, óxido de zinco, alumina, zircônio e titânia.

\subsection{NANOCERÂMICA APLICADA COMO TRATAMENTO SUPERFICIAL}

Segundo Steinbeis-Europa-Zentrum (2005) o desenvolvimento dos tratamentos superficiais nanocerâmicos (NT - Nano-Treatment) encontra-se em fase inicial, sendo que seu sucesso depende da possibilidade de controlar a produção deste material, bem como da garantia que suas propriedades sejam constantes e seus custos aceitáveis para a indústria automotiva, um dos maiores consumidores de tratamentos superficiais. 


\subsubsection{Tecnologia Atual - Fosfatização}

Problemas de oxidação de carrocerias levaram a indústria automotiva a investir no desenvolvimento de tratamentos superficiais. Estes melhoram a aderência das tintas e conseqüentemente aumentam a proteção contra corrosão. Há muito tempo vêm sendo utilizado na indústria automotiva para esta finalidade o processo de fosfatização de superfícies.

A fosfatização consiste da deposição de uma camada de fosfatos metálicos flexíveis, firmemente aderida ao substrato, preparando-o para receber revestimentos orgânicos, proporcionando melhor aderência e resistência a corrosão, ou lubrificantes nas operações de deformação a frio ou em partes móveis. Os fosfatos metálicos encontram-se dissolvidos em solução aquosa de ácido fosfórico, podendo ser aplicado por aspersão ou imersão.

O processo de fosfatização é formado por vários banhos, de acordo com a necessidade de cada aplicação. A configuração básica envolve sete banhos, sendo estes: desengraxe, enxágüe, refinador, fosfato, enxágüe, passivação e enxágüe DI. Além do elevado número de banhos exigido pelo processo de fosfatização, outras desvantagens deste processo são: o alto consumo de energia necessário para aquecimento de alguns banhos, o aumento de massa da peça do material onde 0 fosfato é depositado e a lama (resíduo) gerada pelo processo, trazendo problemas de ordem ambiental. A Tabela 3 apresenta os tipos de fosfato mais utilizados na indústria, suas aplicações específicas e o peso da camada depositada. 
Tabela 3 - Relação de fosfatos utilizados e finalidades.

\begin{tabular}{|c|c|c|c|c|}
\hline Fosfato & Característica & Peso & Aplicação & Finalidade \\
\hline \multirow[t]{3}{*}{ Ferro } & Estrutura amorfa & $2-12 \mathrm{mg} / \mathrm{dm}^{2}$ & Imersão & Pintura \\
\hline & Boa aderência para tintas & & Aspersão & \\
\hline & Boa resistência à corrosão & & & \\
\hline \multirow[t]{3}{*}{ Zinco } & Estrutura cristalina definida & $12-40 \mathrm{mg} / \mathrm{dm}^{2}$ & Imersão & Pintura \\
\hline & $\begin{array}{l}\text { Excelente aderência para } \\
\text { tintas }\end{array}$ & & Aspersão & \\
\hline & $\begin{array}{l}\text { Excelente resistência à } \\
\text { corrosão }\end{array}$ & & & \\
\hline Zinco & $\begin{array}{l}\text { Estrutura cristalina definida } \\
\text { Excelente absorção de } \\
\text { lubrificantes e óleos } \\
\text { protetivos }\end{array}$ & $50-400 \mathrm{mg} / \mathrm{dm}^{2}$ & Imersão & $\begin{array}{l}\text { Deformação } \\
\text { de metais }\end{array}$ \\
\hline Manganês & $\begin{array}{l}\text { Estrutura cristalina definida } \\
\text { Excelente absorção de } \\
\text { lubrificantes e óleos } \\
\text { protetivos }\end{array}$ & $\begin{array}{l}100- \\
400 \mathrm{mg} / \mathrm{dm}^{2}\end{array}$ & Imersão & Antiatrito \\
\hline
\end{tabular}

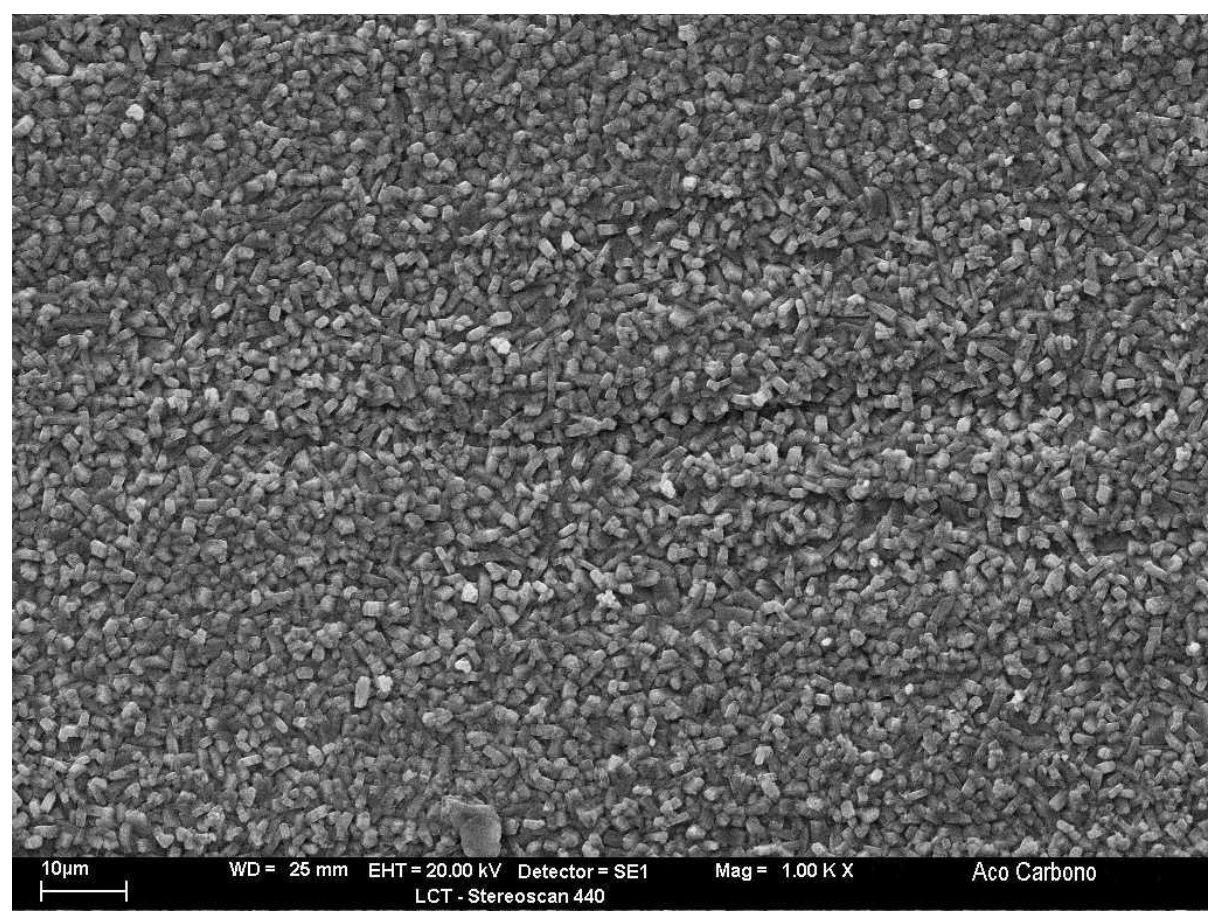

Figura 24 - Estrutura cristalina da camada de fosfato tricatiônico. 


\subsubsection{Nanotecnologia - Bonderite NT1}

A crescente e justificada preocupação com o meio ambiente gerou a necessidade de desenvolvimento de tratamentos de superfície, os quais proporcionem propriedades iguais ou superiores às proporcionadas pela fosfatização, sem o problema da geração de resíduos e o alto consumo de energia (Steinbeis-Europa-Zentrum, 2005). Os problemas ambientais causados pela fosfatização tendem a tornar sua utilização injustificável nos próximos anos. A necessidade citada acima levou as indústrias deste segmento a desenvolver novas tecnologias.

A Nanocerâmica aplicada como tratamento superficial para aumento da adesão de tintas é uma tecnologia, desenvolvida pela empresa Henkel, isenta de fosfato e metais pesados, especialmente formulada para aplicações em aço, zinco ou alumínio. Esta tecnologia é isenta de todos os componentes orgânicos e proporciona aumento de proteção à corrosão de metais pintados. Na maioria dos casos a Nanocerâmica, atualmente disponível no mercado como Bonderite NT-1, proporciona às superfícies pintadas a proteção à corrosão superior à proporcionada pelo fosfato de ferro. A Figura 25 mostra a elevada resistência da superfície tratada com nanocerâmica após 504 horas em teste de "Neutral Salt Spray" com painéis pintados com tinta pó, a migração foi de $0,3 \mathrm{~mm}$ nos painéis onde foi aplicada a nanocerâmica Bonderite NT-1 e 3,1mm nos painéis com aplicação de fosfato de ferro. O Fosfato tricatiônico proporciona proteção inferior à nanocerânica em alumínio, porém levemente superior em aço carbono. Atualmente a empresa Henkel está desenvolvendo nova versão de Nanocerâmica, com desempenho equivalente ao proporcionado pelo fosfato tricatiônico em aço carbono. 


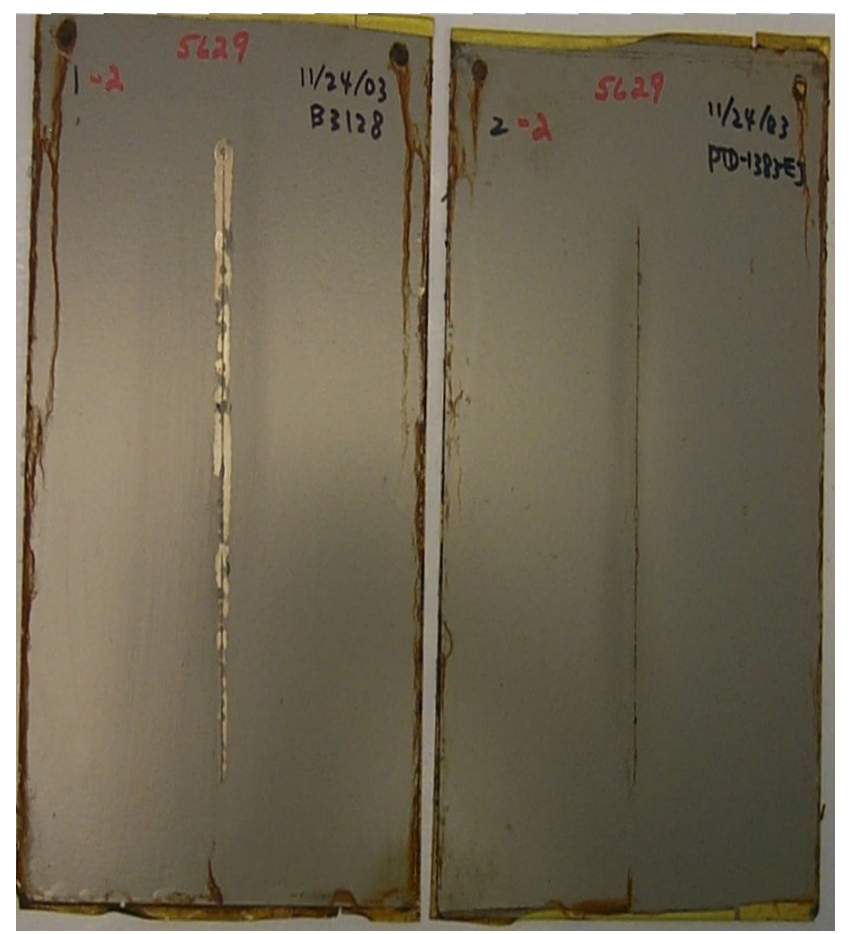

Figura 25 - Painéis com aplicação de Fosfato de Ferro (esquerda) e nanocerâmica Bonderite NT-1 (direita) após 504h em "Neutral Salt Spray".

O tratamento superficial nanocerâmico consiste basicamente da conversão da camada externa da superfície metálica, através da aplicação de nanopartículas. A reação, conversão ou oxidação da camada externa, acontece por atrito, por isso o banho deve ser movimentado e não necessita de aquecimento. O número de banhos necessários para a aplicação da nanocerâmica é inferior ao número de banhos no processo de fosfatização, sendo estes: desengraxe, enxágüe, enxágüe DI, nanocerâmica e enxágüe DI. Seguem abaixo alguns benefícios oferecidos pela Nanocerâmica, quando comparada à fosfatização:

- Menor consumo de energia. Não é necessário aquecer o banho para aplicação da nanocerâmica, procedimento necessário ao aplicar o fosfato;

- Não há geração de resíduos. O Bonderite NT-1 não gera resíduos nocivos ao meio ambiente, grave problema gerado pela tecnologia atual;

- $\quad$ Número reduzido de tanques de aplicação;

- Reduzido acréscimo de massa à superfície. A quantidade de produto aplicado, em massa, é extremamente menor com o mesmo ou maior desempenho que o fosfato de ferro. A massa adicionada pela nanocerâmica é de 0,5 à $2 \mathrm{mg} / \mathrm{dm}^{2}$. 


\section{MODELOS TÉORICOS DE ADESÃO}

Ao longo de décadas vêm sendo desenvolvidos modelos teóricos de adesão, com o intuito de explicar os fenômenos ocorrentes na região de interface entre substrato e adesivo. Diversos métodos foram construídos, os quais atribuem a adesão à fatores de ordem mecânica, física e química.

Intuitivamente é possível perceber, que as condições das superfícies a serem aderidas são de extrema importância para a resistência da junção. Pode-se citar como exemplo a dificuldade de adesão oferecida por superfícies oleadas, ou de forma contraria, a facilidade oferecida por superfícies ásperas ou porosas.

Ainda de forma intuitiva, conclui-se facilmente que caso a adesão realmente seja realmente gerada por fenômenos físicos (diferenças de momentos de dipolos), tornase de extrema importância a ótima distribuição destas cargas em toda a área de contato entre adesivo e substrato.

De acordo com Possart (comunicação pessoal, 2006) atualmente pouco se sabe efetivamente sobre o que realmente ocorre nesta região, porém acredita-se que não ocorram fenômenos isolados, sendo a adesão resultado da combinação do efeito de vários fenômenos simultâneos. Estudos atuais mostram que além das interações mecânicas e físicas, também ocorrem interações químicas nesta região. Desta forma quase nenhuma falha ocorrida na separação de junções seria do tipo adesiva, mesmo que em escalas microscópicas, as falhas são quase totalmente coesivas. Considerando o modelo químico de adesão, verifica-se a importância da molhabilidade do adesivo sobre os substratos, visando contato íntimo entre os mesmos, além de reduzir a distância entre as moléculas e favorecer a atuação das forças de atração de ordem física.

\subsection{MODELO MECÂNICO}

O modelo mecânico retrata a importância da área aderida e da aspereza (rugosidade) da superfície. Estudos mostram que a rugosidade da superfície tem 
influência direta na resistência da adesão, em caso de materiais porosos, o modelo mecânico é quase que predominante.

Os adesivos na forma líquida têm a propriedade de se moldar ao corpo que o contém e preencher todos os espaços vazios deste corpo. Porém, durante o processo de cura, seja este por via física ou química, pode ocorrer uma perda de entropia no adesivo acarretando na diminuição do volume ocupado.

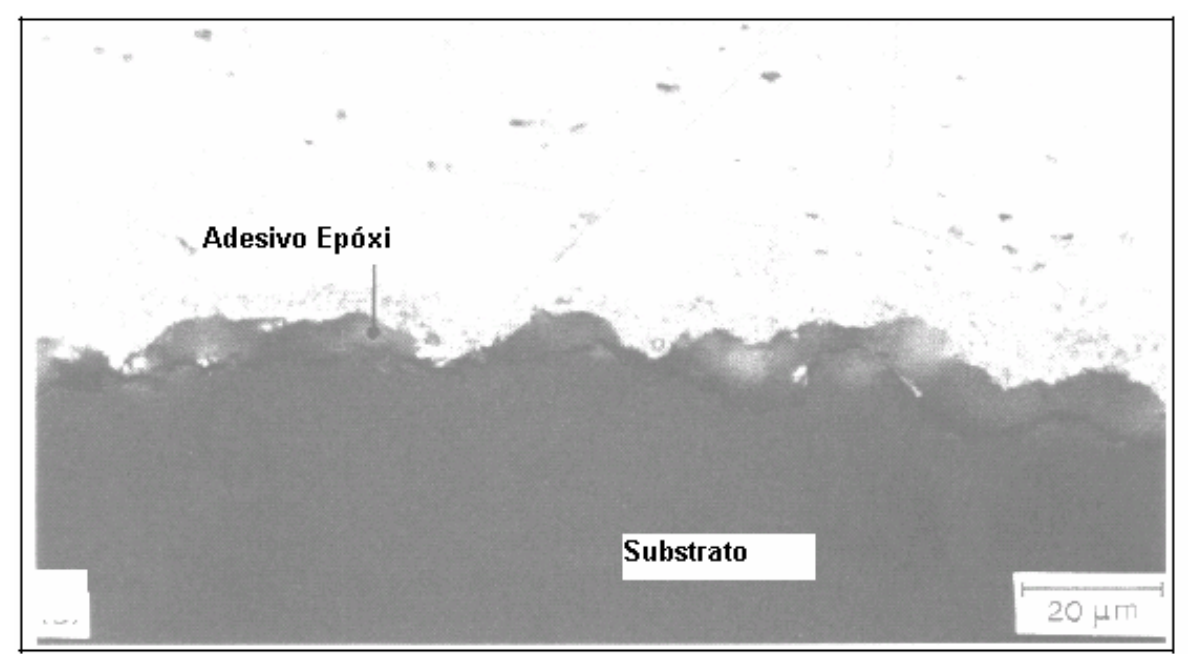

Figura 26 -Região de contato entre superfície metálica e adesivo epóxi polimerizado (Possart, 2006).

A importância da ancoragem mecânica é bem ilustrada através do processo solidificação da água. Ao mudar da fase líquida para sólida a água aumenta seu volume, aumentando a ancoragem na superfície, por isso ocorre a adesão do gelo em certas superfícies, mesmo naquelas de difícil adesão, como por exemplo, superfície de materiais em polipropileno.

\subsection{MODELO ELETROSTÁTICO}

O modelo eletrostático sugere que a adesão resulta da atração entre cargas positivas distribuídas na superfície do substrato e cargas negativas distribuídas na superfície do adesivo e vice-versa. Sabe-se que através do atrito entre corpos, ou seja, por fricção, pode-se gerar cargas eletrostáticas em superfície isolada. Porém o adesivo líquido não possui carga, não é friccionado contra o substrato e não adquire 
carga ao se polimerizar, desta forma o significado prático deste modelo revela-se limitado.

Apesar das observações acima, Deryagin (1950) realizou experimentos que comprovaram a existência de cargas diferentes nas superfícies em equilíbrio, descrevendo de forma satisfatória as componentes eletrostáticas na adesão através da utilização de tal modelo. Este no entanto não tornou possível compreender de que forma os componentes eletrostáticos interferem na resistência da junção adesiva.

\subsection{MODELO TERMODINÂMICO}

O modelo termodinâmico de adesão é basicamente fundamentado nas forças de atração de Van der Waals, propostas em 1873 para explicar o comportamento dos gases reais. Este modelo propunha a existência de uma determinada força de atração entre as moléculas dos gases (MENDES, 2005).

$$
\left(p+\frac{a}{v^{2}}\right)(V-b)=n R T
$$

Onde:

p : pressão do gás;

v : volume específico do gás;

$\mathrm{n}$ : número de moles do gás;

$\mathrm{R}$ : constante dos gases;

$\mathrm{T}$ : temperatura em Kelvin;

a : constante de atração de Van der Waals;

b : constante de volumes finitos de moléculas de gás.

Possart (2006) afirma que posteriormente outras teorias vieram confirmam a teoria das forças de atração de Van der Waals e sua aplicabilidade na adesão, sendo estas: 
1- $\quad$ Ligações dispersivas (Forças de London)

2- $\quad$ Ligações de Momentos de Dipolos Permanentes (Forças de Keesom)

3- $\quad$ Ligações de Momentos de Dipolos Permanentes e Induzidos (Forças de Debye).

\subsubsection{Forças de London}

O modelo de London propõe que átomos têm sua distribuição de cargas, positivas e negativas, perturbada por átomos de moléculas vizinhas. Este modelo propõe configurações dinâmicas entre os átomos, com alterações rápidas, sendo as ligações em ambos os átomos, induzidas. Devido ao dinamismo das configurações, London utilizou a mecânica quântica para modelar o fenômeno, resultando na seguinte equação para determinação da energia potencial de atração mútua ( $\mathrm{V}_{\text {London }}$ ) para átomos com vibrações conhecidas:

$$
V_{\text {LONDON }}=\frac{-3\left(h v_{1} v_{2}\right)}{2\left(v_{1}+v_{2}\right)} \frac{\alpha_{1} \alpha_{2}}{r^{6}}
$$

Onde:

$\mathrm{h}$ : constante de Planck;

$v$ : freqüência característica da molécula;

$\alpha$ : polarisabilidade da molécula;

$r$ : distância entre duas partículas carregadas.

\subsubsection{Forças de Keesom}

Segundo Keesom, qualquer molécula ou qualquer fragmento de molécula que comporte um grupo funcional constitui um dipolo, susceptível de interagir com dipolo vizinho. 


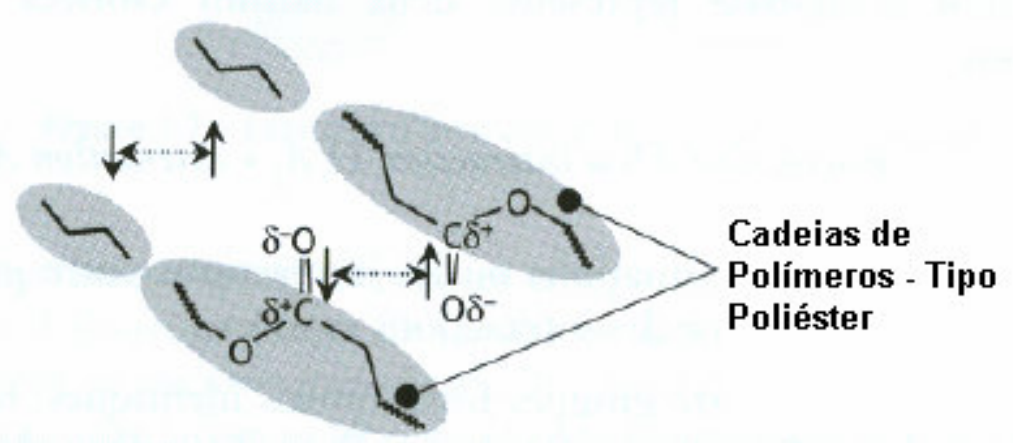

Figura 27 - Interação dipolar de Keesom (Villenave, 2005).

Contrariamente às Forças de London, as Forças de Keesom têm limitações no que diz respeito à sua contribuição para a coesão e a adesão dos líquidos e os sólidos, alguns autores consideram as Forças de Keesom negligenciáveis na soma das ligações dispersivas. Tal consideração geralmente é válida, exceto quando se tem interesse pela coesão de determinados polímeros (celuloses, poliésteres, por exemplo) para os quais as interações de momentos de dipolos permanentes desempenham um papel decisivo, normalmente na constituição de fibras. Outra desvantagem do método de Keesom é a dependência da temperatura, o que reduz, quase anulando, a energia de atração para altas temperaturas, o que nem sempre é encontrado na realidade. $\mathrm{O}$ modelo de Keesom propõe que a atração é máxima quando há o alinhamento das moléculas, sendo a energia potencial de atração mútua $\left(V_{\text {Keesom }}\right)$, para moléculas de momentos de dipolos $\mu_{1}$ e $\mu_{2}$, dada pela equação (MENDES, 2005):

$$
V_{\text {KEESOM }}=\frac{-2 \mu^{2}}{3 k T r^{6}}
$$

Onde:

$\mu$ : energia potencial pata o dipolo permanente;

$\mathrm{k}$ : constante de Boltzman;

$\mathrm{T}$ : temperatura em Kelvin;

$r$ : distância entre duas partículas carregadas. 


\subsubsection{Forças de Debye}

O Modelo de Debye sugere a existência de atração complementar às Forças de Keesom, assegurando e explicando a atração mesmo em temperaturas mais elevadas. Debye demonstra que dipolos permanentes em vizinhança de ligações polarizáveis (dupla ligação $\mathrm{C}=\mathrm{C}$ por exemplo), podem induzir a transformação destes dipolos, participando ainda menos que as ligações de Keesom à adesão ou a coesão. As forças Debye são importantes para explicação da adesão entre polímeros halogênios e elastômeros não saturados (tipo poliisoprano) ou na autoadesão dos neoprenos (VILLENAVE, 2005).

Mendes (2005) apresenta a equação de energia potencial de atração mútua para duas moléculas diferentes segundo Debye:

$$
V_{\text {Debye }}=\frac{-\alpha_{1} \mu_{2}^{2}+-\alpha_{2} \mu_{1}^{2}}{r^{6}}
$$

$\mu$ : energia potencial pata o dipolo permanente;

$\alpha$ : polarisabilidade da molécula;

$r$ : distância entre duas partículas carregadas.

\subsection{MODELO QUÍMICO}

De acordo com Possart (comunicação pessoal, 2006) diversos trabalhos vem sendo realizados com foco no desenvolvimento de modelos químicos de adesão. Tratamse de desenvolvimentos complexos, pois a caracterização da adesão por reações químicas exige uma análise exata do sistema de elétrons das moléculas do adesivo, bem como das moléculas do substrato, procedimentos possíveis somente com equipamentos específicos. Possart (2006) define o modelo químico como complexo jogo de trocas de elétrons entre as moléculas do adesivo e substrato.

A Teoria de Orbital Molecular tem como princípio básico que, assim como nos átomos, nas moléculas os elétrons se distribuem em orbitais, chamados Orbitais 
Moleculares (OM), ocupados na ordem crescente de suas energias. Os orbitais moleculares são formados pela sobreposição de orbitais atômicos, para que essa formação aconteça é necessário que as superposições de orbitais de valências dos átomos gerem estruturas nas quais as densidades eletrônicas máximas se concentrem em átomos passíveis de ligações. Porém nem sempre as sobreposições têm essas características, elas podendo ser positivas, negativas ou nulas, sendo que somente as configurações positivas possibilitam as reações (Oliveira \& Fernandes, 2006). A Figura 28 ilustra as formações de orbitais possíveis.

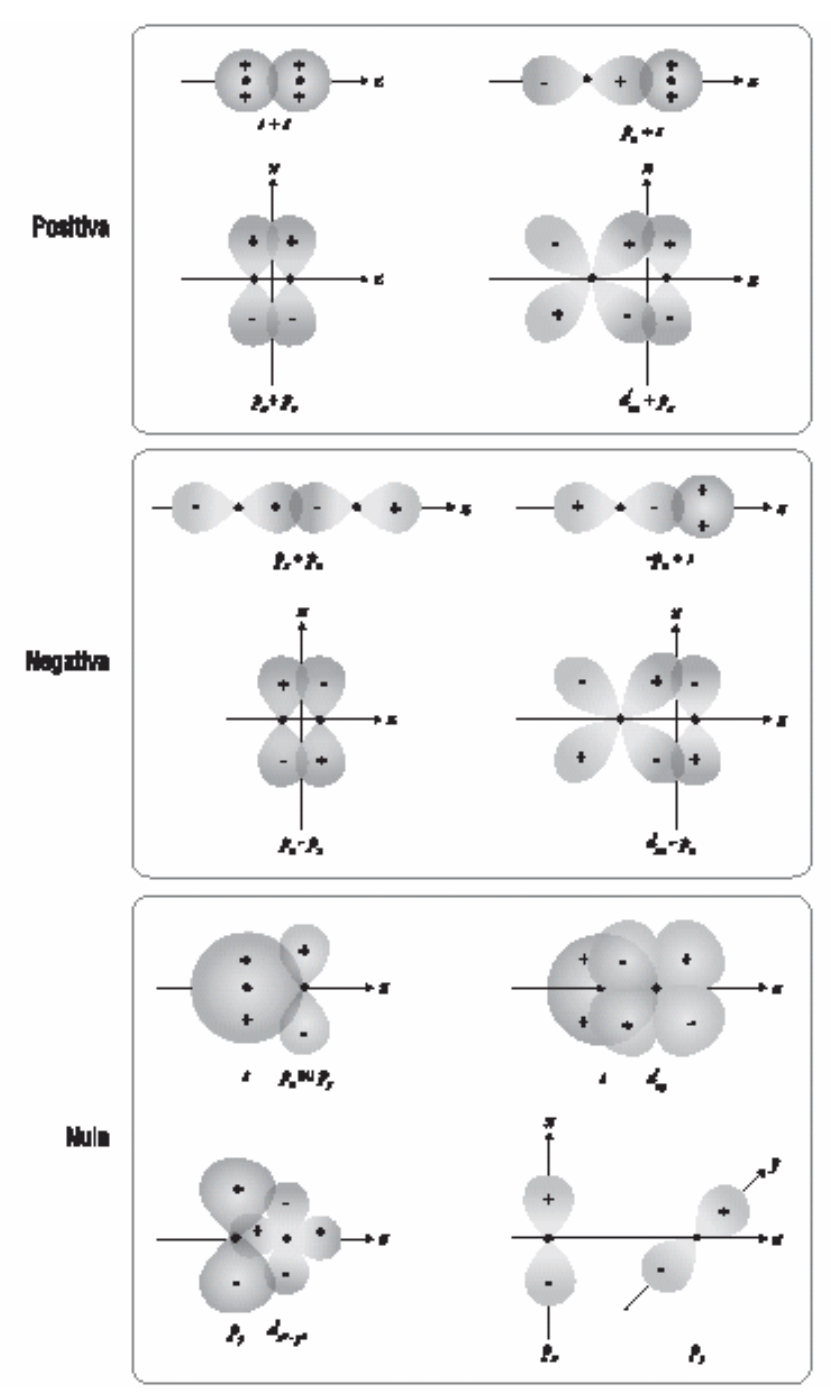

Figura 28 - Superposição de orbitais na formação de Orbitais Moleculares (Oliveira e Fernandes, 2006).

Baseadas em observações espectroscópicos e na TOM publicações apresentam modelos químicos de adesão para adesivos a base de acrilatos, epóxis e poliuretanos. Grande parte destes modelos foi desenvolvida para adesão em metais, 
devido à boa adesão, empiricamente conhecida, de metais com os adesivos anteriormente citados.

Possart (2006) mostra que todas as reações químicas de adesão:

- $\quad$ Produzem orientação das moléculas de polímero sobre a superfície metálica.

- Influenciam a estrutura da interface e conseqüentemente a formação de cadeias ou polimerização em adesivos reativos. 


\section{MATERIAIS E MÉTODOS}

Foram adotados métodos e materiais diferenciados para o atingimento dos objetivos deste trabalho, respeitando as particularidades e necessidades de cada objetivo. Todos os ensaios foram embasados em dados da literatura e/ou normas como ASTM D 1002 - 05.

\subsection{PRIMEIRO MÉTODO - ANÁLISE DOS FATORES DE INFLUÊNCIA}

Conforme citado anteriormente, este trabalho tem como um dos objetivos verificar e quantificar a influência de determinados fatores na resistência mecânica de junções adesivas. As junções analisadas neste primeiro método foram obtidas por sobreposição simples de chapas, unidas por adesivo estrutural de base acrílica e tiveram suas condições de superfície e cura variadas. Para tornar tal desenvolvimento possível foram realizados ensaios de cisalhamento destas junções no laboratório do Centro de Engenharia de Adesivos Loctite (CEAL) da empresa Henkel em Itapevi.

A escolha dos materiais utilizados, chapas metálicas e adesivo, foi feita baseada em informações de mercados. Procurou-se optar por chapas metálicas de uso industrial geral, bem como por adesivo acrílico disponível no mercado local e de larga utilização na indústria. Os fatores de influência a serem estudados foram selecionados após revisão da literatura e recebimento de informações sobre as necessidades do mercado, baseados na experiência profissional do autor.

\subsubsection{Chapas Metálicas}

A fácil obtenção, disponibilidade no mercado, associada ao elevado número de aplicações na indústria geral auxiliaram na definição do aço SAE J403 1010 laminado à quente como material das chapas metálicas utilizadas nos corpos de prova. As chapas, com $2 \mathrm{~mm}$ de espessura, foram fornecidas pela Companhia 
Siderúrgica de Tubarão com a seguinte composição química, de acordo com certificado emitido pela Siderúrgica:

Tabela 4 - Composição química do aço utilizado.

\begin{tabular}{llllllllll}
\hline Elemento & $\mathrm{C}$ & $\mathrm{Si}$ & $\mathrm{Mn}$ & $\mathrm{P}$ & $\mathrm{S}$ & $\mathrm{Al}$ & $\mathrm{Cu}$ & $\mathrm{Ni}$ & $\mathrm{Cr}$ \\
\hline Percentual & $0,10 \%$ & 0,021 & 0,471 & 0,016 & 0,0083 & 0,041 & 0,008 & 0,005 & 0,017 \\
\hline
\end{tabular}

A análise metalográfica das chapas, realizada por laboratório contratado, possibilitou dimensionar o tamanho dos grãos do material, entre 8 e 9 conforme ASTM. As chapas apresentaram estrutura com grãos homogêneos, características de um bom recozimento. A Figura 29 mostra que o material apresenta matriz ferrítica com aproximadamente $10 \%$ de perlita. A Figura 30 mostra a camada de óxido conseqüência do processo de laminação à quente.

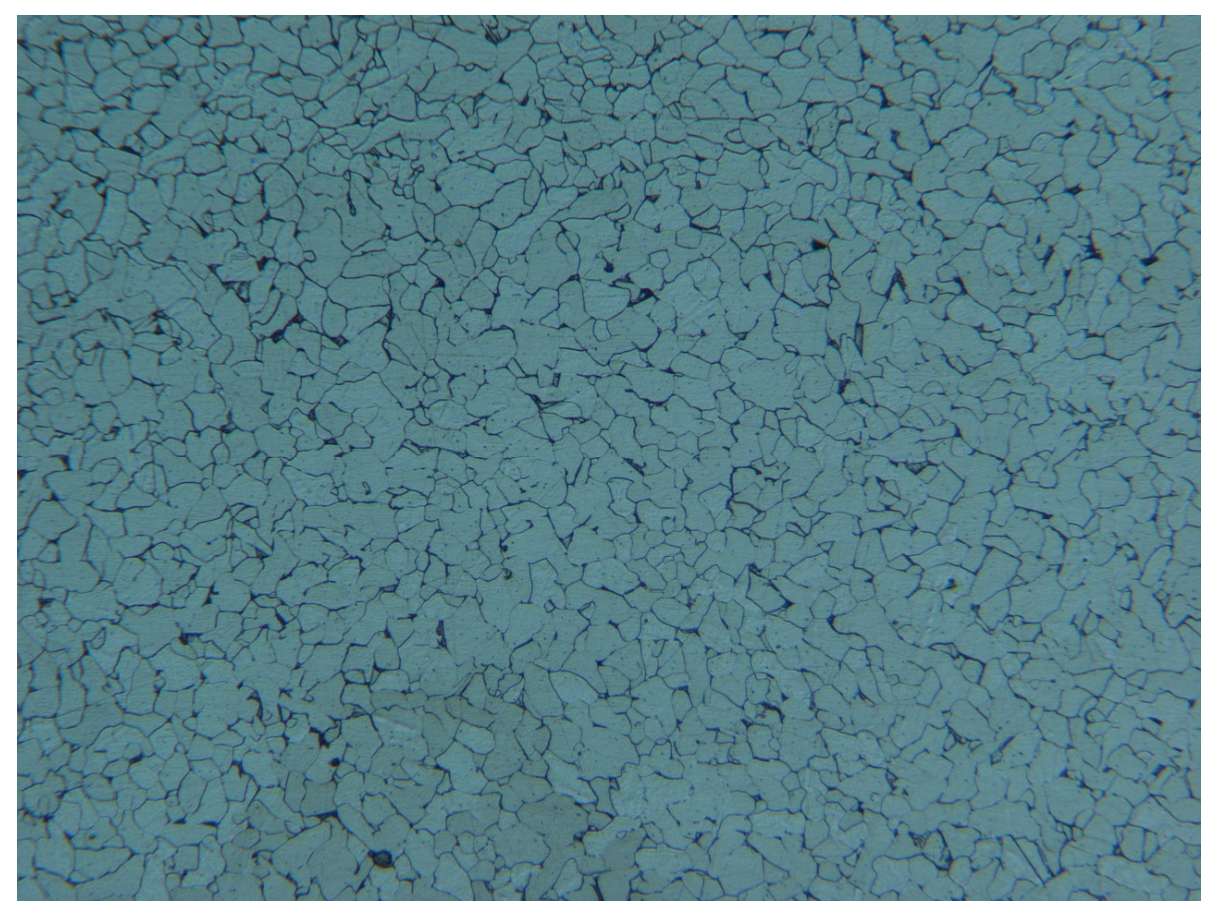

Figura 29 - Matriz ferrítica com aproximadamente $10 \%$ de perlita (foto com aumento de 200 vezes). 


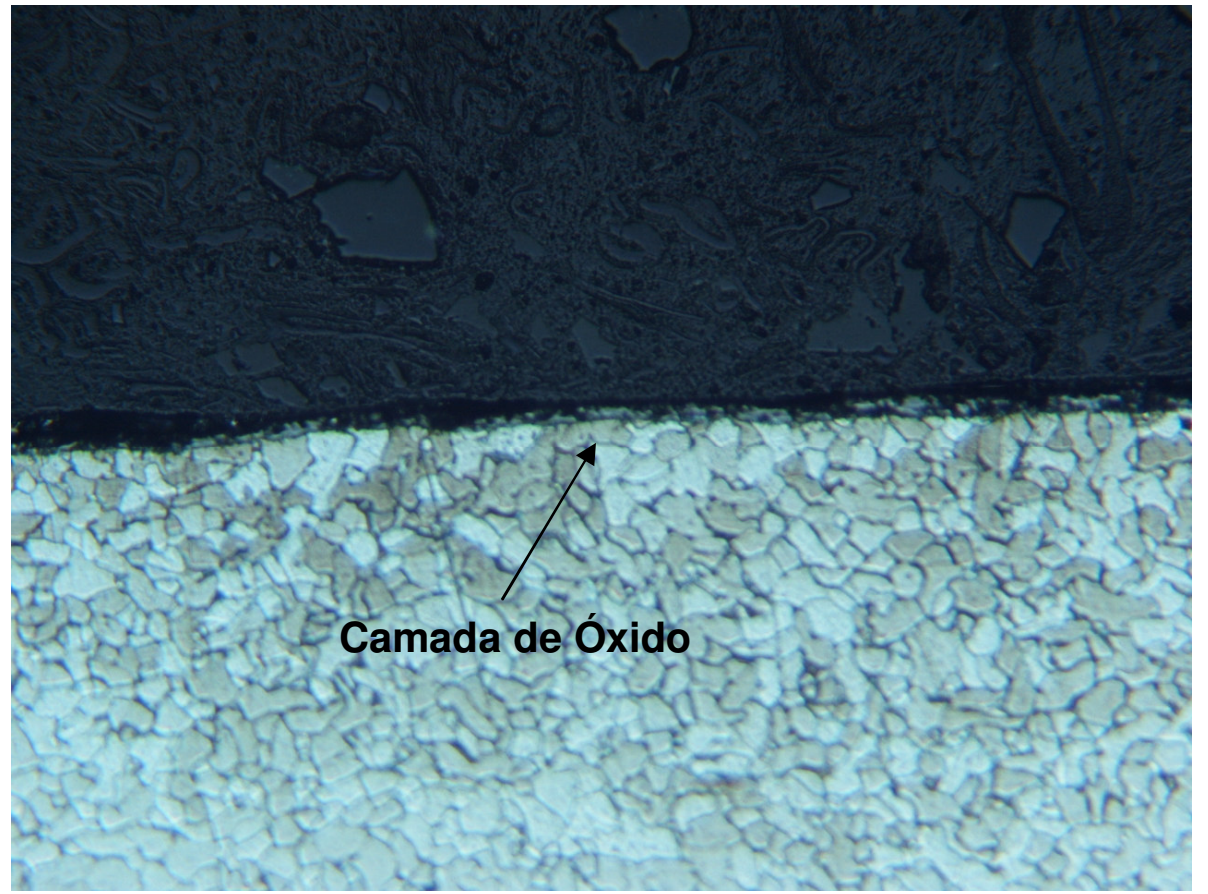

Figura 30 - Camada de óxido formada na superfície das chapas.

\subsubsection{Adesivo Acrílico}

A definição do adesivo utilizado neste estudo foi baseada em informações mercadológicas, onde buscou-se definir um dos principais adesivos acrílicos utilizados hoje nas indústrias geral e automotiva. $O$ adesivo Loctite 326 da empresa Henkel foi encontrado em várias aplicações nestes dois segmentos da indústria, sendo também apontado pelo fabricante como um dos adesivos acrílicos mais aplicados entre disponíveis no mercado brasileiro.

O Loctite 326 é definido pelo fabricante como um adesivo estrutural para aplicações onde é exigida rápida fixação. Este adesivo acrílico a base de uretano metacrilato apresenta ótima resistência à óleo de motor, tem como temperatura máxima de trabalho o limite de $120^{\circ} \mathrm{C}$ em regime contínuo e folga máxima de aplicação de $0,5 \mathrm{~mm}$. A resistência ao cisalhamento apresentada pelo adesivo quando aplicado em substratos de alumínio é em torno de $20 \%$ inferior à resistência apresentada em aço. A seguir segue formulação básica deste adesivo: 
- $45 \%$ até $50 \%$ Resina de poliuretano metacrilato;

- $35 \%$ até $40 \% \quad$ Hidroxialquil metacrilato;

- $10 \%$ até $15 \% \quad$ Metacrilato de alta pressão;

- $1 \%$ até $3 \% \quad$ Ácido acrílico;

- $1 \%$ até $3 \%$ Hidroperóxido de cumeno.

Abaixo encontram-se algumas propriedades mecânicas do adesivo testado:

Módulo de Cisalhamento Transversal $\left(\mathrm{G}_{\mathrm{c}}\right)$ : $\quad 450 \mathrm{MPa}$.

Coeficiente de Poison $(v)$ : $\quad 0,4$.

\subsubsection{Fatores Analisados}

Zoran et al. (2001), Villenave (2005) e Mendes (2005) apresentam em seus trabalhos a necessidade de estudo de fatores de influência relacionados as condições de cura do adesivo e de superfície do substrato. A seleção de tais fatores foi possível devido associação da revisão bibliográfica com experiência profissional do autor.

Devido à ferramenta utilizada para análise de resultados optou-se por trabalhar com quatro variáveis, pois qualquer valor acima deste geraria um número muito alto de corpos de prova, tornando o trabalho inviável. Foram selecionados dois fatores relacionados à superfície e dois fatores relacionados ao adesivo.

\subsubsection{Fatores do Adesivo}

- Temperatura de cura: a revisão da literatura mostrou que o peso molecular do polímero formado tem influência direta nas propriedades mecânicas do adesivo, podendo a temperatura de cura ser um dos fatores responsável pela variação deste peso molecular. $O$ método de análise aplicado, Planejamento Fatorial $2^{k}$, trabalha com dois níveis de cada fator, desta forma foram selecionadas duas condições de cura: $22^{\circ} \mathrm{C}$ por 24 horas e $60^{\circ} \mathrm{C}$ por 2 horas em equipamento Climats do CEAL em Itapevi. 
- Uso de ativador: a ficha técnica do produto Loctite 326 sugere a utilização de ativador, denominado Loctite 7649, para acelerar o tempo de cura em superfícies ativas ou ativar superfícies inativas. Duas condições foram consideradas também para este fator de influência: a utilização do ativador e a ausência do mesmo. Conforme ficha técnica do ativador Loctite 7649 , o produto foi aplicado sobre as duas superfícies, sendo necessário aguardar a evaporação do solvente antes da aplicação do adesivo. Foi aguardado o intervalo de vinte minutos entre aplicação do ativador e aplicação do adesivo.

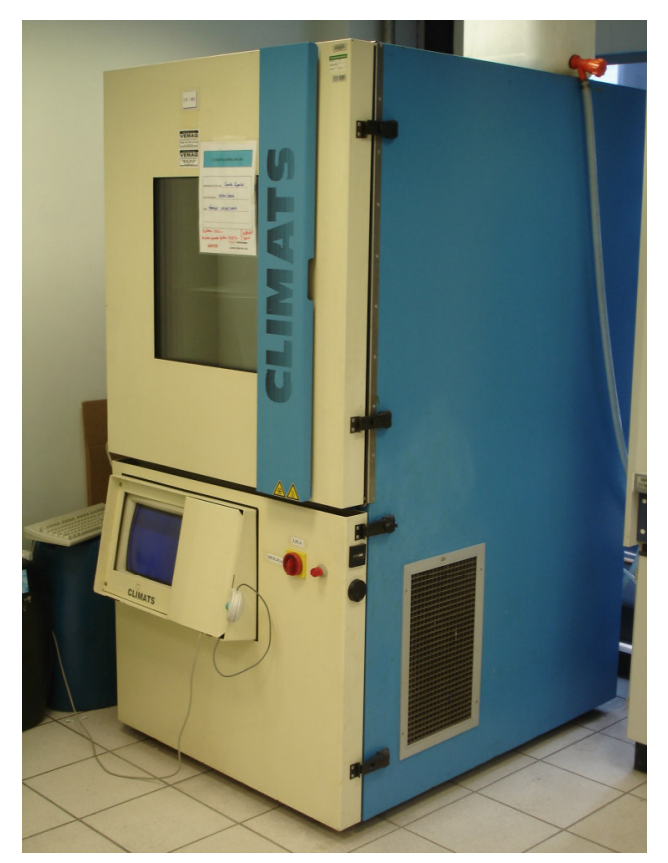

Figura 31 - Equipamento Climats utilizado para controle de temperatura e umidade relativa do ar.

\subsubsection{Fatores do Substrato}

- $\quad$ Rugosidade da superfície: Possart (2006) e Villenave (2005) afirmam que a rugosidade das superfícies interfere na resistência da junção, esta afirmação baseiase na teoria mecânica de adesão, ancoramento mecânico. Devido à isto, optou-se por analisar e quantificar a influência da variação da rugosidade na resistência, para isso duas condições de superfícies foram utilizadas: uma delas obtida pelo jateamento da superfície com areia e a outra pelo próprio processo de laminação da 
chapa, esta segunda gerou uma camada de óxido na peça. O jateamento gerou uma

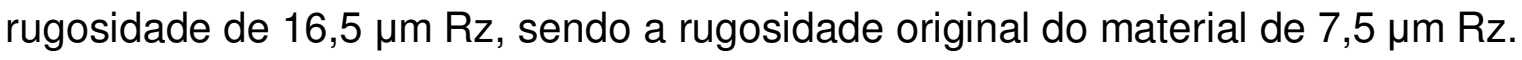

- Tratamento superficial: diferentes tratamentos superficiais proporcionam diferentes condições de superfícies, tanto em aspectos mecânicos como químicos. Devido à oportunidade cedida pela empresa Henkel de utilizar nos experimentos uma nova tecnologia de tratamentos superficiais, optou-se pela utilização da nanocerâmica, tratamento obtido pela aplicação do produto Bonderite NT1. Desta forma as duas condições exigidas pelo método de análise são: com e sem tratamento superficial.

O processo de aplicação de nanocerâmica foi feito no Laboratório de Assistência Técnica da Henkel em Diadema, foi utilizado equipamento para aplicação em baixa escala. Este processo foi divido em cinco etapas, conforme definição do fabricante:

- $\quad 1$ 을 Estágio: Desengraxe;

Produto: Parco Cleaner 1997 IM;

Concentração: 3,0\%;

Temperatura: $77^{\circ} \mathrm{C}$;

Tempo: 4 minutos.

- $\quad 2$ Estágio: Enxágüe;

Produto: Água de Rede;

Tempo: 30 segundos.

- $\quad 3$ Estágio: Enxágüe DI;

Produto: Água Deionizada;

Tempo: 30 segundos.

- 4ํㅡㄹ Estágio: Conversão de Camada;

Produto: Bonderite NT-1;

Concentração: 7,0\%;

Temperatura: ambiente;

$\mathrm{pH}:$ 4,88;

Condutividade:374uS/cm;

Tempo: 2 minutos.

- $\quad$ 5ํㅡㄹógio: Enxágüe DI;

Produto: Água Deionizada;

Tempo: 30 segundos. 
As chapas foram protegidas com papel específico após o tratamento, visando evitar a oxidação precoce das chapas, sendo o adesivo aplicado 24 horas após a finalização do banho. De acordo com Henkel é sugerido o tempo máximo de 48 horas entre a aplicação de tratamento nanocerâmico e a aplicação do polímero, no caso deste trabalho, o adesivo.

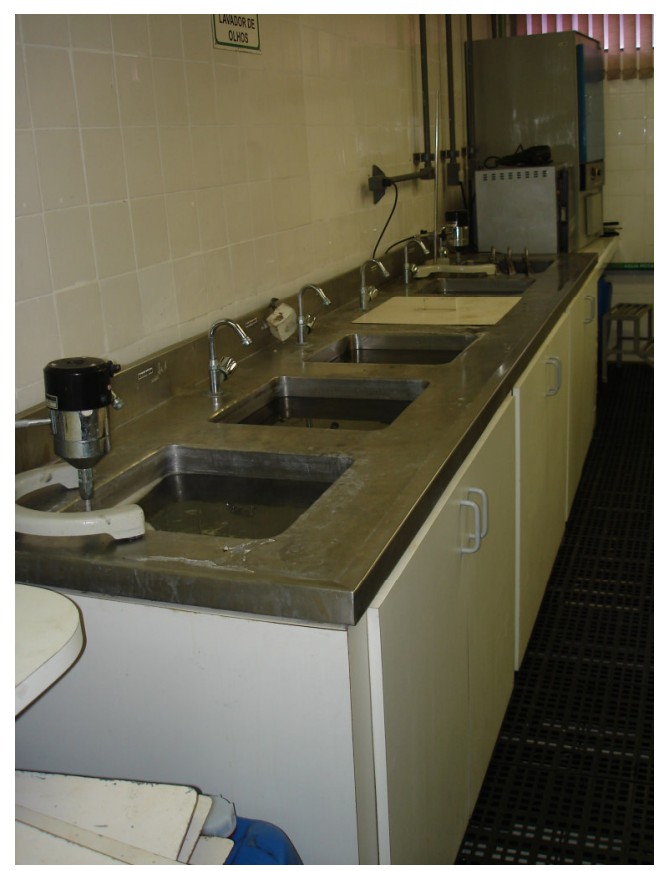

Figura 32 - Tanques com produtos para aplicação de nanocerâmica Bonderite NT1.

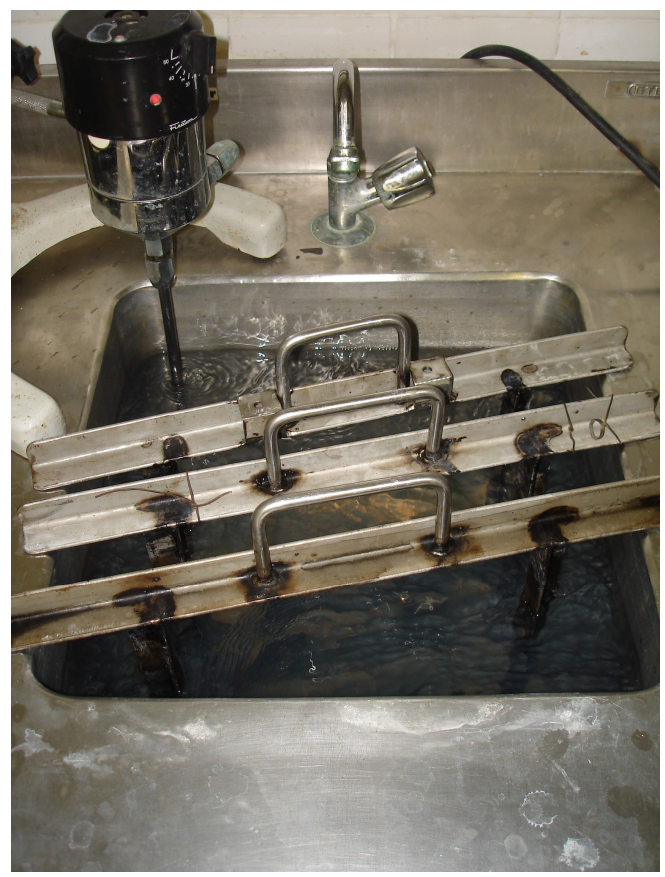

Figura 33 - Corpos de prova em processo de tratamento superficial. 


\subsubsection{Planejamento Fatorial}

Zoran et al. (2001) desenvolveu modelo matemático para cálculo de junções adesivas através da aplicação de um método de planejamento e análise de experimentos, denominado Planejamento Fatorial. Este controla fatores críticos e investiga seus efeitos em dois ou mais níveis. O mais simples e mais comum Planejamento Fatorial é aquele que considera dois níveis de fatores, o Planejamento Fatorial $2^{k}$. A desvantagem deste método é o fato de não ser possível distinguir entre efeitos lineares e efeitos de ordem maior. No Planejamento Fatorial $2^{k}$ fatores são selecionados e ajustados em dois níveis, sendo seu nível inferior indicado por (-1) e o nível superior por $(+1)$.

Os fatores a serem analisados são combinados e a influência causada pela variação de seus níveis é quantificada de forma individual, efeitos principais, ou de forma combinada, efeitos de interação.

O número de combinações em um Planejamento Fatorial aumenta com muita facilidade. Para um projeto com 4 fatores, por exemplo, têm-se 16 combinações. Porém para projetos com 8 fatores, têm-se 256 combinações. Como projetos de engenharia podem envolver de 6 a 10 fatores, o número de fatores exigidos pode facilmente assumir patamares proibitivos em custo. Este trabalho considerou 4 fatores de influência, gerando uma matriz de 16 combinações, relacionadas na Tabela 5. Abaixo encontra-se a relação de fatores analisados com a descrição dos níveis $(-1)$ e $(+1)$ :

Nanocerâmica (A): (-1) Sem nanocerâmica

Temperatura (B):

Rugosidade (C):

Ativador (D):
$(-1) 22^{\circ} \mathrm{C}-24 \mathrm{~h}$

$(-1)$ Sem jateamento

$(-1)$ Sem ativador
(+1) Com nanocerâmica;

(+1) $60^{\circ} \mathrm{C}-2 \mathrm{~h}$;

(+1) Com jateamento;

(+1) Com ativador. 
Tabela 5 - Matriz de combinações de fatores de influência gerada pelo Planejamento Fatorial 2k.

\begin{tabular}{lllll}
\hline Condição & $\begin{array}{l}\text { Nanocerâmica }- \\
\text { Bonderite NT1 }(\mathrm{A})\end{array}$ & $\begin{array}{l}\text { Temperatura de } \\
\text { Cura (B) }\end{array}$ & $\begin{array}{l}\text { Rugosidade } \\
(\mathrm{C})\end{array}$ & $\begin{array}{l}\text { Uso de } \\
\text { Ativador (D) }\end{array}$ \\
\hline 1 & -1 & -1 & -1 & -1 \\
A & +1 & -1 & -1 & -1 \\
B & -1 & +1 & -1 & -1 \\
C & -1 & -1 & +1 & -1 \\
D & -1 & -1 & -1 & +1 \\
AB & +1 & +1 & -1 & -1 \\
AC & +1 & -1 & +1 & -1 \\
AD & +1 & -1 & -1 & +1 \\
BC & -1 & +1 & +1 & -1 \\
BD & -1 & +1 & -1 & +1 \\
DC & -1 & -1 & +1 & +1 \\
ABC & +1 & +1 & +1 & -1 \\
BCD & -1 & +1 & +1 & +1 \\
ACD & +1 & -1 & +1 & +1 \\
ABD & +1 & +1 & -1 & +1 \\
ABCD & +1 & +1 & +1 & +1 \\
\hline
\end{tabular}

\subsubsection{Corpos de Provas}

Definidos os fatores de influência e obtida a matriz de combinações, foram preparadas 10 réplicas para cada combinação, segundo ASTM D 1002 - 05. Toda configuração geométrica foi feita de acordo com Villenave (2005). A espessura das chapas de aço de $2 \mathrm{~mm}$, por exemplo, foi especificada para reduzir os efeitos de deformação nas extremidades e alongamento dos corpos de prova. Também baseado em Villenave (2005) o comprimento de sobreposição foi definido em $10 \mathrm{~mm}$. Nas extremidades dos corpos de prova foram aderidas chapas com $25 \mathrm{~mm}$ de comprimento com a mesma espessura e mesma largura dos corpos de prova, com o intuito de reduzir a excentricidade da força aplicada, procedimento recomendado por Broughton \& Gower (2001). O comprimento da área de fixação na garra do equipamento foi determinado de acordo com Villenave (2005). Estas chapas aderidas auxiliaram no alinhamento dos corpos de prova no equipamento de testes. $O$ adesivo foi aplicado manualmente sobre os substratos. Durante o processo de cura específica, os corpos de prova permaneceram pressionados por garras. Após soltura das garras os corpos de prova aguardaram 72 horas até que fossem submetidos ao ensaio de cisalhamento. 


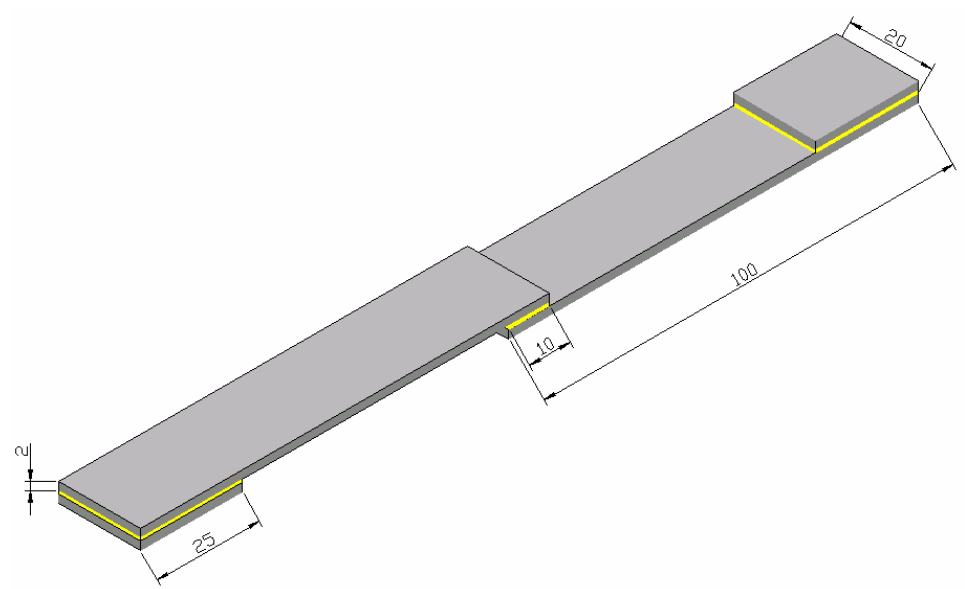

Figura 34 - Configuração geométrica dos corpos de prova.

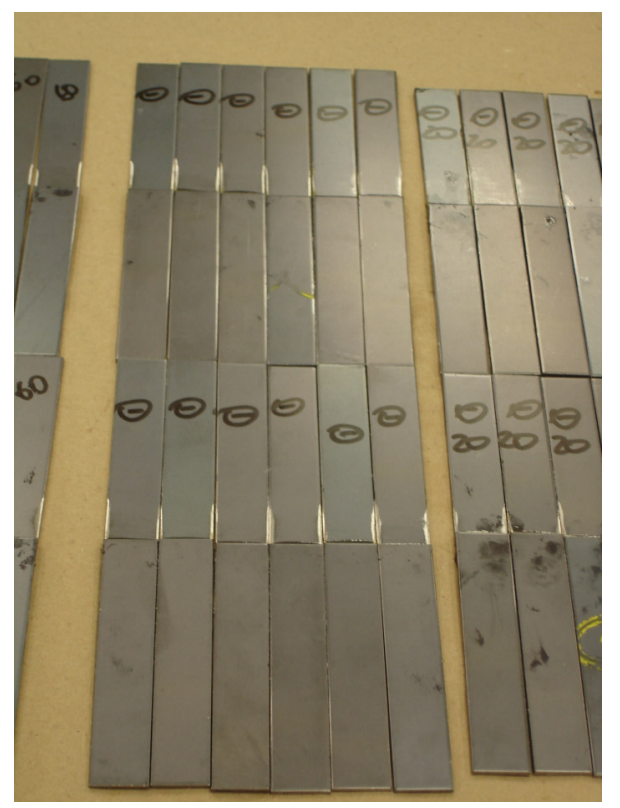

Figura 35 - Corpos de provas aguardando ensaio de cisalhamento.

Mendes (2005) apresenta modelo para determinação do comprimento máximo de sobreposição das chapas, sem que haja deformação dos substratos, em nível capaz de interferir na resistência oferecida pelo adesivo.

$$
l_{\max }=F_{t y} \frac{t}{f \times \tau_{m}}
$$

$I_{\max }$ : comprimento máximo de sobreposição;

$F_{\text {ty }}$ : tensão de escoamento do material;

$f:$ fator de segurança;

$t$ : espessura da chapa. 
Aplicando os valores obtidos nos ensaios preliminares e dimensões dos substratos na Equação 37, obtém-se:

$I_{\max }=10 \mathrm{~mm}$ (valor sugerido por Villenave, 2005);

$\mathrm{t}=2 \mathrm{~mm}$ (valor sugerido por Villenave, 2005);

$\mathrm{F}_{\mathrm{ty}}=165 \mathrm{MPa}$ (Metals Handbook, 1985);

$\tau_{\text {média }}=21 \mathrm{MPa}$ (valor máximo de tensão média de ruptura obtida em ensaios preliminares).

$l_{\max }=F_{t y} \frac{t}{f \times \tau_{\text {édiam }}} \Rightarrow f=\frac{F_{t y} \times t}{l_{\max } \times \tau_{\text {édiam }}}=\frac{165 \mathrm{MPa} \times 2 \mathrm{~mm}}{10 \mathrm{~mm} \times 21 \mathrm{MPa}}=1,57$

O fator de segurança obtido $(1,57)$ mostra que o comprimento de sobreposição de $10 \mathrm{~mm}$ oferece as condições necessárias para realização dos ensaios de cisalhamento sem comprometer os resultados devido a deformação dos substratos, baseado na ASTM D 1002 - 05.

\subsubsection{Ensaio de Cisalhamento}

O ensaio de cisalhamento por tração é o mais utilizado na determinação da resistência de junções adesivas por sobreposição simples de chapas. Os resultados obtidos são de extrema utilidade para determinação das condições geométricas da junção e do tipo de adesivo em aplicações na indústria. Conforme apresentado no capítulo 5, através do ensaio de cisalhamento é possível determinar características importantes dos adesivos e das junções, como por exemplo, a tensão média de ruptura $\tau_{\text {média, }}$ propriedade do adesivo, dada pela relação entre a força máxima aplicada $\mathrm{F}$ e a área de sobreposição das chapas $\left(\tau_{\text {média }}=\mathrm{F} / \mathrm{b} . \mathrm{I}\right)$.

Os ensaios de cisalhamento foram realizados com equipamento EMIC DL5000, com célula de carga de $50 \mathrm{kN}$. Os parâmetros de ensaio, assim como a configuração geométrica da junção, foram baseados em informações de Villenave (2005), bem como a velocidade de tracionamento utilizada $2 \mathrm{~mm} / \mathrm{min}$ e o comprimento de fixação das chapas nas garras de 25mm. De acordo com Broughton \& Gower (2001) o 
ensaio de cisalhamento deve durar entre $60 \mathrm{~s}$ e $90 \mathrm{~s}$, intervalo respeitado pela velocidade sugerida por Villenave (2005).

Como resultado final o equipamento forneceu gráficos tensão $x$ deformação, força

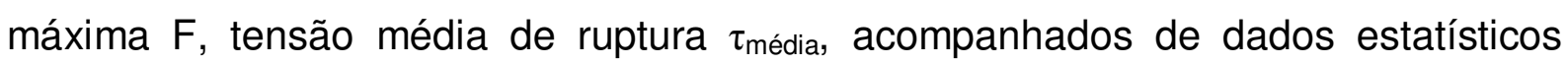
como: média, mediana, desvio padrão e coeficiente de variação de cada combinação.

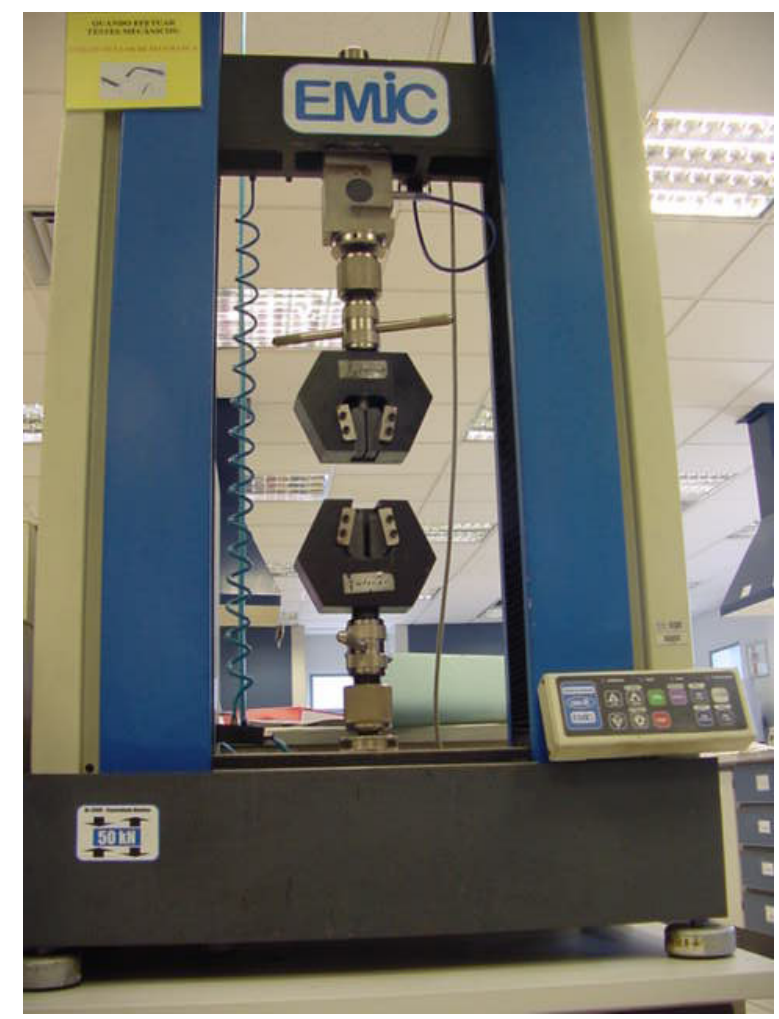

Figura 36 - Equipamento EMIC DL5000 com célula de carga de 50kN.

Após a determinação dos fatores de influência, ensaios foram realizados visando verificar de forma preliminar a significância dos fatores escolhidos. Em processo anterior aos ensaios de cisalhamentos dos 160 corpos de prova definitivos, ensaios de cisalhamento foram realizados com outros 100 corpos de prova, visando identificar possíveis variáveis não controladas, bem como identificar a melhor condição de preparação dos corpos de prova.

O alinhamento dos corpos de prova no dispositivo de fixação foi controlado pela chapa de $25 \mathrm{~mm}$, aderida nas extremidades dos corpos de prova, e por esquadro de luz. Não foi utilizado extensômetro externo ao equipamento de teste, o deslocamento foi medido pela EMIC DL5000, classificado por Broughton \& Gower (2001) como medição por deslocamento de cabeçote. 


\subsubsection{Método de Análise dos Resultados}

As tensões médias de ruptura, obtidas nos ensaios de cisalhamento, foram submetidas aos métodos de Planejamento Fatorial $2^{k}$. Através deste se verificou 0 nível de significância de cada fator e quantificou sua influência na variação da resistência das junções adesivas por sobreposição simples de chapas, unidas por adesivo acrílico estrutural.

\subsection{SEGUNDO MÉTODO - INFLUÊNCIA DO COMPRIMENTO DE SOBREPOSIÇÃO}

Além de quantificar a influência de fatores de superfície e de cura na resistência de junções adesivas por sobreposição simples de chapas, este trabalho objetiva determinar o comportamento das junções ao variar o comprimento de sobreposição destas chapas. Com o intuito de esclarecer a divergência entre algumas publicações, as quais apresentam respostas opostas referentes à esta variação.

\subsubsection{Variação do Comprimento}

Inúmeros trabalhos já demonstraram e quantificaram a influência dos fatores geométricos na resistência das junções adesivas. Porém no decorrer da revisão da literatura apresentada neste trabalho, informações contraditórias foram encontradas no que se refere à influência do comprimento de sobreposição das chapas. Os trabalhos revisados concordam na forma como a tensão é distribuída no adesivo, porém interpretam os resultados de formas diferentes.

Visando esclarecer tal divergência foram preparados diversos corpos de prova com diferentes comprimentos de sobreposição. Utilizou-se a relação entre o comprimento de sobreposição e a largura do substrato para classificar cada configuração de corpo de prova. Inicialmente nestes ensaios foram utilizados corpos de prova idênticos aos utilizados no desenvolvimento do modelo matemático, desta forma os corpos de 
prova com $10 \mathrm{~mm}$ de sobreposição, por exemplo, são representados pela relação 0,5 e assim consecutivamente. Na Tabela 6 são apresentadas todas as configurações ensaiadas.

Tabela 6 - Relação entre comprimentos de sobreposição e largura dos substratos ensaiados.

\begin{tabular}{ll}
\hline $\begin{array}{l}\text { Comprimento de } \\
\text { Sobreposição }\end{array}$ & Relação (Comprimento / Largura) \\
\hline $10 \mathrm{~mm}$ & 0,5 \\
$20 \mathrm{~mm}$ & 1 \\
$30 \mathrm{~mm}$ & 1,5 \\
$40 \mathrm{~mm}$ & 2 \\
$50 \mathrm{~mm}$ & 2,5 \\
\hline
\end{tabular}

Com o objetivo de analisar a influência da camada de óxido das chapas laminadas à quente no comprimento de sobreposição, duas condições diferentes de corpos de prova foram preparadas.

- Para primeira condição foram utilizados corpos de prova sem nanocerâmica, sem ativador, com rugosidade da chapa laminada, sem jateamento e temperatura de cura de $60^{\circ} \mathrm{C}$. A falta de jateamento teve o intuito manter a camada de óxido da chapa.

- Para segunda condição foram utilizados corpos de prova sem nanocerâmica, sem ativador, com jateamento e temperatura de cura de $60^{\circ} \mathrm{C}$. O jateamento teve 0 intuito de retirar a camada de óxido da chapa, permitindo analisar a influência da camada na resistência em função da variação do comprimento de sobreposição.

Em ambas condições foi selecionada a condição de montagem que proporcionou maior resistência à junção, de acordo com os ensaios realizados anteriormente. Devido à isso optou-se pela cura à temperatura de $60^{\circ} \mathrm{C}$ durante duas horas, aguardando 72 horas até a realização dos ensaios de cisalhamento. Foram preparadas 10 réplicas para cada comprimento, totalizando 100 corpos de prova. 


\subsubsection{Ensaios e Análise dos Dados}

Depois de finalizados, os corpos de prova com diferentes comprimentos de sobreposição foram submetidos à ensaios de cisalhamento por tração, em equipamento EMIC DL5000 com célula de carga de $50 \mathrm{kN}$ e velocidade de tracionamento de $2 \mathrm{~mm} / \mathrm{min}$, exatamente como os corpos de prova utilizados nos ensaios anteriores. Para determinar o comportamento da junção em função da variação do comprimento de sobreposição foram utilizados os valores de tensão média de ruptura. A tensão média de ruptura é uma propriedade do adesivo, já que todas as falhas são tratadas como coesivas. Os dados foram fornecidos pelo equipamento EMIC.

A análise dos dados de tensão média de ruptura possibilitou gerar gráfico onde são apresentadas todas as médias para cada comprimento e conseqüentemente a variação da resistência em função do aumento do comprimento.

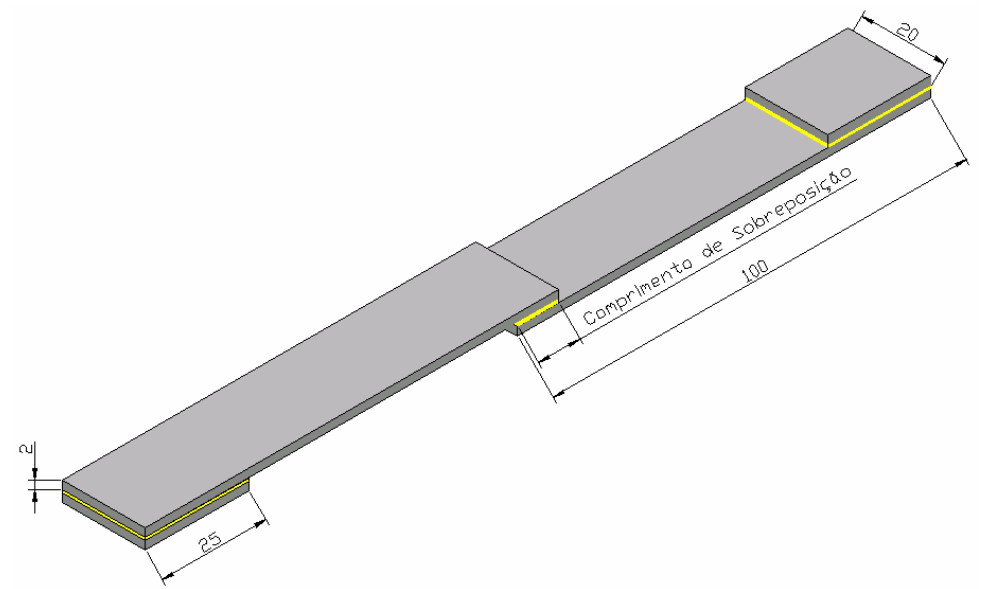

Figura 37 - Configuração geométrica dos corpos de prova para análise do comprimento de sobreposição.

Os resultados experimentais foram aplicados aos Modelos de Volkersen e de Goland e Reissner. Estes modelos apresentaram a distribuição de tensão de cisalhamento do adesivo ao longo do comprimento de sobreposição das chapas. A distribuição gerou informações importantes para justificar a variação da resistência em função do aumento do comprimento de sobreposição. 


\subsection{TERCEIRO MÉTODO - COMPORTAMENTO DA JUNÇÃO SUBMETIDA À ESFORÇOS COMBINADOS}

Visando contribuir com informações para projetos, foram realizados ensaios com dispositivos de Arcan modificados. Foram utilizados dois dispositivos diferentes, sendo um deles desenvolvido por Kavamura (2007) para ensaios de junções soldadas e outro desenvolvido para ensaios de junções adesivas.

\subsubsection{Aplicabilidade dos Corpos de Prova de Lee}

Visando verificar a aplicabilidade dos corpos de prova de Lee (1998) em junções adesivas, foram preparadas 5 réplicas para cada um dos 6 ângulos do dispositivo modificado de Arcan $0^{\circ}, 30^{\circ}, 45^{\circ}, 60^{\circ}, 75^{\circ}$ e $90^{\circ}$, desenvolvido por Kavamura (2007), totalizando 30 corpos de prova.

O material utilizado também foi Aço SAE J403 1010, com comprimento de 150mm, espessura de $2 \mathrm{~mm}$ e largura de $20 \mathrm{~mm}$, conforme Figura 38.

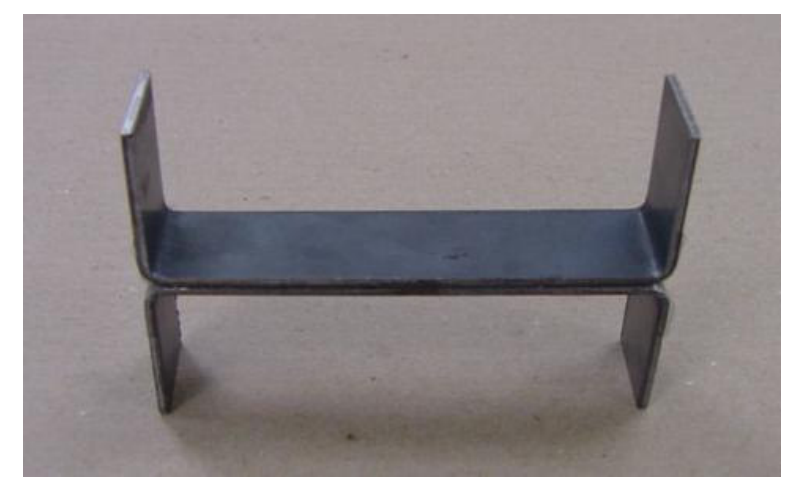

Figura 38 - Corpos de prova baseados em Lee (1998).

O adesivo foi aplicado na região marcada entre as duas linhas vermelhas na Figura 39. Toda a área restante do corpo de prova foi revestida com filme de PE e filme de desmonte Frekote $700 \mathrm{NC}$. A distância entre as linhas vermelhas é de $10 \mathrm{~mm}$, que quando multiplicada pela largura de $20 \mathrm{~mm}$ das chapas, resulta em $200 \mathrm{~mm}^{2}$ de área de adesão. A espessura do filme foi de $0,2 \mathrm{~mm}$, obtida pela soma das espessuras dos filmes plásticos. 


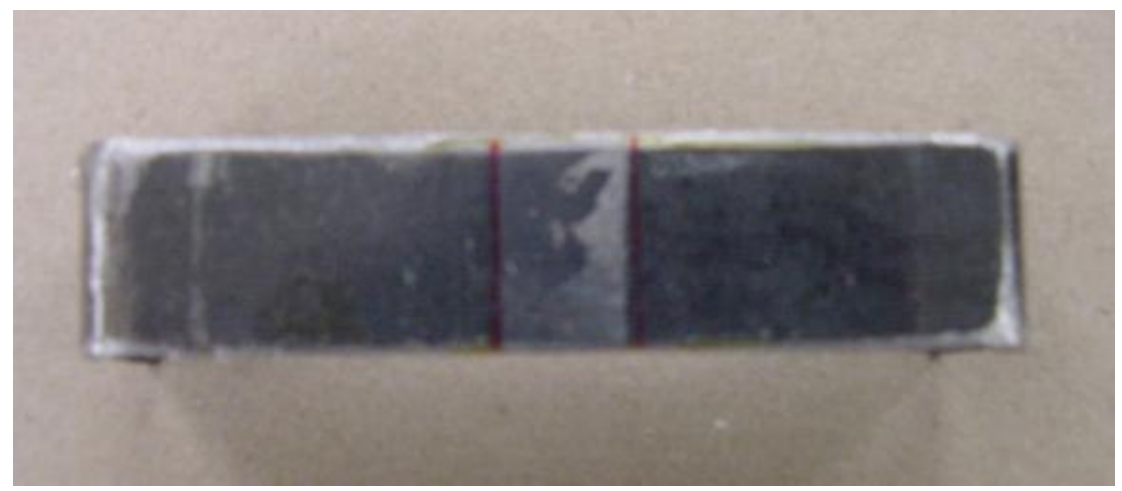

Figura 39 - Região de aplicação do adesivo.

Os corpos de prova foram submetidos à ensaios de tração em equipamento EMIC DL5000, com célula de carga de $50 \mathrm{kN}$. A velocidade de tração utilizada foi de $2 \mathrm{~mm} / \mathrm{min}$, com o intuito de repetir as condições nos ensaios com corpos de prova por sobreposição simples de chapas. O dispositivo utilizado nos ensaios foi 0 mesmo dispositivo desenvolvido por Kavamura (2007) com 6 ângulos: $0^{\circ}$ (cisalhamento puro), $30^{\circ}, 45^{\circ}, 60^{\circ}, 75^{\circ}$ (esforços combinados) e $90^{\circ}$ tração pura.

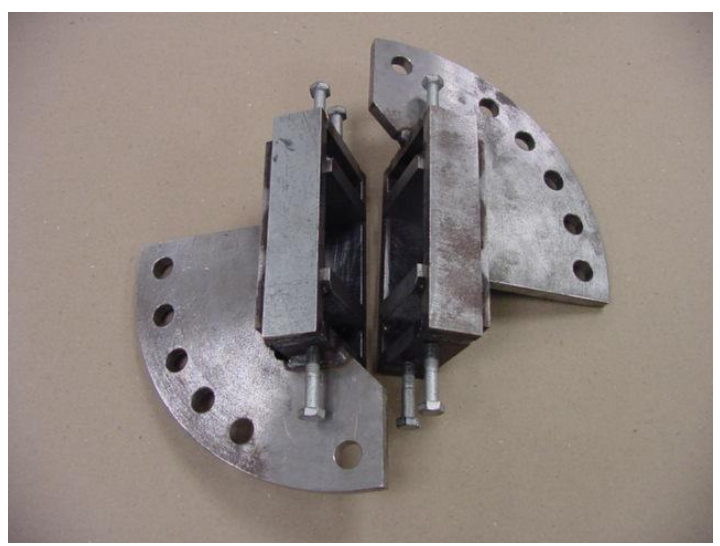

Figura 40 - Dispositivo de Arcan desenvolvido por Kavamura (2007).

\subsubsection{Corpos de Prova para Junções Adesivas}

Alguns trabalhos, os quais apresentaram ensaios de junções adesivas com dispositivo modificado de Arcan, já foram publicados. Nestes trabalhos foram propostos corpos de prova trapezoidais (borboleta) e em forma de paralelepípedo. A 
ausência de normas para a realização de ensaios com dispositivo de Arcan desfavorece a escolha da geometria dos corpos de prova.

Com base nos resultados encontrados nos trabalhos publicados e no grande número de trabalhos que utilizaram corpos de prova trapezoidais, optou-se pela utilização deste tipo de corpo de prova neste estudo.

Duas condições de ensaios, velocidades de tracionamento, foram executadas: $2 \mathrm{~mm} / \mathrm{min}$ e $10 \mathrm{~mm} / \mathrm{min}$. Estas duas velocidades foram determinadas com base nos ensaios de junções por sobreposição simples de chapas $(2 \mathrm{~mm} / \mathrm{min})$ e em trabalhos publicados $(10 \mathrm{~mm} / \mathrm{min})$. As duas velocidades simulam condições quasi-estáticas de carregamento.

O dispositivo modificado de Arcan utilizado nestes ensaios é mostrado na Figura 41, com cinco diferentes ângulos: $0^{\circ}$ (cisalhamento puro), 22,5 $5^{\circ}, 45^{\circ}, 67,5^{\circ}$ (esforços combinados) e $90^{\circ}$ tração pura. O dispositivo é composto por dois discos bi-partidos, sendo o corpo de prova fixado entre estes discos.

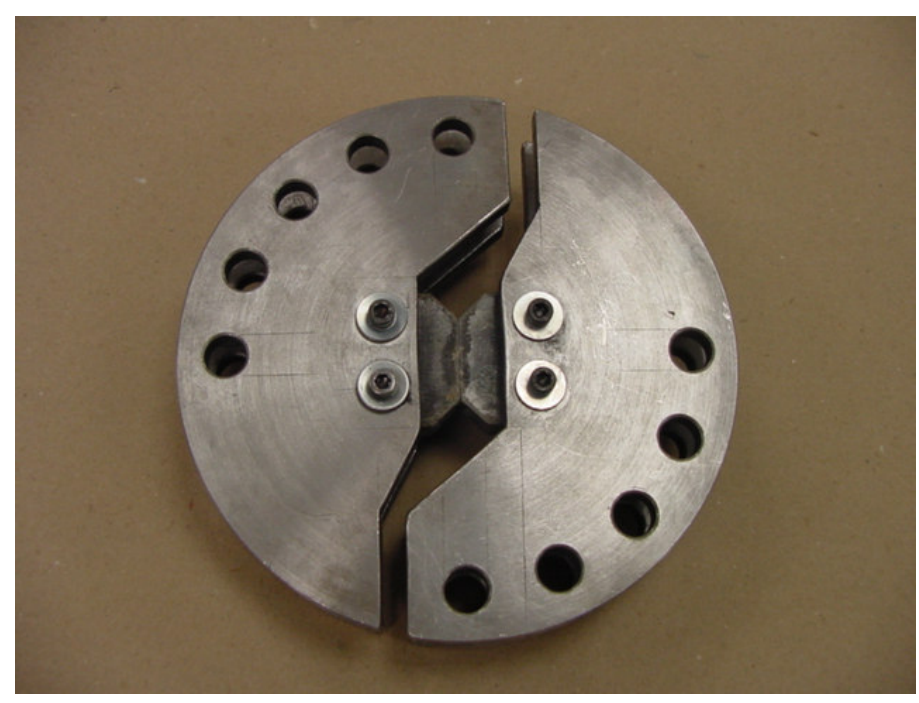

Figura 41 - Dispositivo de Arcan para junções adesivas.

Para cada ângulo do dispositivo foram preparados três corpos de prova, totalizando 30 corpos de prova, devido as duas velocidades testadas. O material utilizado foi aço SAE 1010, a configuração geométrica dos corpos de prova é apresentada na Figura 42. Devido à ausência de normas para este tipo de ensaios, optou-se pela largura de $16 \mathrm{~mm}$, para evitar esforços de clivagem durante os ensaios, presentes em corpos de prova de pequena espessura. O comprimento de sobreposição de $30 \mathrm{~mm}$ foi com base nos ensaios com chapas sobrepostas. A seguir encontram-se dados sobre aço 
SAE 1010 utilizados nestes ensaios (METALS HANDBOOK, 1985): v : 0,28 e E : 207GPa.

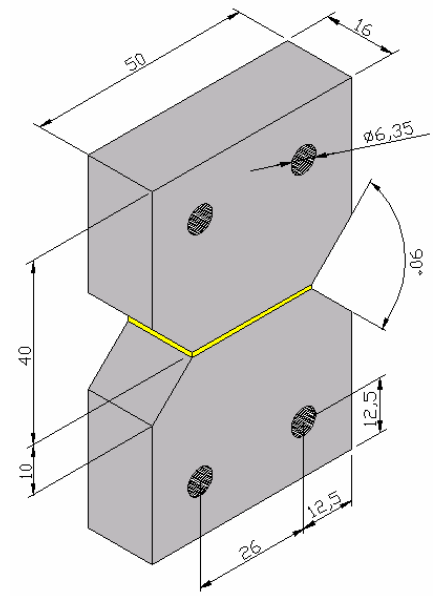

Figura 42 - Corpos de prova para junções adesivas (borboleta).

A Figura 43 mostra os cinco ângulos de ensaios utilizados, partindo da condição de cisalhamento puro $\left(0^{\circ}\right)$ linha superior à esquerda, passando por condições de carregamentos combinados $\left(22,5^{\circ}, 45^{\circ}\right.$ e $\left.67,5^{\circ}\right)$ da esquerda para direita, finalizando com ensaio de tração pura $\left(90^{\circ}\right)$ linha inferior à direita. O dispositivo foi fixado à máquina de tração por dispositivo rígido, assim como o dispositivo modificado de Arcan, feito de aço SAE 1045. Os dispositivos de fixação e o modificado de Arcan foram unidos por eixo com $15 \mathrm{~mm}$ de diâmetro.
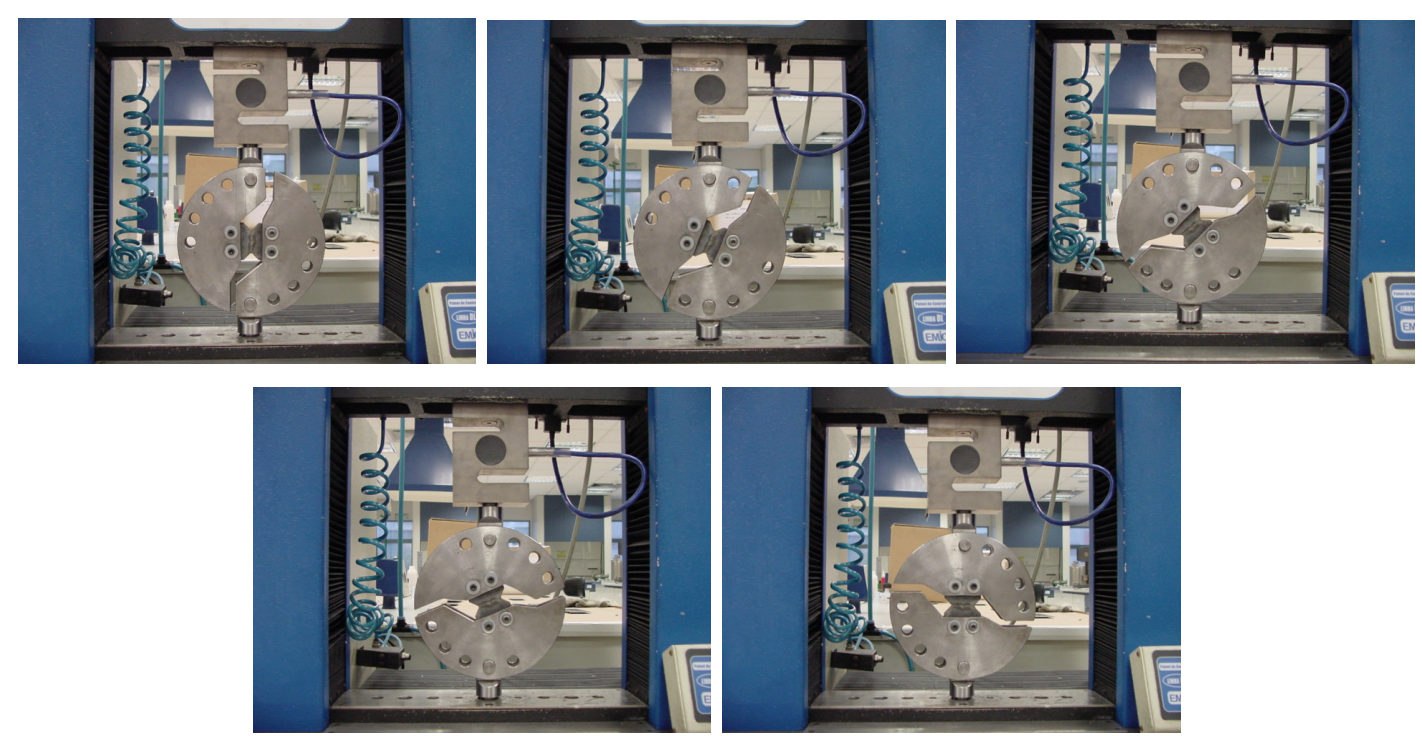

Figura 43 - Ângulos ensaiados $0^{\circ}, 22,5^{\circ}, 45^{\circ}, 67,5^{\circ}$ e $90^{\circ}$. 


\section{RESULTADOS E DISCUSSÃO}

\subsection{INFLUÊNCIA DOS FATORES DE SUPERFÍCIE E DE CURA DO ADESIVO}

\subsubsection{Resultados dos Ensaios de Cisalhamento}

Os corpos de prova foram submetidos à ensaios destrutivos de cisalhamento divididos por combinação de tratamento, as 10 réplicas de cada condição foram testadas sequencialmente em ambiente com temperatura e umidade controladas.

\subsubsection{Ensaios Preliminares}

Antes da realização dos ensaios definitivos, foram testadas 10 réplicas de cinco condições, visando verificar a influência dos fatores principais na resistência da junção. A Tabela 7 contém os resultados dos ensaios preliminares de cisalhamento, com média e desvio padrão.

Tabela 7 - Tensões médias de ruptura dos ensaios preliminares para verificação da influência dos fatores principais.

\begin{tabular}{|c|c|c|c|c|c|c|c|}
\hline \multirow{3}{*}{$\begin{array}{c}\text { Condição } \\
1\end{array}$} & \multicolumn{5}{|c|}{ Tensão Média de Ruptura (MPa) } & \multirow{3}{*}{$\begin{array}{l}\text { Média } \\
13,09\end{array}$} & \multirow{3}{*}{$\begin{array}{c}\text { Desvio } \\
1,92\end{array}$} \\
\hline & 11,74 & 11,80 & 16,55 & 11,41 & 13,48 & & \\
\hline & 12,11 & 13,24 & 16,48 & 11,92 & 12,16 & & \\
\hline \multirow{2}{*}{ A } & 14,19 & 16,31 & 13,17 & 14,19 & 17,13 & \multirow{2}{*}{11,47} & \multirow{2}{*}{3,03} \\
\hline & 10,60 & 11,48 & 9,51 & 13,31 & 14,84 & & \\
\hline \multirow{2}{*}{ B } & 15,08 & 16,13 & 15,31 & 13,98 & 16,24 & \multirow{2}{*}{15,12} & \multirow{2}{*}{0,83} \\
\hline & 15,36 & 14,36 & 14,36 & 14,34 & 16,01 & & \\
\hline \multirow{2}{*}{ C } & 11,13 & 11,03 & 11,38 & 11,99 & 14,33 & \multirow{2}{*}{12,90} & \multirow{2}{*}{1,50} \\
\hline & 13,65 & 15,37 & 13,58 & 14,01 & 12,54 & & \\
\hline \multirow{2}{*}{ D } & 10,93 & 9,46 & 9,21 & 10,51 & 10,29 & \multirow{2}{*}{9,65} & \multirow{2}{*}{1,09} \\
\hline & 11,41 & 9,36 & 8,56 & 8,16 & 8,62 & & \\
\hline
\end{tabular}


10.1.1.2 Ensaios Definitivos

Após confirmação da influência dos fatores principais, verificadas pela análise dos resultados obtidos com os corpos de provas preliminares, foram realizados ensaios definitivos com as 16 combinações possíveis determinadas pela aplicação do Planejamento Fatorial $2^{k}$. Foram testadas 10 réplicas para cada combinação, os resultados dos 160 ensaios encontram-se nas Tabelas 8, 9 e 10.

Tabela 8 - Tensões médias de ruptura dos ensaios com variação dos fatores de influência principais.

\begin{tabular}{|c|c|c|c|c|c|c|c|}
\hline \multirow{3}{*}{$\begin{array}{c}\text { Condição } \\
1\end{array}$} & \multicolumn{5}{|c|}{ Tensão Média de Ruptura (MPa) } & \multirow{3}{*}{$\begin{array}{r}\text { Média } \\
14,98\end{array}$} & \multirow{3}{*}{$\begin{array}{c}\text { Desvio } \\
1,66\end{array}$} \\
\hline & 14,90 & 14,32 & 18,39 & 15,70 & 16,66 & & \\
\hline & 14,04 & 13,76 & 14,28 & 15,28 & 12,46 & & \\
\hline \multirow{2}{*}{$A$} & 13,03 & 15,94 & 15,10 & 15,55 & 14,46 & \multirow{2}{*}{14,58} & \multirow{2}{*}{1,08} \\
\hline & 14,14 & 12,98 & 14,68 & 13,97 & 15,93 & & \\
\hline \multirow{2}{*}{ B } & 18,14 & 19,15 & 17,69 & 17,28 & 17,29 & \multirow{2}{*}{18,21} & \multirow{2}{*}{0,85} \\
\hline & 19,04 & 19,64 & 18,52 & 17,92 & 17,40 & & \\
\hline \multirow{2}{*}{ C } & 15,48 & 17,12 & 16,36 & 18,41 & 19,13 & \multirow{2}{*}{17,28} & \multirow{2}{*}{1,92} \\
\hline & 19,51 & 16,84 & 13,19 & 18,25 & 18,52 & & \\
\hline \multirow{2}{*}{$\mathrm{D}$} & 10,81 & 8,88 & 11,68 & 10,45 & 10,65 & \multirow{2}{*}{10,29} & \multirow{2}{*}{1,04} \\
\hline & 11,42 & 8,84 & 9,03 & 10,97 & 10,11 & & \\
\hline
\end{tabular}

Tabela 9 - Tensões médias de ruptura dos ensaios com combinação de dois fatores em nível superior $(+1)$.

\begin{tabular}{|c|c|c|c|c|c|c|c|}
\hline \multirow{3}{*}{$\begin{array}{c}\text { Condição } \\
A B\end{array}$} & \multicolumn{5}{|c|}{ Tensão Média de Ruptura (MPa) } & \multirow{3}{*}{$\begin{array}{c}\text { Média } \\
17,47\end{array}$} & \multirow{2}{*}{$\begin{array}{c}\text { Desvio } \\
194\end{array}$} \\
\hline & 15,13 & 15,31 & 19,61 & 15,36 & 17,56 & & \\
\hline & 18,35 & 15,67 & 18,30 & 19,90 & 19,51 & & \\
\hline \multirow{2}{*}{$A C$} & 15,19 & 13,40 & 15,38 & 14,84 & 12,88 & \multirow{2}{*}{14,59} & \multirow{2}{*}{1,10} \\
\hline & 15,02 & 14,28 & 13,26 & 15,38 & 16,25 & & \\
\hline \multirow{2}{*}{$A D$} & 11,38 & 8,34 & 10,28 & 9,22 & 10,63 & \multirow{2}{*}{10,12} & \multirow{2}{*}{1,03} \\
\hline & 9,44 & 9,75 & 11,29 & 11,31 & 9,57 & & \\
\hline \multirow{2}{*}{$\mathrm{BC}$} & 20,37 & 18,80 & 18,82 & 18,46 & 17,92 & \multirow{2}{*}{18,42} & \multirow{2}{*}{1,76} \\
\hline & 18,42 & 19,41 & 19,25 & 13,79 & 18,95 & & \\
\hline \multirow{2}{*}{$\mathrm{BD}$} & 11,47 & 14,20 & 16,50 & 13,19 & 11,84 & \multirow{2}{*}{13,42} & \multirow{2}{*}{1,76} \\
\hline & 13,71 & 12,14 & 16,03 & 13,45 & 11,71 & & \\
\hline \multirow{2}{*}{$C D$} & 13,03 & 13,40 & 14,59 & 11,86 & 9,13 & \multirow{2}{*}{12,57} & \multirow{2}{*}{1,49} \\
\hline & 11,87 & 12,16 & 12,68 & 13,79 & 13,23 & & \\
\hline
\end{tabular}


Tabela 10 - Tensões médias de ruptura dos ensaios com combinação de mais de dois fatores em nível superior $(+1)$.

\begin{tabular}{|c|c|c|c|c|c|c|c|}
\hline \multirow{3}{*}{$\begin{array}{c}\text { Condição } \\
A B C\end{array}$} & \multicolumn{5}{|c|}{ Tensão Média de Ruptura (MPa) } & \multirow{3}{*}{$\begin{array}{l}\text { Média } \\
16,80\end{array}$} & \multirow{2}{*}{$\begin{array}{c}\text { Desvio } \\
168\end{array}$} \\
\hline & 13,50 & 18,58 & 15,91 & 18,27 & 16,50 & & \\
\hline & 17,64 & 17,85 & 18,64 & 15,86 & 15,29 & & \\
\hline \multirow{2}{*}{$B C D$} & 13,75 & 12,61 & 16,29 & 16,26 & 14,12 & \multirow{2}{*}{14,12} & \multirow{2}{*}{1,49} \\
\hline & 12,13 & 15,06 & 12,28 & 14,52 & 14,21 & & \\
\hline \multirow{2}{*}{ ACD } & 13,24 & 10,32 & 9,96 & 11,85 & 10,44 & \multirow{2}{*}{11,30} & \multirow{2}{*}{1,67} \\
\hline & 9,12 & 9,84 & 14,47 & 11,87 & 11,85 & & \\
\hline \multirow{2}{*}{$\mathrm{ABD}$} & 12,06 & 12,91 & 9,98 & 11,10 & 9,59 & \multirow{2}{*}{12,05} & \multirow{2}{*}{1,54} \\
\hline & 12,70 & 12,10 & 13,35 & 14,74 & 11,96 & & \\
\hline \multirow{2}{*}{$A B C D$} & 13,63 & 13,79 & 12,25 & 13,57 & 12,40 & \multirow{2}{*}{12,92} & \multirow{2}{*}{0,74} \\
\hline & 13,84 & 12,05 & 13,07 & 12,63 & 12,02 & & \\
\hline
\end{tabular}

10.1.1.3 Ensaios Confirmativos

Para verificar a repetibilidade dos valores obtidos nos ensaios definitivos e confirmar a não existência de outros fatores de influência não considerados, foram repetidos os testes preliminares, denominando-os como confirmativos e comparado-os com os resultados obtidos nos ensaios definitivos, valores apresentados na Tabela 11.

Tabela 11 - Tensões médias de ruptura dos ensaios confirmativos para verificação da influência dos fatores principais.

\begin{tabular}{|c|c|c|c|c|c|c|c|}
\hline \multirow{3}{*}{$\begin{array}{c}\text { Condição } \\
1\end{array}$} & \multicolumn{5}{|c|}{ Tensão Média de Ruptura (MPa) } & \multirow{3}{*}{$\begin{array}{c}\text { Média } \\
15,21\end{array}$} & \multirow{3}{*}{$\begin{array}{c}\text { Desvio } \\
1,26\end{array}$} \\
\hline & 15,67 & 14,44 & 14,14 & 17,18 & 13,04 & & \\
\hline & 15,14 & 16,44 & 14,70 & 16,57 & 14,77 & & \\
\hline \multirow{2}{*}{ A } & 15,79 & 14,04 & 16,39 & 14,02 & 13,21 & \multirow{2}{*}{14,62} & \multirow{2}{*}{1,20} \\
\hline & 12,93 & 16,13 & 13,99 & 15,13 & 14,55 & & \\
\hline \multirow{2}{*}{ B } & 18,60 & 19,42 & 20,11 & 15,50 & 17,56 & \multirow{2}{*}{18,10} & \multirow{2}{*}{1,70} \\
\hline & 17,99 & 20,12 & 15,60 & 19,60 & 17,51 & & \\
\hline \multirow{2}{*}{ C } & 19,37 & 17,06 & 19,32 & 16,31 & 18,35 & \multirow{2}{*}{17,82} & \multirow{2}{*}{1,10} \\
\hline & 17,01 & 18,13 & 17,07 & 18,72 & 16,87 & & \\
\hline \multirow{2}{*}{ D } & 11,82 & 12,04 & 10,29 & 9,60 & 11,59 & \multirow{2}{*}{10,56} & \multirow{2}{*}{1,36} \\
\hline & 10,40 & 10,05 & 12,36 & 8,19 & 9,24 & & \\
\hline
\end{tabular}




\subsubsection{Planejamento Fatorial $2^{k}$}

Os resultados experimentais definitivos foram processados pelo Software Minitab, através do qual foi aplicado o Planejamento Fatorial $2^{k}$. Na Tabela 12 são apresentados os efeitos de cada fator principal, bem como das combinações de dois ou mais fatores. Os valores da coluna "Efeitos" na Tabela 12 quantificam a influência de cada fator, ou combinação de fatores, na resistência da junção, com um nível de significância de 95\%. Os valores negativos desta coluna indicam que houve redução da resistência. Os valores positivos conseqüentemente indicam aumento da resistência.

Tabela 12 - Efeitos e coeficientes estimados pelo Planejamento Fatorial $2^{k}$.

\begin{tabular}{|c|c|c|c|c|}
\hline Fator & Efeito & Coeficiente. & Incerteza & \\
\hline Constante & 14,321 & & 1,163 & \\
\hline A & $-1,183$ & $-0,591$ & 1,163 & \\
\hline B & 2,215 & 1,107 & 1,163 & \\
\hline $\mathrm{C}$ & 0,863 & 0,431 & 1,163 & \\
\hline $\mathrm{D}$ & $-4,441$ & $-2,221$ & 1,163 & \\
\hline$A * B$ & $-0,048$ & $-0,024$ & 1,163 & \\
\hline$A^{*} \mathrm{C}$ & $-0,513$ & $-0,257$ & 1,163 & \\
\hline$A * D$. & 0,178 & 0,089 & 1,163 & \\
\hline $\mathrm{B} * \mathrm{C}$ & $-0,582$ & $-0,291$ & 1,163 & \\
\hline$B * D$ & $-0,154$ & $-0,077$ & 1,163 & \\
\hline$C^{*} \mathrm{D}$ & 0,398 & 0,199 & 1,163 & \\
\hline$A * B * C$ & 0,338 & 0,169 & 1,163 & \\
\hline$A * B . * D$ & $-0,234$ & $-0,117$ & 1,163 & \\
\hline$A * C * D$ & 0,279 & 0,140 & 1,163 & \\
\hline $\mathrm{B} * \mathrm{C} * \mathrm{D}$ & 0,110 & 0,055 & 1,163 & \\
\hline$A^{*} B * C * D$ & $-0,015$ & $-0,008$ & 1,163 & - \\
\hline
\end{tabular}

O Gráfico de Pareto, apresentado na Figura 44, apresenta de forma padronizada a influência dos fatores analisados. A linha vermelha no gráfico representa o limite de significância de 95\%. Desta forma a variação de resistência na junção, cujo efeito padronizado ultrapassa a linha vermelha, é significante. Sendo assim são significantes todos os efeitos principais $e$ as interações entre os fatores temperatura/rugosidade (jato de areia) e nanocerâmica/rugosidade. 


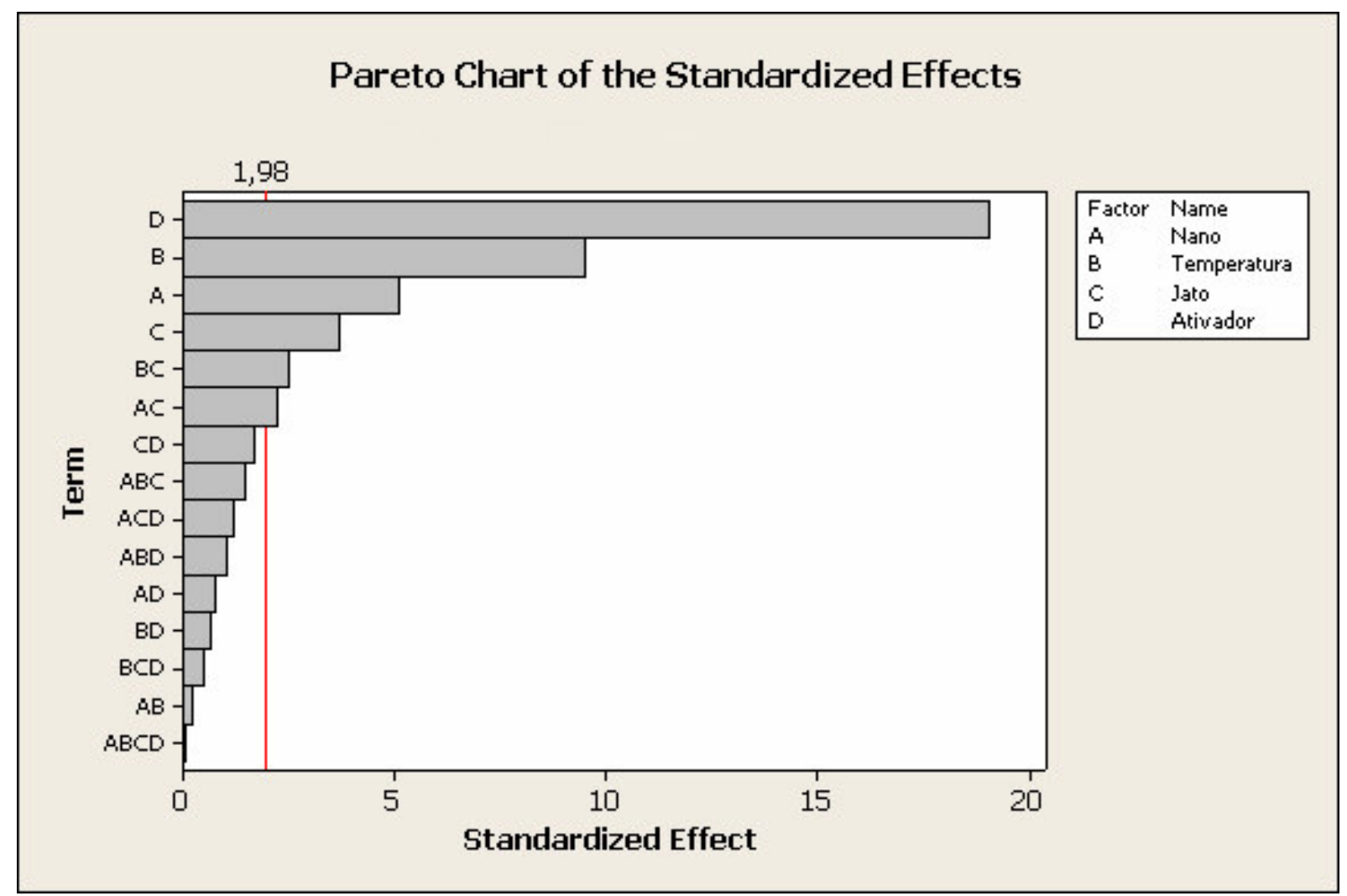

Figura 44 - Efeito Pareto das tensões médias de ruptura.

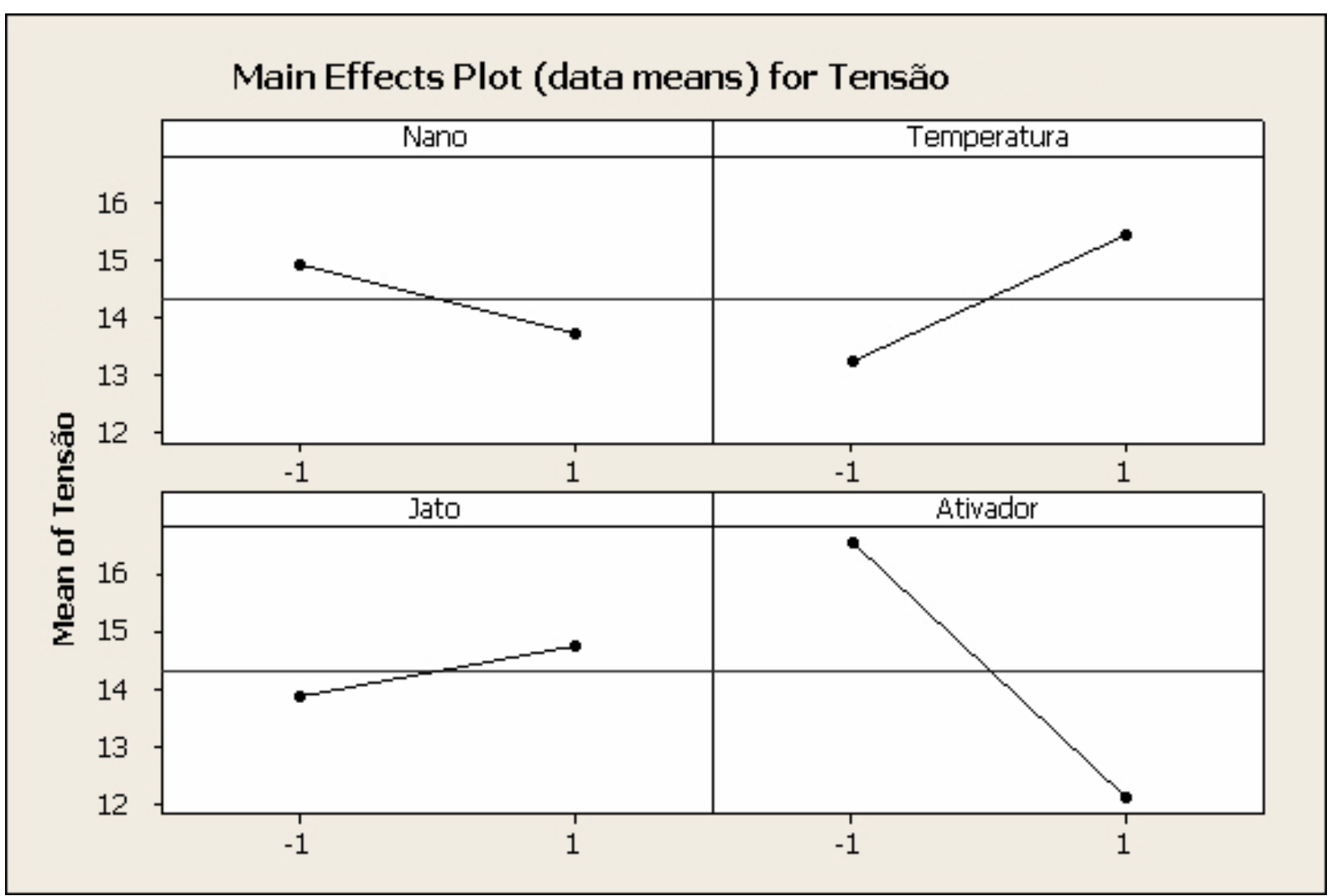

Figura 45 -Efeitos principais das tensões médias de ruptura. 
A Figura 45 apresenta a variação da resistência causada pela alteração de cada fator principal. Os valores $(-1)$ e $(+1)$ representam respectivamente os níveis inferior e superior de cada fator. A superfície sem ativador, por exemplo, é representada por $(-1)$, com (+1) para a superfície com ativador. Este gráfico deixa claro que a variação da resistência é tratada de forma linear, devido à limitação do método de análise. Mesmo as condições onde não há condição intermediária, com a nanocerâmica, o método apresenta a variação como linear. No eixo vertical do gráfico está disposta a escala da tensão média de ruptura (MPa).

Ao manter uma condição em seu nível superior, por exemplo, Nanocerâmica $(+1)$ e variar outra condição entre dois níveis, como a rugosidade entre $(-1)$ e $(+1)$, notou-se a variação da resistência da junção. Quando o mesmo procedimento é realizado para o nível inferior da primeira condição citada, por exemplo, Nanocerâmica (-1), e ao variar o segundo fator (rugosidade) nota-se que a inclinação da curva de variação se diferencia da inclinação da primeira, considera-se que a interação entre os fatores é significante. A variação da inclinação deve ultrapassar níveis pré-estabelecidos para ser considerada significativa. A Figura 46 apresenta todas as interações possíveis neste estudo. A análise deste gráfico permite identificar as interações significativas. O eixo vertical direito contém a escala de tensão média de ruptura (MPa), as retas pretas representam o nível inferior e as vermelhas o nível superior do fator citado no final da linha, à direita do gráfico. A primeira linha do gráfico por exemplo se refere à Nanocerâmica. Abaixo de cada quadrante está descrito o fator variado, os níveis de variação destes fatores estão descritos na linha horizontal superior. 


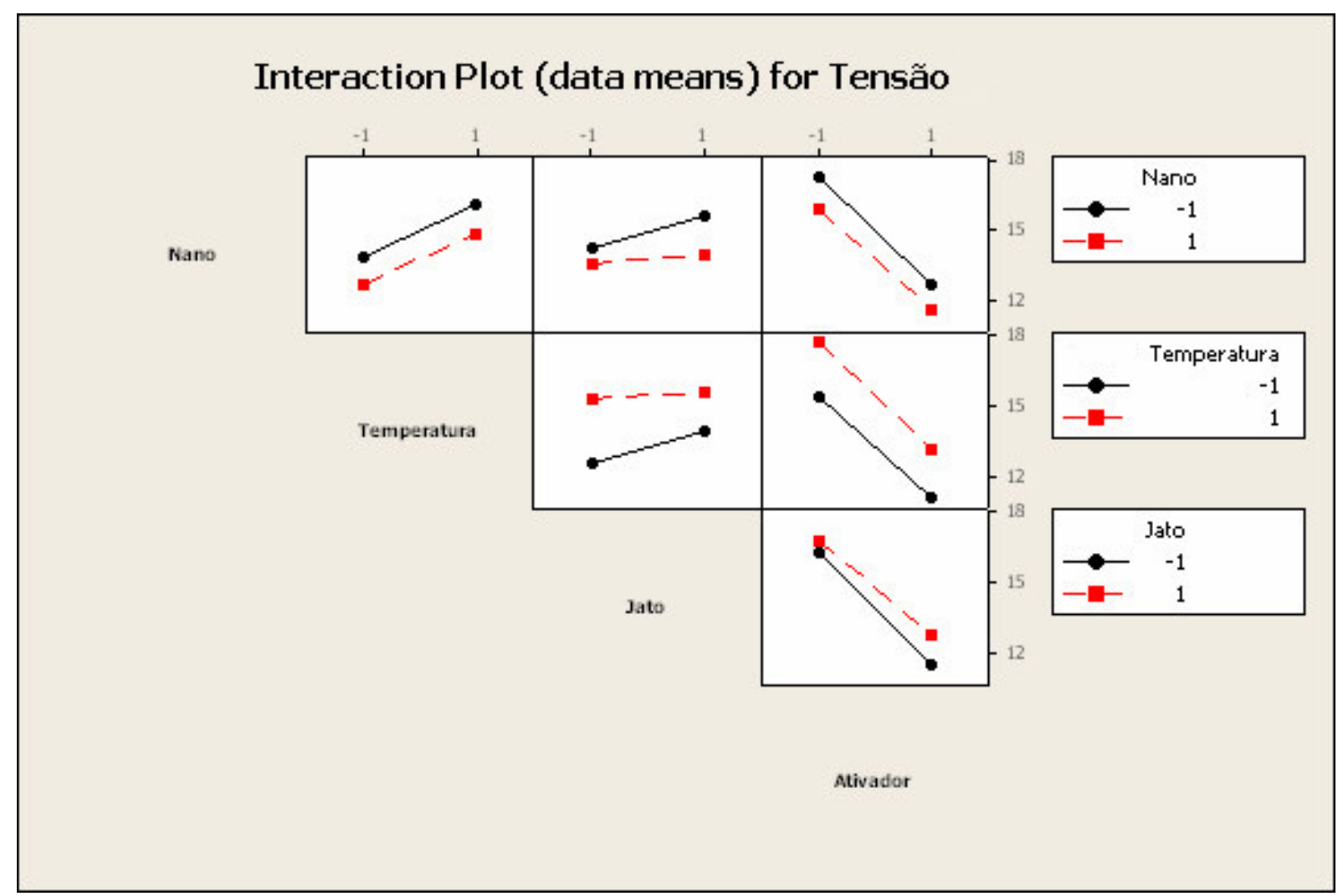

Figura 46 - Representação dos efeitos de interação.

\subsubsection{Discussão de Resultados}

Os ensaios preliminares mostraram que a variação dos fatores propostos gera alteração na resistência da junção, qualificando os fatores para realização dos ensaios definitivos. Durante a realização destes ensaios verificou-se a existência de rebarbas nos corpos de prova, as quais podem interferir no resultado final.

As chapas utilizadas nos corpos de prova definitivos tiveram essas rebarbas retiradas e sua planicidade conferida com o uso de régua de luz, garantindo que folgas indesejadas não foram geradas. A comparação entre os resultados obtidos mostrou que a retirada da rebarba aumentou a resistência da junção, confirmando a importância da preparação correta dos corpos de prova.

Os ensaios confirmativos tiveram o objetivo de verificar se nenhum fator havia sido desconsiderado, a comparação entre os resultados dos ensaios definitivos e confirmativos mostrou pequeno desvio entre os as médias obtidas para as mesmas condições. Os valores individuais para cada condição ocupam a mesma faixa de variação. 
A análise pela aplicação do Planejamento Fatorial $2^{k}$ mostra que houve grande variação da resistência da junção em função da alteração dos fatores de influência de superfície e cura, sendo que todos os fatores principais são significativos, com diferentes amplitudes de variação. Os sinais negativos da Tabela 12 indicam que o aumento destas variáveis resultou em redução da resistência da junção. A análise de significância, Figura 44, mostra que somente duas interações são significativas, $A^{*} C$ e $B^{\star} C$, ou seja, somente as interações entre nanocerâmica/temperatura e temperatura/rugosidade são significativas.

As variações na resistência da junção adesiva, causadas pela alteração dos fatores de influência, tiveram diferentes amplitudes, mostrando que cada fator de influência causa efeitos diferentes não só em amplitude como também em sentido de atuação. A alteração de alguns fatores causou aumento da resistência, enquanto a variação de outros causou a redução da resistência.

A Figura 44 e a Tabela 12 mostram que os dois fatores de maior influência na variação da resistência são a temperatura de cura e o uso de ativador. Ambos fatores estão relacionados com a cura do produto influenciando no peso molecular do adesivo e segundo Canevarolo (2002) nas propriedades mecânicas dos polímeros.

O fator de maior influência foi o uso do ativador, gerador de uma considerável queda na resistência da junção. Segundo Andrade (comunicação pessoal, 2007) a utilização de ativadores acelera o processo de cura, reduzindo o tempo necessário para a mesma, porém gera polímeros de menor peso molecular, consecutivamente polímeros com menor resistência mecânica. Esta redução está diretamente relacionada ao tipo do material testado, se aplicado em materiais inativos, como cerâmica, o ativador será indispensável para a cura do adesivo aumentando a resistência da junção.

O segundo fator mais influente foi o aumento da temperatura de cura de $22^{\circ} \mathrm{C}$ para $60^{\circ} \mathrm{C}$, resultando em grande aumento da resistência da junção. Andrade (comunicação pessoal, 2007) afirma que em oposição ao uso de ativador, o aumento da temperatura de cura gera polímeros de maior peso molecular e resistência mecânica elevada, confirmando Canevarolo (2002). As condições de cura do adesivo mostraram maior influência na resistência da junção, porém com sentidos de atuação diferentes. Isto se deve pelo fato do ativador agir diretamente sobre os geradores de radicais livres, diminuindo o peso molecular do polímero 
formado. Enquanto a temperatura age sobre o monômero, transformando-os em geradores de radicais livres. Desta forma a possibilidade de interrupção de formação da cadeia é menor, conseqüentemente o polímero formado tem maior peso molecular e melhores propriedades mecânicas.

Superfícies jateadas, maior rugosidade, geraram leve aumento na resistência da junção adesiva. Segundo Villenave (2005) existe um limite na influência da rugosidade na resistência de junções adesivas, informação baseada no modelo mecânico de adesão. Rugosidades altas geram maior área de contato entre adesivo e substrato, além de favorecer a formação de uma espécie de microchavetas, aumentando a resistência da junção.

A aplicação de nanocerâmica gerou leve redução na resistência da junção. Possart apresentou uma teoria química de adesão, a qual propõe uma reação química entre o adesivo e a superfície. Desta forma a alteração da superfície por conversão da camada externa, através da oxidação micropartículas e conseqüentemente a alteração da reação química entre os materiais, pode ser a responsável pela redução. Outra possibilidade é a alteração das características mecânicas na superfície, uma varredura com microscópio eletrônico poderia mostrar se houve alteração mecânica significativa, capaz de alterar as condições de rugosidade da superfície.

$A$ interação $A^{*} C$ (nanocerâmica/rugosidade) é significativa e resulta em leve enfraquecimento da resistência.

A interação $B^{*} C$ é (temperatura/rugosidade) significativa e resulta em leve enfraquecimento da resistência da junção.

A alteração do nível de rugosidade apresentar maior influência na determinação da significância de interações. Quando a variação da rugosidade interagiu com a nanocerâmica em nível superior $(+1)$ a variação da resistência foi inferior à obtida com a interação com nanocerâmica em nível inferior (-1). O oposto aconteceu ao interagir rugosidade e temperatura. 
10.2 INFLUÊNCIA DO COMPRIMENTO DE SOBREPOSIÇÃO

\subsubsection{Resultados dos Ensaios de Cisalhamento}

Conforme citado anteriormente o mesmo material foi utilizado para realização destes testes, porém o comprimento de sobreposição foi variado de $10 \mathrm{~mm}$ a $50 \mathrm{~mm}$ em intervalos de $10 \mathrm{~mm}$.

Ensaios anteriores mostraram desplacamento da camada de óxido dos corpos de prova para longos comprimentos de sobreposição, mais precisamente acima de $30 \mathrm{~mm}$ para esta configuração geométrica. Por este motivo, optou-se por realizar ensaios em duas condições diferentes, onde a única variável entre elas foi a existência ou não da camada superficial de óxido.

Visando submeter as junções ao maior esforço possível, foram selecionadas as duas condições que apresentaram maior resistência nos ensaios definitivos no primeiro método. A primeira bateria de ensaios foi realizada com corpos de prova na condição: rugosidade $(-1)$, temperatura $(+1)$, nanocerâmica $(-1)$ e ativador $(-1)$. A Tabela 13 traz os resultados experimentais obtidos.

Tabela 13 - Tensões médias de ruptura dos ensaios com diferentes comprimentos de sobreposição, chapas de aço com rugosidade de $7,5 \mu \mathrm{m} R z$, sem jateamento (-1), e temperatura de cura de $60^{\circ} \mathrm{C}$.

\begin{tabular}{|c|c|c|c|c|c|c|c|}
\hline \multirow{3}{*}{$\begin{array}{c}\text { Condição } \\
10 \mathrm{~mm}\end{array}$} & \multicolumn{5}{|c|}{ Tensão Média de Ruptura (MPa) } & \multirow{3}{*}{$\begin{array}{r}\text { Média } \\
18,01\end{array}$} & \multirow{2}{*}{$\begin{array}{c}\text { Desvio } \\
1,76\end{array}$} \\
\hline & 18,23 & 18,95 & 17,59 & 20,36 & 17,87 & & \\
\hline & 14,76 & 15,68 & 20,28 & 18,14 & 18,25 & & \\
\hline \multirow{2}{*}{$20 \mathrm{~mm}$} & 17,83 & 16,62 & 18,43 & 18,31 & 17,83 & \multirow{2}{*}{17,77} & \multirow{2}{*}{0,54} \\
\hline & 17,76 & 17,90 & 17,55 & 17,27 & 18,22 & & \\
\hline \multirow{2}{*}{$30 \mathrm{~mm}$} & 15,39 & 15,09 & 15,01 & 15,45 & 14,58 & \multirow{2}{*}{15,18} & \multirow{2}{*}{0,65} \\
\hline & 14,87 & 15,77 & 14,15 & 14,94 & 16,51 & & \\
\hline \multirow{2}{*}{$40 \mathrm{~mm}$} & 13,98 & 15,17 & 13,91 & 13,94 & 13,40 & \multirow{2}{*}{14,15} & \multirow{2}{*}{0,64} \\
\hline & 13,59 & 14,67 & 14,20 & 15,11 & 13,51 & & \\
\hline \multirow{2}{*}{$50 \mathrm{~mm}$} & 13,53 & 12,30 & 12,78 & 12,37 & 11,51 & \multirow{2}{*}{12,23} & \multirow{2}{*}{0,65} \\
\hline & 11,80 & 12,43 & 11,96 & 12,36 & 11,27 & & \\
\hline
\end{tabular}

A primeira bateria de ensaios confirmou o desplacamento da camada de óxido em corpos de prova com comprimentos de sobreposição igual maior que $30 \mathrm{~mm}$, a Tabela 47 mostra tal desplacamento para chapas com $40 \mathrm{~mm}$ de sobreposição. Em 
seqüência foi realizada a segunda bateria de ensaios, com corpos de prova com rugosidade alterada, ou seja, sem a camada de óxido. A camada de óxido foi retirada por jateamento, elevando o fator rugosidade para o nível $(+1)$, sendo possível verificar a influência da camada de óxido nos resultados. Os resultados obtidos para condição com camada de óxido extraída encontram-se na Tabela 14.

Tabela 14 - Tensões médias de ruptura dos ensaios com diferentes comprimentos de sobreposição, chapas de aço com rugosidade de $16,5 \mu \mathrm{m} \mathrm{Rz}$, com jateamento $(+1)$, e temperatura de cura de $60^{\circ} \mathrm{C}$.

\begin{tabular}{|c|c|c|c|c|c|c|c|}
\hline \multirow{3}{*}{$\begin{array}{c}\text { Condição } \\
10 \mathrm{~mm}\end{array}$} & \multicolumn{5}{|c|}{ Tensão Média de Ruptura (MPa) } & \multirow{3}{*}{$\begin{array}{l}\text { Média } \\
19,44\end{array}$} & \multirow{2}{*}{$\begin{array}{c}\text { Desvio } \\
0.72\end{array}$} \\
\hline & 20,16 & 20,65 & 18,55 & 19,69 & 19,23 & & \\
\hline & 19,82 & 18,64 & 19,64 & 18,46 & 19,60 & & \\
\hline \multirow{2}{*}{$20 \mathrm{~mm}$} & 19,65 & 19,61 & 16,83 & 19,43 & 17,17 & \multirow{2}{*}{18,77} & \multirow{2}{*}{1,09} \\
\hline & 19,59 & 19,57 & 18,52 & 19,38 & 17,93 & & \\
\hline \multirow{2}{*}{$30 \mathrm{~mm}$} & 16,60 & 17,80 & 18,97 & 19,26 & 19,39 & \multirow{2}{*}{18,15} & \multirow{2}{*}{1,16} \\
\hline & 16,27 & 16,98 & 18,38 & 18,68 & 19,11 & & \\
\hline \multirow{2}{*}{$40 \mathrm{~mm}$} & 18,17 & 18,42 & 15,71 & 15,81 & 16,31 & \multirow{2}{*}{16,48} & \multirow{2}{*}{1,08} \\
\hline & 17,20 & 16,17 & 16,07 & 15,56 & 15,34 & & \\
\hline \multirow{2}{*}{$50 \mathrm{~mm}$} & 13,10 & 13,03 & 14,63 & 13,47 & 13,72 & \multirow{2}{*}{13,95} & \multirow{2}{*}{0,74} \\
\hline & 15,18 & 13,96 & 14,86 & 14,14 & 13,44 & & \\
\hline
\end{tabular}

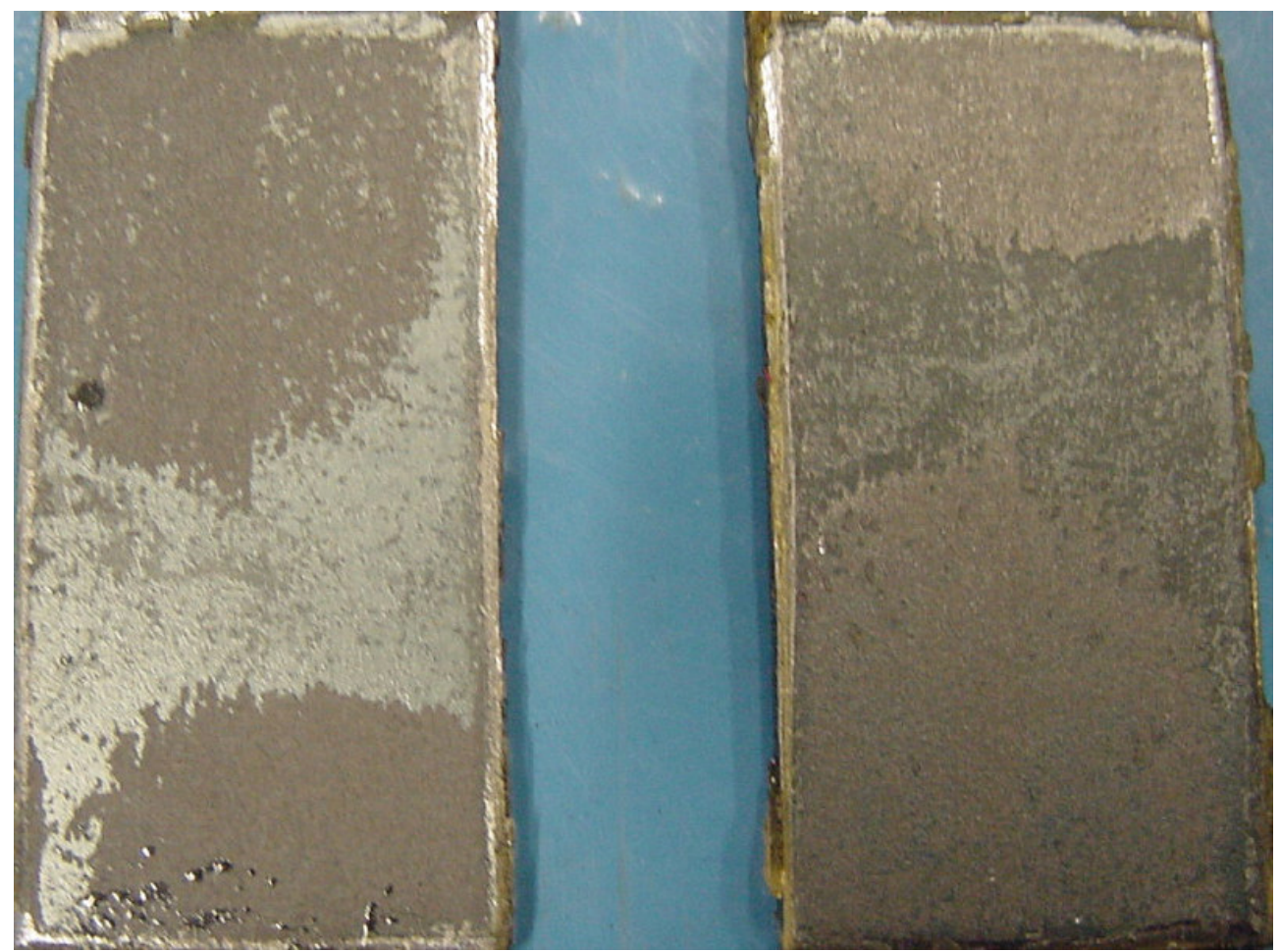

Figura 47 - Desplacamento da camada de óxido nas extremidades (40mm). 


\subsubsection{Representação Gráfica}

Utilizando o Software Maple foi possível plotar de forma pontual cada tensão média de ruptura medida para as duas condições. A Figura 48 mostra as amplitudes de variação da tensão média de ruptura para cada comprimento de sobreposição, nas duas condições. A análise do gráfico permite observar que para o comprimento de sobreposição de $10 \mathrm{~mm}$ a condição com rugosidade (-1), pontos vermelhos, apresentou maior variação de resultados (amplitude).

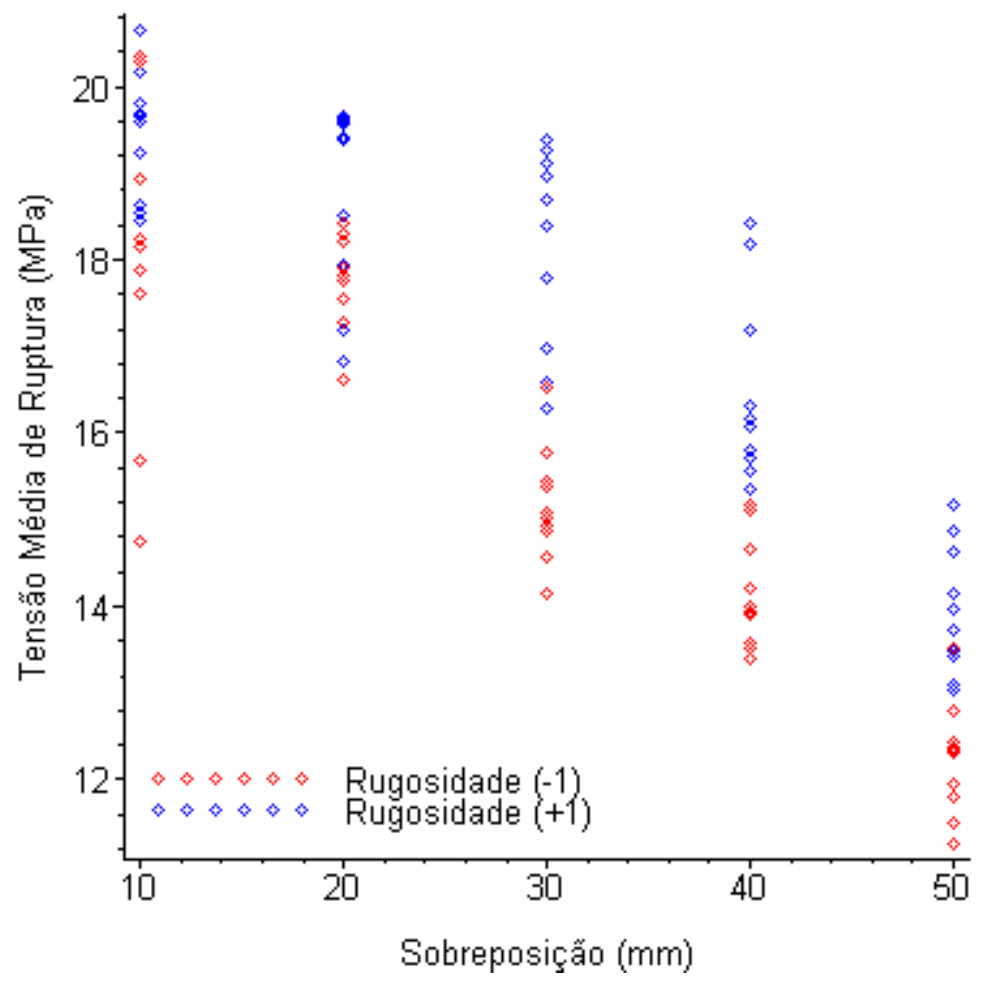

Figura 48 - Resultados experimentais - comprimento de sobreposição.

Ao utilizar as médias das tensões para cada comprimento de sobreposição, unindoas através de retas entre os pontos, percebe-se que a resistência da junção com rugosidade $(+1)$ foi maior em todos os comprimentos de sobreposição. Para a condição de rugosidade (-1), com camada de óxido, a partir do comprimento de sobreposição de 30mm ocorreu uma brusca queda da resistência, devido ao início do desplacamento da camada de óxido. A mesma queda de resistência não foi apresentada pelos corpos de prova com superfície jateada, mostrando que o desplacamento da camada de óxido interfere na resistência da junção. 


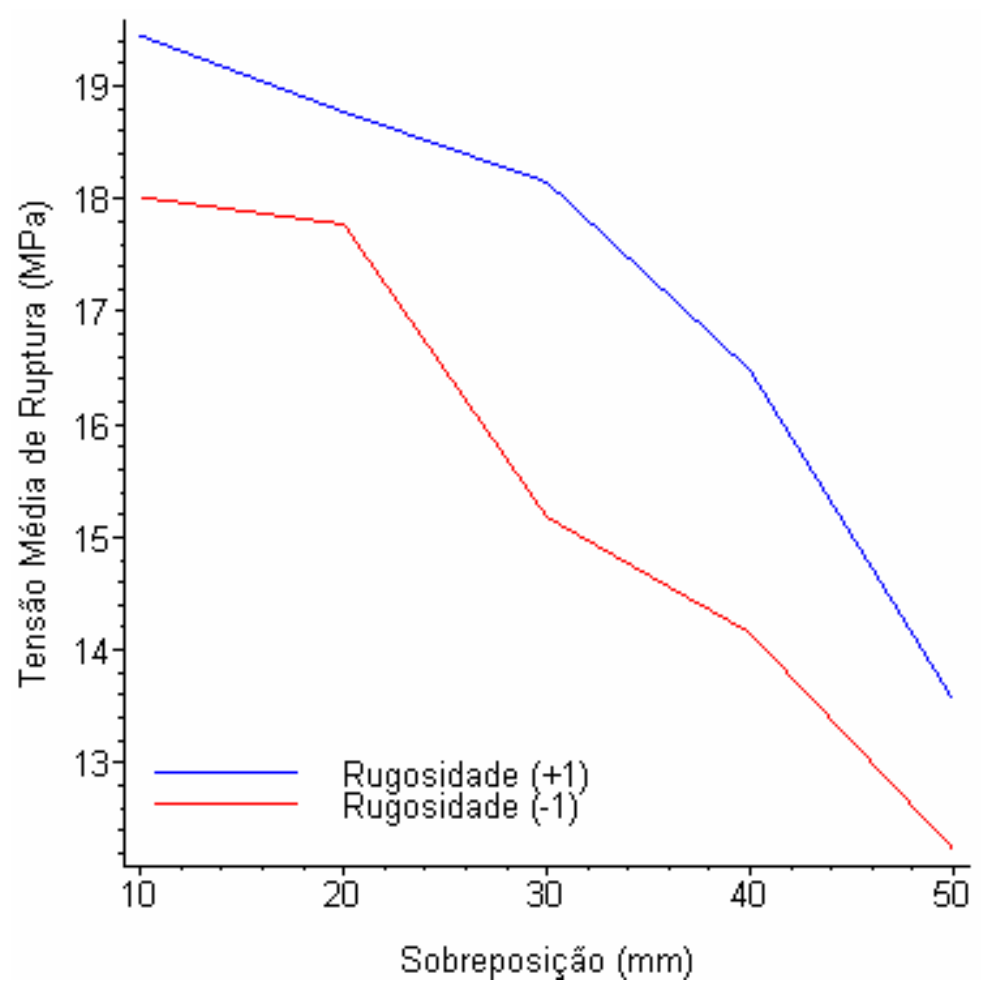

Figura 49 - Curva da média das tensões médias de ruptura.

\subsubsection{Modelos Aplicados aos Resultados Experimentais}

Com o objetivo de fundamentar o comportamento da resistência em função do comprimento de sobreposição, os dados experimentais da condição com rugosidade em nível inferior (-1), foram aplicados ao Modelo de Volkersen e ao Modelo de Goland e Reissner, ambos modificados e apresentados por Tsai et al. (1997).

Para o Modelo de Volkersen considerou-se a condição sem deformação do substrato por tensão de cisalhamento, utilizando $\alpha=1$ e como segunda condição o modelo modificado, proposto por Tsai, com $\alpha$ obtido através da Equação 15. Para $\alpha=1$ a rigidez do substrato tende à infinito, desconsiderando a deformação do mesmo em função do carregamento. Com o valor obtido pela Equação 15, a deformação longitudinal do substrato é considerada, porém ainda com comportamento de treliça, desprezando os momentos.

O Modelo de Goland e Reissner foi aplicado sob as mesmas condições com $\alpha=1$, desconsiderando a deformação do substrato, e com a obtido através da Equação 22 para a condição que considera a deformação dos substratos. Note que duas 
equações diferentes são utilizadas na determinação do $\alpha$, cada uma delas específica para um modelo.

As Figuras 50, 51, 52, 53 e 54 apresentam os resultados obtidos pela aplicação dos dois modelos. Para pequenos comprimentos de sobreposição e conseqüentemente baixos carregamentos, pode-se notar que os dois modelos apresentam resultados muito próximos, e ambas as situações. Isto de deve ao fato de que o substrato realmente não deforma, conforme mostrado através da Equação 21. Para este comprimento existe um fator de segurança que garante que a deformação do substrato não interfere na resistência da junção.

Ao aumentar o comprimento de sobreposição e conseqüentemente o carregamento, ou força externa aplicada, as condições que consideram a deformação dos substratos como a se diferenciar da condição de infinita rigidez. Para as condições de rigidez infinita, pode-se observar a partir do comprimento de sobreposição de 20mm, Figura 51, um aumento significante da tensão de cisalhamento nas extremidades da junção e uma considerável redução na região central. Isto ocorre, pois o modelo com alta rigidez propõe que por não se deformarem os substratos oferecem maior resistência à deformação do filme de adesivo e conseqüentemente maior tensão.

A condição de ambos os modelos com deformação dos substratos apresenta uma tensão inferior, porém constante, na região central e picos de tensão nas extremidades. Os picos de tensão nas extremidades apresentam menor variação quando comparados com os picos obtidos nos modelos com condição de rigidez infinita. Sendo assim pode-se propor que a condição com tensão de cisalhamento nos substratos é a condição que mais se aproxima da realidade, podendo ser utilizada para fundamentar a diminuição da resistência em função do comprimento de sobreposição. 


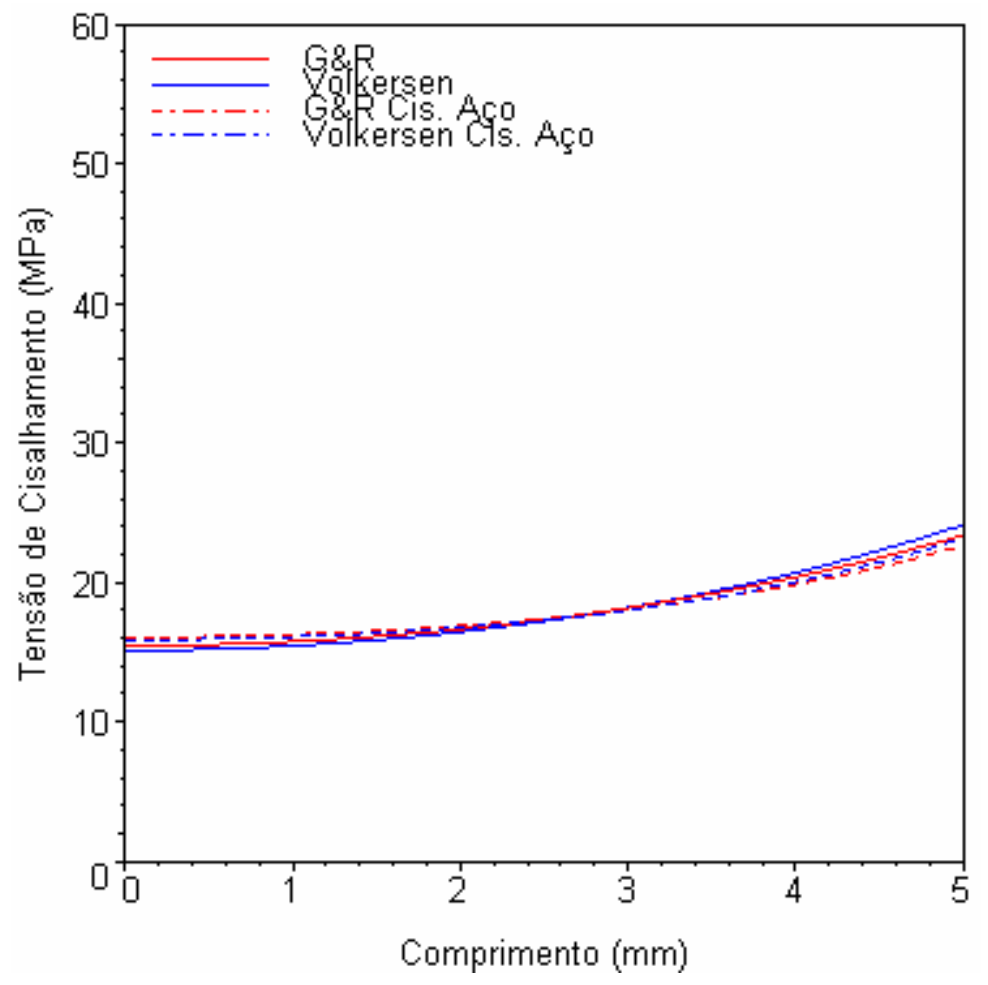

Figura 50 - Distribuição da tensão com sobreposição de $10 \mathrm{~mm}$.

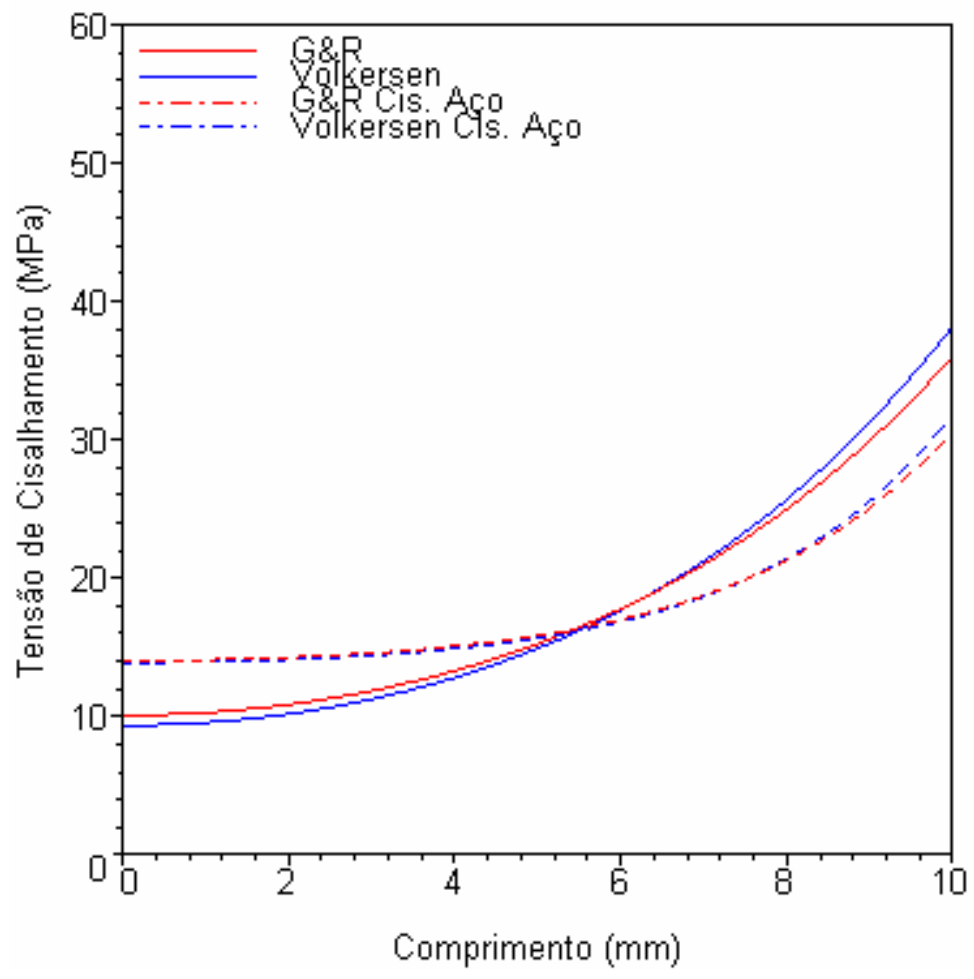

Figura 51 - Distribuição da tensão com sobreposição de 20 mm 


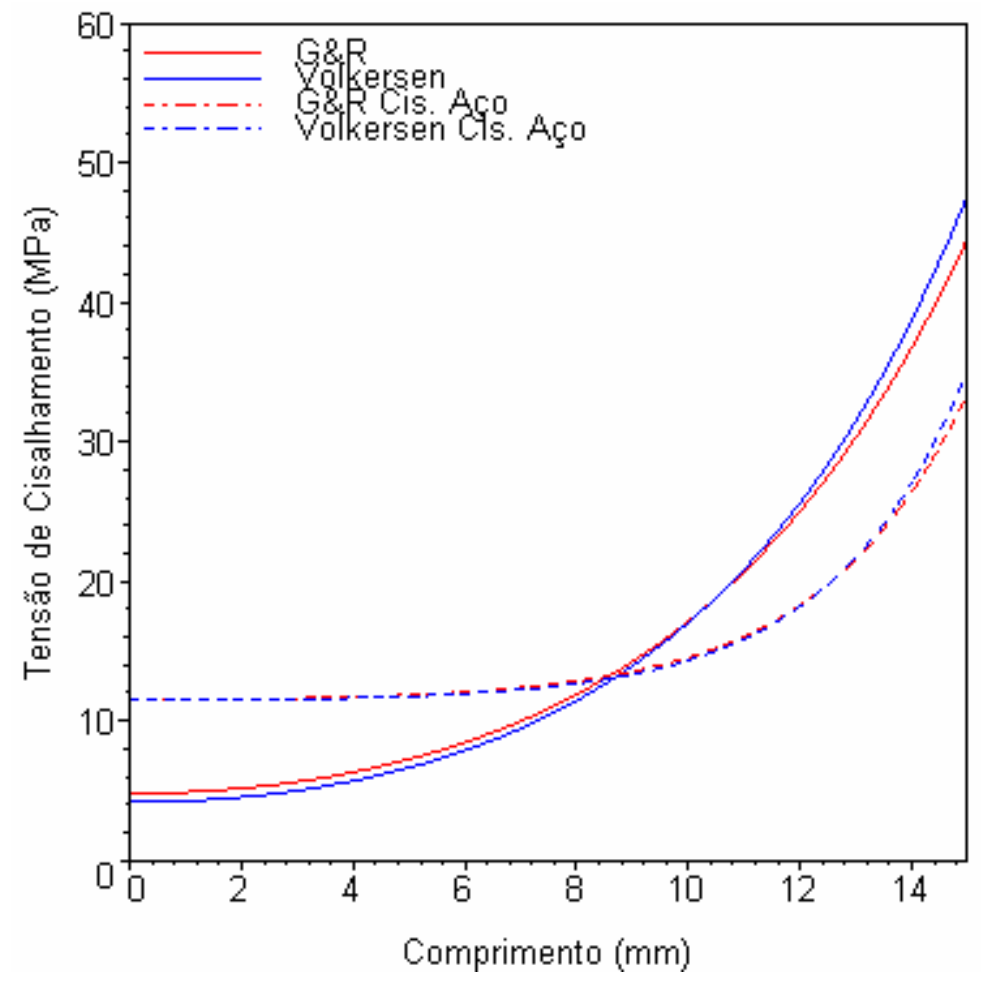

Figura 52 - Distribuição da tensão com sobreposição de $30 \mathrm{~mm}$.

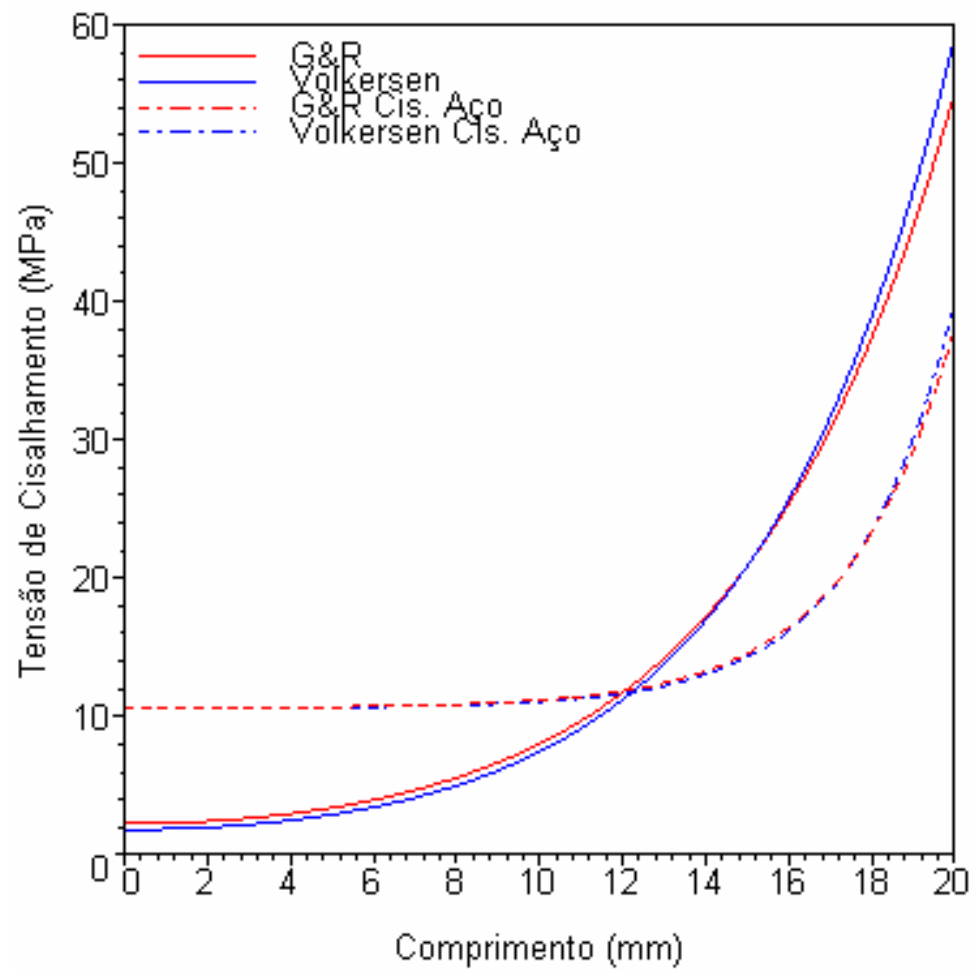

Figura 53 - Distribuição da tensão para com sobreposição de 40 mm 


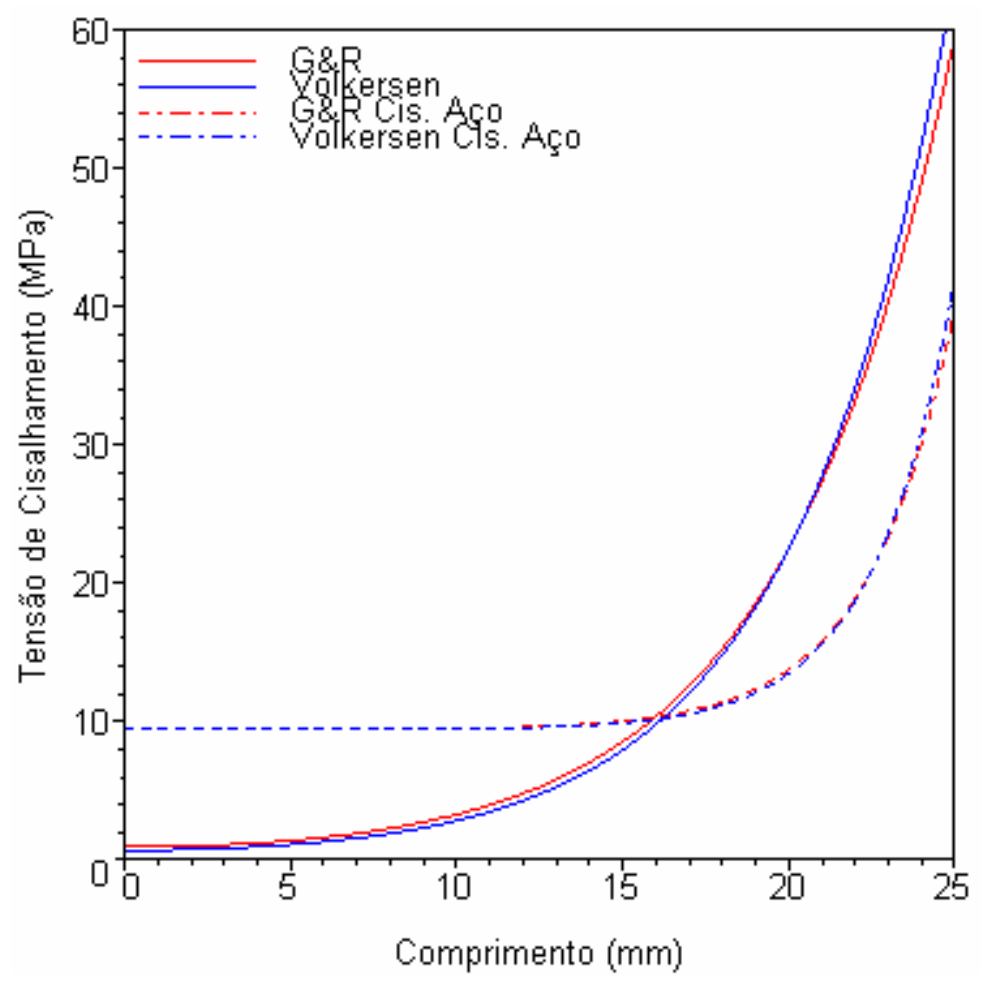

Figura 54 - Distribuição da tensão com sobreposição de 50 mm

\subsubsection{Discussão de Resultados}

Villenave (2005), Zoran et al. (2001) e Lucic (2006) apresentaram interpretações da variação da resistência da junção adesiva em função do comprimento de sobreposição. Os três autores concordam com a distribuição das tensões ao longo do comprimento, afirmando que ocorre uma concentração de esforços nas extremidades de junções por sobreposição simples de chapas. Tal comportamento é fortalecido através da aplicação dos Modelos de Volkersen e de Goland \& Reissner. Porém apresentam uma divergência no que diz respeito ao aumento ou redução da resistência da junção em função do comprimento de sobreposição.

Villenave (2005) propõe que a tensão média de ruptura aumenta junto com o comprimento de sobreposição, atingindo um patamar máximo, o qual é mantido mesmo que se continue a aumentar o comprimento de sobreposição.

Zoran et al. (2001) e Lucic (2006) propõe a redução da tensão média de ruptura em função do aumento do comprimento de sobreposição. 
Os resultados destes ensaios, com chapas de aço SAE 1010 e adesivo Loctite 326, mostraram que a tensão média de ruptura sofre redução com o aumento do comprimento de sobreposição. Este aumento foi apresentado pelas junções nas duas condições de rugosidade da superfície, com ou sem jateamento.

A análise dos corpos de prova mostra que as chapas sofreram deformação significativa durante os ensaios nas condições com comprimento de sobreposição de $30 \mathrm{~mm}$ e superiores, evidenciando o efeito de deformação e aumento significativo da concentração de tensão nas extremidades da junção. A deformação dos substratos é confirmada pela Equação 37, que estabelece um limite máximo de comprimento de sobreposição para as junções. Para o comprimento de sobreposição de $10 \mathrm{~mm}$, ainda existe um coeficiente de segurança, capacitando este comprimento para os ensaios. Para o comprimento de $20 \mathrm{~mm}$ e superiores, a deformação do substrato passa a interferir na resistência, pois estão acima do limite estabelecido pela Equação 37.

A redução da tensão média de ruptura pode ser explicada através da afirmação de Broughton \& Gower (2001) de que junções por sobreposição simples de chapas, a falha se inicia nas extremidades, devido à concentração de tensão gerada na região. Villenave (2005), Zoran (2001) e Lucic (2006) afirmam que a tensão nas extremidades é muito superior, quando comparada à tensão na região central da junção, a diferença entre as tensões nas duas regiões aumenta proporcionalmente ao comprimento de sobreposição. Desta forma para pequenos comprimentos de sobreposição a tensão é máxima em quase todo o comprimento, ocasionando total aproveitamento da resistência da junção, pois quando a falha na extremidade se inicia, a região central também já apresenta altos níveis de tensão. Enquanto que para grandes comprimentos de sobreposição a tensão na extremidade assume níveis capazes de romper a junção, enquanto a tensão na região central ainda é baixa, resultando em tensão média de ruptura reduzida.

A aplicação dos modelos matemáticos apresentou resultados condizentes para condições similares. Sendo que a condição que considera a deformação dos substratos apresenta maior proximidade da realidade. Esta condição apontou um nível de tensão na extremidade da junção onde a falha inicia. Este nível variou de acordo com o comprimento de sobreposição, esta variação se deve ao fato de que o momento na extremidade das chapas é negligenciado. 
As condições que consideram a rigidez dos substratos como infinita apresentam excessivo aumento do pico de tensão nas extremidades, em função do aumento do comprimento. Estes níveis de pico são inaceitáveis, pois causariam ruptura da junção antes de serem atingidos.

Os corpos de prova com superfície com camada de óxido e nível de rugosidade inferior, ou seja, sem jateamento, apresentaram desplacamento da camada de óxido para comprimentos de sobreposição de $30 \mathrm{~mm}$ e superiores durante os ensaios. A Figura 49 mostra que a curva de tensões médias de ruptura dos corpos de prova com camada de óxido, muda de forma acentuada a partir do comprimento de sobreposição de $30 \mathrm{~mm}$. Comprimento a partir do qual também ocorre o desplacamento da camada de óxido. O mesmo comportamento não é apresentado nos corpos de prova sem a camada inicial de óxido, desta forma concluí-se que a camada de óxido altera o comportamento da resistência, desplacando antes da falha coesiva do adesivo.

\subsection{ESFORÇOS COMBINADOS}

\subsubsection{Resultados Experimentais com Corpos de Prova de Lee}

Durante a realização dos ensaios com dispositivo de Arcan, com corpos de prova baseados em Lee (1998), a baixa rigidez dos corpos de prova afetou os resultados dos ensaios. Conforme citado anteriormente os corpos de prova foram feitos com chapas de aço SAE 1010 dobradas, com 2mm de espessuras, 20mm de largura e $10 \mathrm{~mm}$ de largura de filme de adesivo.

Os primeiros problemas ocorreram durante a fixação dos corpos de prova no dispositivo, ao apertar os parafusos de fixação os corpos de prova eram deformados, gerando uma tensão inicial indesejada na região aderida, além de criar um esforço indesejado de clivagem na região.

Os adesivos geralmente apresentam reduzida resistência quando submetidos à esforços de clivagem. De 10 corpos de prova montados somente dois ofereceram condições de teste, os 8 restantes romperam devido à tensão gerada no momento 
da montagem, sendo que estes 2 corpos de prova testados apresentaram variação de mais de $100 \%$ nos resultados, desqualificando esta configuração de corpos de prova para este tipo de ensaio.

Outra observação importante realizada durante os ensaios, foi o desplacamento da camada de óxido da chapa, condição também ocorrida nos corpos de prova onde a rótula plástica foi evidenciada pela deformação dos substratos durante o teste, nos ensaios que analisaram a influência do comprimento de sobreposição na resistência da junção. Este fato levanta a necessidade da averiguação da influência do ângulo de tracionamento no desplacamento da camada de óxido e confecção de corpos de prova com maior rigidez para realização dos ensaios com esforços combinados.

\subsubsection{Resultados Experimentais com Corpos de Prova Específicos}

Após a averiguação de que os corpos de prova baseados em Lee (1998) não possuem rigidez suficiente para serem aplicados em ensaios com junções adesivas, foram realizados ensaios com corpos de prova específicos para adesivos, baseados em publicações, já que não existem normas para este tipo de ensaio.

Os resultados experimentais encontram-se expressos nas Tabelas 15 e 16. Estes mostraram que as junções adesivas apresentam maior resistência quando submetidas à esforços de tração pura. Dentre os ângulos ensaiados, foi o de $45^{\circ}$ que suportou menor carga, além de descrever curva força $x$ deformação mais irregular. Isto provavelmente se deve às limitações do dispositivo utilizado, como folga e alinhamento.

Os ensaios de tração pura $\left(90^{\circ}\right)$ além de maior resistência, apresentaram comportamento mais regular (linear). Os ensaios de cisalhamento puro $\left(0^{\circ}\right)$ apresentaram alta deformação do filme antes do rompimento.

A variação da velocidade de tracionamento não resultou em alterações expressivas na resistência das junções. Apresentando apenas leve aumento da média da tensão média de ruptura, com o aumento da velocidade, porém os resultados variaram dentro da mesma faixa. 
Tabela 15 - Tensões médias de ruptura dos ensaios com dispositivo modificado de Arcan e velocidade de $2 \mathrm{~mm} / \mathrm{min}$.

\begin{tabular}{cccccc}
\hline Condição & \multicolumn{3}{c}{ Tensão Média de Ruptura (MPa) } & Média & Desvio \\
\hline $0^{\circ}$ & 19,17 & 19,67 & 17,74 & 18,86 & 1,00 \\
$22,5^{\circ}$ & 19,18 & 19,16 & 16,66 & 18,33 & 1,45 \\
$45^{\circ}$ & 14,34 & 15,91 & 18,04 & 16,09 & 1,86 \\
$67,5^{\circ}$ & 20,70 & 21,99 & 24,74 & 22,48 & 2,06 \\
$90^{\circ}$ & 24,26 & 29,99 & 28,00 & 27,42 & 2,91 \\
\hline
\end{tabular}

Tabela 16 - Tensões médias de ruptura dos ensaios com diferentes comprimentos de sobreposição, chapas de aço com rugosidade de $16,5 \mu \mathrm{m} \mathrm{Rz}$, com jateamento (+1), e temperatura de cura de $60^{\circ} \mathrm{C}$.

\begin{tabular}{cccccc}
\hline Condição & \multicolumn{3}{c}{ Tensão Média de Ruptura (MPa) } & Média & Desvio \\
\hline $0^{\circ}$ & 19,88 & 17,74 & 19,56 & 19,06 & 1,15 \\
$22,5^{\circ}$ & 18,33 & 19,82 & 16,04 & 17,88 & 1,67 \\
$45^{\circ}$ & 15,93 & 14,97 & 17,69 & 16,20 & 1,38 \\
$67,5^{\circ}$ & 23,68 & 20,05 & 19,15 & 20,96 & 2,40 \\
$90^{\circ}$ & 31,03 & 29,53 & 24,20 & 28,25 & 3,59 \\
\hline
\end{tabular}

Os resultados experimentais foram aplicados ao Critério de Escoamento de DruckerPager (Critério de Von Mises Modificado), com o objetivo de determinar uma curva de escoamento para o adesivo. As curvas obtidas para as velocidades de $2 \mathrm{~mm} / \mathrm{min}$ e $10 \mathrm{~mm} / \mathrm{min}$, bem como os resultados de cada ensaio encontram-se plotados nas Figuras 55 e 56 respectivamente. Ao submeter os resultados resultados experimentais e o modelo proposto à uma análise de variação, observou que:

- O modelo obtido, utilizando as médias das tensões médias de ruptura com velocidade de deslocamento de $2 \mathrm{~mm} / \mathrm{min}$, explica no melhor caso $94,45 \%$ da variação nos resultados experimentais. Ou seja, a variação causada na tensão média de ruptura em função da alteração do ângulo de carregamento.

- Para a velocidade de deslocamento de $10 \mathrm{~mm} / \mathrm{min}$, aplicando os maiores valores de tensões médias de rupturas obtidas no modelo, a análise de variância mostrou que $86,31 \%$ da variação causada na tensão média de ruptura foi influenciada pela variação no ângulo de carregamento, sendo esta a condição com menor relação entre as variações. 


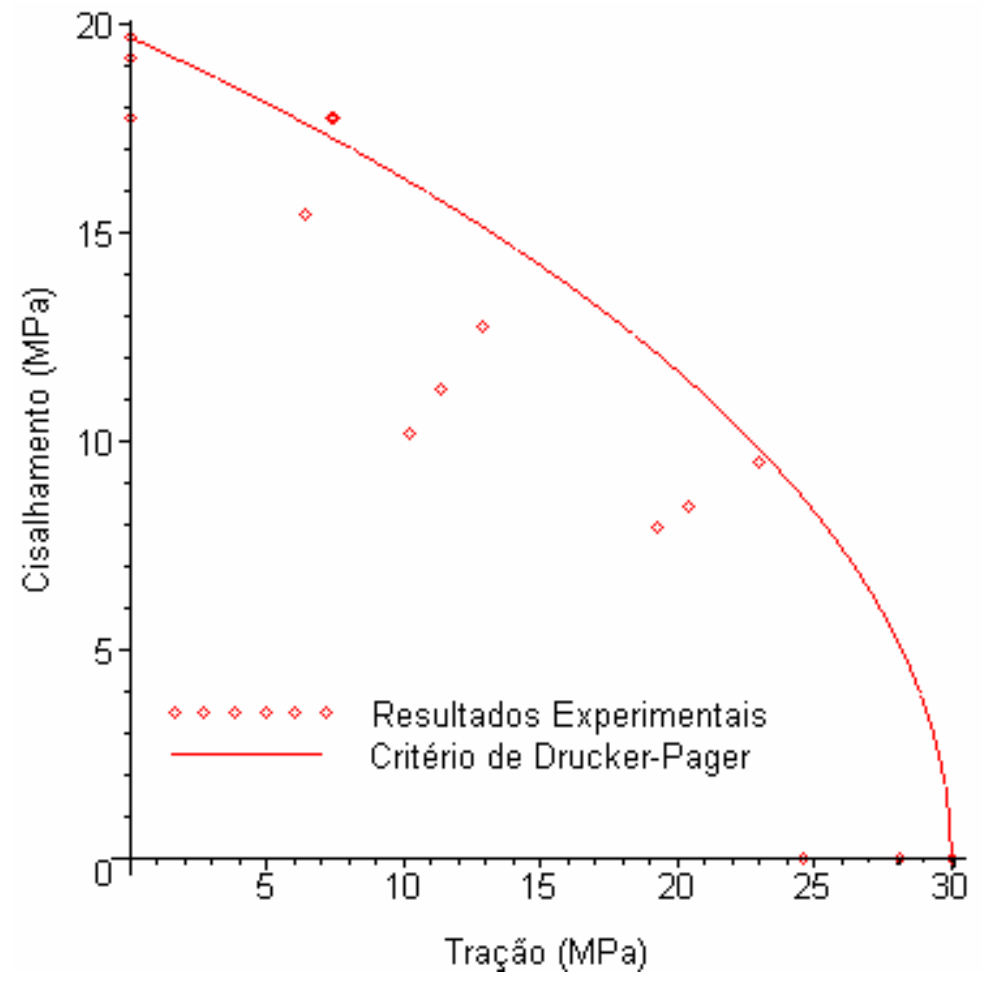

Figura 55 -Drucker-Pager $x$ Resultados experimentais $-2 \mathrm{~mm} / \mathrm{min}$.

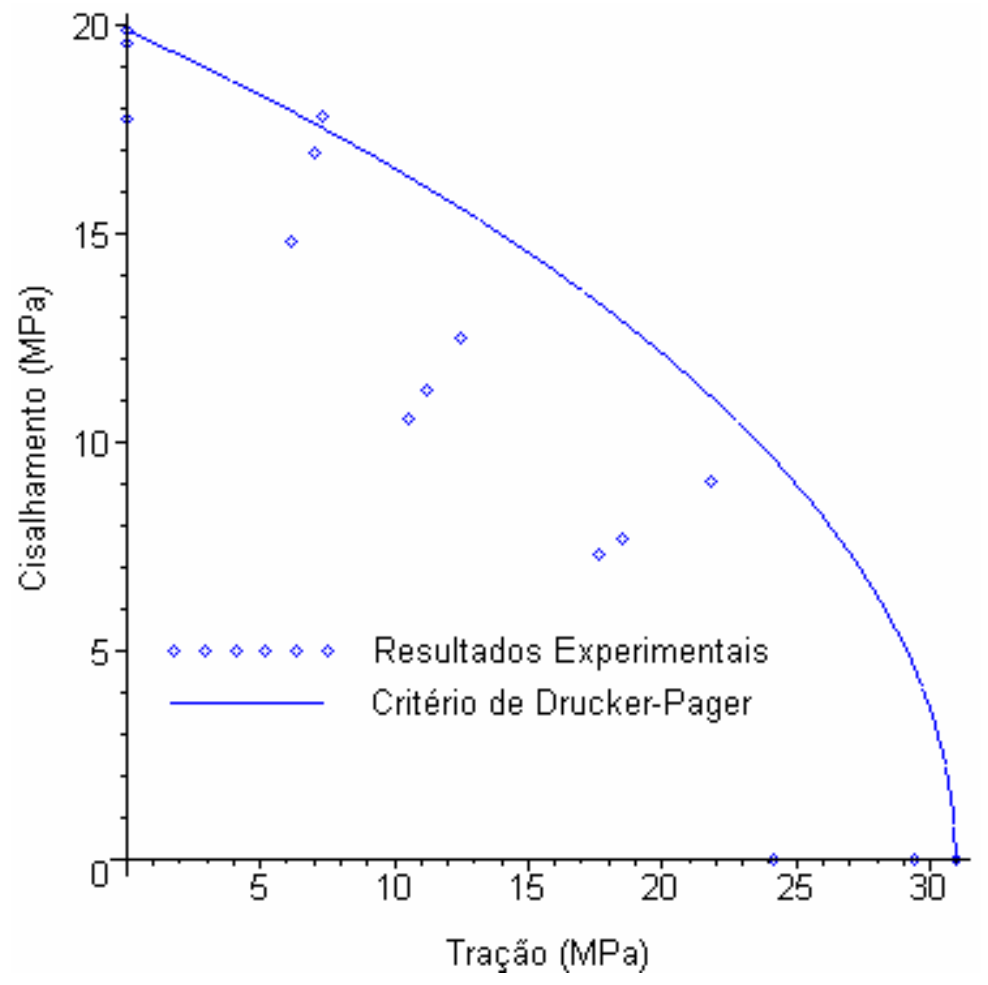

Figura 56 -Drucker-Pager x Resultados experimentais $-10 \mathrm{~mm} / \mathrm{min}$. 


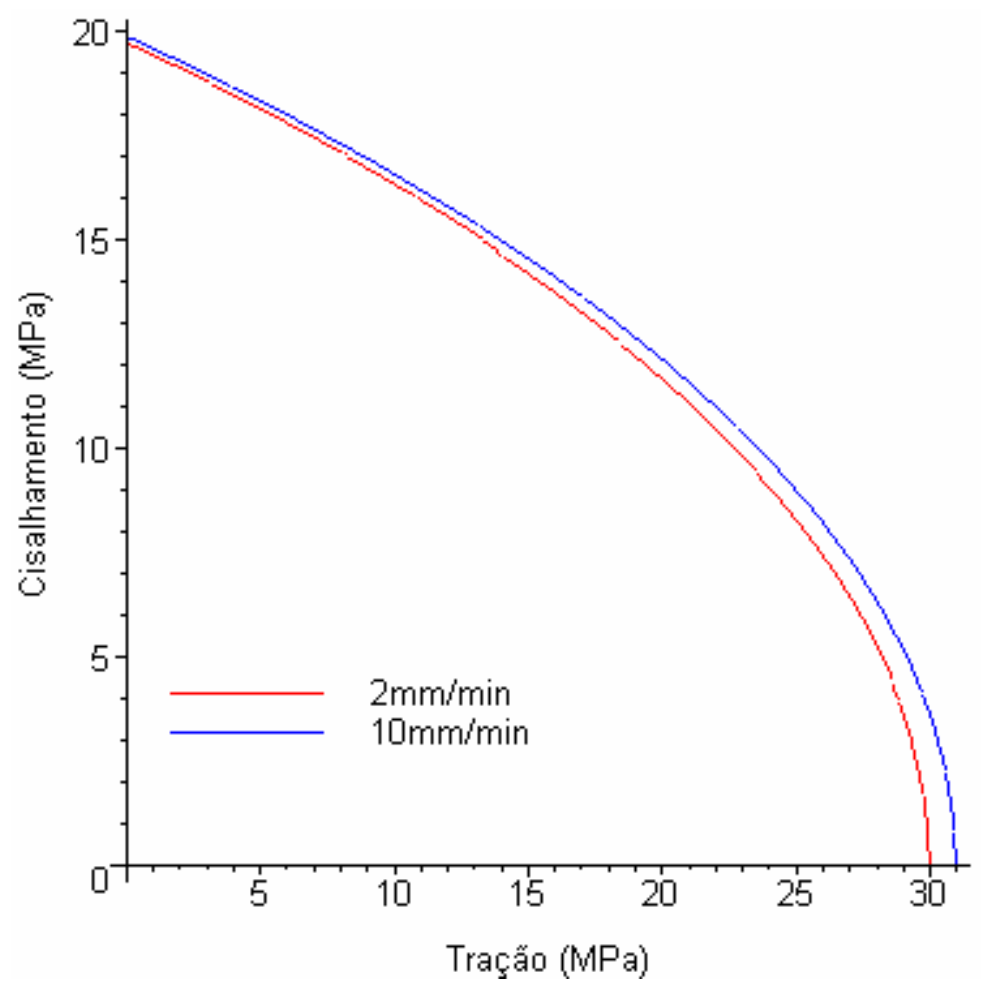

Figura 57 - Comparativo entre curvas obtidas através do Critério de Escoamento de Drucker-Pager.

Ambas apresentam comportamento similar, tendo como principal diferença uma leve variação das resistências máximas nos eixos de cisalhamento e tração. Isto se deve ao fato da equação para determinar a curva utilizar os valores máximos obtidos nos ensaios. Como os ensaios à $10 \mathrm{~mm} / \mathrm{min}$ apresentaram resultados individuais levemente superiores, estes possuem valores levemente maiores nos eixos.

Os resultados experimentais se aproximaram bastante dos teóricos, com maior desvio apresentado pelos resultados obtidos à $45^{\circ}$, os quais ficarem abaixo do teórico nas duas velocidades.

\subsubsection{Discussão de Resultados}

Os ensaios com dispositivo modificado de Arcan forneceram resultados importantes para aplicação em projetos e planejamento de experimentos. Inicialmente, a baixa rigidez dos corpos de prova de Lee (1998) gerou, além de pré-tensões nos substratos, esforços indesejados de clivagem. Tais esforços impossibilitaram a 
realização dos ensaios com este tipo de substrato, criando a necessidade da utilização de corpos de prova específicos.

Corpos de prova trapezoidais apresentaram maior rigidez e tornaram possível a realização dos experimentos com dispositivo modificado de Arcan. Dos cinco ângulos ensaiados, a maior resistência foi apresentada em condições de tração pura $\left(90^{\circ}\right)$, seguida pela condição de aplicação com ângulo de 67,5. As junções apresentaram maior sensibilidade, conseqüentemente menor resistência, aos esforços aplicados à $45^{\circ}$, condições que suportou as menores forças nas duas condições de velocidade de tração ensaiadas. Isto mostra a necessidade da realização de ensaios com esforços combinados, pois esforços unidirecionais não detectariam tal variação.

As duas diferentes velocidades de tracionamento ensaiadas, $2 \mathrm{~mm} / \mathrm{min}$ e $10 \mathrm{~mm} / \mathrm{min}$, apresentaram resultados experimentos muito próximos. Sendo que a condição de maior velocidade apresentou leve aumento de resistência nas condições com esforços unidirecionais. As demais condições oscilaram, em alguns casos a maior velocidade apresentou maior resistência, sendo que em outros casos apresentou menor resistência.

O Critério de Escoamento de Drucker-Pager utilizou os maiores resultados obtidos em ensaios de tração e cisalhamento puros, por isso a curva obtida para a maior velocidade apresentou resultados superiores em toda sua extensão. Caso o valor médio das tensões médias de ruptura tivesse sido utilizado, a diferença entre as curvas seria ainda menor.

Com maior desvio apresentado nos ensaios à $45^{\circ}$, os resultados experimentais se aproximaram da curva teórica proposta pelo Critério de Drucker-Pager. Este critério pode ser aplicado à condições onde existem esforços de compressão, como por exemplo, junções adesivas utilizadas para vedação de flanges. Kreuzer \& Romanos apresentaram trabalho aplicando tal modelo à adesivos aplicados para vedação de câmbios. 


\subsection{LIMITAÇÕES DO ESTUDO}

Devido aos diversos fatores que interferem na resistência de junções adesivas, ainda hoje é praticamente impossível determinar um modelo matemático universal, bem como uma base de pesquisa aplicável à todos os tipos de adesivos e condições de aplicação.

Desta forma este estudo também possui suas limitações:

- $\quad$ Os Modelos de Volkersen e de Reissner \& Goland (Tsai et. al., 1997) tratam o filme de adesivo como material rígido, condição válida somente para região abaixo da $\mathrm{Tg}$ do adesivo. Os ensaios deste estudo foram realizados nesta região, porém estes modelos não são válidos para regiões acima da temperatura de transição vítrea (Tg). Para tais regiões outros modelos devem ser analisados, os quais tratam os adesivos como fluidos de altíssima viscosidade.

- $\quad$ Os corpos de prova não forma testados com extensômetros individuais, desta forma foi medido o deslocamento do cabeçote da máquina e não do filme de adesivo. O extensômetro utilizado foi do cabeçote de fixação do equipamento utilizado.

- Não existem normas para a realização de ensaios com dispositivos modificados de Arcan. 


\section{CONCLUSÕES}

A realização deste estudo evidencia a importância da preparação dos corpos de prova na resistência mecânica de junções adesivas. Tornando possível verificar e concluir que rebarbas, sujidades e outros tipos de contaminação comprometem a resistência de tais junções.

Fatores referentes à superfície onde o adesivo é aplicado, ao método e às condições de cura do adesivo, alteram de forma significativa a resistência das junções. Dentre os quatro fatores analisados, aqueles relacionados à cura do adesivo são os mais influentes na resistência. $O$ uso de ativador em superfície de aço atua de forma negativa, reduzindo a resistência. A temperatura é o segundo fator mais influente, atuando de forma positiva, aumentando a resistência. Os fatores de superfície alteram de forma significativa, porém reduzida, a resistência mecânica de junções. A nanocerâmica apresenta leve redução na resistência das junções, ao contrário do que acontece quando à na preparação de superfícies a serem pintadas.

A geometria da junção é de extrema importância para sua resistência. $O$ aumento do comprimento de sobreposição causou redução da resistência da mesma devido à distribuição de tensões. As extremidades assumem valores de tensão elevados, gerando ruptura inicial nas extremidades e baixa tensão média de ruptura para longos comprimentos de sobreposição.

Os Modelos de Volkersen e de Reissner \& Goland modificados apresentam resultados próximos, quando aplicados nas mesmas condições. Indicando precisão de ambos modelos. A aplicação destes modelos evidenciou a influência da deformação do substrato na distribuição das tensões ao longo do filme de adesivos. Ao considerar a deformação dos substratos ambos os modelos mostraram resultados mais próximos da realidade, com distribuição de tensão constante próxima a região central. Ao negligenciar a deformação dos substratos, os modelos mostram tensões baixíssimas na região central.

Camadas superfícies, como óxidos, interferem diretamente na resistência de junções adesivas. Estas podem desplacar antes da ruptura do filme de adesivo, causando redução da resistência. Para longos comprimentos de sobreposição o desplacamento da camada tende a ocorrer nas extremidades, regiões de alta concentração de tensão. 
A rigidez dos corpos de prova é de extrema importância para junções adesivas, corpos de prova utilizados para análise de soldas, como os baseados em Lee, não podem ser utilizados para ensaios com esforços combinados de junções adesivas. Corpos de prova trapezoidais (borboleta) oferecem boas condições para estes tipos de ensaios.

Os ensaios com dispositivo modificado de Arcan mostraram que as cargas se tornam críticas quando aplicadas próximo ao ângulo de $45^{\circ}$. Sendo que as junções adesivas oferecem maior resistência ao esforço de tração $90^{\circ}$. A alteração da velocidade de tracionamento não alterou de forma significativa a resistência da junção. Os resultados experimentais se aproximaram do Critério de Falha de Drucker-Pager, indicando a aplicação deste como critério de falha de junções adesivas.

Projetos envolvendo junções adesivas devem levar em consideração diversos fatores. Devem ser consideradas desde a geometria da junção, condições de superfície dos substratos, condições de cura do adesivo e tipos de esforços aplicados. 


\section{TRABALHOS FUTUROS}

- Modelagem da resistência mecânica de junções adesivas após serem submetidas à processos de envelhecimento.

- Comparativo entre tecnologias de adesivos utilizadas na vedação de caixas de transmissão, bem como determinação de fatores de influência na resistência da vedação para cada tecnologia.

- Análise dos tipos de reações ocorridas na interface entre adesivo e substrato, apresentando fatores influentes para cada tipo de reação.

- Estudo da fadiga de filmes adesivos e comportamento dos mesmos quando submetidos à carregamentos dinâmicos. 


\section{REFERÊNCIAS BIBLIOGRÁFICAS}

Andrade, G. - Comunicação pessoal, 2007.

AMERICAN SOCIETY FOR TESTING MATERIALS. ASTM D 1002 - 05: Standard Test Method for Apparent Shear Strength of Single-Lap-Joint Adhesively Bonded Metal Specimens by Tension Loads (Metal to Metal). USA, 2005.

Brinson, H. F. - Engineered Materials Handbook - Adhesives and Sealants. ASM International, USA 1990.

Broughton, B. \& Gower, M. - Preparation and test of adhesive joints - National Physical Laboratory, UK, ISSN1368 6550, set. 2001.

Canevarolo, J. S. - Ciência dos Polímeros. Artliber, São Paulo, 2001. 280 p

Carlac, D. \& Hemery, Y. - Le collage en France: un atout pour l'assemblage industriel - Ministère de L'Économie des Finances et de L'Industrie. France, 2003. $107 \mathrm{p}$.

Chao, J. - Ultimate strength and failure mechanism of resistance spots weld subjected to tension, shear or combined tension/shear loads - Journal Department of Mechanical Engineering, v. 125, p. 125-132. April, 2003.

Cognard, J.Y..; Davies, P.; Gineste, B. \& Sohier, L. - Development of an improved adhesive test method for composite assembly design - Composite Science and Technology, França, v.65, p. 359-368, mar. 2005.

Duncan, B. - The hyperelastic properties of polyurethane adhesive - National Physical Laboratory, UK, ISSN1368 4061, mai. 2001.

Henkel Ltd. - Nanoceramic Technology Bonderite NT1: Global Launch Manual Alemanha, jun, 2006. 
Kavamura, A. - Aplicação de solda laser na construção de carrocerias para veículos auotmotivos; estudo de caso para verificação de viabilidade no uso de solda laser em assoalho no Brasil - Dissertação de Mestrado; USP-POLI DEM. Brasil, 2007.

Kreuzer, R. \& Romanos, G. - Formed-in-place gaskets in powertrain applications - experimental and numerical evaluations under service conditions - SAE International. USA, October, 2006-01-3353.

Langrand, B. \& Combescure, A. - Non-linear behaviour of spotwelds: a "global" finite element and experiments in pure and mixed modes I/II - Department of Solid and Damages Mechanics, INSA-Lyon. France, 2004).

Lee, Y.; Wehner, T.; Lu, M.; Morrissett, T. \& Pakalnins, E. - Ultimate strength of resistance spots weld subjected to combined tension and shear - Journal of Testing and Evaluation, JTEVA, v. 26, p. 213-219. May, 1998.

Loctite Handbook - Second Edition - Loctite, 1995. 451p.

Lucic, M.; Stoic, A. \& Kopac, J. - Investigation of aluminum single lap adhesively bonded joints - Journal of Achievements in Materials and Manufacturing Engineering, v. 15, p. 79-87. Polônia, 2006.

Mendes, N. - Contribuição ao desenvolvimento de projeto de carrocerias automotivas utilizando adesivo estrutural para junção de chapas metálicas Dissertação de Mestrado; USP-POLI-DEM. Brasil, 2005.

Metals Handbook- Ninth Edition - Mechanical Testing, ASM International, USA, v.8, 1985. 778p.

Neto, B.; Scarminio, I. \& Bruns, R. - Como Fazer Experimentos: pesquisa e desenvolvimento na ciência e na indústria - Campinas: Editora UNICAMP. 2003. $401 \mathrm{p}$. 
Oliveira, O. \& Fernandes, J. - Arquitetura Atómica e Molecular - Natal: EDUFRN Editora da UFRN, 2006. 280p.

Possat, W. - Comunicação pessoal, 2006.

Possart, W. - Vorlesung "Klebstoffe \& Klebtechnoogie" - Saarland Universitaet, 2006.

Takiguchi, M.; Izumi, S. \& Yoshida, F. - Rate-dependent shear deformation of ductile acrylic adhesive and its constitutive modelling - Journal Mechanical Engineering Science, v. 218, p. 623-629. Japan, 2004.

Tsai, M.; Oplinger, D. \& Morton, J. - Improved Theoretical Solution for Adhesive Lap Joints - International Journal Solids Structures, v. 35, n. 12, p. 1163-1185. Reini Unido, 1997.

Villenave, J. - Assemblage par collage - Paris: DUNOD, 2005. 319 p.

Wiebeck, Hélio. \& Harada, J. - Plásticos de Engenharia - São Paulo: Editora Artiliber. 2005. $350 \mathrm{p}$.

Will, R.; Kaelin, T. \& Kishi, A. - Adhesives and Sealants - Specialty Chemicals SRI International, p. 57-73. 2003.

Zoran K.; Kralj, D. S.; Zagred, D. N. S. \& Dorn, L. et al. - Mathematical model for calculating the strength of a single lap adhesive joint - Schweissen und Schneiden, Alemanha, v.2, p. 32-37, fev. 2001.

AIMPLAS Instituto Tecnológico del Plástico - State of Art Report 3: Advanced Materials, Valencia Parc Tecnologic, Espanha. Disponível em:

<http://www.eurovipp.com/opencms/export/euroVIPP/bin/TWR V1 Advancedmateri Is.pdf $>$. Acesso em 23 fevereiro /2007. 
EUROPEAN COMMUNITY \& STEINBEIS EUROPA ZENTRUM 6TH Framework Programme: Overview on Promissing Nanomaterials for Industrail Applications. In: Nanomaterial Roadmap 2015. Development of Avanced Technologies Roadmaps to Small and Medium sized Enterprises (NanoroadSME). Disponível em:

$<$ http://www.nanoroad.net/download/overview nanomaterials.pdf $>$. Acesso em 23 fevereiro /2007. 
APÊNDICE A - RESULTADOS EXPERIMENTAIS

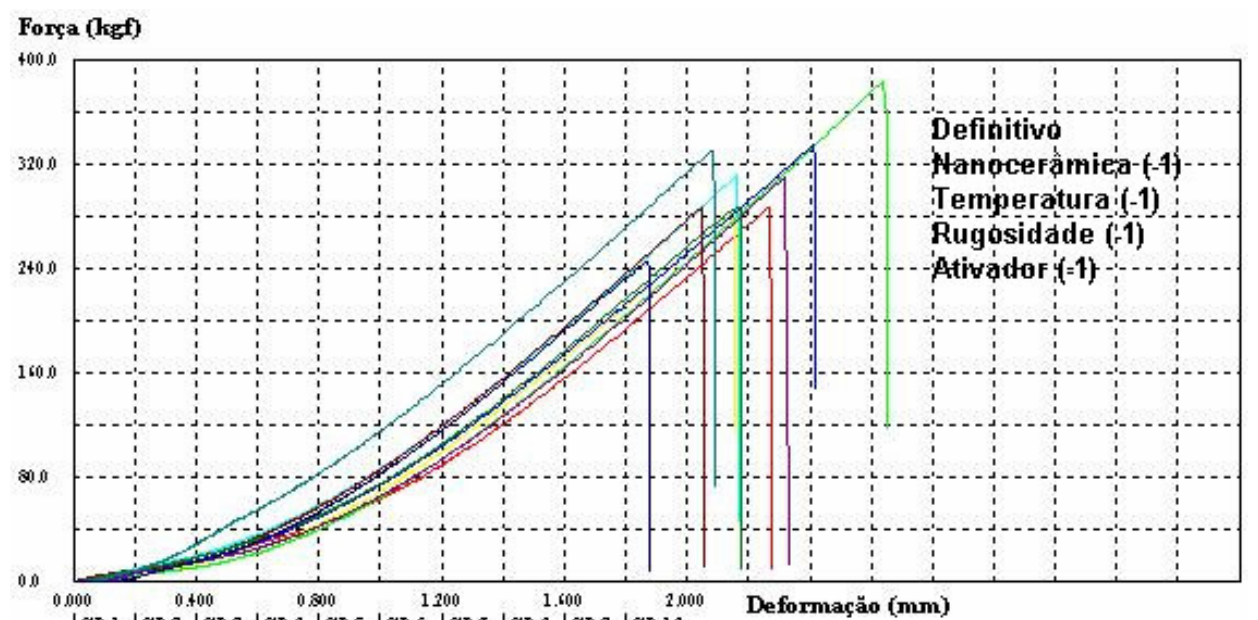

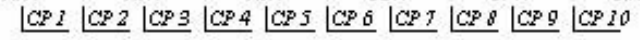

Método I - 10 réplicas $A(-1), B(-1), C(-1)$ e $D(-1)$.

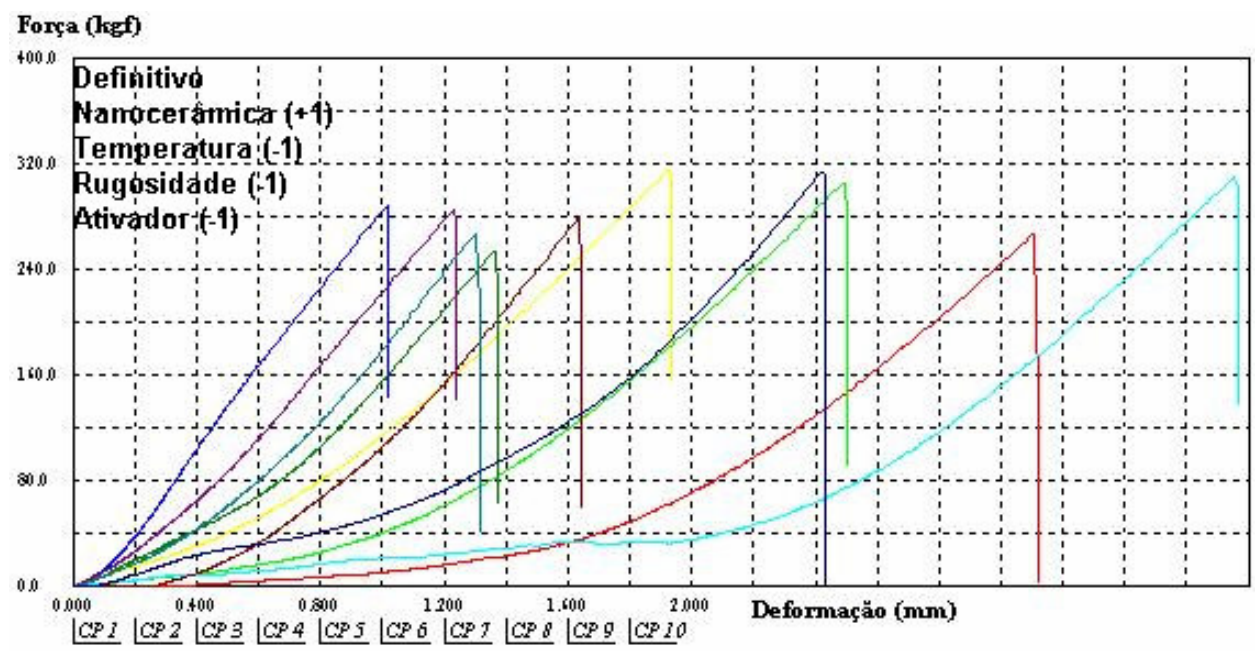

Método I - 10 réplicas $A(+1), B(-1), C(-1)$ e $D(-1)$. 


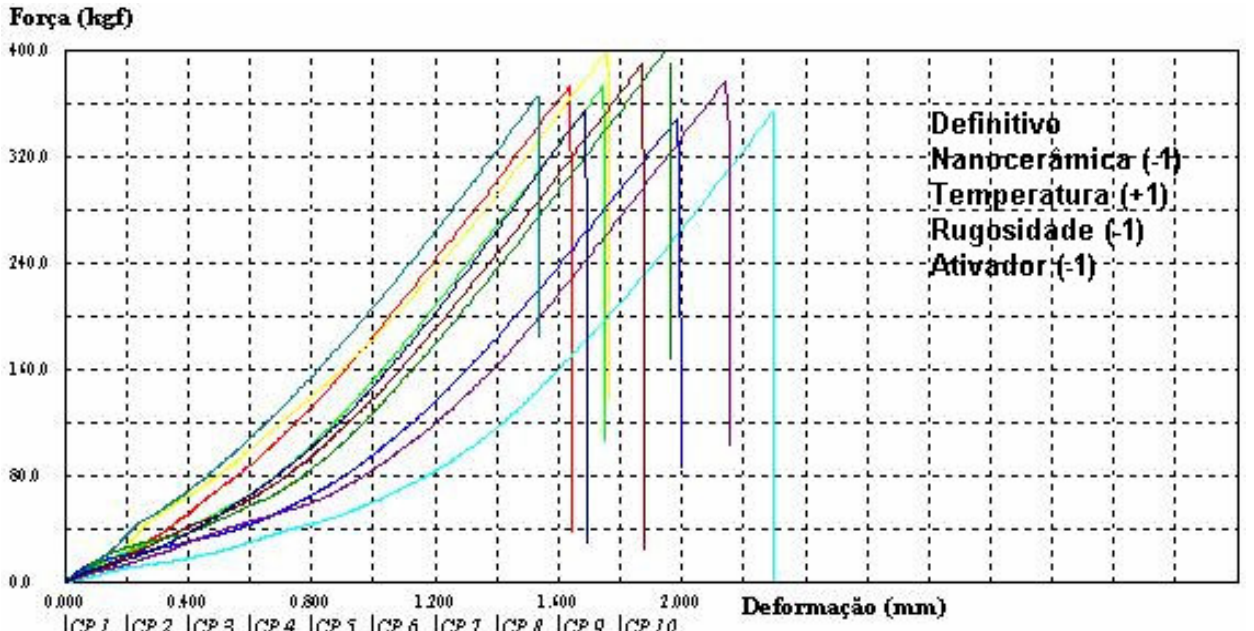

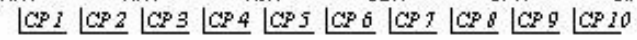

Método I - 10 réplicas $A(-1), B(+1), C(-1)$ e $D(-1)$.

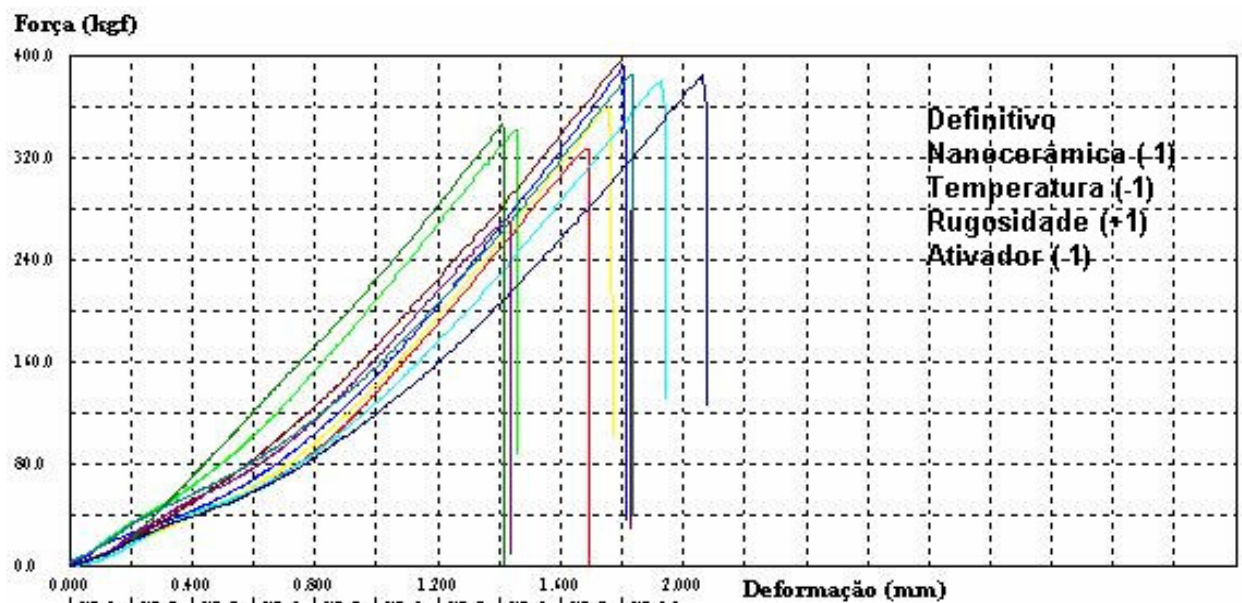

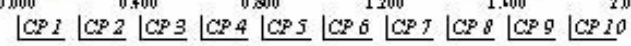

Método I - 10 réplicas $A(-1), B(-1), C(+1)$ e $D(-1)$.

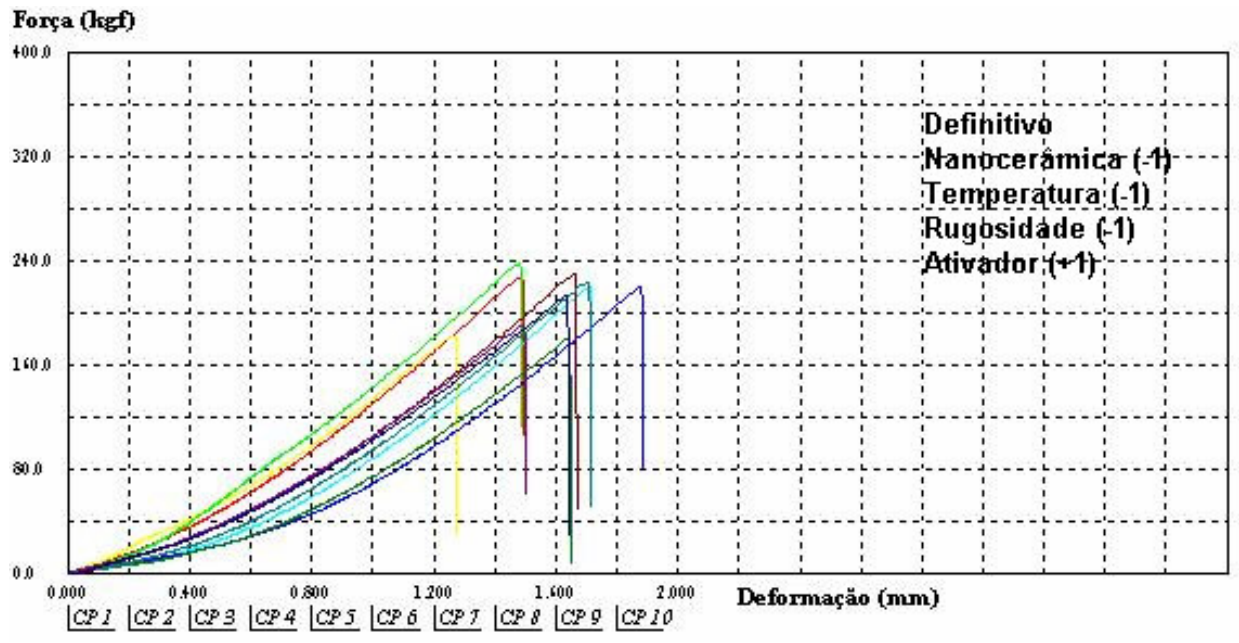

Método I - 10 réplicas $A(-1), B(-1), C(-1)$ e $D(+1)$. 


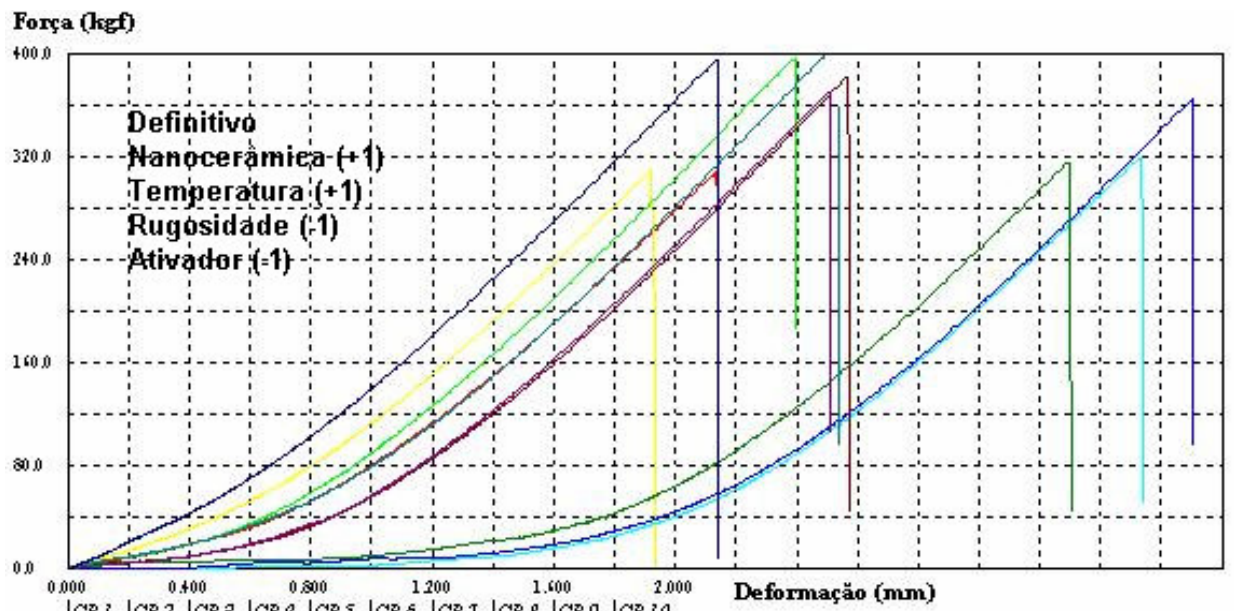

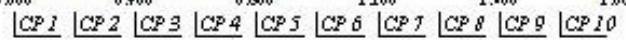

Método I - 10 réplicas $A(+1), B(+1), C(-1)$ e $D(-1)$.

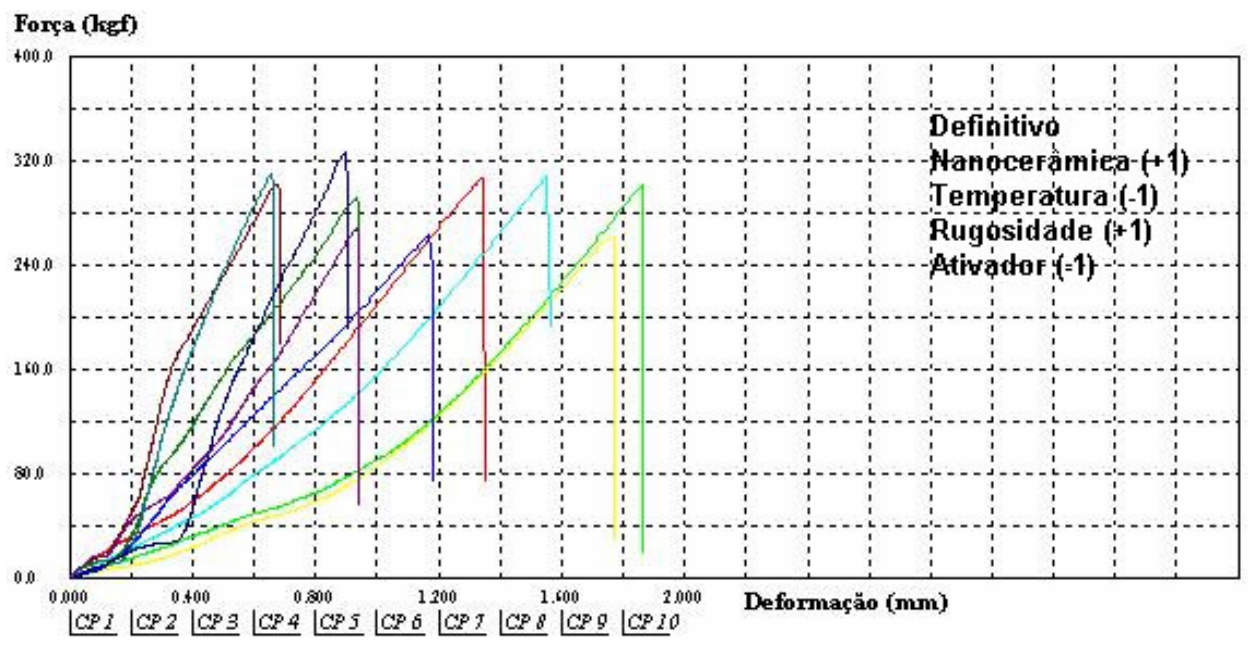

Método I - 10 réplicas $A(+1), B(-1), C(+1)$ e $D(-1)$.

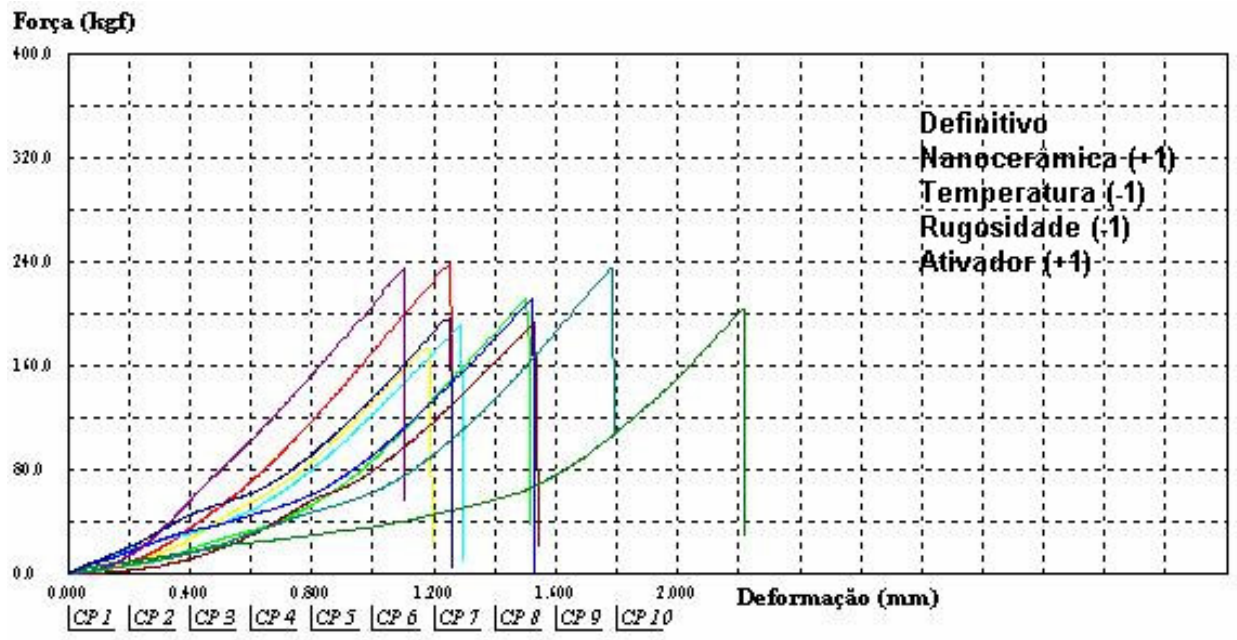

Método I - 10 réplicas $A(+1), B(-1), C(-1)$ e $D(+1)$. 


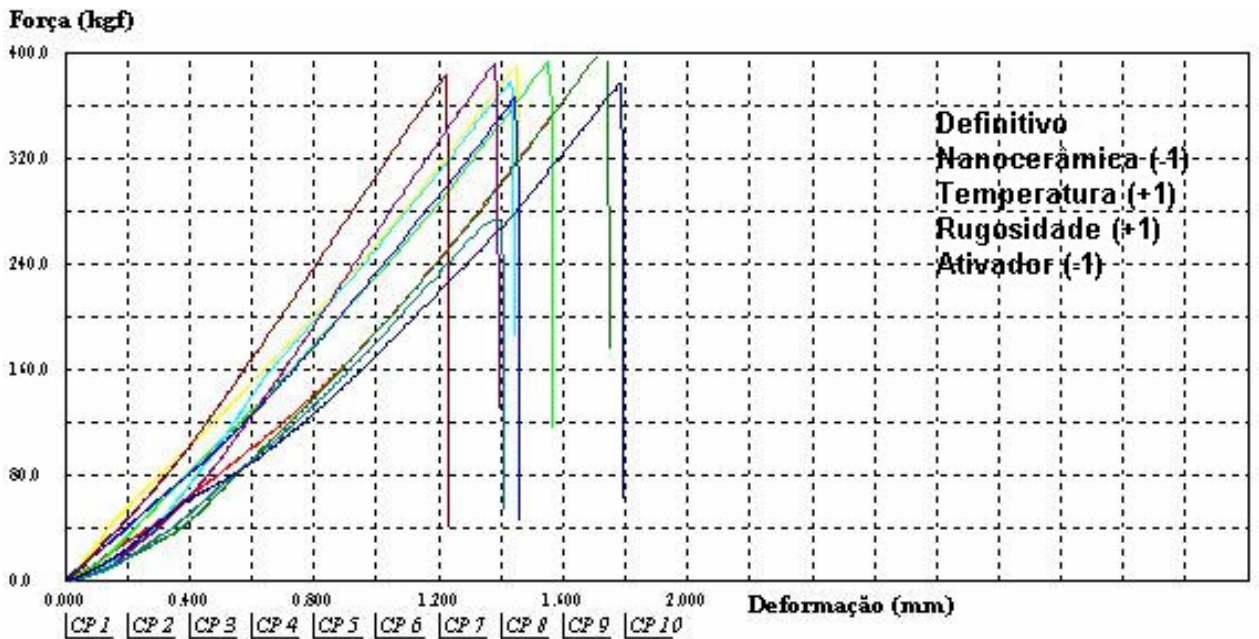

Método I - 10 réplicas $A(-1), B(+1), C(+1)$ e $D(-1)$.

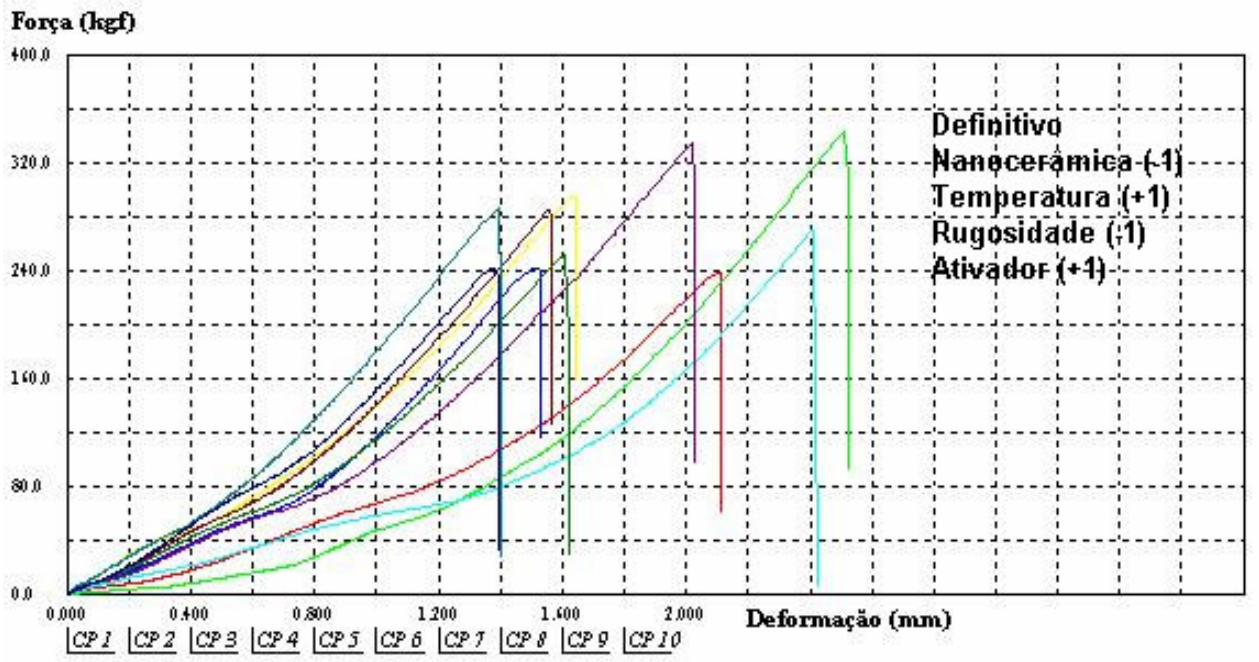

Método I - 10 réplicas $A(-1), B(+1), C(-1)$ e $D(+1)$.

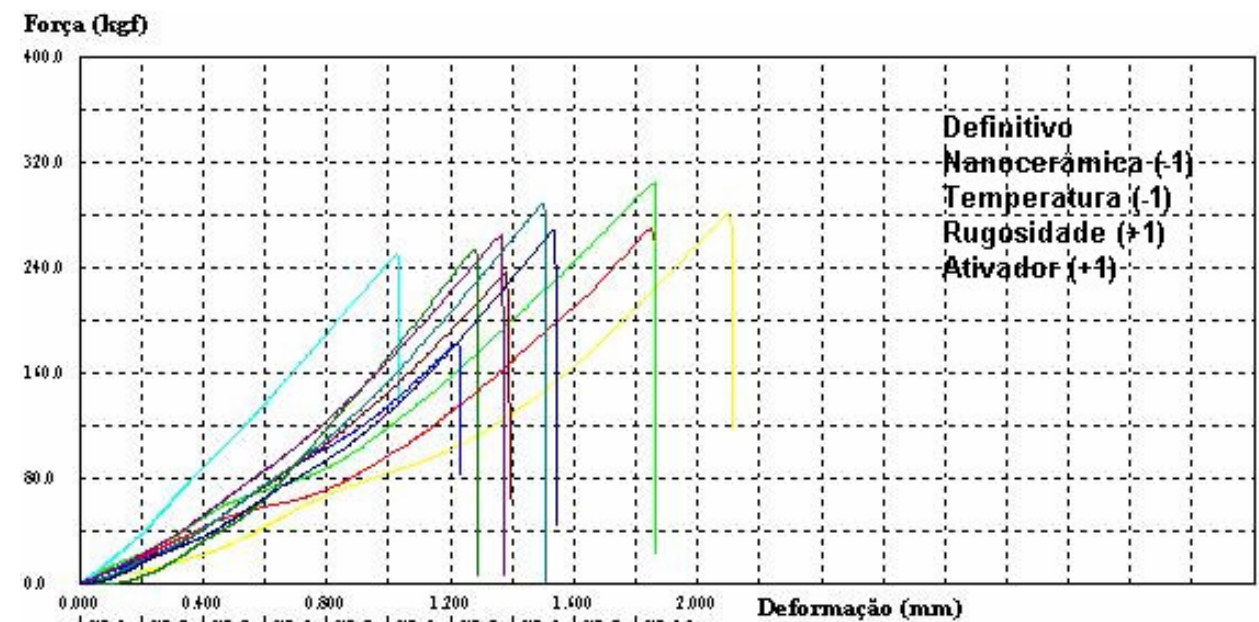

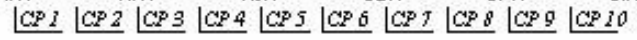

Método $\mathrm{I}-10$ réplicas $\mathrm{A}(-1), \mathrm{B}(-1), \mathrm{C}(+1)$ e $\mathrm{D}(+1)$. 


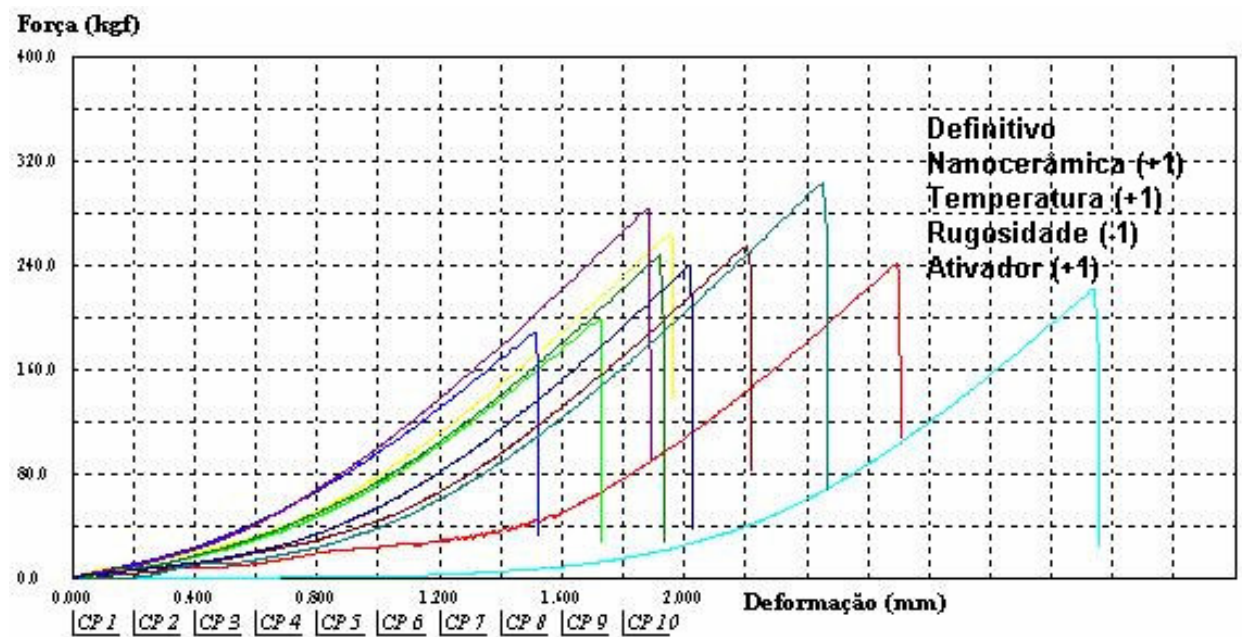

Método I - 10 réplicas $A(+1), B(+1), C(-1)$ e $D(+1)$.

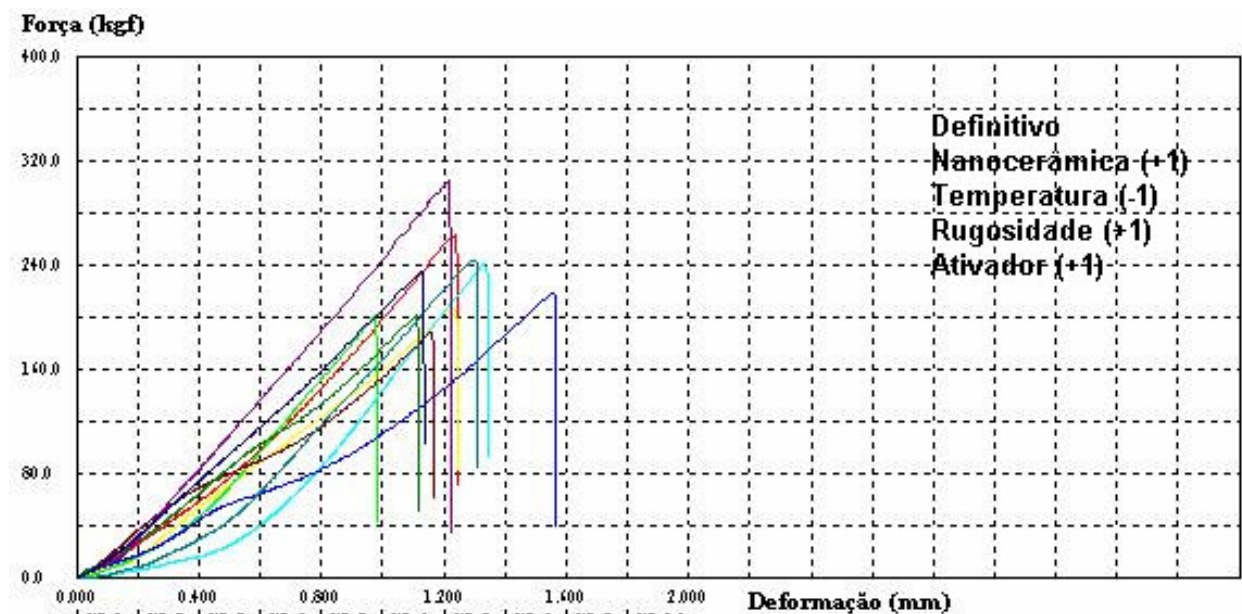

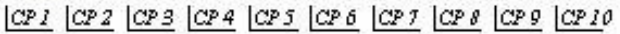

Método I -10 réplicas $A(+1), B(-1), C(+1)$ e $D(+1)$.

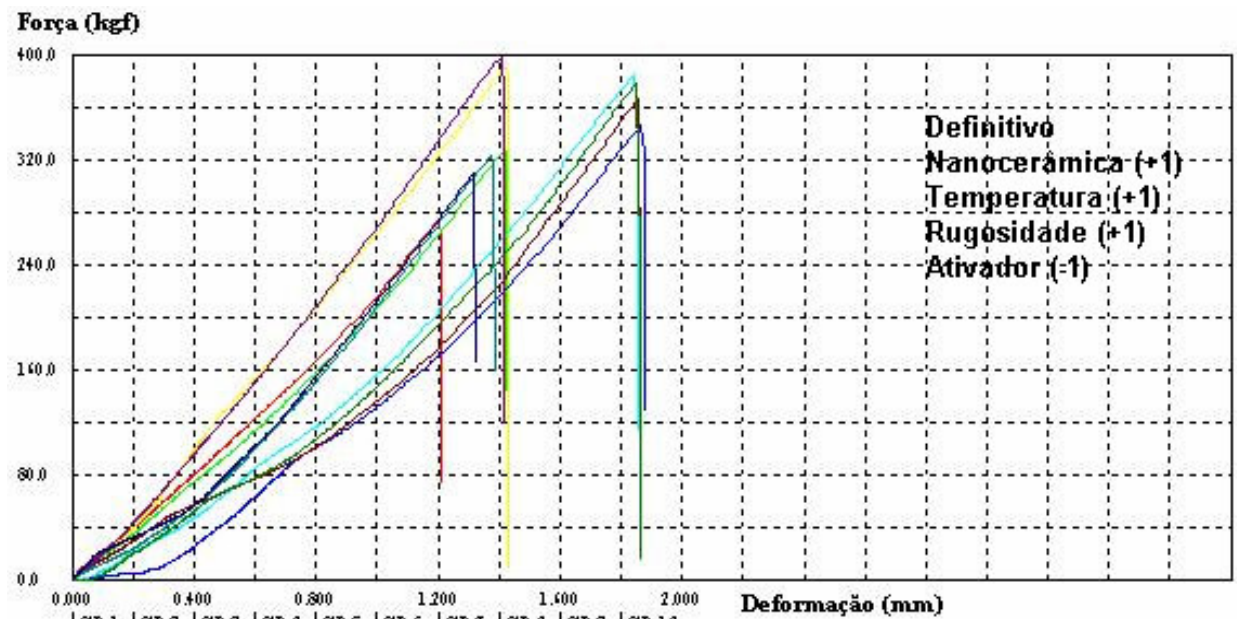

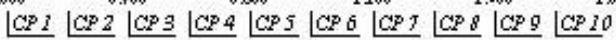

Método I - 10 réplicas $A(+1), B(+1), C(+1)$ e $D(-1)$. 


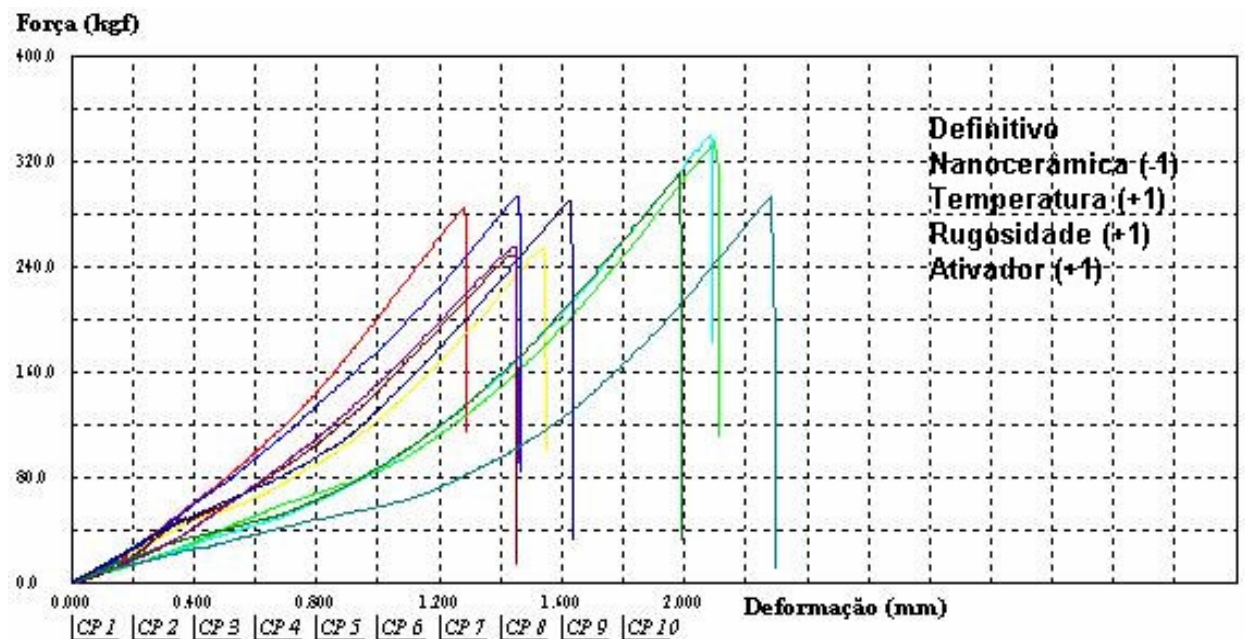

Método I - 10 réplicas $A(-1), B(+1), C(+1)$ e $D(+1)$.

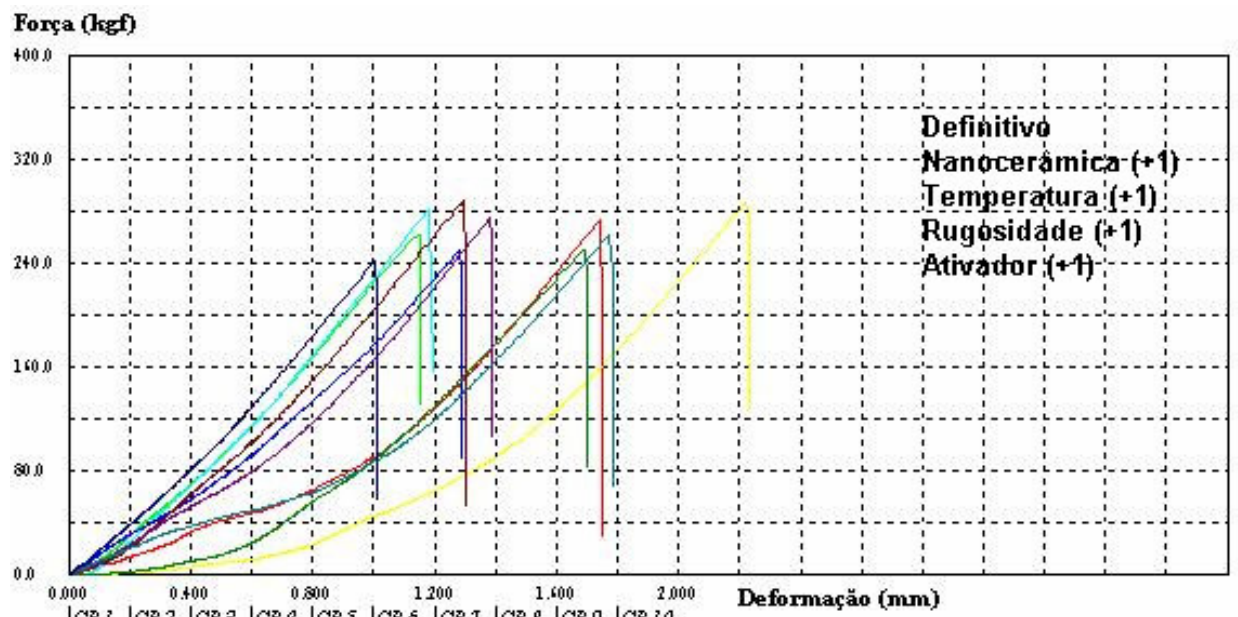

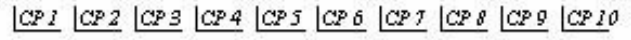

Método I - 10 réplicas $A(+1), B(+1), C(+1)$ e $D(+1)$.

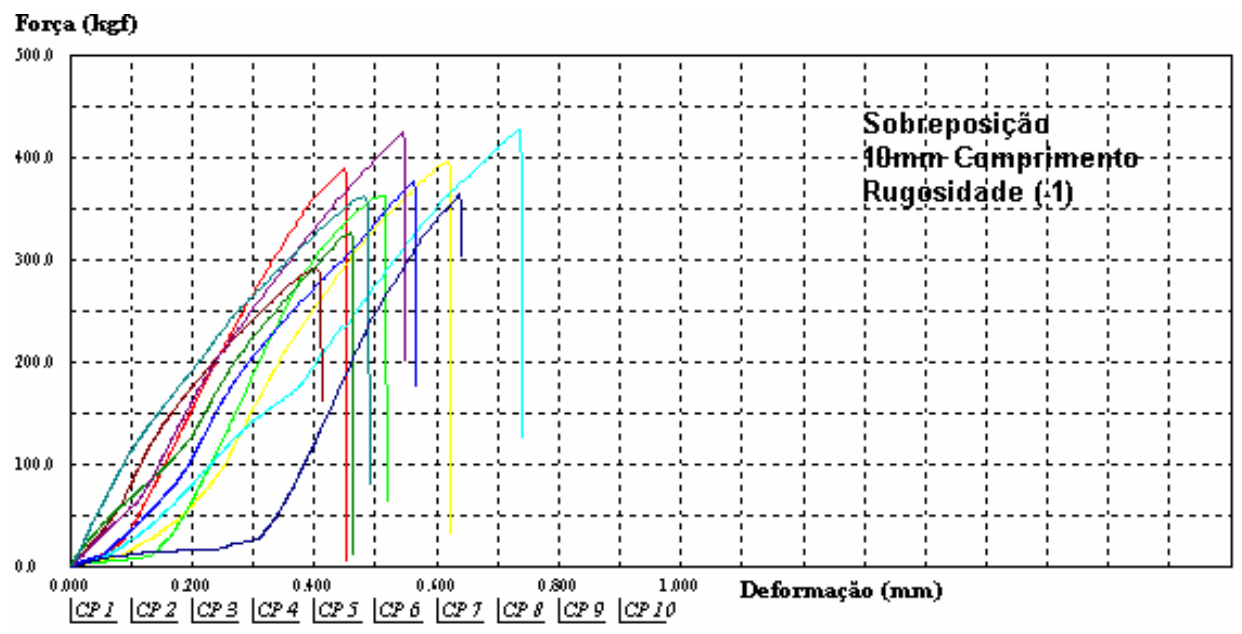

Método II - 10 réplicas, $10 \mathrm{~mm}$ de sobreposição e $\mathrm{A}(-1), \mathrm{B}(-1), \mathrm{C}(-1)$ e $\mathrm{D}(-1)$. 


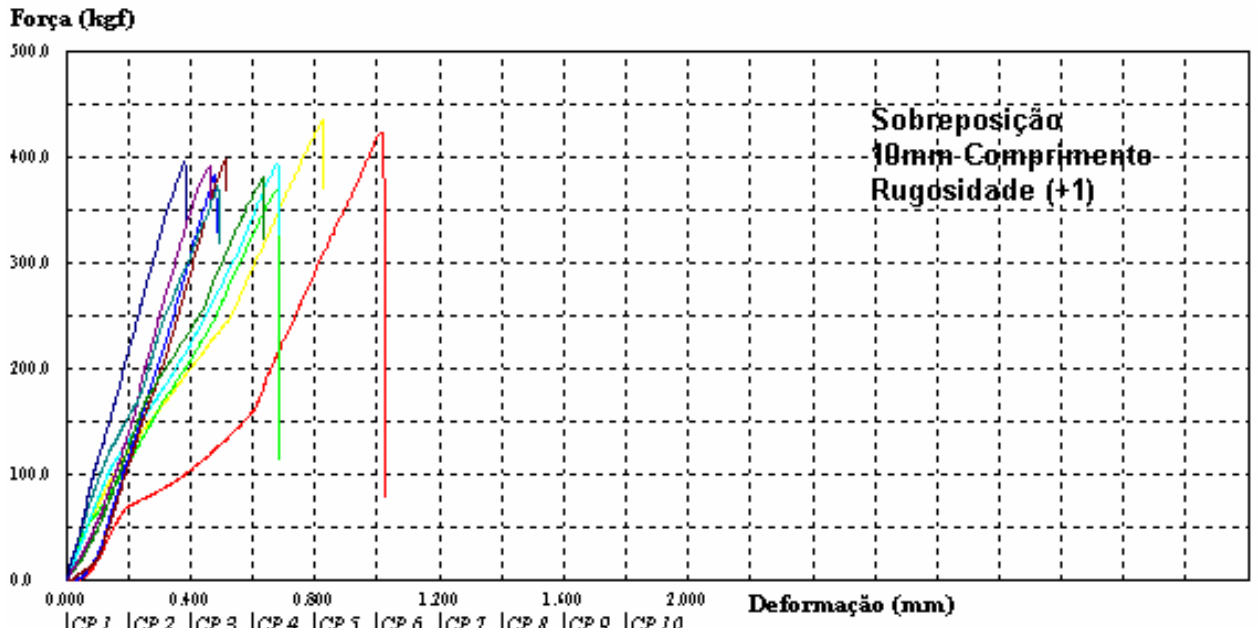

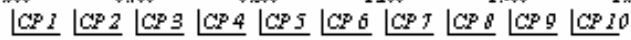

Método II -10 réplicas, $10 \mathrm{~mm}$ de sobreposição e $A(-1), B(-1), C(+1)$ e $D(-1)$.

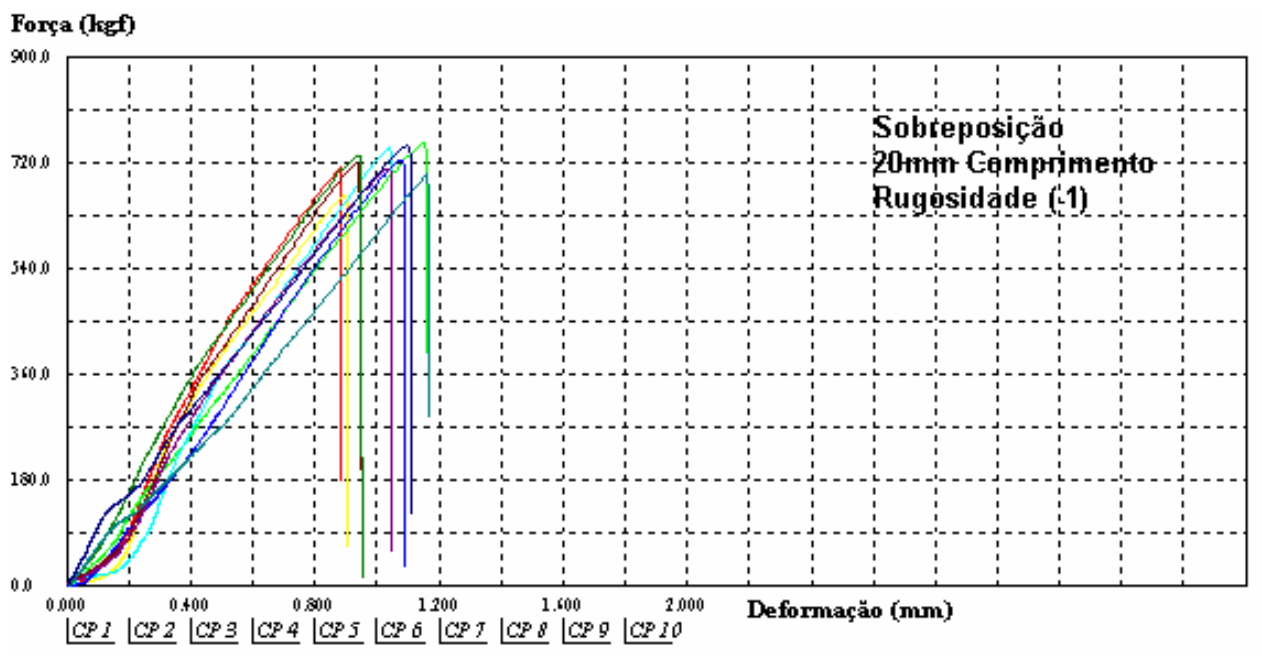

Método $\|-10$ réplicas, $20 \mathrm{~mm}$ de sobreposição e $A(-1), B(-1), C(-1)$ e $D(-1)$.

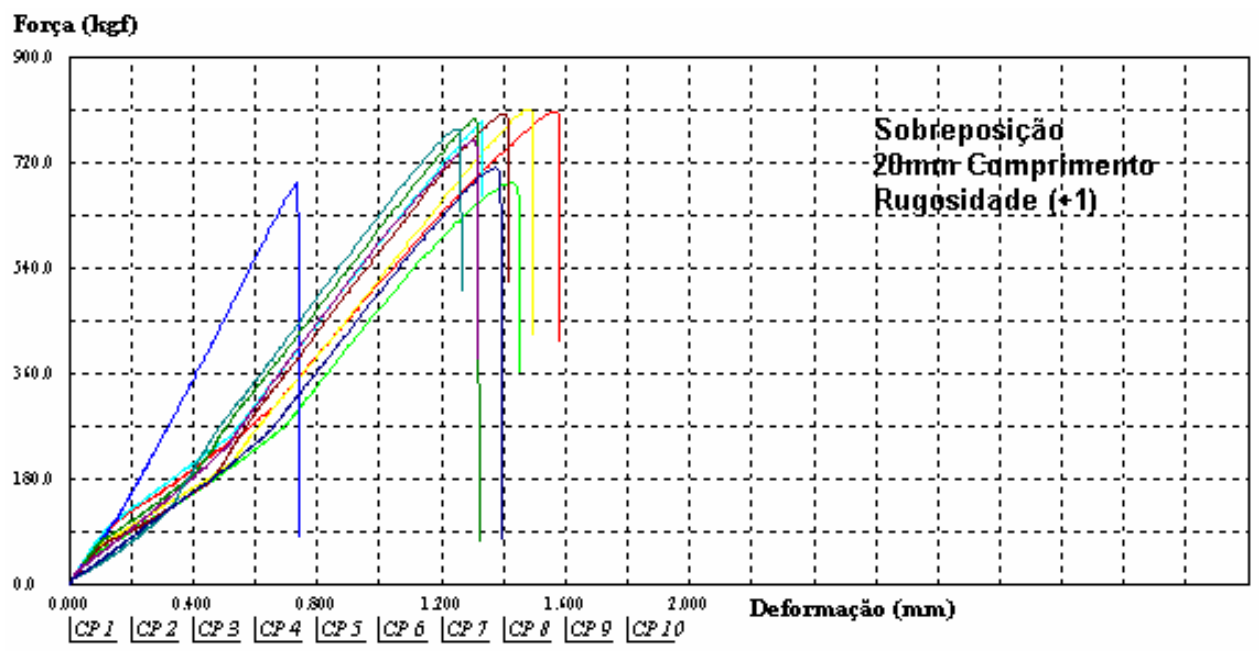

Método II - 10 réplicas, 20mm de sobreposição e $A(-1), B(-1), C(+1)$ e $D(-1)$. 


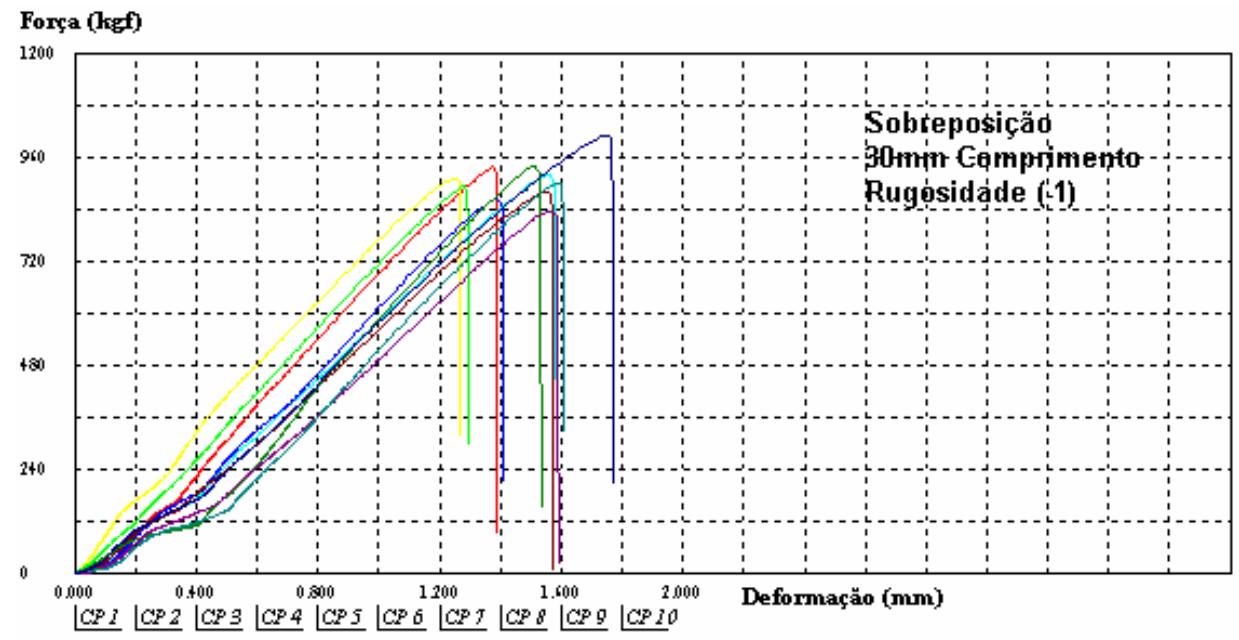

Método $\|-10$ réplicas, $30 \mathrm{~mm}$ de sobreposição e $A(-1), B(-1), C(-1)$ e $D(-1)$.

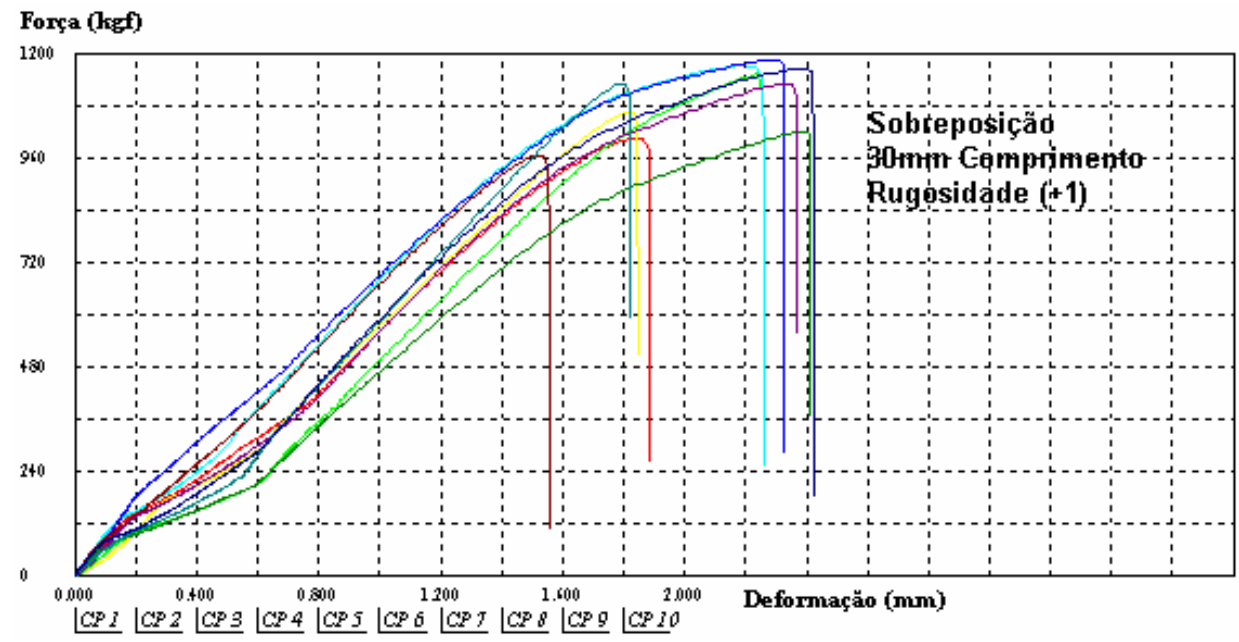

Método II -10 réplicas, 30mm de sobreposição e $A(-1), B(-1), C(+1)$ e $D(-1)$.

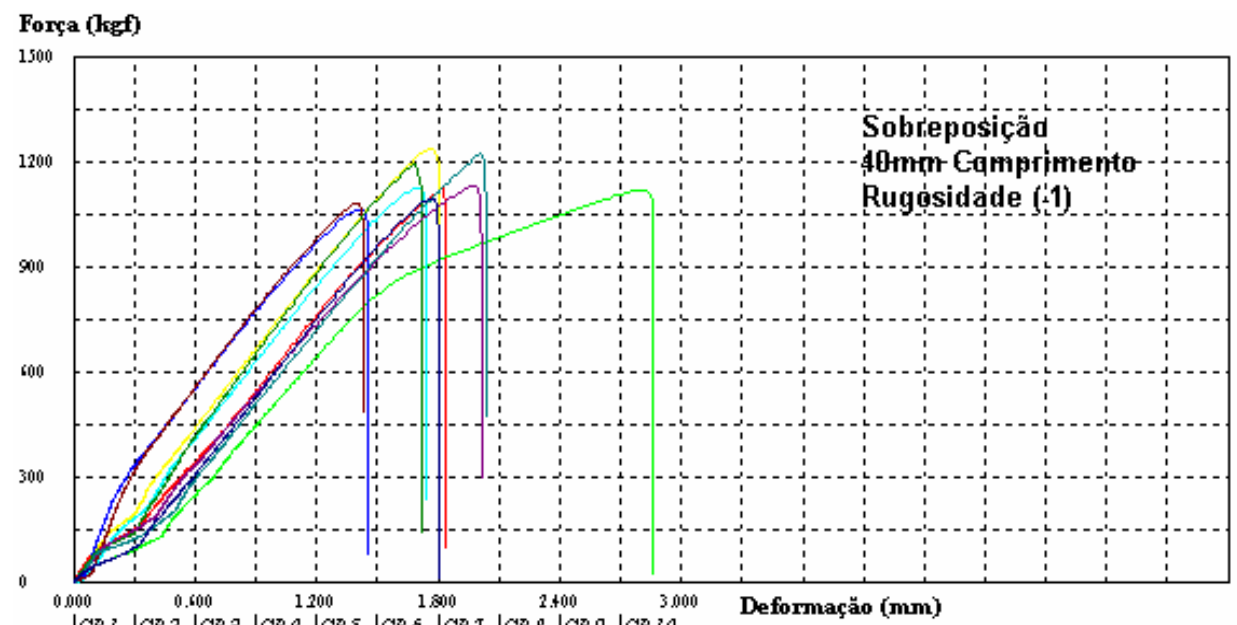

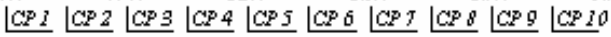

Método II -10 réplicas, $40 \mathrm{~mm}$ de sobreposição e $A(-1), B(-1), C(-1)$ e $D(-1)$. 


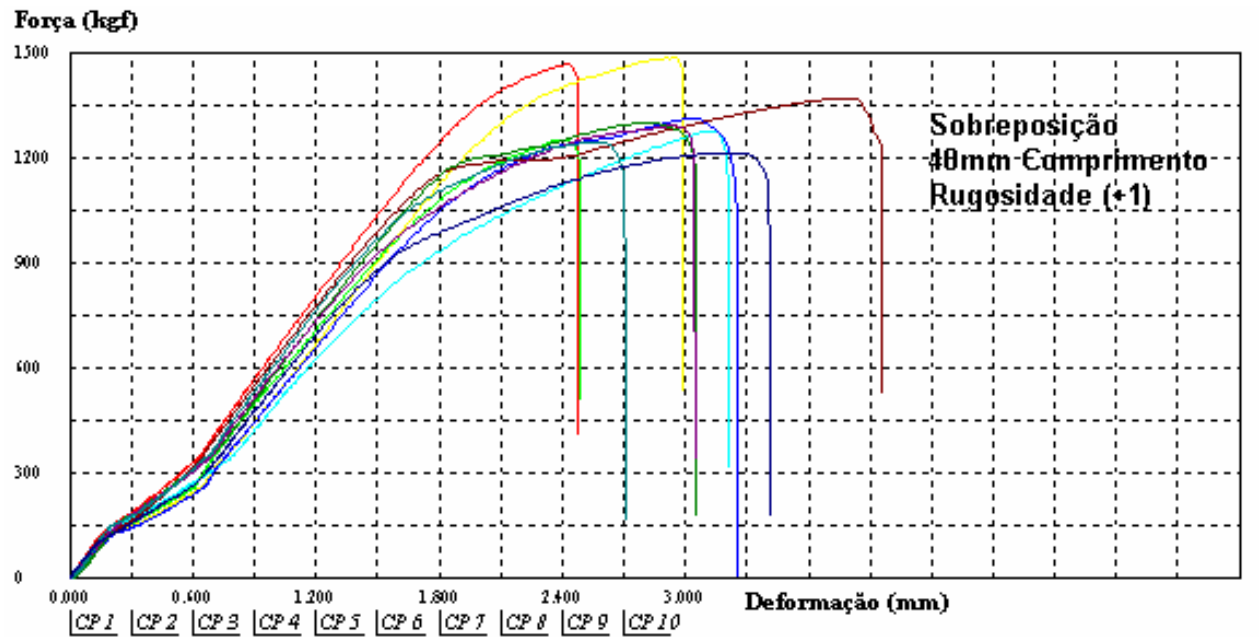

Método $\|-10$ réplicas, $40 \mathrm{~mm}$ de sobreposição e $A(-1), B(-1), C(+1)$ e $D(-1)$.

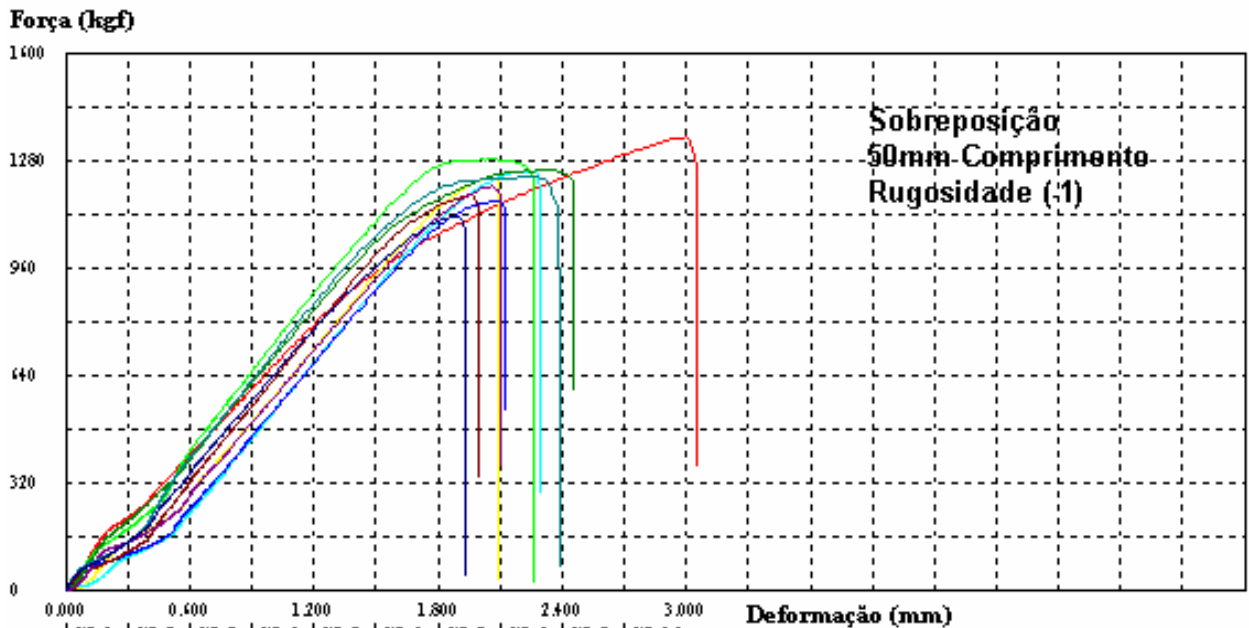

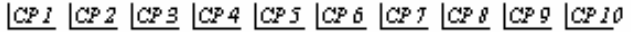

Método $\|-10$ réplicas, $50 \mathrm{~mm}$ de sobreposição e $A(-1), B(-1), C(-1)$ e $D(-1)$.

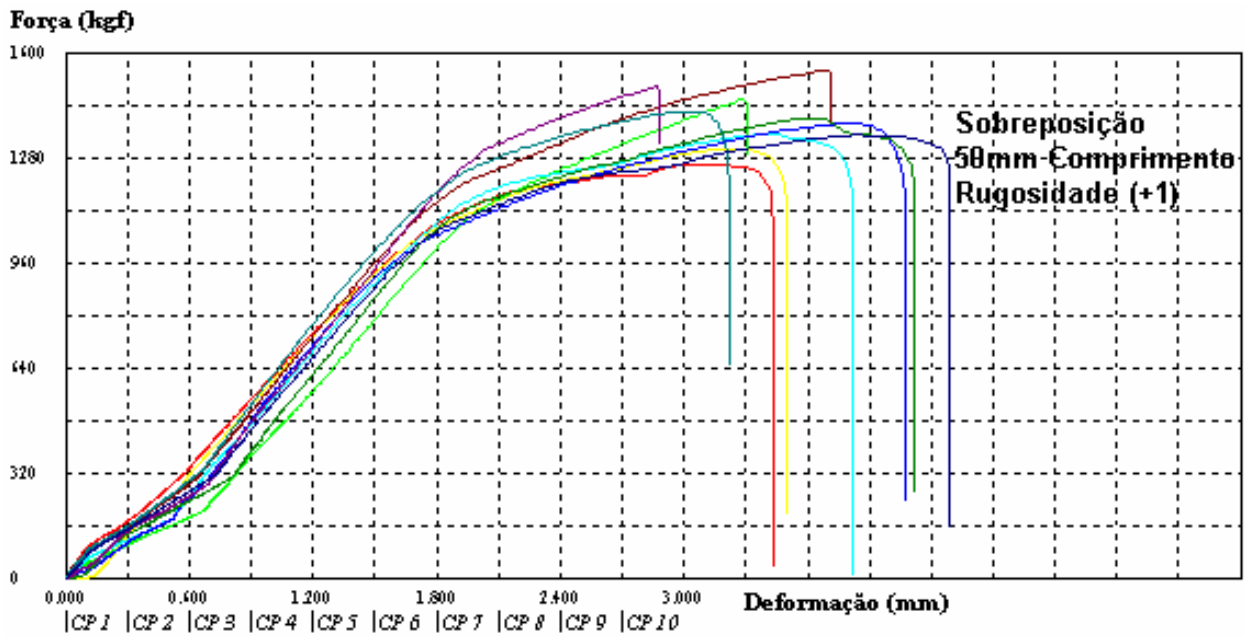

Método $\|$ - 10 réplicas, $50 \mathrm{~mm}$ de sobreposição e $A(-1), B(-1), C(+1)$ e $D(-1)$. 

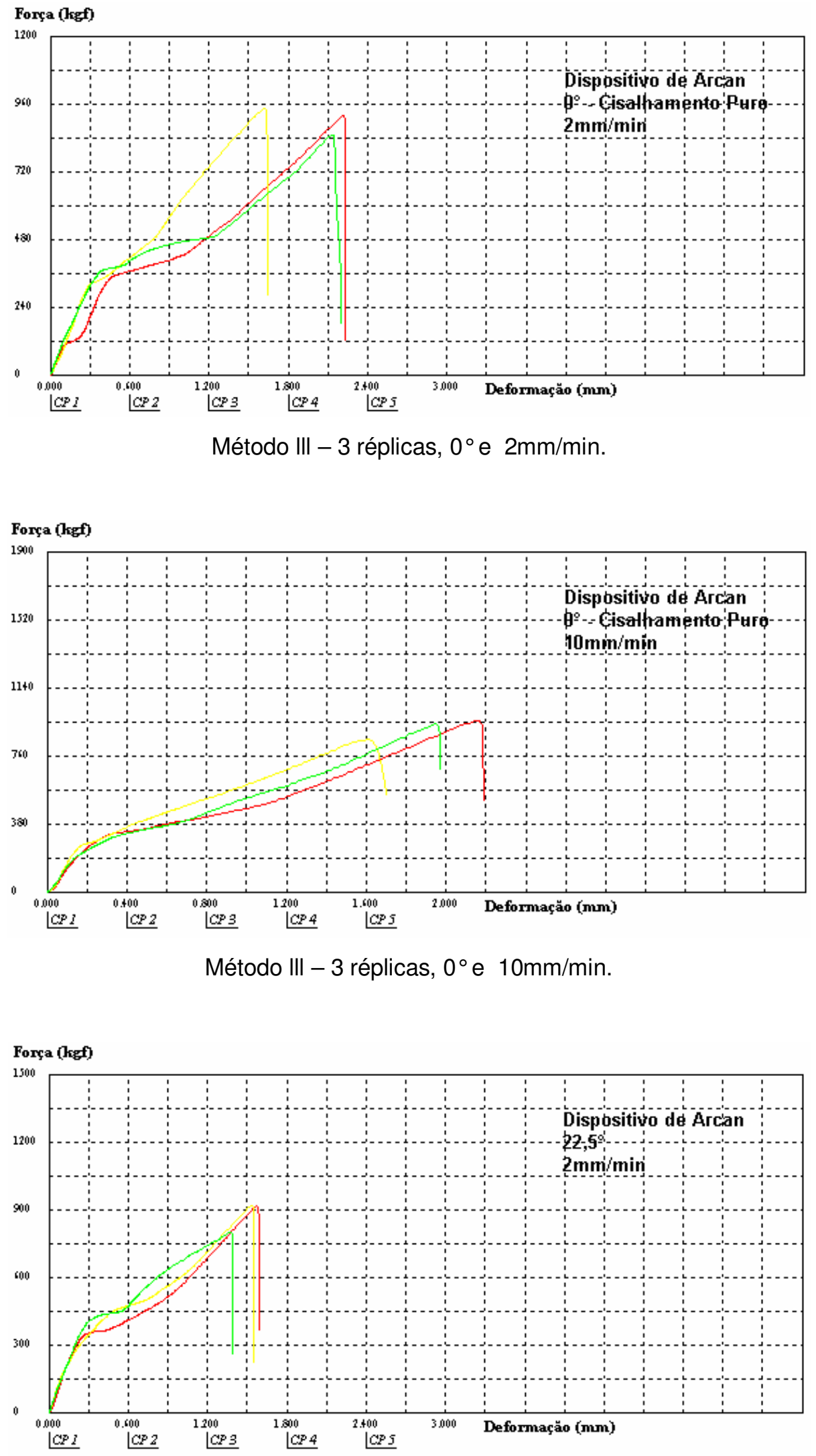

Método III -3 réplicas, $22,5^{\circ} \mathrm{e} 2 \mathrm{~mm} / \mathrm{min}$. 


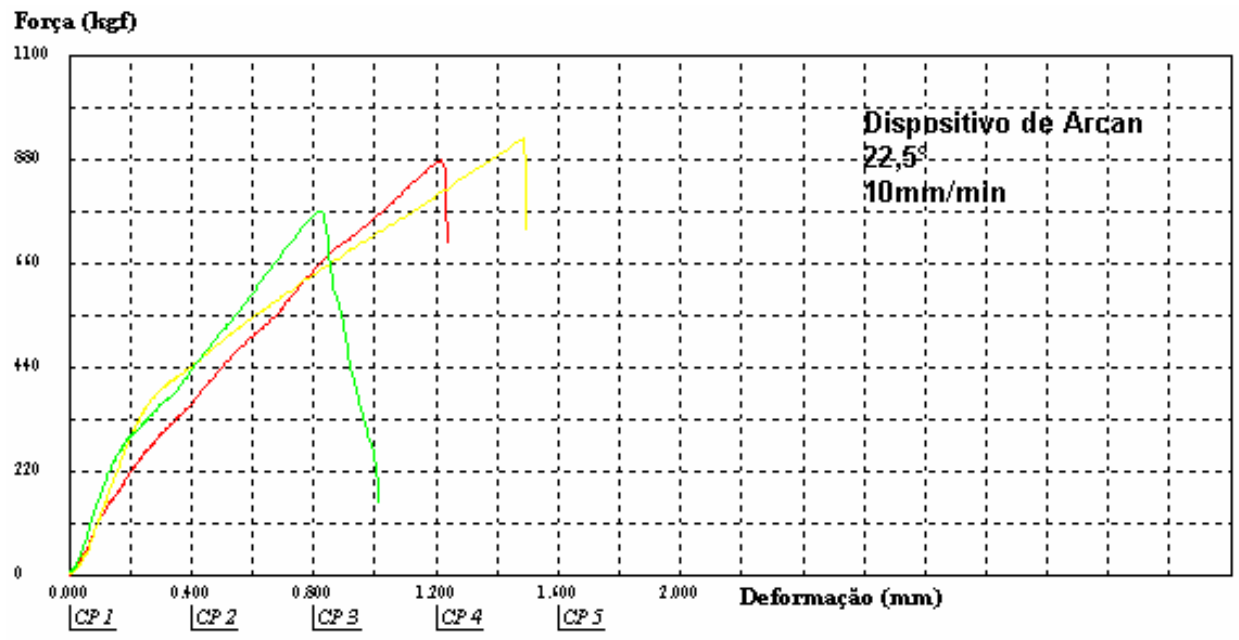

Método III -3 réplicas, $22,5^{\circ}$ e $10 \mathrm{~mm} / \mathrm{min}$.
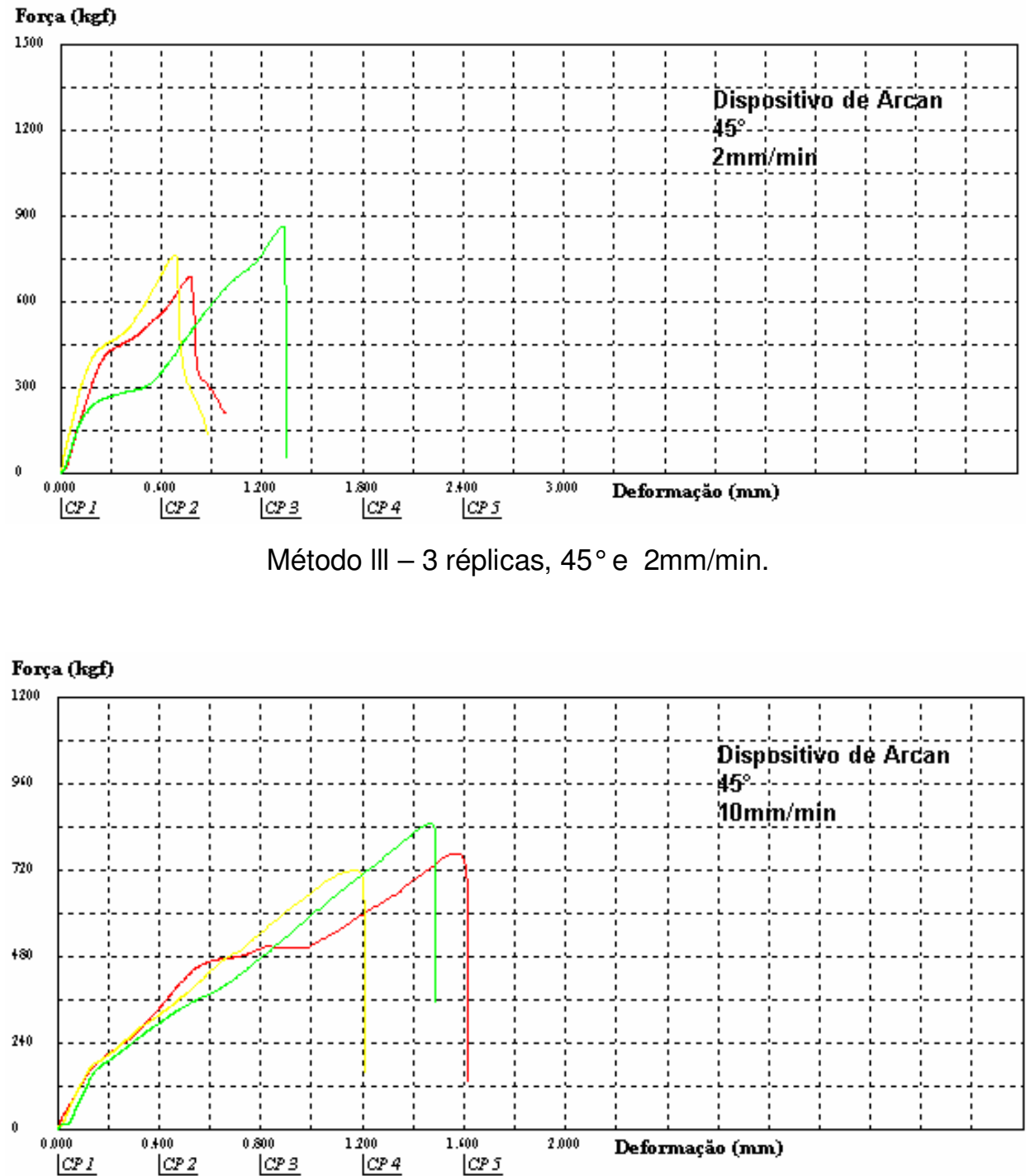

Método III -3 réplicas, $45^{\circ}$ e $10 \mathrm{~mm} / \mathrm{min}$. 


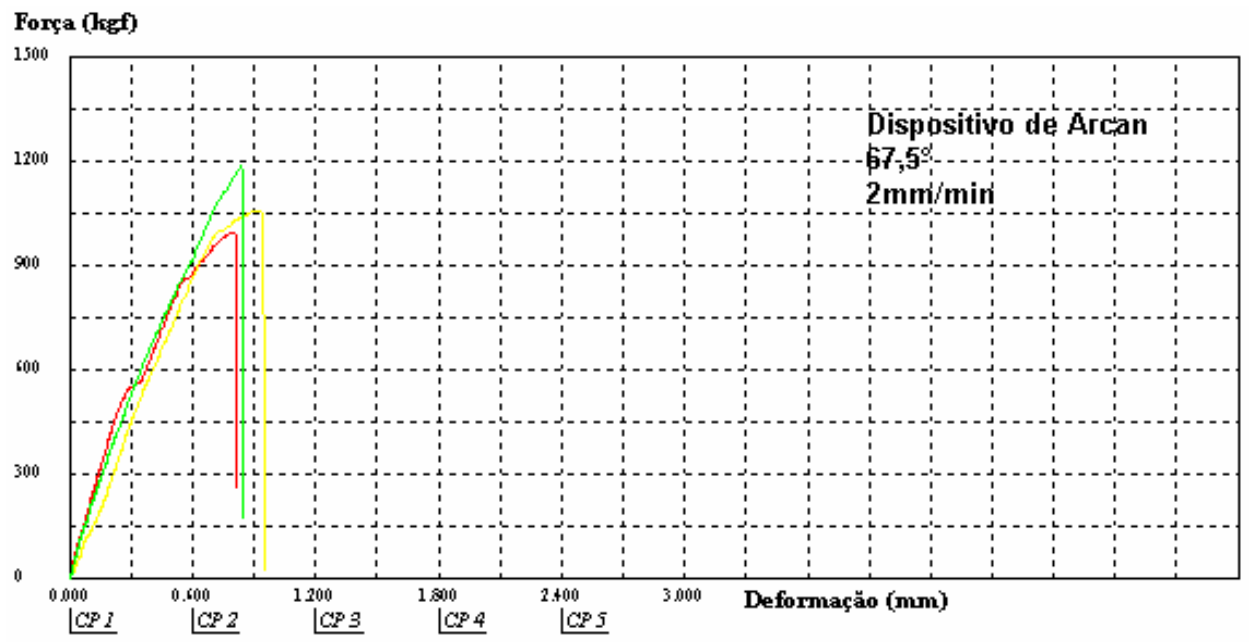

Método $\mathrm{III}-3$ réplicas, $67,5^{\circ}$ e $2 \mathrm{~mm} / \mathrm{min}$.

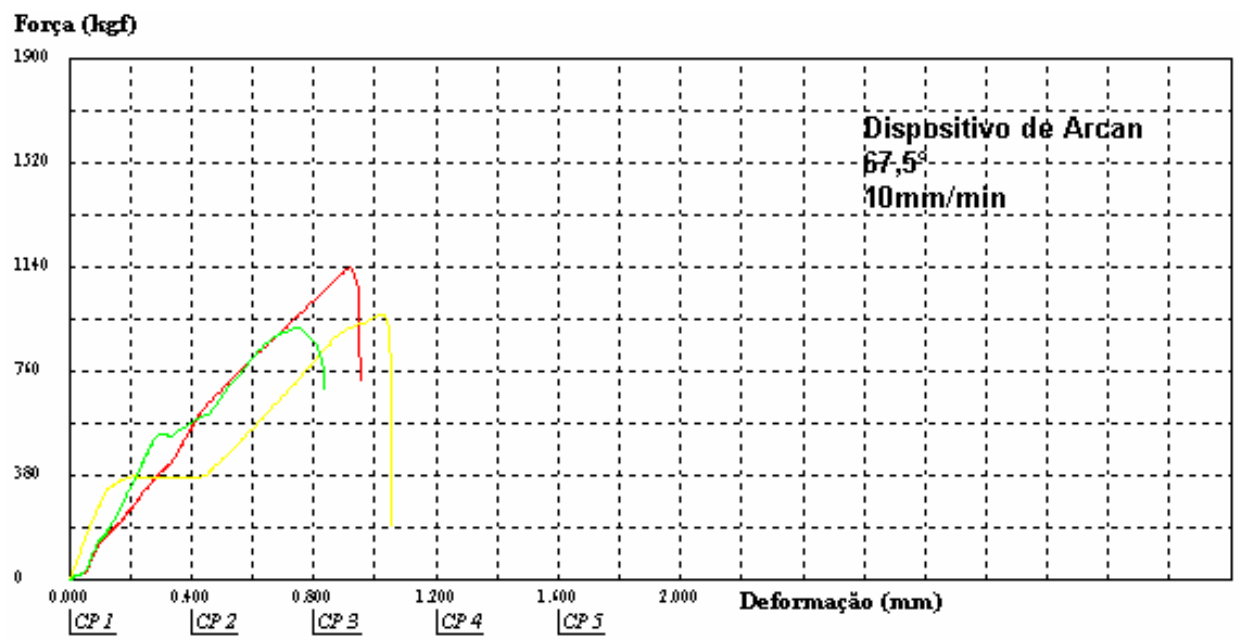

Método III -3 réplicas, $67,5^{\circ} \mathrm{e} 10 \mathrm{~mm} / \mathrm{min}$.

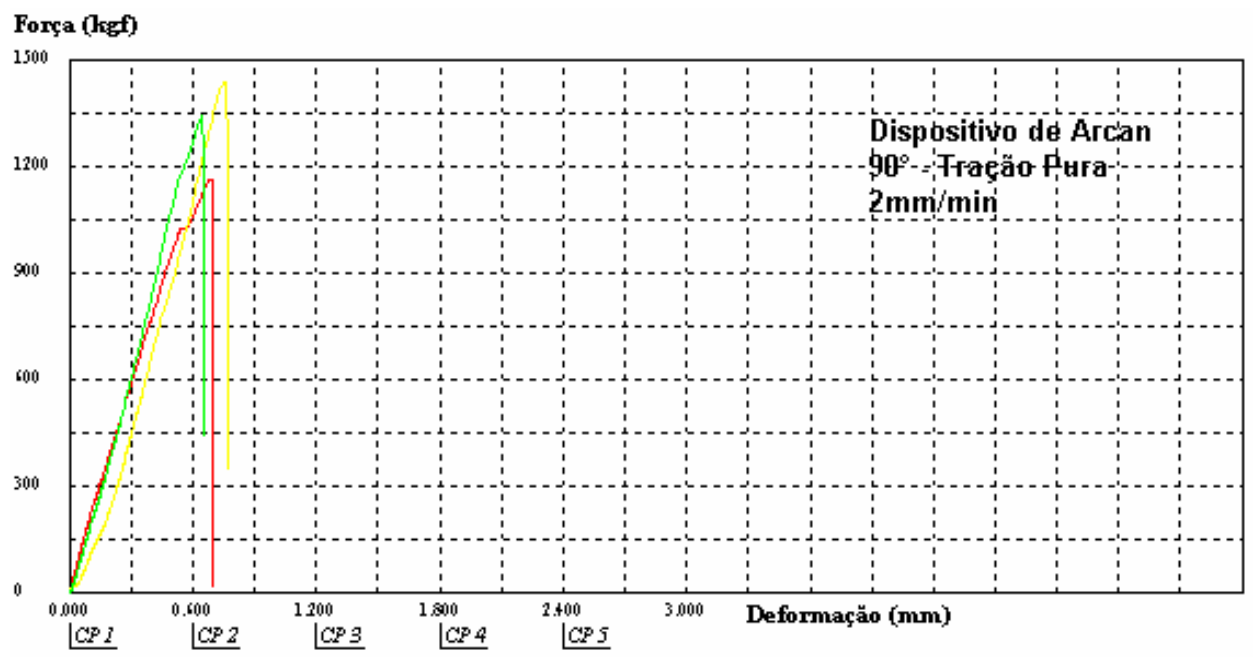

Método III - 3 réplicas, $90^{\circ} \mathrm{e} 2 \mathrm{~mm} / \mathrm{min}$. 


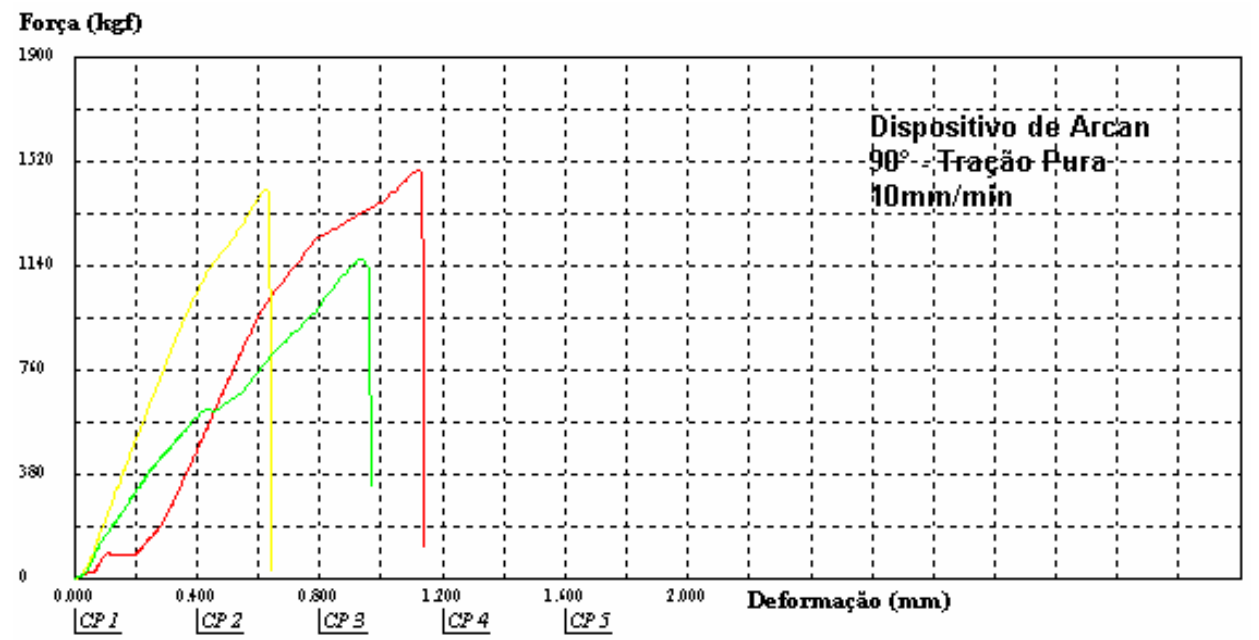

Método III -3 réplicas, $90^{\circ}$ e $10 \mathrm{~mm} / \mathrm{min}$. 